UNIVERSIDADE DE SÃO PAULO

ESCOLA DE ARTES, CIÊNCIAS E HUMANIDADES

PROGRAMA DE PÓS-GRADUAÇÃO EM SUSTENTABILIDADE

\title{
CAUÊ GIRÃO DE ABREU
}

Estudo de caso sobre tratamento de esgoto sanitário através de wetlands construídos em escala real no sudeste brasileiro: questões operacionais, eficiências de tratamento e interferências do tempo de operação e da sazonalidade

São Paulo

2019 


\section{CAUÊ GIRÃO DE ABREU}

Estudo de caso sobre tratamento de esgoto sanitário através de wetlands construídos em escala real no sudeste brasileiro: questões operacionais, eficiências de tratamento e interferências do tempo de operação e da sazonalidade

Dissertação apresentada à Escola de Artes, Ciências e Humanidades da Universidade de São Paulo para obtenção do título de Mestre em Ciências pelo Programa de Pós-graduação em Sustentabilidade.

Versão corrigida contendo as alterações solicitadas pela comissão julgadora em 27/06/2019. A versão original encontra-se em acervo reservado na Biblioteca da EACH/USP e na Biblioteca Digital de Teses e Dissertações da USP (BDTD), de acordo com a Resolução CoPGr 6018, de 13 de outubro de 2011.

Área de Concentração:

Ciência e Tecnologia Ambiental

Orientador:

Prof. Dr. Marcelo Antunes Nolasco

São Paulo 
Autorizo a reprodução e divulgação total ou parcial deste trabalho, por qualquer meio convencional ou eletrônico, para fins de estudo e pesquisa, desde que citada a fonte.

\section{CATÁLOGAÇÃO-NA-PUBLICAÇÃO}

(Universidade de São Paulo. Escola de Artes, Ciências e Humanidades. Biblioteca)

CRB $8-4936$

\section{Abreu, Caue Girăo de}

Estudo de caso sobre tratamento de esgoto sanitário através de wetlands construidos em escala real no sudeste brasileiro: questöes operacionais, eficiências de tratamento e Interferénclas do tempo de operaçāo e da sazonalidade / Caué Girâo de Abreu ; orientador, Marcelo Antunes Nolasco -2019.

$137 \mathrm{f}$ : : il.

Dissertaçäo (Mestrado em Cièncias) - Programa de PósGraduaçăo em Sustentabilldade, Escola de Artes, Ciencias e Humanidades, Universidade de Sāo Paulo.

Versäo corrigida

1. Tratamento de esgotos sanitários - Brasil. 2. Tratamento de águas residuárias - Brasil. 3. Wotiand's constru idos. I. Nolasco, Marcelo Antunes, crient. II. Título. 
Nome: ABREU, Cauê Girão de

Título: Estudo de caso sobre tratamento de esgoto sanitário através de wetlands construídos em escala real no sudeste brasileiro: questões operacionais, eficiências de tratamento e interferências do tempo de operação e da sazonalidade

Dissertação apresentada à Escola de Artes, Ciências e Humanidades da Universidade de São Paulo para obtenção do título de Mestre em Ciências pelo Programa de Pós-graduação em Sustentabilidade.

Área de Concentração:

Ciência e Tecnologia Ambiental

Aprovado em:

\section{Banca Examinadora}

Prof. Dr. $\quad$ Sérgio Almeida Paca

Julgamento:

Prof. Dr. $\quad$ Fabio Campos

Julgamento:

Prof. Dr. Rodrigo de Freitas Bueno

Julgamento:
Instituição: EACH-USP

Assinatura:

Instituição: EP-USP

Assinatura:

Instituição: _UFABC

Assinatura: 


\section{Agradecimentos}

À minha família, por estar sempre presente e me apoiar, não só neste, mas em todos os desafios que decidi enfrentar ao longo dos anos. Em especial à minha mãe, que apesar de viver tão pouco tempo ao meu lado, me passou os valores fundamentais que me permitiram seguir em frente após sua partida e chegar até aqui.

Ao meu orientador, Marcelo Nolasco, pela oportunidade de desenvolver este trabalho e pelas incontáveis contribuições e direcionamentos dados ao longo do desenvolvimento.

Aos meus amigos que sempre estiveram ao meu lado e sempre me apoiaram nos meus projetos de vida.

À empresa proprietária do sistema de wetland construído utilizado neste estudo, por

possibilitar sua utilização e fornecer os dados necessários e apoiar a execução deste trabalho. 
"You, me, or nobody is gonna hit as hard as life. But it ain't about how hard you hit. It's about how hard you can get hit and keep moving forward; how much you can take and keep moving forward. That's how winning is done!" (ROCKY BALBOA, Revolution Studios e Metro-Goldwyn-Mayer Columbia Pictures, 2006) 


\section{RESUMO}

ABREU, Cauê Girão de. Estudo de caso sobre tratamento de esgoto sanitário através de wetlands construídos em escala real no sudeste brasileiro: questões operacionais, eficiências de tratamento e interferências do tempo de operação e da sazonalidade. 2019. 123 f. Dissertação (Mestrado em Ciências) - Programa de Pós-graduação em Sustentabilidade Escola de Artes, Ciências e Humanidades, Universidade de São Paulo, São Paulo, 2019. Versão original.

No Brasil, o modelo implantado de esgotamento sanitário é centralizado, baseado em grandes redes de coleta de esgoto para transporte até as estações de tratamento. No entanto, o atendimento para que uma maior parcela da população possa ser atendida, modelos e sistemas descentralizados devemser adotados. Os wetlands construídos são amplamente citados como soluções sustentáveis, com apelo natural e de custo competitivo para o tratamento de águas residuárias de diversas fontes e são ainda apontados como uma tecnologia adequada e viável para a implantação de sistemas descentralizados de esgotamento sanitário. Nesse contexto, o presente estudo buscou a partir de um estudo de caso compreender o comportamento de um wetlands construídos híbridos em escala real no tratamento de esgoto sanitário, com operação registrada de 50 meses. O estudo buscou compreender os problemas operacionais ocorridos e os efeitos sobre as eficiências de remoção de carga orgânica, as possíveis correlações entre o tempo de operação, dos wetlands construídos na eficiência de remoção de carga orgânica além da influência da temperatura do ar e pluviometria. A eficiência de remoção média ao longo dos 50 meses para $\mathrm{DBO}_{5}{ }^{20}$ e DQO foi de $82 \%$ e $72 \%$ respectivamente. Nenhuma correlação de grande representatividade foi encontrada, mas correlações negativas fracas foram observadas entre a eficiência de remoção de carga orgânica e a temperatura ambiente e entre a mesma eficiência e o tempo de operação.

Palavras-chave: Wetlands. Alagados Construídos. Banhados Construídos. Carga orgânica. Escala real. Eficiência. Sazonalidade. Clima. Temperatura. Idade. Águas residuárias. 


\begin{abstract}
ABREU, Cauê Girão de. Case study about domestic wastewater through full scale constructed wetlands in the Brazilian Southeast: operational matters, treatment efficiency and interference of time of operation and seasonality. 2019. 123 p. Dissertation (Master of Science) - Program of postgraduate in sustainability - School of Arts, Sciences and Humanities, University of São Paulo, São Paulo, 2019. Original version.
\end{abstract}

The wastewater collection and treatment model adopted in Brazil is centralized, based on great networks and treatment plants; however, the provision to a large part of the population requires that models and systems be decentralized. The constructed wetlands are often mentioned as sustainable solutions, for its natural appeal and competitive cost for treating wastewater from several sources; they are also pointed out as a viable and adequate technology for the implementation of decentralized sanitation systems. In this scenario, this study aims at applying a scientific analysis, based on a case study, of a system of hybrid constructed wetlands for treating domestic sewage, in full-scale, whose operation was registered for 50 months. This dissertation aims at describing, in detail, the project criteria and the constructive methodologies used by reporting the advantages and problems created by these criteria, besides analyzing the efficiency in the removal of organic load affected by the wastewater system, testing if there is any correlation between time of operation of the wetland system and its efficiency to remove organic load, and between the variations of temperature in the region where the system is operating and the efficiency, and, finally, between pluviometry in the region where the system is operating and the efficiency. In conclusion, the study compares the results obtained from data of other full-scale systems in different locations, in full-scale. The study found average removal efficiency throughout the 50 months for BOD5 and COD of $82 \%$ and $72 \%$, respectively. No major correlation was found, but weak negative correlations were observed between the organic load removal efficiency and room temperature, and between efficiency and time of operation. Keywords: Constructed wetlands. Organic load. Full scale. Efficiency. Seasonality. Climate. Wastewater. Temperature. Age. 


\section{LISTA DE FIGURAS}

Figura 1- Tipos de macrófitas.

Figura 2 - Tipos de fluxo nos wetlands construídos .............................................................. 36

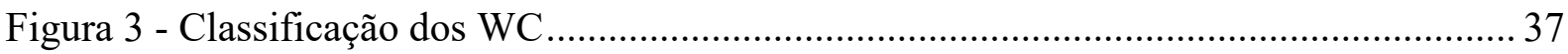

Figura 4 - Eficiência de tratamento de esgoto em WC. ................................................................ 39

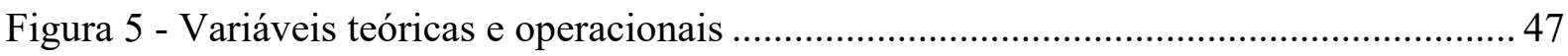

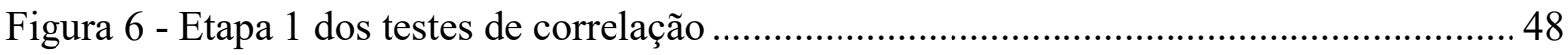

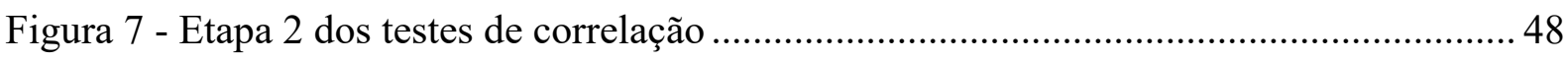

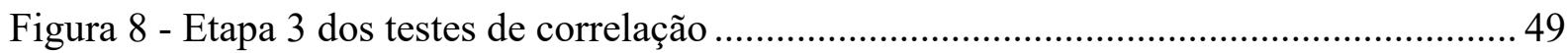

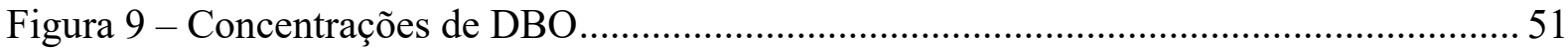

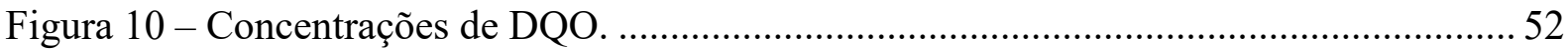

Figura 11 - Diagrama de caixas das eficiências de tratamento ................................................ 53

Figura 12 - Comparação das eficiências de remoção de DBO e DQO …................................ 54

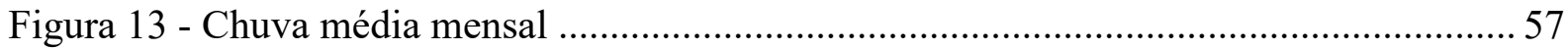

Figura 14 - Temperatura média mensal por período …........................................................ 58

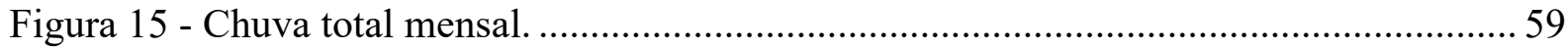

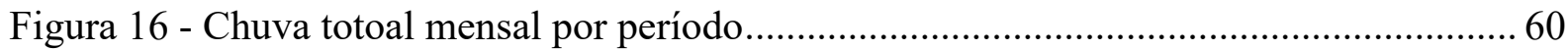

Figura 17 - Séries de dados de temperatura chuva e eficiências de remoção ......................... 61

Figura 18 - Correlação entre as eficiências e a temperatura. …............................................. 62

Figura 19 - Correlação entre a s eficiências e o tempo decorrido............................................ 64

Figura 20 - Concentrações de DBO5 e DQO em diferentes estações.................................... 65

Figura 21 - Concentrações de DBO e DQO em relação ã idade do sistema............................ 66 


\section{LISTA DE QUADROS}

Quadro 1 - Elementos do cenário de saneamento no Brasil.................................................... 28

Quadro 2 - Princípios fundamentais da política nacional de saneamento .............................. 29

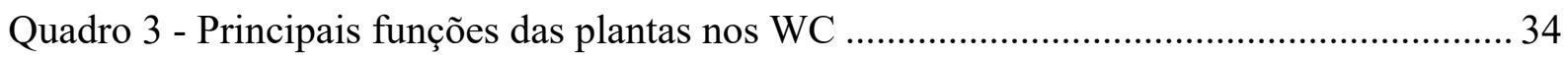

Quadro 4 - Processos de remoção de parâmetros de interesse nos WC ................................... 38

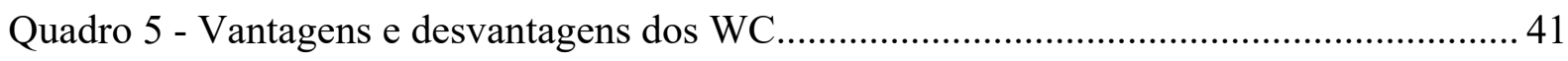




\section{LISTA DE TABELAS}

Tabela 1 - Geração típica de esgoto sanitário por tipo de ocupação ......................................... 25

Tabela 2 - Contribuição típica por habitante de carga poluente no esgoto sanitário ............... 26

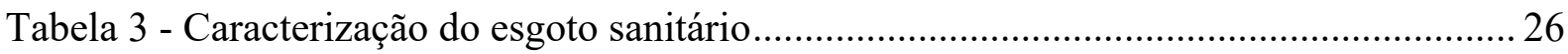

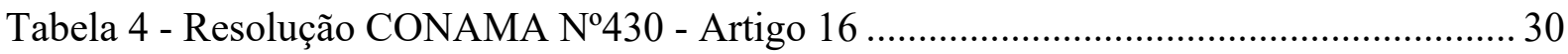

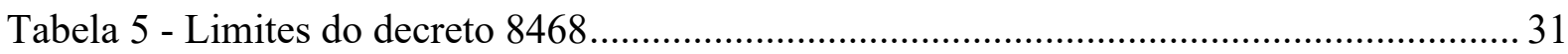

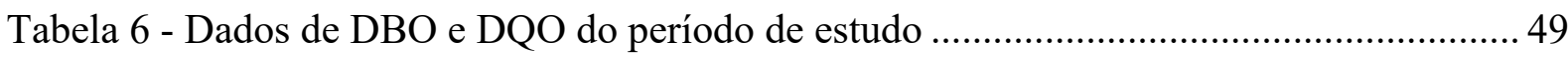

Tabela 7 - Dados de temperatura e pluviometria na região de estudo ................................... 56

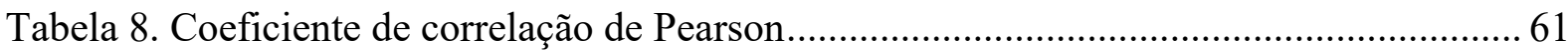

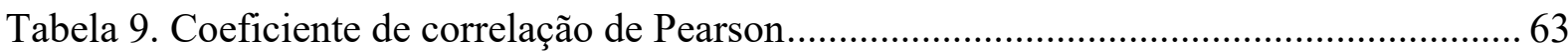

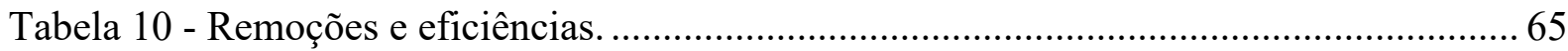




\section{LISTA DE ABREVIATURAS E SIGLAS}

ABNT

ANA

CONAMA

DAEE-SP.

$\mathrm{DBO}_{5}{ }^{20}(\mathrm{DBO})$

DQO

EMBRAPA

FEAGRI-UNICAMP

FUNASA

GEE

MMA

NT

OMS

PE

PLANASA

PT

SS

UN

WC
Associação Brasileira de Normas Técnicas

Agência Nacional de Águas

Conselho Nacional do Meio Ambiente

Departamento de Águas e Energia Elétrica do Estado de São Paulo

Demanda bioquímica de oxigênio, de 5 dias a $20^{\circ} \mathrm{C}$

Demanda química de oxigênio

Empresa Brasileira de Pesquisa Agronopecuária

Faculdade de Engenharia Agrícola da Universidade Estadual de

Campinas

Fundação Nacional de Saúde

Gases do efeito estufa

Ministério do Meio Ambiente

Nitrogênio total

Organização Mundial de Saúde

População equivalente

Plano Nacional de Saneamento

Fósforo total

Sólidos suspensos

United Nations

Wetlands Construídos 


\section{SUMÁRIO}

1 INTRODUÇÃO........................................................................................................... 21

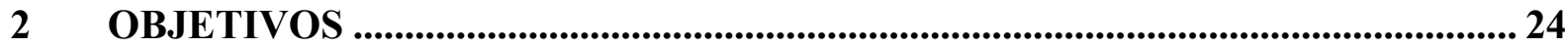

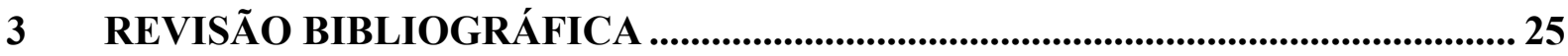

3.1 Tratamento de esgoto doméstico e sanitário .................................................................... 25

3.1.1 Geração e caracterização do esgoto doméstico e sanitário ...................................... 25

3.1.2 Tratamento descentralizado de esgoto sanitário .......................................................... 27

3.1.3 Legislação brasileira para tratamento e lançamento de esgoto sanitário ................ 29

3.2 Sistemas naturais de tratamento de esgoto sanitário .............................................31

3.3 Os wetlands construídos no tratamento de águas residuárias.................................. 32

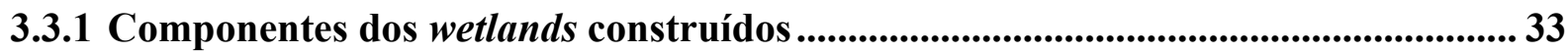

3.3.2 Tipos e classificações dos wetlands construídos........................................................ 35

3.3.3 Processos e mecanismos de remoção de poluentes nos wetlands construídos........... 37

3.3.4 Eficiência de tratamento de efluentes dos wetlands construídos ............................... 39

3.4 Dimensionamento e aplicações de wetlands construídos no tratamento de esgoto

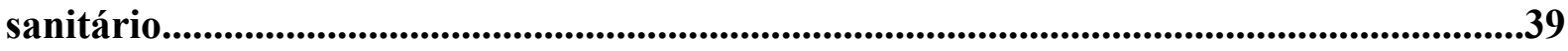

3.4.1 Vantagens e desvantagens dos sistemas de wetlands construídos........................... 40

3.5 Interferência do clima e do tempo de operação no tratamento de esgoto em wetlands construídos................................................................................................................................................... 41

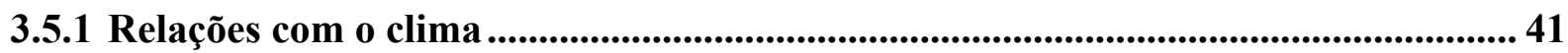

3.5.2 Relações com o tempo de operação (idade do sistema) ............................................... 43

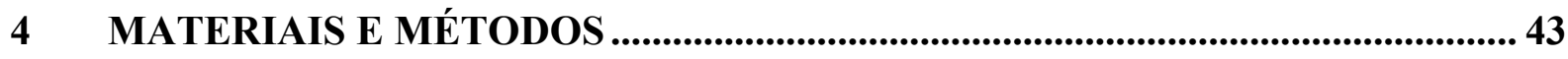




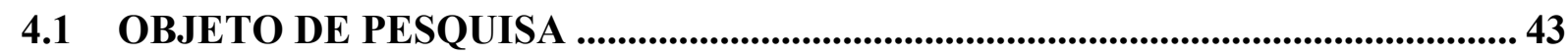

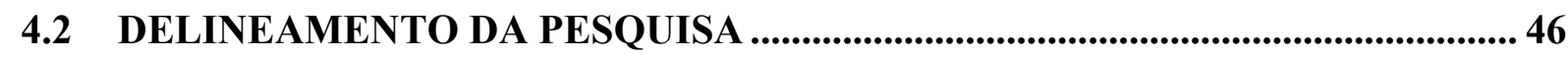

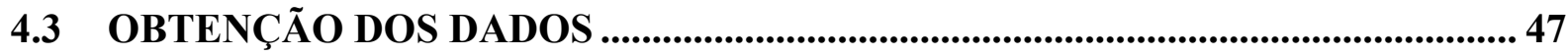

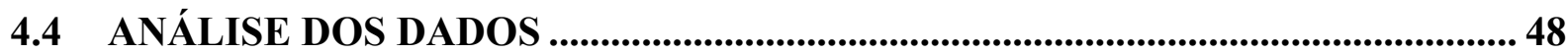

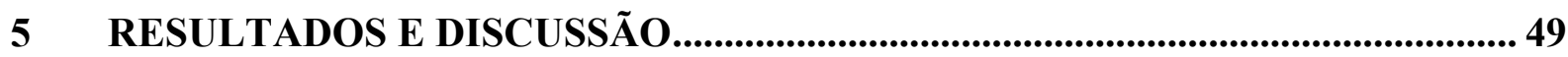

5.1 CARACTERIZAÇÃO E EFICIÊNCIA DO TRATAMENTO................................ 49

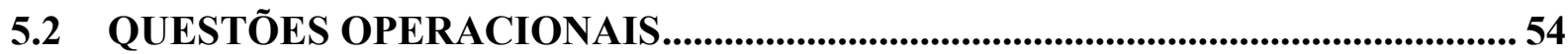

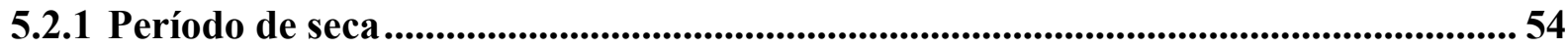

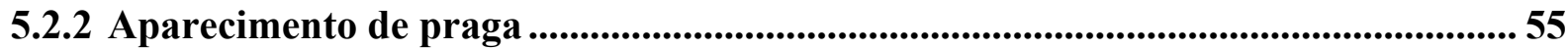

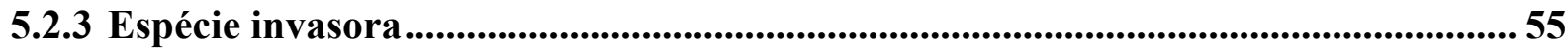

5.3 CORRELAÇÃO DA EFICIÊNCIA DE REMOÇÃO DE CARGA ORGÂNICA E

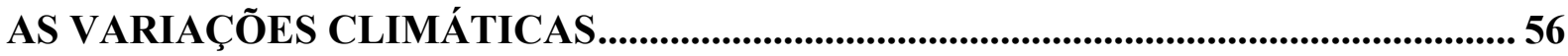

5.4 CORRELAÇÃO COM TEMPO DE TRATAMENTO ........................................... 63

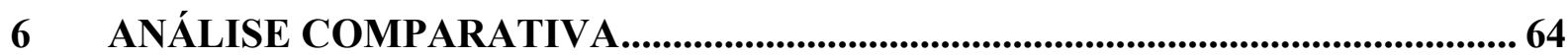

6.1 EFICIÊNCIA DE REMOÇÃO DE CARGA ORGÂNICA ...................................... 65

6.2 RELAÇÃO COM A VARIAÇÃO DE TEMPERATURA ..................................... 65

6.3 RELAÇÃO COM A IDADE (TEMPO DE OPERAÇÃO) DOS SISTEMAS ........ 66

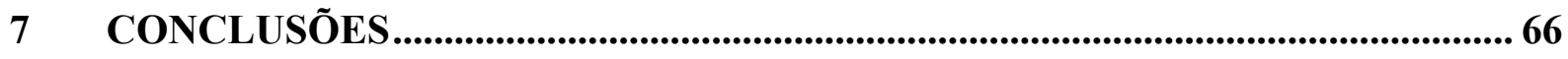

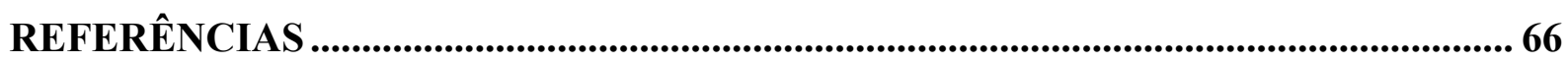

APÊNDICE I: LEVANTAMENTO QUANTITATIVO (BIBLIOMETRIA) ................. 78

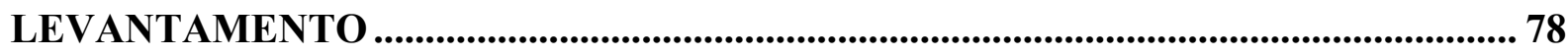

DOCUMENTOS ENCONTRADOS.................................................................................. 80 


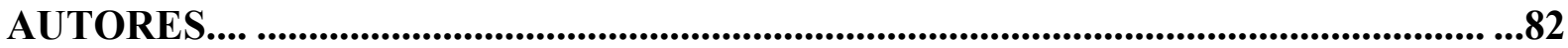

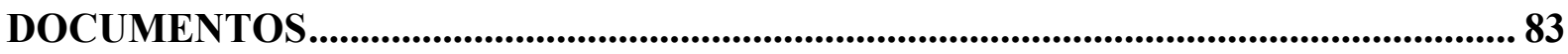

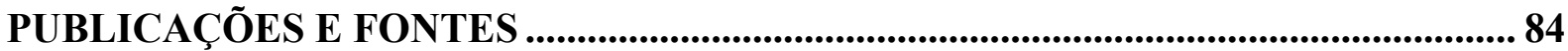

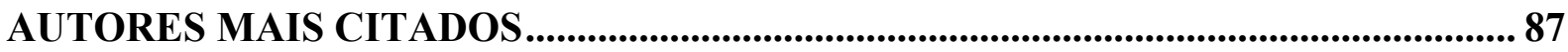

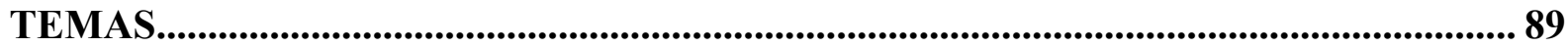

CONCLUSÕES ACERCA DO LEVANTAMENTO QUANTITATIVO.......................91

APÊNDICE II - DETALHES SISTEMA ESTUDADO...............................................96

CONFIGURAÇÃO E DADOS DO SISTEMA EXISTENTE......................................... 96

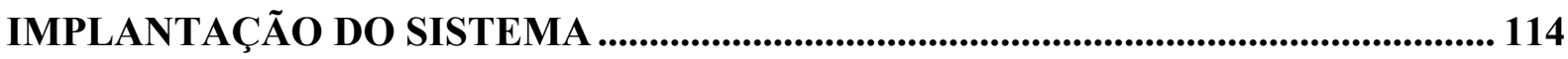

METODOLOGIA OPERACIONAL ADOTADA PELO PROPRIETÁRIO DO

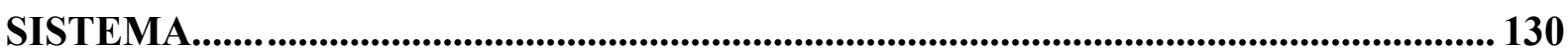

Tanque de equalização..................................................................................................................... 130

Wetlands construídos verticais e horizontais ............................................................... 132

Manipulação de válvulas .............................................................................................................. 132

Manutenção das plantas ....................................................................................................... 134

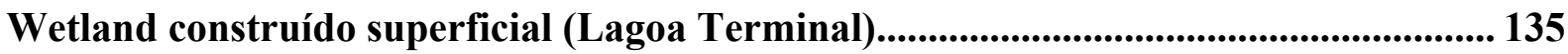

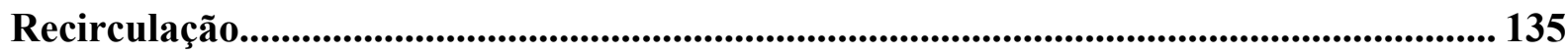

Medição e lançamento.............................................................................................................. 136

Estabelecimento de um acompanhamento analítico .............................................................. 136 


\section{INTRODUÇ̃̃̃}

O tratamento de efluentes e seu impacto nas águas naturais são questões que atraem bastante preocupação, pela escassez do recurso e pelos impactos diretos na saúde humana.

Além de limitar o desenvolvimento através da disponibilidade de água de boa qualidade a falta de saneamento ainda impacta diretamente na saúde da população e nos custos de investimento em saúde feitos pelo poder público, a Organização Mundial de Saúde (OMS) afirma que para cada dólar investido em saneamento, 4 dólares são economizados em saúde pública.

Existem ainda relações entre os sistemas de tratamento de esgoto e os ciclos de energia em sua geração e consumo, e com o ciclo de emissão e absorção de gases do efeito estufa (GEE), de forma que sistemas de saneamento e de tratamento de esgoto podem impactar positiva ou negativamente nestes ciclos.

No Brasil o tema assume grande importância, pois uma grande parte da população não tem acesso regular ao saneamento, sendo que mais de 100 milhões de habitantes não tem seu esgoto coletado e tratado de forma adequada.

De fato, o Atlas Esgoto (ANA e MINISTÉRIO DAS CIDADES, 2017) mostra que:

"No Brasil, 43\% da população possui esgoto coletado e tratado e 12\% utilizam-se de fossa séptica (solução individual), ou seja, 55\% possuem tratamento considerado adequado; $18 \%$ têm seu esgoto coletado e não tratado, o que pode ser considerado como um atendimento precário; e $27 \%$ não possuem coleta nem tratamento, isto é, sem atendimento por serviço de coleta sanitário."

Esta situação de carência de tratamento de esgotos leva a um impacto direto nas águas superficiais do país, prejudicando os usuários que dependem da qualidade desta água, gerando impactos na saúde humana e no ambiente aquático. De acordo com o Atlas Esgoto a qualidade da água já está comprometida em mais de cento e dez mil quilômetros, sendo que em mais de oitenta mil destes a captação para abastecimento público já não é mais permitida.

O modelo adotado no Brasil para implantação dos serviços de esgotamento sanitário é um modelo centralizado, baseado em grandes redes e estações, porém o atendimento de uma maior parcela da população demanda que modelos e sistemas descentralizados sejam adotados.

Os sistemas de coleta e tratamento de esgotos descentralizados podem ser dimensionados e implantados para atender as necessidades locais de áreas fora dos grandes centros urbanos, além de diminuir os impactos ambientais, sociais e econômicos dos sistemas de esgotamento sanitário.

Além do objetivo de universalização dos serviços de esgotamento sanitário, os sistemas descentralizados podem ainda ser planejados de forma a considerar as características regionais e locais, contribuindo não só para o ciclo da água, mas colaborando com os ciclos de energia, nutrientes, alimentos e emissões de GEE, na forma de um gerenciamento integrado destes ciclos.

Muitas tecnologias diferentes são conhecidas e amplamente utilizadas para tratar os esgotos sanitários e reduzir o seu impacto no meio natural e, indiretamente, na saúde da população. Algumas tecnologias são consideradas mais adequadas ou mais viáveis para a implantação de sistemas descentralizados, entre elas a tecnologia conhecida como wetlands construídos (WC).

Wetlands construídos são sistemas naturais de tratamento e melhoria de qualidade da água, caracterizados basicamente pela presença de um substrato e plantas. Esses sistemas têm se tornado uma opção cada vez mais comum para tratamento de águas residuárias. 
Os wetlands construídos são amplamente citados como soluções sustentáveis, com apelo natural e de custo competitivo para o tratamento de águas residuárias de diversas fontes e são ainda apontados como uma tecnologia adequada e viável para a implantação de sistemas descentralizados de esgotamento sanitário.

As características do sistema de wetlands construídos, que englobam sua possibilidade de aproveitamento de biomassa, suas influências positivas no ciclo de absorção de GEE, a criação de ecossistemas e abrigos de espécies semelhantes aos naturais e a possibilidade de aproveitamento de nutrientes, transformam esta tecnologia em uma opção de sistema de esgotamento sanitário com excelente possibilidade de aplicação no gerenciamento integrado dos ciclos de água, nutrientes e energia.

Assim como em qualquer sistema de tratamento, a aplicação eficiente dos wetlands demanda um conhecimento dos processos envolvidos e das interferências sofridas por estes processos, de forma que se possa projetar e operar os sistemas dentro das eficiências necessárias.

Os diversos estudos feitos nos últimos anos sobre as eficiências de tratamento dos wetlands para esgoto sanitário apresentam grandes variações, com trabalhos mostrando, por exemplo, eficiência de remoção de carga orgânica, representada pela demanda bioquímica de oxigênio, de 5 dias a $20^{\circ} \mathrm{C}\left(\mathrm{DBO}_{5}{ }^{20}\right)$, variando de valores em torno de $50 \%$ (RIVAS et al., 2011) a 98\% (SILVA, 2007).

Esta grande variação nas eficiências de tratamento é associada, principalmente, às diferentes condições de estudo aplicadas. Entre elas se encontram a configuração do sistema de wetlands construídos, o tipo de efluente tratado, a região de estudo e seu clima, o tempo de acompanhamento de operação, a escala do sistema de tratamento e a taxa de aplicação de esgoto, a etapa de tratamento atribuída ao sistema (primário, secundário, terciário) e, ainda, o tipo e a variedade de plantas utilizadas.

Os modelos de dimensionamento dos wetlands são simplificados e omitem uma série de processos intrínsecos e de interações com o meio, como a sazonalidade e clima por exemplo.

Por se tratar de um sistema de tratamento biológico e natural, existe a possibilidade de as características da região de implantação do sistema afetarem diretamente esta eficiência de várias formas. Estudos mostram que em algumas regiões existem grandes variações, enquanto em outras elas são quase significantes (KIM, et al., 2015; VALIPOUR; AHN, 2016; ROZEMA et al., 2016; YAN; XU, 2014). Em regiões de climas intermediários estudos demonstraram pequenas variações de remoção no inverno (KIM, et al., 2015), enquanto em climas mais frios ora demonstra-se perdas significativas de eficiência (VALIPOUR; AHN, 2016) e ora mostrase que o sistema consegue atingir estas remoções sem nenhuma modificação (ROZEMA et al., 2016); YAN; XU, 2014).

Este estudo avaliou a eficiência de tratamento de um sistema de wetlands construídos em escala real no clima do sudeste brasileiro, na região de Campinas-SP, efetuando tratamento de esgoto sanitário com dados de eficiência de remoção de carga orgânica disponíveis em um prazo de 52 meses e verificar a existência de influência das variações do meio na eficiência de tratamento.

A utilização de sistemas em escala real, operando há um prazo mais longo e tratando esgoto, é bastante escassa nos estudos recentes. Este modelo de estudo é importante por gerar uma base de dados operacionais reais, que leva ao melhor entendimento dos processos e das aplicações reais desse tipo de sistema nas regiões e climas do Brasil.

Para verificar a influência do meio nos processos foi escolhida a principal característica que se altera regionalmente: o clima e sua sazonalidade, para ser confrontado com a eficiência em busca de uma correlação. 
O entendimento desta correlação para os climas brasileiros pode gerar dados importantes para o projeto de sistemas, de forma que se possa prever as variações e dimensionar sistemas que mantenham sua eficiência acima daquela desejada, mesmo mediante a tais variações.

Outro fator analisado foi o tempo decorrido durante o estudo, focando em sistemas em operação por longos períodos, e a variação desta eficiência em função do tempo de operação. 


\section{OBJETIVOS}

O objetivo geral deste estudo foi avaliar a correlação da eficiência de tratamento com fatores climáticos e com o tempo de operação, a partir de um estudo de caso, em um WC para tratamento de esgoto sanitário em escala real com operação registrada de 50 meses.

Os objetivos específicos foram:

a. Analisar as eficiências de remoção de carga orgânica atingidas pelo sistema de tratamento.

b. Testar a correlação entre o tempo de operação do sistema de wetlands construídos e sua eficiência de remoção de carga orgânica.

c. Testar a correlação entre as variações de temperatura na região de operação do sistema de wetlands construídos e sua eficiência de remoção de carga orgânica.

d. Testar a correlação entre a pluviometria na região de operação do sistema de wetlands construídos e sua eficiência de tratamento de carga orgânica.

e. Comparar os resultados obtidos com dados de outros sistemas em diferentes locais em escala real. 


\section{REVISÃO BIBLIOGRÁFICA}

\subsection{Tratamento de esgoto doméstico e sanitário}

\subsubsection{Geração e caracterização do esgoto doméstico e sanitário}

De acordo com a NBR 9648/1986, o esgoto doméstico é o despejo líquido resultante da utilização de água para higiene e necessidades fisiológicas humanas. Segundo Fernandes (1997), o esgoto sanitário engloba toda vazão esgotável provinda diretamente das atividades domésticas, incluindo lavagens de roupas, preparação de alimentos, descarga de vasos sanitários, ralos de pias e chuveiros etc. O Manual de Saneamento da Fundação Nacional de Saúde (FUNASA) define ainda o esgoto doméstico da seguinte forma:

“O esgoto doméstico é aquele que provem principalmente de residências, estabelecimentos comerciais, instituições ou quaisquer edificações que dispõe de instalações de banheiros, lavanderias e cozinhas. Compõem-se essencialmente da água de banho, excretas, papel higiênico, restos de comida, sabão, detergentes e águas de lavagem.”

Em resumo, o esgoto doméstico é aquele gerado nas atividades domésticas enquanto o sanitário compreende, além do doméstico, todo o despejo líquido das águas utilizadas pelas atividades humanas não industriais ou não produtivas.

O volume típico diário de geração de esgoto sanitário pelas principais ocupações e atividades humanas está apresentado na tabela 1:

Tabela 1 - Geração típica de esgoto sanitário por tipo de ocupação

\begin{tabular}{|lll|}
\hline Tipo de ocupação & Unidade & Contribuição \\
\hline 1. Ocupantes permanentes & & \\
Residência & & \\
Padrão alto & L/pessoa*dia & 160 \\
Padrão médio & L/pessoa*dia & 130 \\
Padrão baixo & L/pessoa*dia & 100 \\
Hotel (exceto lavanderia e cozinha) & L/pessoa*dia & 100 \\
Alojamento provisório & L/pessoa*dia & 80 \\
2. Ocupantes temporários & & \\
Fábrica em geral & L/pessoa*dia \\
Escritório & L/pessoa*dia \\
Edifícios públicos ou comerciais & L/pessoa*dia \\
Escolas (externatos) e locais de longa permanência & L/pessoa*dia & 70 \\
Bares & L/pessoa*dia & 50 \\
Restaurantes e similares & L/refeição*dia & 50 \\
Cinemas, teatros e locais de curta permanência & L/lugar*dia & 25 \\
Sanitários públicos (acesso aberto ao público) & L/bacia & 480 \\
& sanitária*dia & \\
\hline
\end{tabular}

Fonte: NBR 7229/1993 - Adaptado

Em termos de caracterização da poluição contida no esgoto sanitário, a contribuição típica por habitante das cinco principais características físico-químicas do esgoto sanitário é mostrada na tabela 2: 
Tabela 2 - Contribuição típica por habitante de carga poluente no esgoto sanitário

\begin{tabular}{|lll|} 
Contaminante & Unidade & Contribuição \\
\hline $\begin{array}{l}\text { Demanda bioquímica de oxigênio } \\
\left(\mathrm{DBO}_{5}^{20}\right)\end{array}$ & $\mathrm{g} /$ habitante*dia & 45 a 60 \\
Demanda química de oxigênio (DQO) & $\mathrm{g} /$ habitante*dia & 90 a 120 \\
Sólidos suspensos (SS) & $\mathrm{g} /$ habitante*dia & 45 a 70 \\
Nitrogênio total (NT) & $\mathrm{g} /$ habitante*dia & 8 a 12 \\
Fósforo total (PT) & $\mathrm{g} /$ habitante*dia & 1 a 1,6 \\
\hline
\end{tabular}

Fonte: NBR 12209/2011 - Adaptado

Os principais constituintes e poluentes deste tipo de despejo e suas concentrações características são apresentados na tabela 3, a seguir:

Tabela 3 - Caracterização do esgoto sanitário

\begin{tabular}{|c|c|c|c|}
\hline \multirow{2}{*}{ Parâmetro } & \multicolumn{3}{|c|}{ Concentração } \\
\cline { 2 - 4 } & Unidade & Faixa & Típico \\
\hline Sólidos Totais & $\mathrm{mg} / \mathrm{L}$ & $700-1350$ & 1100 \\
\hline Em suspensão & $\mathrm{mg} / \mathrm{L}$ & $200-450$ & 350 \\
\hline Fixos & $\mathrm{mg} / \mathrm{L}$ & $40-100$ & 80 \\
\hline Voláteis & $\mathrm{mg} / \mathrm{L}$ & $165-350$ & 320 \\
\hline Dissolvidos & $\mathrm{mg} / \mathrm{L}$ & $600-900$ & 700 \\
\hline Fixos & $\mathrm{mg} / \mathrm{L}$ & $300-550$ & 400 \\
\hline Voláteis & $\mathrm{mg} / \mathrm{L}$ & $200-350$ & 300 \\
\hline Sedimentáveis & $\mathrm{mL} / \mathrm{L}$ & $10-20$ & 15 \\
\hline Matéria orgânica & & & \\
\hline DBO ${ }^{20}$ & $\mathrm{mg} / \mathrm{L}$ & $250-400$ & 300 \\
\hline DQO & $\mathrm{mg} / \mathrm{L}$ & $450-800$ & 600 \\
\hline DBO Última & $\mathrm{mg} / \mathrm{L}$ & $350-600$ & 450 \\
\hline Nitrogênio total & $\mathrm{mgN} / \mathrm{L}$ & $35-60$ & 45 \\
\hline Nitrogênio orgânico & $\mathrm{mgN} / \mathrm{L}$ & $15-25$ & 20 \\
\hline Amônia & $\mathrm{mgNH}{ }_{3}-\mathrm{N} / \mathrm{L}$ & $20-35$ & 25 \\
\hline Nitrito & $\mathrm{mgNO}$ - $\mathrm{N} / \mathrm{L}$ & $\approx 0$ & $\approx 0$ \\
\hline Nitrato & $\mathrm{mgNO}-\mathrm{N} / \mathrm{L}$ & $0-1$ & $\approx 0$ \\
\hline Fósforo & $\mathrm{mgP} / \mathrm{L}$ & $4-15$ & 7 \\
\hline Fósforo orgânico & $\mathrm{mgP} / \mathrm{L}$ & $1-6$ & 2 \\
\hline Fósforo inorgânico & $\mathrm{mgP} / \mathrm{L}$ & $3-9$ & 6 \\
\hline pH & & $6,7-8,0$ & 7 \\
\hline Alcalinidade & $\mathrm{mgCaCO} / \mathrm{L}$ & $100-250$ & 200 \\
\hline Metais Pesados & $\mathrm{mg} / \mathrm{L}$ & traços & traços \\
\hline Compostos orgânicos tóxicos & $\mathrm{mg} / \mathrm{L}$ & traços & traços \\
\hline
\end{tabular}

Fonte: VON SPERLING, 2014 - Adaptado

O esgoto sanitário possui diversas substâncias que, quando lançadas ao meio ambiente sem o correto tratamento, podem causar impacto na qualidade ambiental.

A matéria orgânica, quando lançada em águas naturais, faz com que os microrganismos que a degradam reduzam a quantidade de oxigênio disponível em solução, tornando o ambiente inabitável para várias espécies de peixes (PIVELI; KATO, 2005). 
Segundo estes autores, os nutrientes contidos no esgoto sanitário, principalmente os macronutrientes, como nitrogênio e fósforo, quando lançados em ambientes aquáticos, fornecem condições de crescimento e desenvolvimento de seres vivos que os utilizam, especialmente algas, em um processo conhecido como eutrofização. Este fenômeno inviabiliza diversos usos desta água e causa poluição por matéria orgânica através da morte e decomposição desses organismos e existem ainda formas de nitrogênio, como o nitrato e a amônia, que podem ser tóxicas para a vida aquática a partir de certas concentrações.

Assim como para a vida aquática, os autores apontam que, algumas formas de nitrogênio são também tóxicas para o ser humano. É o caso do nitrato, que pode causar uma doença conhecida como metaemoglobinemia infantil, que causa a morte de crianças.

Também está presente no esgoto sanitário uma série de microrganismos causadores de danos à saúde humana, como bactérias, vírus, fungos, protozoários e helmintos (VON SPERLING, 2014). De fato, diversas doenças estão relacionadas ao contato direto do ser humano com o esgoto ou com água poluída pelo lançamento de esgotos (CASTRO et al., 1995).

O impacto na saúde é tão grande que pesquisas da Organização Mundial de Saúde (OMS) afirmam que, para cada dólar investido em saneamento básico, economizam-se 4,3 dólares em investimentos na área da saúde (UN-OMS 2014).

\subsubsection{Tratamento descentralizado de esgoto sanitário}

A definição de sistema descentralizado ou local de tratamento de esgoto pode ser encontrada na norma NBR 13969 (ABNT, 1997):

"Sistema de saneamento onde as distâncias entre as fontes geradoras de esgotos, seu tratamento e disposição final são próximas entre si, não necessitando normalmente de rede coletora extensa, coletor-tronco, poços de visita, emissários, elevatórias etc."

Este tipo de sistema é particularmente importante para atendimento de locais em condições que desfavoreçam sua inclusão no sistema centralizado de coleta e tratamento, ressaltando-se algumas situações (CRITES; TCHOBANOGLOUS, 1998):

- Locais de baixa densidade populacional

- Comunidades afastadas de sistemas centralizados

- Comunidades sem verbas para construir sistemas convencionais

- Locais isolados que demandem maior eficiência de tratamento

- Locais com escassez de água

- Locais com possibilidade de reuso local do esgoto tratado

Os autores afirmam, ainda, que não é possível promover o tratamento de todo o esgoto de uma nação, no caso, os EUA, sem a aplicação de sistemas descentralizados, e que, por esta razão, os mesmos vêm ganhando muita importância perante as entidades deste país.

Em um país de grandes extensões e de grandes diferenças sociais e demográficas como o Brasil, há de se esperar que este tipo de tratamento tenha a mesma importância para o objetivo de universalização do saneamento básico.

De fato, no Brasil, aproximadamente $70 \%$ do atendimento de esgotamento sanitário implantado encontra-se sob responsabilidade das concessionárias estaduais, o que faz com que os 
municípios gerem um esforço para atendimento de suas demandas específicas, gerando assim um espaço a ser preenchido por sistemas descentralizados (TRATA BRASIL, 2016).

Sezerino (2005) afirma que após mais de 30 anos da implantação do plano nacional de saneamento (PLANASA), seguindo o modelo de centralização do atendimento, ainda não existe um atendimento eficiente do tratamento de esgoto sanitário.

Segundo Phillipi (2000), os elementos que regem as políticas do cenário de saneamento no Brasil, resultado do Plano Nacional de Saneamento (PLANASA - 1971-1989) e de programas que o substituíram (1990-1997), estão sintetizadas no Quadro 1 a seguir:

Quadro 1 - Elementos do cenário de saneamento no Brasil

- Visão centralizadora tanto em nível da administração quanto tecnológico;

- Privilegia grandes projetos;

- Baixo atendimento às populações carentes e/ou periféricas;

- Baixo atendimento às populações rurais;

- Baixo nível de participação comunitária ou de controle social sobre os programas;

- Falta de integração das funções do saneamento, resultando numa postura de pouca interatividade, interinstitucionalidade e interdisciplinaridade; e baixo nível de adesão a programas de educação sanitária e ambiental.

Fonte: PHILLIPI, 2000 - Adaptado

Estes elementos mostram que até então não foi privilegiado o modelo de descentralização, para um maior atendimento de áreas periféricas e rurais.

A partir disso, é promulgada em 2003 a Secretaria Nacional de Saneamento Ambiental do Ministério das Cidades e, em 2007, a Lei 11.445/2007, que instituiu as diretrizes nacionais e a política federal do saneamento básico.

A referida lei coloca como diretrizes nacionais para o saneamento os seguintes princípios fundamentais, apresentados no quadro 2 a seguir: 
Quadro 2 - Princípios fundamentais da política nacional de saneamento

I - Universalização do acesso;

II - Integralidade, compreendida como o conjunto de todas as atividades e componentes de cada um dos diversos serviços de saneamento básico, propiciando à população o acesso na conformidade de suas necessidades e maximizando a eficácia das ações e resultados;

III - abastecimento de água, esgotamento sanitário, limpeza urbana e manejo dos resíduos sólidos realizados de formas adequadas à saúde pública e à proteção do meio ambiente;

IV - Disponibilidade, em todas as áreas urbanas, de serviços de drenagem e de manejo das águas pluviais adequados à saúde pública e à segurança da vida e do patrimônio público e privado;

IV - Disponibilidade, em todas as áreas urbanas, de serviços de drenagem e manejo das águas pluviais, limpeza e fiscalização preventiva das respectivas redes, adequados à saúde pública e à segurança da vida e do patrimônio público e privado;(Redação dada pela Lei $n^{\circ} 13.308$, de 2016)

V - Adoção de métodos, técnicas e processos que considerem as peculiaridades locais e regionais;

VI - Articulação com as políticas de desenvolvimento urbano e regional, de habitação, de combate à pobreza e de sua erradicação, de proteção ambiental, de promoção da saúde e outras de relevante interesse social voltadas para a melhoria da qualidade de vida, para as quais o saneamento básico seja fator determinante;

VII - eficiência e sustentabilidade econômica;

VIII - utilização de tecnologias apropriadas, considerando a capacidade de pagamento dos usuários e a adoção de soluções graduais e progressivas;

IX - Transparência das ações, baseada em sistemas de informações e processos decisórios institucionalizados;

X - Controle social;

XI - Segurança, qualidade e regularidade;

XII - Integração das infraestruturas e serviços com a gestão eficiente dos recursos hídricos.

XIII - Adoção de medidas de fomento à moderação do consumo de água

Fonte: BRASIL, 2007

Esta nova diretriz mostra, especialmente em seu parágrafo $\mathrm{V}$, que a descentralização passa a fazer parte da realidade das políticas de saneamento no país, como forma de expandir o atendimento.

\subsubsection{Legislação brasileira para tratamento e lançamento de esgoto sanitário}

O tratamento, a emissão e o lançamento de esgoto sanitário no Brasil é regido por legislações federais, estaduais e municipais. Alguns municípios e Estados possuem legislações com 
exigências de tratamento que superam aquelas das legislações federais, como é o caso do Rio de Janeiro e São Paulo, por exemplo, onde as exigências em termos de carga orgânica, representada pela demanda bioquímica de oxigênio, é de $60 \mathrm{mg} / \mathrm{L}$ em São Paulo (SÃ̃ PAULO, 1976) e chega até $90 \%$ de remoção no Rio de Janeiro (RIO DE JANEIRO, 2007), contra $120 \mathrm{mg} / \mathrm{L}$ ou $60 \%$ de remoção da legislação federal (BRASIL, 2011).

Apesar de existirem alguns municípios com restrições mais exigentes, muitos dos municípios e Estados adotam a lei federal ou legislações que utilizam as mesmas exigências.

De forma geral, duas regulamentações federais regem o tratamento de efluente: uma diz respeito aos parâmetros de emissão do efluente na fonte poluidora e outra trata de seu lançamento em corpos d'água. As duas se complementam. São duas resoluções do Conselho Nacional do Meio Ambiente (CONAMA) - Resolução 430, de 2011, e Resolução 357, de 2005.

A Resolução 430 substitui o trecho da Resolução 357, que regulamenta as eficiências de tratamento e os parâmetros de emissão de efluentes de diversas fontes geradoras. Em seu artigo 21, a legislação define essas variáveis para o esgoto sanitário. A Tabela 4 - Resolução CONAMA N 430 - Artigo 16, a seguir, apresenta os principais parâmetros deste artigo e seus limites máximos de emissão ou eficiência mínima de tratamento:

Tabela 4 - Resolução CONAMA Nº430 - Artigo 16

\begin{tabular}{|lcc|}
\hline PARÂMETRO & LIMITE MÁXIMO & UNIDADE \\
$\mathrm{pH}$ & 5 a 9 & $\mathrm{UpH}$ \\
Temperatura & 40 & ${ }^{\circ} \mathrm{C}$ \\
$\begin{array}{l}\text { Materiais } \\
\text { sedimentáveis }\end{array}$ & 1 & $\mathrm{~mL} / \mathrm{L}$ \\
O\&G & 100 & $\mathrm{mg} / \mathrm{L}$ \\
$\mathrm{DBO}_{5}{ }^{20}$ & $120 \mathrm{mg} / \mathrm{L}$ ou $60 \%$ remoção \\
\hline
\end{tabular}

Fonte: BRASIL, 2011 - Adaptado

Já o trecho da 357, que trata da classificação das águas, continua válido, e o lançamento de efluentes em corpos d'água deve respeitar o enquadramento dos mesmos e os parâmetros deste enquadramento definidos em cada uma das classes. O lançamento de efluentes não pode prejudicar o enquadramento dos parâmetros de qualidade da água do rio dentro dos limites da classe definida para ele (BRASIL, 2005).

Para o caso do estado de São Paulo, onde foi feito o estudo, existe um decreto específico do governo do estado que estabelece os limites para lançamento de efluentes, tanto em redes de esgoto quanto em corpos d'água. O Decreto 8468 (SÃO PAULO, 1976) estabelece como limites os seguintes parâmetros, apresentados na tabela 5: 
Tabela 5 - Limites do decreto 8468

\begin{tabular}{|c|c|c|c|}
\hline PARÂMETRO & UNIDADE & $\begin{array}{l}\text { Lançamento em } \\
\text { rede de esgoto }\end{array}$ & Lançamento no ambiente \\
\hline $\mathrm{pH}$ & UpH & 6 a 10 & 5 a 9 \\
\hline Temperatura & ${ }^{\circ} \mathrm{C}$ & 40 & 40 \\
\hline Materiais sedimentáveis & $\mathrm{ml} / \mathrm{l}$ & 20 & 1 \\
\hline O\&G & $\mathrm{mg} / \mathrm{l}$ & 150 & 100 \\
\hline $\mathrm{DBO}_{5}{ }^{20}$ & $\mathrm{mg} / \mathrm{l}$ & - & $60 \mathrm{mg} / \mathrm{l}$ ou $80 \%$ remoção \\
\hline Arsênico & $\mathrm{mg} / \mathrm{l}$ & 1,5 & 0,2 \\
\hline Bário total & $\mathrm{mg} / \mathrm{l}$ & - & 5 \\
\hline Boro total & $\mathrm{mg} / \mathrm{l}$ & - & 5 \\
\hline Cádmio total & $\mathrm{mg} / \mathrm{l}$ & 1,5 & 0,2 \\
\hline Chumbo total & $\mathrm{mg} / \mathrm{l}$ & 1,5 & 0,5 \\
\hline Cianeto total & $\mathrm{mg} / \mathrm{l}$ & - & 0,2 \\
\hline Cobre dissolvido & $\mathrm{mg} / \mathrm{l}$ & 1,5 & 1 \\
\hline Cromo Hexavalente & $\mathrm{mg} / \mathrm{l}$ & 1,5 & 0,1 \\
\hline Cromo total & $\mathrm{mg} / \mathrm{l}$ & 5 & 5 \\
\hline Prata total & $\mathrm{mg} / \mathrm{l}$ & 1,5 & 0,02 \\
\hline Selênio total & $\mathrm{mg} / \mathrm{l}$ & 1,5 & 0,02 \\
\hline Cromo total & $\mathrm{mg} / \mathrm{l}$ & 5 & 5 \\
\hline Estanho & $\mathrm{mg} / \mathrm{l}$ & 4 & - \\
\hline Fenol & $\mathrm{mg} / \mathrm{l}$ & 5 & 0,5 \\
\hline Ferro Solúvel & $\mathrm{mg} / \mathrm{l}$ & 15 & 15 \\
\hline Fluoreto total & $\mathrm{mg} / \mathrm{l}$ & - & 10 \\
\hline Manganês dissolvido & $\mathrm{mg} / \mathrm{l}$ & - & 1 \\
\hline Mercúrio total & $\mathrm{mg} / \mathrm{l}$ & 1,5 & 0,01 \\
\hline Niquel & $\mathrm{mg} / \mathrm{l}$ & 2 & - \\
\hline Prata total & $\mathrm{mg} / \mathrm{l}$ & 1,5 & 0,02 \\
\hline Selênio total & $\mathrm{mg} / \mathrm{l}$ & 1,5 & 0,02 \\
\hline Sulfeto & $\mathrm{mg} / \mathrm{l}$ & 1 & - \\
\hline Sulfato & $\mathrm{mg} / \mathrm{l}$ & 1000 & - \\
\hline Zinco & $\mathrm{mg} / \mathrm{l}$ & 5 & - \\
\hline Inflamáveis ou explosivos & Presença & Ausentes & - \\
\hline Tóxico para biológico & Presença & Ausentes & - \\
\hline
\end{tabular}

\subsection{Sistemas naturais de tratamento de esgoto sanitário}

A maioria dos sistemas de tratamento de esgoto depende de processos naturais, como a força gravitacional e a atividade biológica de organismos vivos. Porém, tipicamente os sistemas utilizam esses processos em arranjos que dependem de um alto consumo de energia com equipamentos mecânicos. Os sistemas naturais de tratamento dependem principalmente dos componentes naturais, e não dependem exclusivamente de fontes externas de energia para atender os objetivos do tratamento (CRITES; MIDDLEBROOK; REED, 2014). 
Os sistemas de tratamento podem ser classificados como naturais quando são baseados na capacidade de ciclagem dos elementos contidos no esgoto em ecossistemas naturais, sem aporte de energia externa para acelerar os processos bioquímicos (SEZERINO et al. 2005).

Os sistemas naturais efetivos para tratamento de esgoto podem ser divididos em três principais categorias: Aquáticos, terrestres e de alagados. Os sistemas aquáticos são compostos por lagoas de tratamento. Os sistemas de alagados são definidos por um terreno com um nível de água acima do solo suficiente para manter o mesmo saturado e propiciar o crescimento de espécies típicas de plantas. Os sistemas terrestres funcionam com a aplicação e percolação do esgoto através do solo (CRITES; MIDDLEBROOK; REED, 2014).

Os sistemas naturais de tratamento, como os wetlands construídos, têm chamado atenção e ganhado importância por serem soluções com baixo custo de implantação e baixa complexidade de operação, privilegiando soluções para a descentralização dos sistemas de tratamento (CRITES; MIDDLEBROOK; REED, 2014; HENCH et al., 2003; ÁVILA et al., 2013b; WU et al., 2015; MEYER et al., 2013).

Hench (2003) afirma que os WC tem se tornado uma opção popular nas áreas rurais dos Estados Unidos por questões de tipo de solo, topografia e por terem um custo acessível. Ávila (2013b) afirma que com a implementação de novas diretivas na Europa as pequenas comunidades, com menos de 2000 habitantes, tem aumentado seu interesse em soluções descentralizadas para o tratamento de esgoto, e que tem aumentado também a busca por soluções que tenham custo acessível e que tenham valor estético e ecológico, como é o caso dos WC. Wu (2015) mostra que o mesmo ocorre na China, onde as pequenas comunidades têm buscado soluções descentralizadas e os WC tem ganhado espaço.

\subsection{Os wetlands construídos no tratamento de águas residuárias}

Os wetlands construídos (WC) são apresentados na literatura com diversas outras nomenclaturas, entre elas as mais comuns são: "sistemas alagados construídos", "terras úmidas construídas", "leitos plantados", "leitos com macrófitas", "filtros plantados com macrófitas", "filtros com macrófitas", "leitos cultivados", "sistemas de zonas de raízes", "jardins filtrantes" etc. (VON SPERLING e SEZERINO, 2018).

Os wetlands construídos são sistemas artificiais que simulam as condições das áreas alagadas naturais, utilizando os seus princípios básicos de modificação da qualidade da água (SALATI, 2000).

A utilização ou observação de wetlands construídos como depuradores de águas residuárias remonta à história da civilização antiga na China e Egito, onde estes ambientes foram envolvidos, de uma forma quase intencional, na purificação e tratamento das águas residuárias (CARVALHO et al., 2017).

O primeiro experimento científico de tratamento de águas residuárias com plantas de áreas alagadas é atribuído a Seidel, em 1952, mas somente a partir da década de 1990 o número de experimentos teve um grande aumento e ganhou um volume significativo. A primeira aparição 
do termo "wetlands construídos" (constructed wetlands, em inglês) no campo científico data de 1989¹ , nos Estados Unidos. (HOFFMANN et al., 2011; CARVALHO et al., 2017)

Os wetlands construídos oferecem melhores condições de tratamento de águas residuárias do que os wetlands naturais, pois podem ser projetados para otimizar o desempenho de remoção de carga orgânica e nutrientes (VERHOEVEN; MUELEN, 1999).

\subsubsection{Componentes dos wetlands construídos}

Os três principais componentes da maioria dos sistemas de wetlands construídos são os mesmos encontrados nos wetlands naturais. Porém, nos WC eles são escolhidos e dimensionados para maximizar sua capacidade de depuração dos esgotos e efluentes os quais se destinam a tratar (SALATI, 2000; UCKER et al., 2014; BRIX, 1994;).

Esses componentes, bem como suas principais funções relativas ao tratamento e ao funcionamento do sistema, são apresentados a seguir.

I. Meio suporte

O meio suporte apresenta três principais funções: filtração do efluente, suporte para fixação e desenvolvimento das plantas e dos microrganismos e adsorção de alguns compostos. As características de uniformidade, porosidade e condutividade hidráulica afetam os processos de tratamento e depuração dos efluentes, portanto, é necessário que as considere durante a escolha do meio. Esta escolha deve levar em consideração o tipo de escoamento e os objetivos do tratamento (UCKER et al., 2014; BRIX, 1993).

O meio suporte ou substrato ainda desempenha uma função importante de adsorção de alguns compostos, em especial o fósforo contido nos esgotos sanitários (BRIX, 1994). Por esta razão, diversos estudos têm testado diferentes substratos para remoção de substâncias e poluentes dos mais variados (LU et al., 2016; SAEED; SUN, 2012; ZHANG et al., 2015; ROZARI et al., 2016)

\section{Plantas}

A disponibilidade de oxigênio nos solos saturados de água é menor do que nos solos secos, pois nestes os poros são preenchidos com ar, que contém uma concentração mais alta de oxigênio dissolvido do que a água que preenche os poros do solo saturado. As plantas típicas dos wetlands são adaptadas para crescer neste solo, contendo espaços internos que transportam ar para as raízes, liberando-o também na rizosfera. Essas plantas são conhecidas como macrófitas (BRIX, 1994).

As macrófitas são vegetais terrestres que ao longo de sua evolução se adaptaram ao ambiente aquático, por isso apresentam tanto características de vegetais terrestres quanto aquáticos. As macrófitas são classificadas em 5 grupos ecológicos, de acordo com seu modo de vida no ambiente aquático. (PROBIO, 2017). A figura 1 ilustra estes três tipos de macrófitas:

${ }^{1}$ Snoddy, E.L.; Cooney, J.C. Insecticides for Insect Pest-Control in Constructed Wetlands for Waste-Water Treatment-A Dilemma. In Proceedings of the National Pesticide Conference, Richmond, VA, USA, 11-12 May 1989; pp. 440-443. 
Figura 1- Tipos de macrófitas.

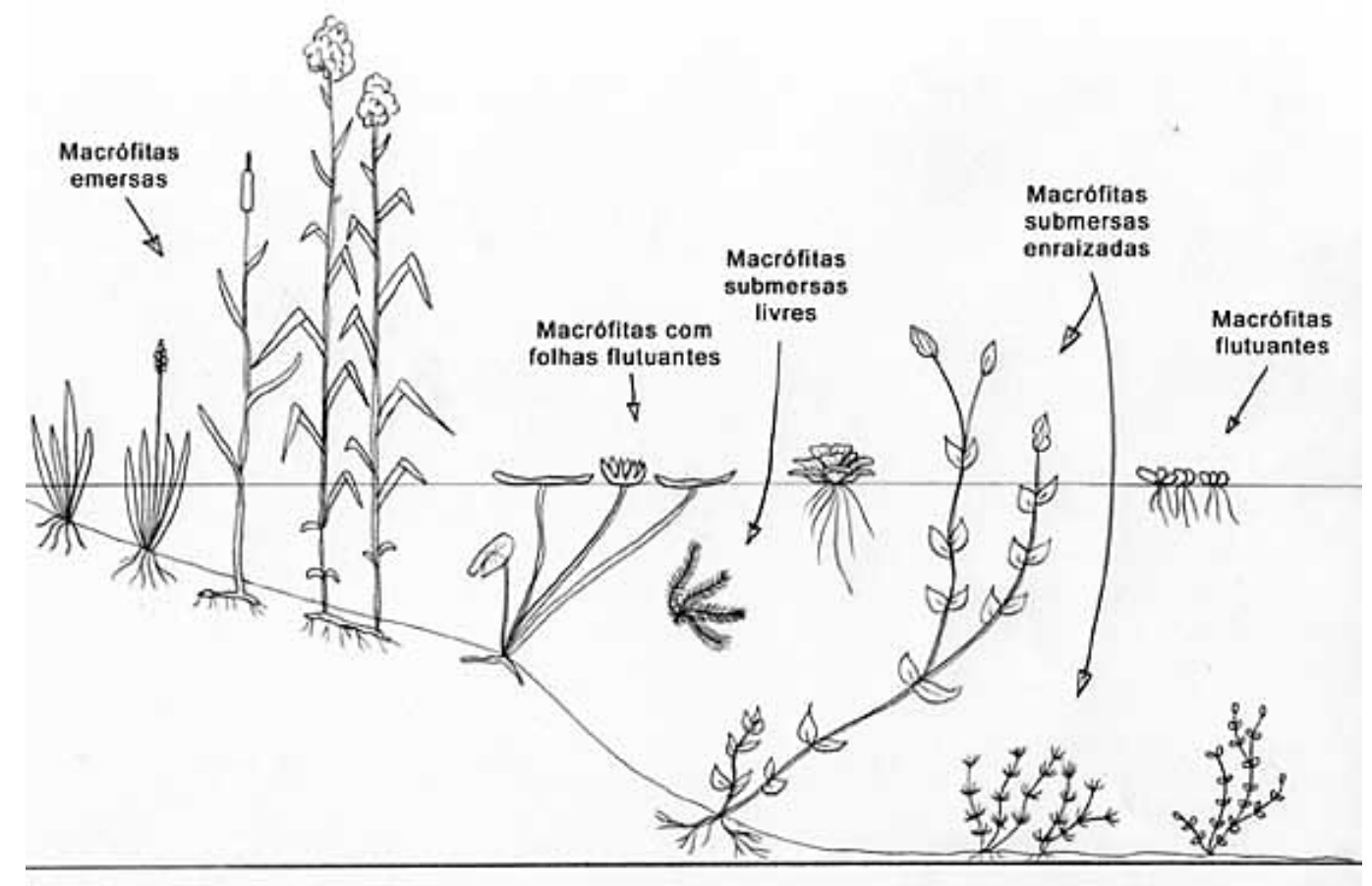

Fonte: PROBIO, 2017

As duas principais funções das plantas nos sistemas de WC são a liberação de oxigênio na rizosfera e a absorção de nutrientes através do seu metabolismo (BRIX, 1994).

As plantas desempenham ainda mais algumas que auxiliam nos processos de tratamento. São responsáveis por proteger o sistema das intempéries e da radiação solar, fornecem área superficial para desenvolvimento de microrganismos, favorecem algumas espécies de microrganismos (mutualismo), influenciam na configuração do substrato e na filtração através do crescimento das raízes, auxiliam na estabilização do substrato, através das raízes, evitando erosão, e ajudam a minimizar os efeitos de colmatação (BRIX, 1994; SILVA, 2007).

As plantas ainda possuem importância estética na paisagem, no desenvolvimento de ecossistemas locais e podem, inclusive, ser utilizadas para diversos fins, como alimentação, construções naturais, entre outros (ZANELLA, 2008).

O Quadro 3, apresenta um resumo das principais funções de cada parte da planta no processo de tratamento:

Quadro 3 - Principais funções das plantas nos WC

\begin{tabular}{|l|l|}
\hline Partes da Planta & \multicolumn{1}{c|}{ Funções } \\
\hline \multirow{4}{*}{ Parte aérea } & Atenuação de luz $\rightarrow$ reduz o crescimento de fitoplâncton \\
\cline { 2 - 3 } & Redução da velocidade do vento \\
\cline { 2 - 3 } & Efeito estético \\
\cline { 2 - 3 } & Armazenamento de nutrientes \\
\hline \multirow{4}{*}{ Tecidos submersos } & Filtragem \\
\cline { 2 - 2 } & Redução da velocidade da corrente de água \\
\cline { 2 - 2 } & Superfície para formação de biofilmes \\
\cline { 2 - 2 } & Consumo de nutrientes \\
\hline
\end{tabular}




\begin{tabular}{|l|l|}
\hline & Excreção de oxigênio fotossintético \\
\hline \multirow{4}{*}{ Raízes e Rizomas nos sedimentos } & Bio-Drenagem $\rightarrow$ inviabiliza a colmatação do substrato \\
\cline { 2 - 3 } & $\begin{array}{l}\text { Liberação de oxigênio } \rightarrow \text { favorece a degradação da } \\
\text { matéria } \\
\text { orgânica }\end{array}$ \\
\cline { 2 - 2 } & Absorção de nutrientes \\
\cline { 2 - 3 } & Liberação de antibióticos \\
\cline { 2 - 3 } & Habitat de micro e macro biotas \\
\hline
\end{tabular}

Fonte: Tradução livre de UCKER et al., 2014

\section{Microrganismos}

Os principais processos de depuração de poluentes ocorridos nos wetlands construídos, assim como em sistemas convencionais de tratamento de esgoto, são promovidos por processos físicos e pela atividade dos microrganismos (BRIX, 1997).

Os ambientes dos wetlands construídos possuem uma grande quantidade de microrganismos, especialmente fungos e bactérias, que, através de seu metabolismo, promovem transformações bioquímicas dos contaminantes contidos no esgoto (MANSOR, 1998).

Na presença de oxigênio, os microrganismos transformam a matéria orgânica contida no esgoto em compostos mais simples, como água e gás carbônico (UCKER et al., 2014). O oxigênio necessário para essas reações é fornecido por dois principais processos: difusão através da interface com a atmosfera e introdução no meio pelas raízes das macrófitas (SEZERINO, 2005).

Entre os diversos microrganismos presentes nos sistemas de wetlands, podemos destacar as bactérias como principais responsáveis pela depuração da matéria orgânica através de seu metabolismo. A atividade das bactérias inclui uma grande capacidade de remoção de nutrientes, removendo-os do esgoto, em especial fósforo e nitrogênio (VON SPERLING, 2014). As bactérias são particularmente importantes por apresentarem caminhos metabólicos versáteis, altas taxas metabólicas e curtos tempos de reprodução (VALIPOUR; AHN, 2016).

\subsubsection{Tipos e classificações dos wetlands construídos}

A grande maioria dos autores, como Brix, Schierup, Valipour, Ahn, entre outros, classifica os sistemas de wetlands construídos de acordo com duas características: o tipo de macrófita utilizado e o tipo de fluxo de fluído no sistema.

Em relação às macrófitas, existem três possibilidades para o tipo de planta dominante no sistema: flutuantes ou de folhas flutuantes, enraizadas emersas ou emergentes, submersas livres ou enraizadas (BRIX; SCHIERUP, 1989).

Em relação ao fluxo podemos classificar os sistemas em duas vertentes: Fluxo superficial e fluxo sub-superficial, sendo possível, nesta segunda vertente, trabalhar com fluxo horizontal ou vertical de fluído (VALIPOUR; AHN, 2016).

Os wetlands de fluxo superficial contam com um fluxo de fluido acima do nível do substrato, com uma lâmina de fluido aparente. Nestes sistemas, o fluido escoa horizontalmente. Nos sistemas de fluxo sub-superficial, o fluído escoa abaixo do nível de substrato, sem lâmina aparente. Esses sistemas podem trabalhar tanto com fluxo vertical como horizontal (VALIPOUR; AHN, 2016). A figura 2, a seguir, ilustra essas possibilidades de fluxo: 
Figura 2 - Tipos de fluxo nos wetlands construídos

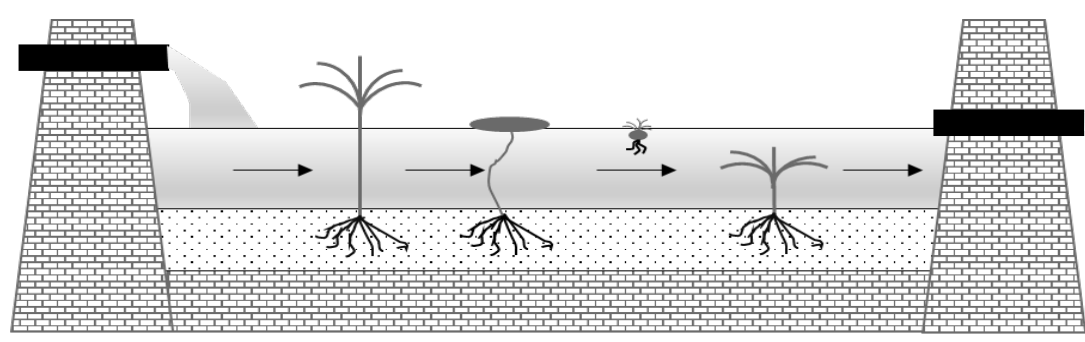

Fluxo superficial horizontal

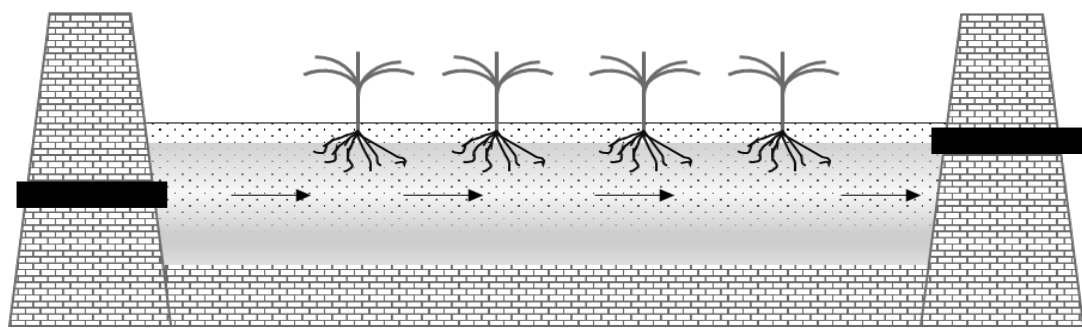

Fluxo sub-superficial horizontal

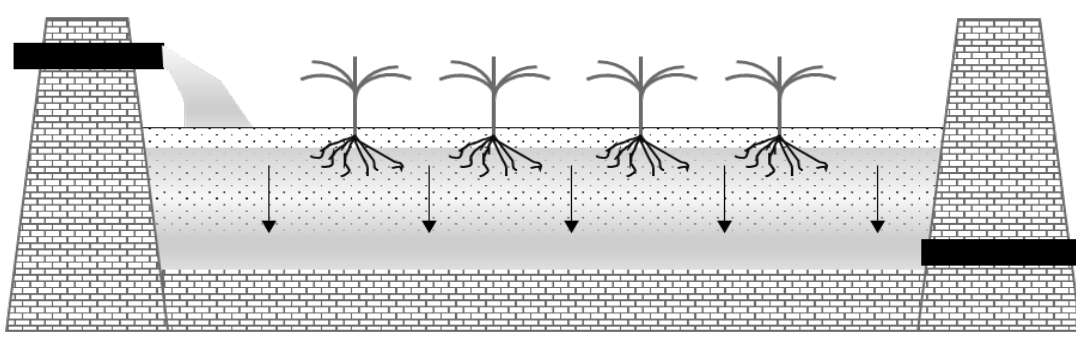

Fluxo sub-superficial vertical

Fonte: Cauê Girão de Abreu, 2019

Existe ainda a possibilidade de se classificar os sistemas em relação à condição do substrato, relativa à presença do fluído. O sistema pode ser classificado como saturado quando o substrato permanece constantemente submerso, e não saturado quando existem períodos em que todo o fluido é extraído do sistema e o substrato permanece sem lâmina de água ou efluente (SAEED; SUN, 2012).

Afigura 3, a seguir, ilustra as possibilidades de classificação dos sistemas: 
Figura 3 - Classificação dos WC

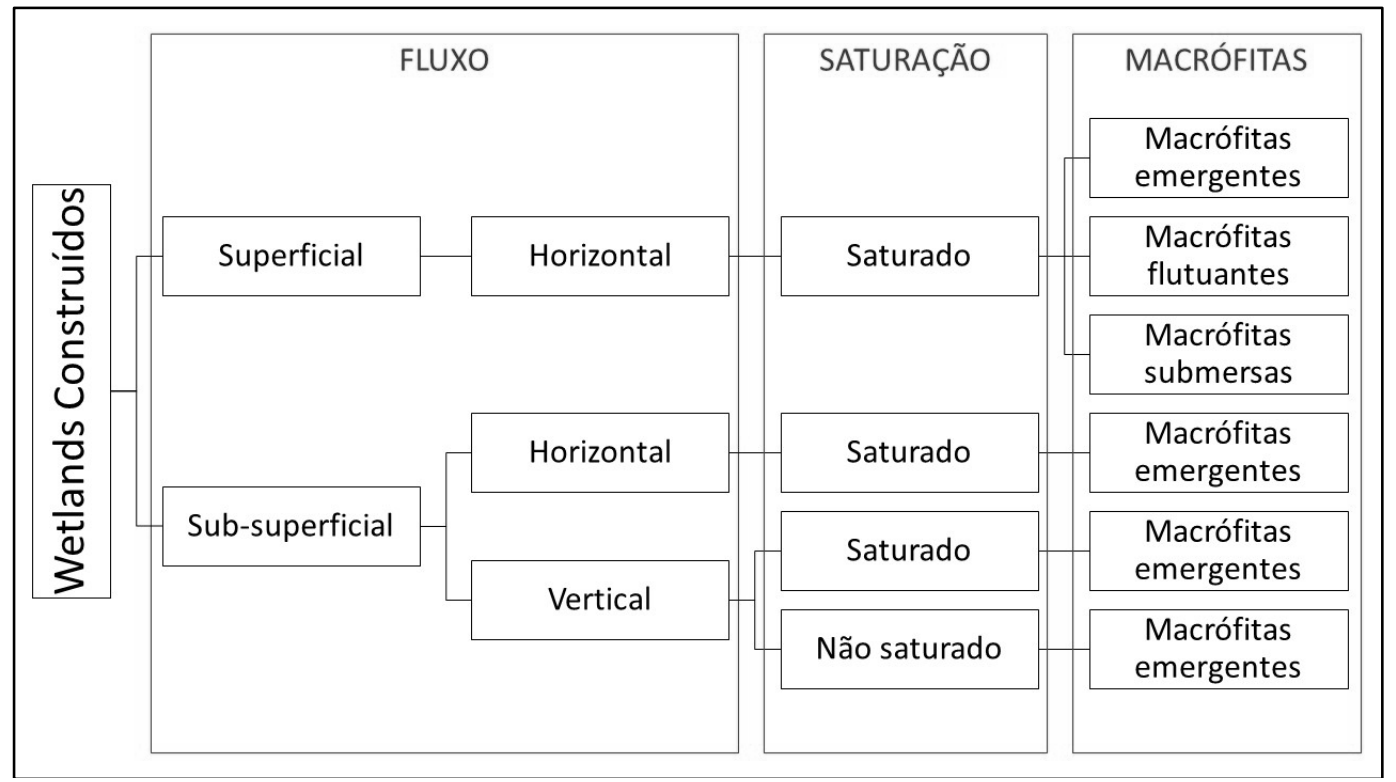

Fonte: Adaptado de BRIX; SCHIERUP, 1989 e VALIPOUR; AHN, 2016.

Além desses apresentados, existem sistemas que apresentam combinações e variações dessas classificações. São conhecidos como sistemas híbridos.

Os sistemas híbridos combinam as vantagens dos sistemas saturados e não saturados, vertical e horizontal, de forma a obter melhores eficiências de tratamento, principalmente em relação à remoção de nutrientes e, em especial, o nitrogênio, pela diferente concentração de oxigênio em cada uma das etapas, permitindo tanto a nitrificação quanto a desnitrificação (VYMAZAL, 2013).

\subsubsection{Processos e mecanismos de remoção de poluentes nos wetlands construídos}

A remoção dos poluentes nos wetlands construídos ocorre por meio de inúmeros processos físicos, químicos e biológicos, promovidos pelos diversos componentes dos sistemas.

Segundo Brix (1993), a remoção dos contaminantes ocorre da seguinte maneira:

- Sólidos suspensos são removidos por meio de processos físicos, na percolação do efluente através do substrato, que atua como um filtro, e da sedimentação, quando existe lâmina de líquido aparente.

- A carga orgânica é removida através do metabolismo dos microrganismos que crescem tanto em suspensão quanto aderidos ao substrato e às plantas e raízes.

- Para o nitrogênio, a degradação ocorre por meio de processos de nitrificação e desnitrificação, que ocorrem na presença e ausência de oxigênio, respectivamente, em diferentes etapas da passagem do efluente pelo sistema, em ambientes que sofrem variações na quantidade de oxigênio dissolvido. Além desses processos existe também a volatilização da amônia para a atmosfera e a retirada de nitrogênio pelas plantas, que o utilizam como nutriente no seu metabolismo. 
- O fósforo é, em sua maioria, adsorvido pelo substrato e precipitado por compostos de alumínio, ferro, cálcio e argila contidos no mesmo. Uma parte desse nutriente é também removida e aproveitada pelas plantas.

- Os organismos patógenos são eliminados pelo tempo de detenção que causa morte natural devido à duração de seu ciclo de vida e falta de condições de desenvolvimento, além de predação por outros organismos. São retidos também nos processos de filtração e sedimentação ocorridos no substrato e na lâmina de liquido, eliminados por radiação ultravioleta e, ainda, mortos por substâncias antibióticas eliminadas pelas raízes das plantas.

Para a remoção dos metais, que podem estar presentes no esgoto, alguns mecanismos e processos contribuem diminuindo suas concentrações no efluente tratados: complexação com substâncias presentes no substrato e consequente precipitação; sedimentação dos metais precipitados na lâmina líquida e filtração deles no substrato; utilização pelas plantas na forma de micronutrientes; e acumulação deles nos tecidos vegetais e oxidação bioquímica pelo metabolismo dos microrganismos (SÍMA et al., 2016).

O Quadro 4 apresenta as principais características físico-químicas do esgoto, os respectivos processos de remoção e os componentes do sistema responsável pelo processo:

Quadro 4 - Processos de remoção de variáveis de interesse nos WC

\begin{tabular}{|c|c|c|}
\hline Constituintes & Mecanismos de remoção & Componentes do WC \\
\hline Sólidos suspensos & Sedimentação e filtração & $\begin{array}{l}\text { Substrato e lâmina } \\
\text { líquida }\end{array}$ \\
\hline $\begin{array}{c}\text { Material orgânico } \\
\text { solúvel }\end{array}$ & Degradação aeróbia e anaeróbia & Microrganismos \\
\hline \multirow{3}{*}{ Nitrogênio } & Utilização pela planta & Plantas \\
\hline & $\begin{array}{c}\text { Amonificação, nitrificação e desnitrificação } \\
\text { (biológico) }\end{array}$ & Microrganismos \\
\hline & Volatilização de amônia & Lâmina líquida \\
\hline \multirow{3}{*}{ Fósforo } & Adsorção & Substrato \\
\hline & Utilização pela planta & Plantas \\
\hline & Adsorção e troca de cátions & Substrato \\
\hline \multirow{5}{*}{ Metais } & Complexação, precipitação & $\begin{array}{l}\text { Substrato e lâmina } \\
\text { líquida }\end{array}$ \\
\hline & Utilização pela planta e acumulação & Plantas \\
\hline & Oxidação redução (bioquímica) & Microrganismos \\
\hline & Sedimentação & Lâmina líquida \\
\hline & Filtração & Substrato \\
\hline \multirow{4}{*}{ Patógenos } & Predação & Microrganismos \\
\hline & Morte Natural & Tempo de detenção \\
\hline & Irradiação UV & Lâmina líquida \\
\hline & $\begin{array}{l}\text { Excreção de antibiótico pelas raízes das } \\
\text { macrófitas }\end{array}$ & Plantas \\
\hline
\end{tabular}

Fontes: BRIX, 1993, e SÍMA et al., 2016 


\subsubsection{Eficiência de tratamento de efluentes dos wetlands construídos}

As principais características físico-químicas dos esgotos sanitários, conforme apresentado, são carga orgânica, sólidos suspensos e nutrientes (nitrogênio e fósforo). As eficiências de tratamento de efluentes nos sistemas de wetlands construídos em relação à remoção destes parâmetros podem variar bastante, de acordo com as condições específicas de aplicação, por exemplo em relação à taxa de aplicação $\left(\mathrm{m}^{3} / \mathrm{m}^{2 *}\right.$ dia; $\mathrm{kg} \mathrm{DBO}_{5}{ }^{20} / \mathrm{m}^{2 *}$ dia; $\mathrm{Kg} \mathrm{N} / \mathrm{m}^{2 *}$ dia; etc.) e ao tipo de sistema utilizado (superficial, sub-superficial, vertical, horizontal, híbrido etc.).

A figura 4, mostra eficiências encontradas em diversos sistemas, todos efetuando tratamento de esgoto sanitário municipal:

Figura 4 - Eficiência de tratamento de esgoto em WC.

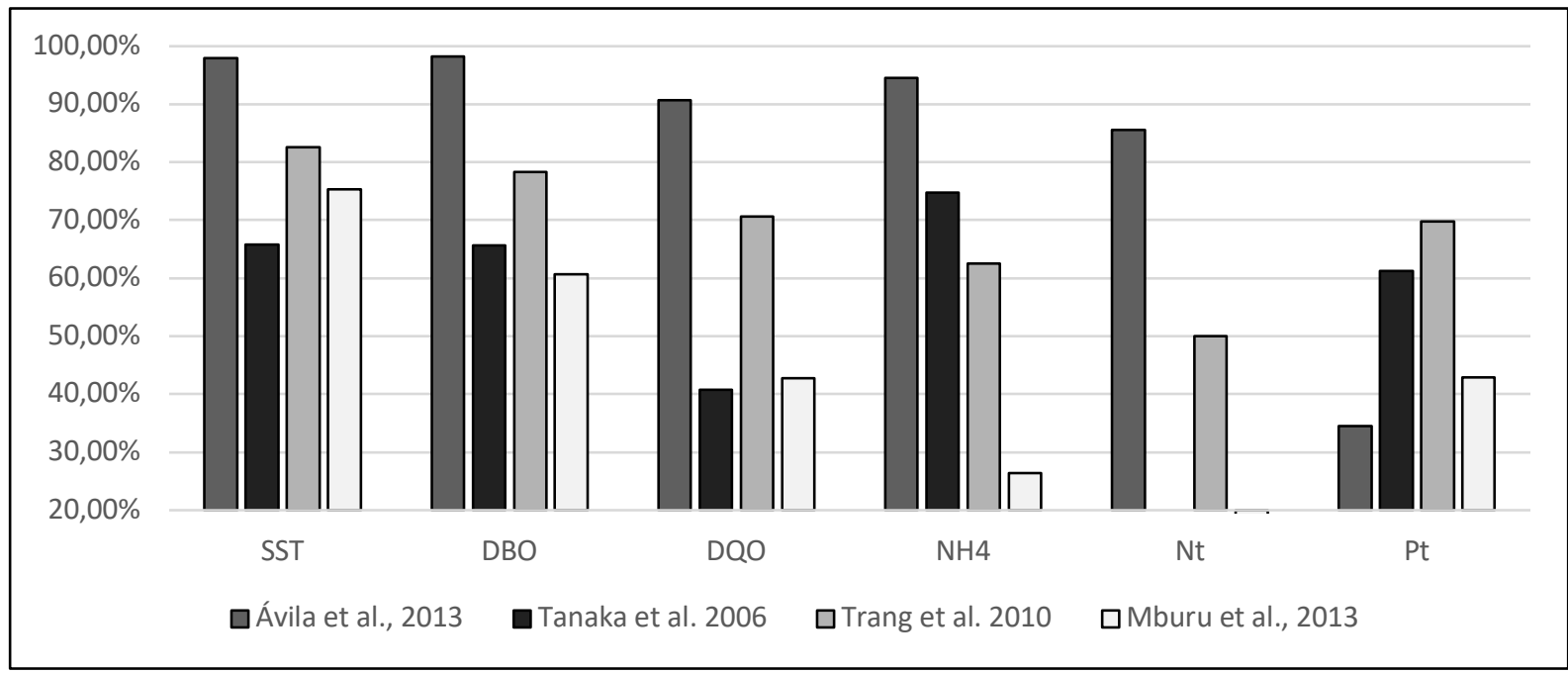

Fonte: Cauê Girão de Abreu, 2019

As eficiências apresentadas ilustram as grandes variações de eficiência que ocorrem na aplicação dos sistemas, com remoções variando de valores bastante discretos até valores de quase totalidade de remoção, para todos os parâmetros.

Estes resultados mostram ainda que os sistemas de wetlands construídos podem atingir altas eficiências, sendo capazes de remover os 6 contaminantes do esgoto sanitário apresentados ,em níveis que o tornam seguro para disposição no meio ambiente.

Alguns estudos que mostram boa eficiência dos WC em relação a outros parâmetros, referentes à poluentes de reconhecimento mais recente e à poluentes com presença de antibióticos (YIDONG et al. 2017), anti-inflamatórios (ÁVILA et al. 2014); vírus (RACHMADI et al. 2016); hormônios (VYMAZAL et al. 2015) e metais (SÍMA et al. 2016).

\subsection{Dimensionamento e aplicações de wetlands construídos no tratamento de esgoto sanitário}

O dimensionamento dos sistemas de wetlands construídos é feito de forma empírica, com base nos conhecimentos adquiridos através de muitos anos de estudos em laboratório e escala real na implantação e operação destes sistemas. O dimensionamento é feito com base no valor de carga orgânica aplicada, na forma de uma relação entre a carga e a área superficial do sistema, sendo a carga expressada em número de população equivalente (PE) (MOLLE et al. 2005).

Várias relações de área por pessoa equivalente foram propostas e estudadas por diferentes autores, com variações típicas entre 2 e $5 \mathrm{~m}^{2} \mathrm{PE}^{-1}$. Alguns autores chegaram até a propor equações de dimensionamento para determinados tipos de wetlands (VYMAZAL, 2005). 
Recentemente, foi proposto por Von Sperlig e Sezerino (2018) um roteiro de dimensionamento para WC de escoamento horizontal subsuperficial, WC de escoamento vertical e WC de escoamento vertical (sistema francês) ${ }^{2}$. O dimensionamento proposto também segue na linha empírica, baseado em taxas de aplicação e relação de área por habitante equivalente. (VON SPERLING e SEZERINO, 2018).

Diversos modelos foram criados para dimensionar os sistemas. Meyer et al. (2015) apresenta um comparativo de diversos modelos e separa-os em três diferentes grupos, de acordo com as principais características: modelos baseados na biocinética inspirada nos sistemas de lodos ativados e aplicados a softwares de modelagem (CWM1 e CW2D); modelos utilizando relações entre gases e bactérias e focados em fenômenos específicos como remoções de fósforo e nitrogênio (Diph_M e DPM) e modelos combinando fluxo hidráulico com cinética (RTD/GPSX, ASM1 e RSF_Sim).

O primeiro grupo, baseado em cinética, traz bons resultados, porém é demasiadamente complexo em sua aplicação, demandando muito tempo e investimento. Por esta razão ele é indicado apenas para fins de pesquisa, e não para aplicações práticas (MEYER et al., 2015).

O segundo grupo demanda o levantamento de parâmetros que não são fáceis de se obter na prática e que não estão abundantemente disponíveis na literatura, além de fazer aproximações i ignorar algumas condições reais. Estas limitações tornam estes modelos bastante específicos para cada caso de aplicação, tornando difícil sua aplicação no uso prático em larga escala (MEYER et al., 2015).

O terceiro grupo estima com sucesso as eficiências de longo prazo do sistema, porem baseia-se apenas em carga hidráulica e precisa ser aperfeiçoado para considerar as cargas de poluentes, caso contrário sua aplicação fica restrita ao grupo de efluente a que foi calibrado (MEYER et al., 2015).

Diferentes configurações de wetlands construídos são usados para tratar uma grande variedade de efluentes ao redor do mundo, suas características e seus dimensionamentos variam bastante de acordo com o clima local, as cargas de aplicação de poluentes e com os tipos e composições dos efluentes (BRIX, 1994).

Em relação ao tratamento de esgoto sanitário, são encontrados muitos trabalhos e aplicações dos WC com excelentes resultados, seja como tratamento primário (VALIPOUR et al., 2014; KIM et al., 2015; MILLOT et al. 2016), secundário (VYMAZAL e KRÖPFELOVÁ, 2015; SARTORI et al.,2016; RAI et al., 2015) ou terciário (CUI et al., 2015; ROZARI et al., 2016; TOSCANO et al., 2015).

\subsubsection{Vantagens e desvantagens dos sistemas de wetlands construídos}

Assim como todas as tecnologias, os wetlands construídos possuem vantagens e desvantagens em relação a outras opções de tratamento de esgoto. As principais vantagens e desvantagens estão descritas no Quadro 5:

${ }^{2}$ Sistema com duas etapas de tratamento em série, que dispensa o tratamento primário (VON SPERLING e SEZERINO, 2018). 
Quadro 5 - Vantagens e desvantagens dos WC

\begin{tabular}{|l|l|}
\hline \multicolumn{1}{|c|}{ Vantagens } & \multicolumn{1}{|c|}{ Desvantagens } \\
\hline $\begin{array}{l}\text { São relativamente baratos para se construir e } \\
\text { operar. }\end{array}$ & $\begin{array}{l}\text { Demanda grande área para construção (custo e } \\
\text { disponibilidade satisfatórios de área). }\end{array}$ \\
\hline $\begin{array}{l}\text { Possuem manutenção mais simples que } \\
\text { sistemas tradicionais. }\end{array}$ & $\begin{array}{l}\text { Apresentam recorrentes imprecisões para os } \\
\text { critérios de design e operação. }\end{array}$ \\
\hline $\begin{array}{l}\text { Fornecem tratamento efetivo e seguro de de } \\
\text { águas residuárias. }\end{array}$ & $\begin{array}{l}\text { Complexidade biológica e hidrológica do } \\
\text { sistema e a falta de conhecimento da dinâmica } \\
\text { dos processos de tratamento . }\end{array}$ \\
\hline $\begin{array}{l}\text { São relativamente tolerantes a variações } \\
\text { hidráulicas e de cargas de contaminantes }\end{array}$ & Altos custos de alguns meios de enchimento. \\
\hline $\begin{array}{l}\text { Fornecem benefícios indiretos como área } \\
\text { verde, habitats para a vida selvagem e áreas } \\
\text { recreativas e educacionais. }\end{array}$ & $\begin{array}{l}\text { Possíveis problemas com pragas nas tipologias } \\
\text { superficiais. }\end{array}$ \\
\hline
\end{tabular}

Fonte: PHILIPPI; SEZERINO, 2004

3.5 Interferência do clima e do tempo de operação no tratamento de esgoto em wetlands construídos

\subsubsection{Relações com o clima}

As variações climáticas, representadas por variações de temperatura e pluviometria, podem ter influência direta nas eficiências de tratamento dos sistemas de WC. De acordo com a localização do sistema e a respectiva amplitude destas variações os efeitos podem ser mais ou menos representativos. Estudos mostram que em algumas regiões existem grandes variações, enquanto em outras elas não são significantes (KIM, et al., 2015; VALIPOUR; AHN, 2016; ROZEMA et al., 2016; YAN; XU, 2014).

Kim (2015) apresenta remoções de nitrogênio total e sua relação com a temperatura em cada uma das estações do ano, em diferentes sistemas implantados na Coréia do Sul. Em seu estudo a eficiência de remoção variou de $75,2 \%$ no verão a $66,4 \%$ no inverno. Valipur e Ahn (2016) mostram diversas diferenças de remoção de poluentes em sistemas instalados em locais de clima frio e ainda propões algumas modificações para sistemas implantados nestas condições que podem amenizar esta diferença. Rozema (2016) apresenta dados de eficiência de remoções de diversos parâmetros em um sistema instalado no Canadá, em clima frio. Ele acompanha as eficiências ao longo de 6 anos e apresenta diferenças nas eficiências ao longo das variações de temperatura do ano.

Estas variações são resultado de uma relação de interferência entre as duas variáveis que representam o clima e os processos biológicos, físicos e químicos envolvidos na remoção de poluentes nos wetlands.

O clima influencia diretamente em alguns dos processos mais importantes de remoção e degradação de poluentes, entre eles destacam os seguintes (KADLEC \& REDDY, 2001):

I. Crescimento das plantas

O crescimento e desenvolvimento das plantas é regido, em parte, pela intensidade luminosa, pluviometria e pela temperatura, variando ao longo das estações do ano juntamente com a variação do clima. Durante a temporada de maior crescimento as plantas absorvem mais nutrientes, podendo influenciar na eficiência global do sistema.

II. Tempo de detenção 
O tempo de detenção do efluente dentro do sistema de tratamento é alterado pela pluviometria e pela evapotranspiração, ambos fatores relacionados diretamente com a variação do clima, na forma da pluviometria por si só e da temperatura e radiação solar. A variação de tempo de detenção pode impactar diretamente nas eficiências, uma vez que os processos de remoção e degradação dependem de tempo para ocorrer.

\section{Condições físico-químicas}

As variações climáticas, principalmente de temperatura, alteram as condições físico-químicas do meio de tratamento, alterando solubilidade de gases, principalmente oxigênio. A disponibilidade de aceptores de elétrons para as reações, assim como a capacidade de adsorção e saturação do substrato, são diretamente afetados pela temperatura.

As reações de transporte de massa através das membranas dos microrganismos sofrem influência direta da viscosidade e da densidade da água contida no ambiente dos wetlands construídos, e essas propriedades da água são variáveis que também sofrem influência direta da temperatura.

Muitos coeficientes de reações químicas como a volatilização da amônia por exemplo, variam de acordo com a temperatura no ambiente de reação. Estas variações atuam diretamente nos processos de remoção e podem impactar a eficiência do sistema.

Os processos de formação de material particulado e de sedimentação também tem dependência e relacionamento com a temperatura do meio. Apesar de sofrer apenas uma fraca influência, estes processos podem ser diminuídos em temperaturas baixas. Fennessy (1994) mostra que enquanto as taxas de sedimentação variam 0.2 a $52 \mathrm{~g} \mathrm{~m}^{-2} \mathrm{~d}^{-1}$ no inverno elas atingem valores de 2,1 a $167 \mathrm{~g} \mathrm{~m}^{-2} \mathrm{~d}^{-1}$.

A capacidade de adsorção de poluentes, notadamente fósforo e metais, é diretamente afetada pela temperatura, sendo maior nas temperaturas mais amenas.

\section{Processos microbiológicos}

A atividade microbiológica e os processos de remoção e degradação de poluentes ligados a ela são dependentes da temperatura, ocorrendo em taxas maiores dentro de faixas determinadas de temperatura, de forma que variações na temperatura do sistema podem acelerar ou frear a atividade e, por consequência, interferir na eficiência de remoção.

$\mathrm{O}$ crescimento e desenvolvimento microbiológico tem uma temperatura ótima, sendo que as taxas são mais elevadas quando se trabalha em temperaturas mais perto deste ponto ótimo. Quanto maior esta taxa de crescimento, maior a eficiência do microrganismo na remoção dos poluentes.

Os coeficientes das reações do modelo de primeira ordem utilizado para modelar a remoção biológica de matéria orgânica devem ser ajustados por um fator relacionado à temperatura, sendo estas remoções, portanto, dependentes também da temperatura no ambiente de reação.

As reações microbiológicas envolvidas na remoção de nitrogênio também sofrem impacto da temperatura. A concentração de nitrogênio orgânico, em wetlands construídos, conta com contribuição do nitrogênio liberado pela decomposição de partes das plantas que habitam o sistema e essa decomposição ocorre mais acentuadamente em climas mais quentes. A mineralização de nitrogênio orgânico também ocorre mais acentuadamente em temperaturas mais altas. As reações de nitrificação e denitrificação também dependem da temperatura e tem seus pontos ótimos em temperaturas entre 15 e 35 graus célsius. 
A remoção biológica de fósforo também depende da taxa de crescimento dos microrganismos, sendo, portanto, relacionada também à temperatura, assim como a extração de fósforo feita pelas plantas, que depende das taxas de crescimento e desenvolvimento das plantas.

\subsubsection{Relações com o tempo de operação (idade do sistema)}

O primeiro efeito que pode decorrer do tempo de operação de um sistema de wetlands construídos é o fenômeno de obstrução dos espaços do substrato, dificultando e interferindo no fluxo hidráulico que ali ocorre. Esta colmatação pode interferir diretamente nas eficiências de tratamento através da criação de curtos circuitos hidráulicos, zonas mortas e alteração dos fluxos hidráulicos, prejudicando os processos de sedimentação, filtração, adsorção e biodegradação (HUA et al., 2014)

Em relação ao processo de adsorção existe ainda o conceito de capacidade de adsorção e saturação, tornando este processo dependente do volume de material a ser adsorvido que é aplicado e, indiretamente, do tempo de operação do sistema. Após a aplicação de um determinado volume de carga a tendência é de que o material se aproxime da saturação e diminua sua capacidade de adsorção, diminuindo assim a eficiência de remoção de alguns poluentes, especialmente o fósforo (DRIZO et al., 2002).

\section{MATERIAIS E MÉTODOS}

\subsection{OBJETO DE PESQUISA}

O objeto de pesquisa foi um sistema de tratamento de esgoto sanitário através da tecnologia de wetlands construídos. $\mathrm{O}$ apêndice 2 apresenta mais detalhes e ilustrações do sistema estudado.

O sistema objeto deste estudo foi dimensionado para tratar esgoto sanitário de uma indústria. A contribuição será de esgoto sanitário bruto de uma população máxima de 650 pessoas com contribuição unitária de $160 \mathrm{~L} /$ pessoa*dia, totalizando $104.000 \mathrm{~L} /$ dia ou 1,2L/s, sendo o esgoto composto por todas a água residuárias das atividades não industriais: banheiros, vestiários, cozinha, refeitório e limpeza e lavagem das áreas não industriais. Com uma concentração de carga orgânica, em termos de $\mathrm{DBO}_{5}{ }^{20}$ considerada de $400 \mathrm{mg} / \mathrm{L}$, o sistema foi projetado para receber uma carga de $41,6 \mathrm{~kg}$ de $\mathrm{DBO}_{5}{ }^{20}$ por dia. Estes foram os dados utilizados pela projetista do sistema.

O sistema é composto por pré-tratamento para separação de sólidos grosseiros, tanque de recebimento e equalização do esgoto e aeração do mesmo, wetlands verticais subsuperficiais, wetlands horizontais subsuperficiais e wetlands horizontais superficiais, conforme descrição e detalhamento a seguir.

O pré-tratamento foi concebido apenas para remoção de sólidos grosseiros, através de um gradeamento simples construído em aço inox com distância entre barras de $10 \mathrm{~mm}$. O gradeamento foi dimensionado para instalação em uma canaleta de concreto na chegada do esgoto, onde foi também instalada uma calha Parshall com medidor ultrassônico de vazão. Todos os componentes desta etapa foram dimensionados para uma vazão máxima de até 10L/s.

Após o pré-tratamento, o esgoto segue por gravidade para um tanque de equalização e aeração, onde é acumulado até que obtenha o volume necessário para a alimentação dos $\mathrm{WC}$, que trabalham em intervalos intermitentes (bateladas). As bateladas são enviadas a cada vez que se atinge o volume máximo do tanque de equalização, variando de acordo com a vazão de contribuição e com tempo médio de aproximadamente 7 horas. 
O tanque de equalização foi dimensionado para um tempo de detenção de aproximadamente 7 horas, com um volume útil total de $30 \mathrm{~m}^{3}$, profundidade útil de $1,6 \mathrm{~m}$ e borda livre de $0,3 \mathrm{~m}$. $\mathrm{O}$ tanque foi construído enterrado em alvenaria. Foi construída ainda uma contenção com $110 \%$ do volume total do tanque para o caso de rompimento ou vazamento do tanque. Dentro do tanque foram instaladas chaves de nível para controle do volume, aeradores submersíveis do tipo venturi, para mistura e oxigenação do esgoto, e bombas submersíveis para a alimentação dos WC.

Os aeradores funcionam ininterruptamente para garantir introdução de oxigênio e impedir que o esgoto não entre em anaerobiose, que libera metano e sulfeto como subproduto do processo microbiológico e pode ocasionar maus odores no seu entorno. Desta forma, o esgoto acumulado é enviado com oxigênio aos WC e homogêneo em relação às variações diárias de carga e vazão.

As bombas de alimentação funcionam automaticamente, através do sinal enviado pelas chaves de nível, sendo ligadas quando o tanque atinge seu nível máximo e desligadas quando ele atinge seu nível mínimo. O volume total enviado para tratamento em cada operação da bomba equivale a $20 \mathrm{~m}^{3}$.

Como o tempo de detenção é consideravelmente baixo, o tanque não tem função de reator aeróbio, não sendo, portanto, considerado um tratamento primário e não tendo grande influência em termos de remoção de carga orgânica.

Após esta etapa o esgoto é encaminhado para o sistema de wetland propriamente dito, em sua primeira etapa, constituída por Wetlands verticais não saturados de fluxo subsuperficial descendente, chamados no projeto de filtros verticais. Estes filtros foram projetados e construídos em triplicatas, ou seja, são três filtros trabalhando paralelamente. A operação é feita de forma que apenas um filtro seja alimentado por vez, enquanto os outros dois entram em um período de recesso da operação a fim de reduzir o stress hídrico e de carga poluente nas plantas.

O dimensionamento destes filtros foi feito seguindo os seguintes critérios:

- Profundidade útil de $70 \mathrm{~cm}$.

- Borda livre de $70 \mathrm{~cm}$ para suportar chuvas intensas com um período de retorno de até 50 anos.

- Substrato de britas com granulometrias diferentes em diferentes camadas, ocupando toda a profundida útil, sendo os primeiros $30 \mathrm{~cm}$ a partir do fundo preenchidos com brita número 3 (granulometria variando de $25 \mathrm{~mm}$ a $50 \mathrm{~mm}$ ), os $20 \mathrm{~cm}$ intermediários com brita número 2 (granulometria variando de $19 \mathrm{~mm}$ a $25 \mathrm{~mm}$ ) e os $20 \mathrm{~cm}$ superiores com brita número 1 (granulometria variando de $9,5 \mathrm{~mm}$ a $19 \mathrm{~mm}$ ).

- Plantação de espécies variadas (policultura).

- Alimentação na superfície e drenagem no fundo.

- Sistema de aeração passiva (sem motor) através de tubulações perfuradas no fundo do filtro e a 30cm dele (acima da brita 3 ). 
- Aplicação superficial: $42 \mathrm{~L} / \mathrm{m}^{2 *}$ dia.

Desta forma os filtros ficaram dimensionados com $223 \mathrm{~m}^{2}$ cada.

Após a passagem pelos filtros verticais o esgoto segue, ainda por gravidade, para a etapa seguinte, composta de wetlands horizontais saturados de fluxo subsuperficial, chamados no projeto de filtros horizontais. Estes filtros foram projetados e construídos em duplicidade, ou seja, são dois filtros trabalhando em paralelo. A operação é feita de forma que apenas um filtro seja alimentado por vez, enquanto o outro entra em um período de recesso da operação a fim de reduzir o stress hídrico e de carga poluente nas plantas.

O dimensionamento destes filtros foi feito seguindo os seguintes critérios:

- Profundidade útil de $50 \mathrm{~cm}$

- Borda livre de $30 \mathrm{~cm}$ para suportar chuvas intensas com um período de retorno de até 50 anos.

- Substrato de britas número 2 (granulometria variando de $19 \mathrm{~mm}$ a $25 \mathrm{~mm}$ ).

- Plantação de espécies variadas (policultura)

- Alimentação em uma extremidade horizontal e drenagem na outra.

- Saída do esgoto com coleta no fundo e sistema sifonado com altura $5 \mathrm{~cm}$ abaixo do nível do substrato, para manter o sistema sempre saturado e com fluxo subsuperficial

- Aplicação superficial: $94 \mathrm{~L} / \mathrm{m}^{2 *}$ dia.

Desta forma os filtros ficaram dimensionados com $223 \mathrm{~m}^{2}$ cada.

Após a filtração horizontal o esgoto segue para a última etapa do tratamento, composta por um wetland saturado de fluxo horizontal superficial, chamado no projeto de lagoa plantada. $\mathrm{O}$ dimensionamento desta etapa contempla os seguintes critérios:

- Profundidade útil de $80 \mathrm{~cm}$

- Borda livre de $30 \mathrm{~cm}$ para suportar chuvas intensas com um período de retorno de até 50 anos.

- Substrato de terra vegetal apenas no fundo, em uma camada de $30 \mathrm{~cm}$ para plantação das espécies.

- Plantação de espécies variadas (policultura).

- Alimentação em uma extremidade horizontal e drenagem na outra. 
- Saída do esgoto com coleta no fundo e sistema sifonado com altura no nível do espelho d'água, para manter o sistema sempre saturado.

- Tempo de detenção hidráulico de 5 dias.

Desta forma a lagoa foi dimensionada com $520 \mathrm{~m}^{2}$.

Após o término do tratamento o esgoto passa por uma última canaleta para medição de vazão e é encaminhado para disposição final.

O sistema foi avaliado no que diz respeito a seus critérios de dimensionamento e projeto, suas particularidades operacionais, sua eficiência de tratamento bem como sua relação com as variáveis de tempo de operação e clima da região de implantação, sendo a segunda variável representada pela temperatura e pluviometria do local de estudo.

\subsection{DELINEAMENTO DA PESQUISA}

Além da avaliação direta do funcionamento do sistema, foi realizada uma pesquisa de correlação da eficiência de tratamento do sistema com algumas variáveis, apresentadas na figura 5 .

A pesquisa proposta foi de análise de correlação entre variáveis.

Para desenvolver os testes de correlação, inicialmente foram definidas variáveis operacionais para cada uma das variáveis teóricas de estudo, como mostra a figura 5.

As variáveis de eficiência de remoção de carga orgânica foram definidas em função da disponibilidade de dados do sistema no período de estudo de cada um dos sistemas. desta forma foram delineadas como sendo $\mathrm{DBO}_{5}{ }^{20} \mathrm{e} \mathrm{DQO}$.

A variável de tempo de operação foi definida como sendo o tempo (em meses) decorrido entre primeira e última análises de qualidade obtidas para cada sistema.

Por último, as variáveis relativas às variações climáticas foram definidas como sendo a temperatura média do ar em cada mês e a pluviometria mensal.

A figura 5, a seguir, ilustra esta definição de variáveis operacionais: 
Figura 5 - Variáveis teóricas e operacionais

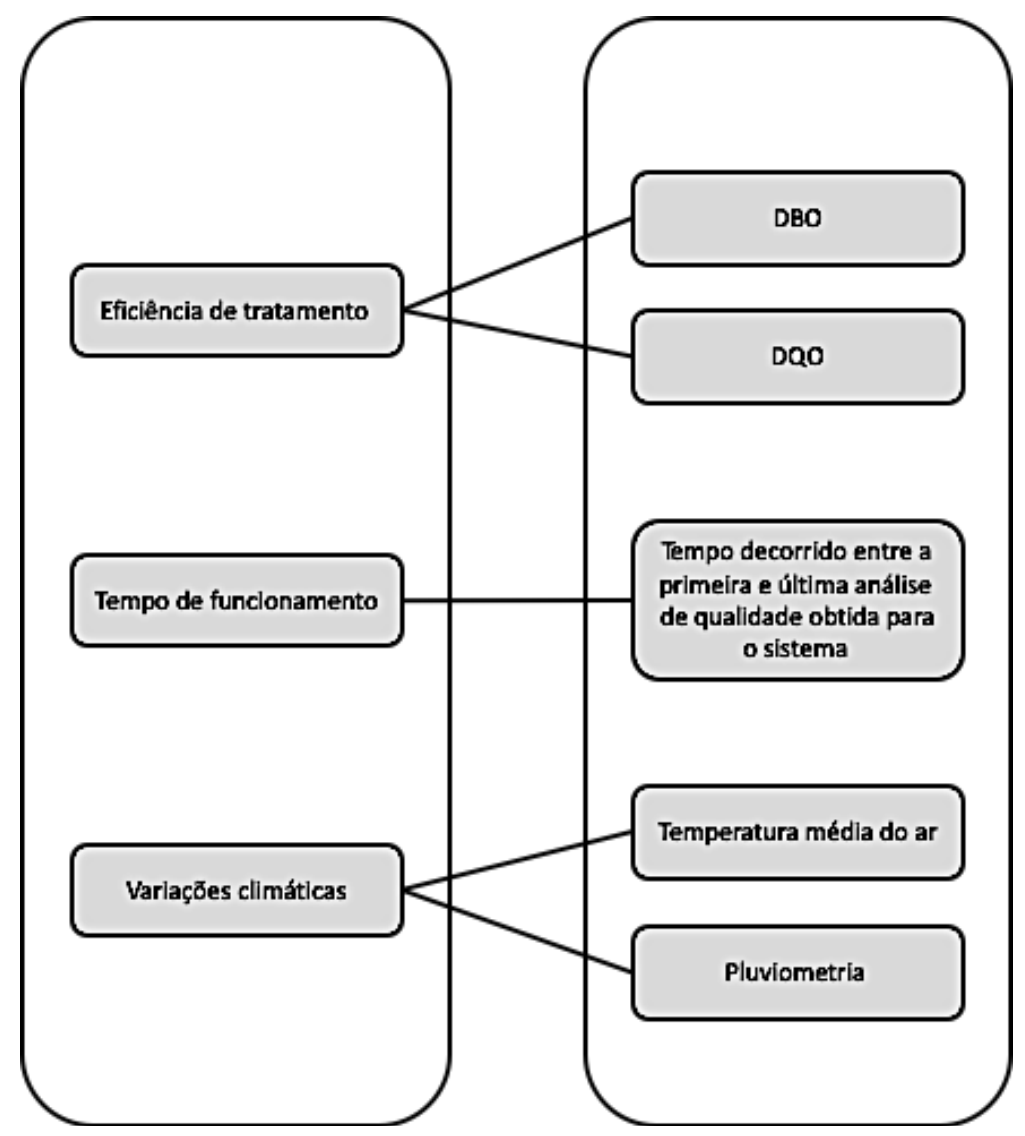

Fonte: Cauê Girão de Abreu, 2019.

Para testar a correlação das variáveis operacionais, as mesmas foram obtidas com apresentação de valores mensais ao longo dos períodos considerados em cada um dos estudos. Os dados obtidos foram comparados estatisticamente, cruzando separadamente as variáveis relativas à eficiência do tratamento com a variável relativa ao tempo de operação e com as variáveis relativas às variações climáticas.

\subsection{OBTENÇÃO DOS DADOS}

A obtenção dos dados de projeto e operação foi feita junto ao projetista do sistema, através da obtenção da documentação completa de projeto executivo e dos documentos de implantação e operação.

A obtenção dos dados de eficiência do sistema foi feita junto à empresa responsável pela operação e manutenção do sistema, através de relatórios de análise gerados mensalmente por laboratórios acreditados e certificados pelos órgãos competentes.

Foram obtidas análises realizadas mensalmente na entrada e na saída do sistema de tratamento ao longo do tempo de operação, sendo as análises datadas de abril de 2013 a julho de 2017 Através da comparação dos valores de entrada e saída foi atribuída uma eficiência de remoção específica para cada parâmetro considerado, para cada mês do estudo.

As coletas de amostras para as análises foram feitas mensalmente em um único dia, de forma composta ao longo do dia, com amostragens horárias as 08 às $18 \mathrm{~h}$.

O tempo de operação, bem como as questões e dificuldades operacionais ocorridas ao longo do período, foram obtidos por meio de uma entrevista com o responsável pelo sistema de 
tratamento, onde foi questionado a data de partida inicial do sistema e foi questionado se durante os meses analisados houve algum fenômeno ou acontecimento que pudesse distorcer os resultados das análises e se houveram questões ou dificuldades operacionais que pudessem ser relatadas. O sistema iniciou sua operação em abril de 2013 e não foi relatado nenhum incidente representativo, apenas algumas questões e dificuldades operacionais que serão relatadas mais a frente.

A pluviometria da região de estudo do sistema foi obtida no banco de dados históricos hidrológicos do DAEE-SP. Foram utilizadas as estações mais próximas ao ponto de estudo e que apresentam dados registrados no período considerado.

Para Campinas, além de quatro estações pluviométricas do DAEE, foi utilizada também a estação meteorológica da FEAGRI-UNICAMP, cujos dados estão disponíveis no website do Sistema de Monitoramento Agrometeorológico do Governo federal .

Através dos valores de temperatura e chuva mensal de cada uma das estações foi obtida uma média, ponderada pelas distâncias entre as estações e o ponto de estudo. Estas médias foram utilizadas como variáveis de pluviometria e temperatura no ponto de estudo.

\subsection{ANÁLISE DOS DADOS}

Os dados relativos à operação foram organizados na forma de relatórios e analisados em relação às principais questões encontradas, conforme será apresentado ne seção de resutados.

Os dados de eficiência de tratamento e clima foram organizados em planilhas, para a verificação direta das alterações de cada variável, por meio de cálculos estatísticos de médias e desviospadrão. Em seguida, foi feito um teste estatístico de correlação entre essas variações, através do coeficiente de correlação de Pearson. Foram verificadas as existências de correlação entre as variações de eficiência de tratamento para cada parâmetro e as três demais variáveis, em três etapas, conforme ilustrado nas figuras 6 a 8:

Figura 6 - Etapa 1 dos testes de correlação

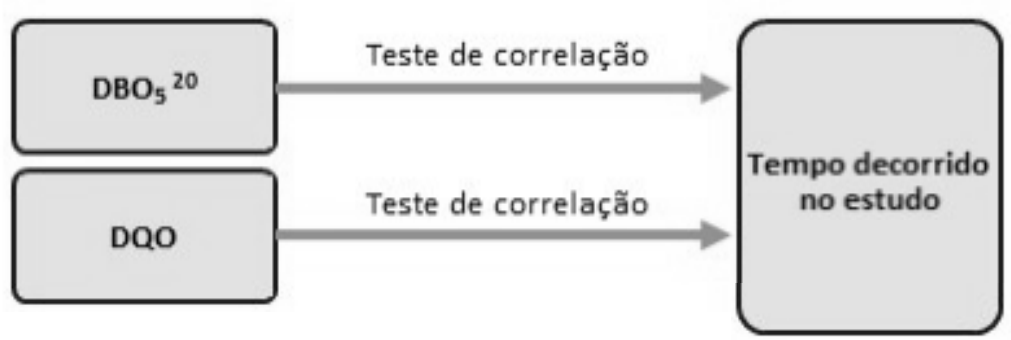

Fonte: Cauê Girão de Abreu, 2019.

Figura 7 - Etapa 2 dos testes de correlação

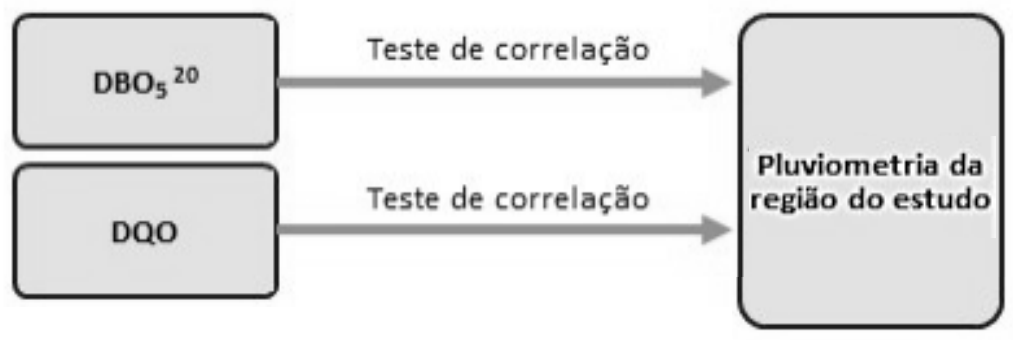

Fonte: Cauê Girão de Abreu, 2019. 
Figura 8 - Etapa 3 dos testes de correlação

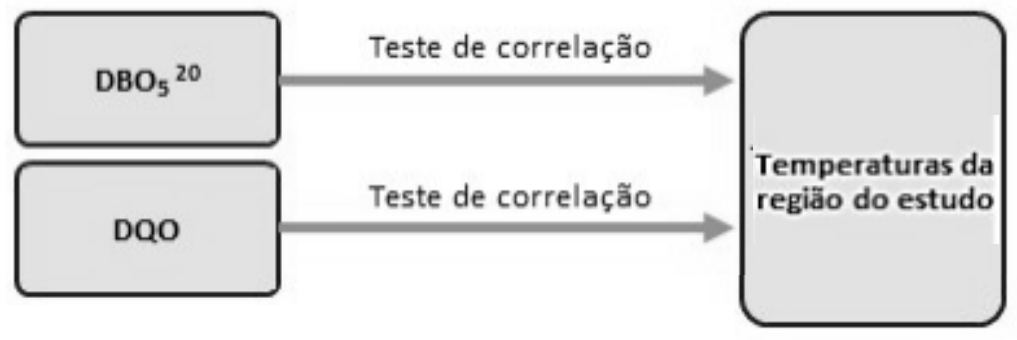

Fonte: Cauê Girão de Abreu, 2019.

\section{RESULTADOS E DISCUSSÃO}

Nesta seção do estudo estão explicitados os resultados de cada uma dás análises estatísticas feitas para os dados obtidos, além de alguns problemas operacionais enfrentados pelo sistema durante o período em que este estudo foi realizado.

São apresentados os resultados para a pluviometria ocorrida no período estudado, a temperatura média do ar no local de estudo para o mesmo período e as concentrações de $\mathrm{DBO}_{5}{ }^{20}$ e DQO na entrada e saída do sistema.

Os resultados do estudo foram divididos de forma apresentar separadamente as análises feitas. A organização da apresentação foi feita de forma a apresentar primeiramente as concentrações de $\mathrm{DBO}_{5}{ }^{20}$ e DQO e a eficiência do sistema estudado, em seguida trazendo os relatos dos problemas operacionais encontrados no período do estudo e por fim as análise de chuva e temperatura e os testes de correlação. Os testes foram também separados para exibir separadamente cada uma das variáveis testadas.

\subsection{CARACTERIZAÇÃO E EFICIÊNCIA DO TRATAMENTO}

Foram obtidas e comparadas as concentrações de $\mathrm{DBO}_{5}{ }^{20}$ e DQO no esgoto bruto, imediatamente antes da entrada do sistema, e no esgoto tratado da estação, coletado após a saída do último estágio de tratamento.

A seguir, na tabela 6, são apresentados os dados de $\mathrm{DBO}_{5}{ }^{20}$ e DQO de entrada e saída do sistema durante o período de estudo, bem como as eficiências resultantes:

Tabela 6 - Dados de $\mathrm{DBO}_{5}^{20}$ e DQO do período de estudo

\begin{tabular}{|c|c|c|c|c|c|c|c|}
\hline & & \multicolumn{3}{|c|}{$\mathrm{DBO}_{5}{ }^{20}$} & \multicolumn{3}{|c|}{ DQO } \\
\hline & & 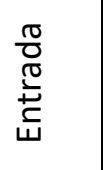 & $\frac{\pi}{\frac{\pi}{\pi}}$ & 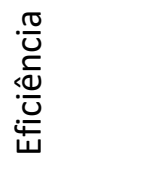 & $\begin{array}{l}\frac{\pi}{0} \\
\frac{\pi}{ \pm} \\
\stackrel{5}{ \pm}\end{array}$ & $\frac{\pi}{\frac{\pi}{\pi}}$ & 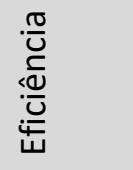 \\
\hline \multirow{6}{*}{$\stackrel{m}{\stackrel{n}{D}}$} & $26 / 04 / 2013$ & 40 & 2,99 & $92,53 \%$ & 353 & 30 & $91,50 \%$ \\
\hline & $06 / 05 / 2013$ & 486 & 13,3 & $97,26 \%$ & 1131 & 65 & $94,25 \%$ \\
\hline & $15 / 05 / 2013$ & 93,6 & 3,88 & $95,85 \%$ & 500 & 60 & $88,00 \%$ \\
\hline & $20 / 05 / 2013$ & 137 & 23 & $83,21 \%$ & 350 & 76 & $78,29 \%$ \\
\hline & $12 / 08 / 2013$ & 233 & 20,8 & $91,07 \%$ & 700 & 100 & $85,71 \%$ \\
\hline & $11 / 09 / 2013$ & 141 & 12,6 & $91,06 \%$ & 521 & 108 & $79,27 \%$ \\
\hline
\end{tabular}




\begin{tabular}{|c|c|c|c|c|c|c|c|}
\hline & $10 / 10 / 2013$ & 120 & 2,9 & $97,58 \%$ & 312 & 9 & $97,12 \%$ \\
\hline \multirow{6}{*}{$\underset{\sim}{\stackrel{\nabla}{\circ}}$} & $15 / 01 / 2014$ & 139 & 2,99 & $97,85 \%$ & 415 & 40 & $90,36 \%$ \\
\hline & $11 / 06 / 2014$ & 248 & 12 & $95,16 \%$ & 438 & 78 & $82,19 \%$ \\
\hline & $16 / 07 / 2014$ & 15,3 & 11,1 & $27,45 \%$ & 137 & 66 & $51,82 \%$ \\
\hline & $15 / 08 / 2014$ & 255 & 3,2 & $98,75 \%$ & 607 & 19 & $96,87 \%$ \\
\hline & $23 / 09 / 2014$ & 410 & 7,8 & $98,10 \%$ & 795 & 67 & $91,57 \%$ \\
\hline & $26 / 11 / 2014$ & 257 & 16,9 & $93,42 \%$ & 510 & 141 & $72,35 \%$ \\
\hline \multirow{12}{*}{$\stackrel{n}{\stackrel{n}{\sigma}}$} & $16 / 01 / 2015$ & 59,9 & 20,3 & $66,11 \%$ & 297 & 119 & $59,93 \%$ \\
\hline & $09 / 02 / 2015$ & 73,9 & 6 & $91,88 \%$ & 294 & 60 & $79,59 \%$ \\
\hline & $24 / 03 / 2015$ & 85,5 & 16,1 & $81,17 \%$ & 285 & 87 & $69,47 \%$ \\
\hline & $10 / 04 / 2015$ & 59 & 7,9 & $86,61 \%$ & 206 & 85 & $58,74 \%$ \\
\hline & $11 / 05 / 2015$ & 121 & 11,2 & $90,74 \%$ & 412 & 64 & $84,47 \%$ \\
\hline & $09 / 06 / 2015$ & 115 & 3,9 & $96,61 \%$ & 503 & 22 & $95,63 \%$ \\
\hline & $17 / 07 / 2015$ & 193 & 4 & $97,93 \%$ & 989 & 36 & $96,36 \%$ \\
\hline & $07 / 08 / 2015$ & 250 & 11,9 & $95,24 \%$ & 817 & 70,4 & $91,38 \%$ \\
\hline & $17 / 09 / 2015$ & 72,8 & 19,6 & $73,08 \%$ & 219 & 82,9 & $62,15 \%$ \\
\hline & $21 / 10 / 2015$ & 42,4 & 3,9 & $90,80 \%$ & 177 & 136 & $23,16 \%$ \\
\hline & $03 / 11 / 2015$ & 103 & 9,87 & $90,42 \%$ & 320 & 117 & $63,44 \%$ \\
\hline & $01 / 12 / 2015$ & 515 & 51,9 & $89,92 \%$ & 1260 & 274 & $78,25 \%$ \\
\hline \multirow{12}{*}{$\begin{array}{l}0 \\
\stackrel{0}{0} \\
\stackrel{0}{0}\end{array}$} & $01 / 01 / 2016$ & 70,3 & 15,4 & $78,09 \%$ & 215 & 89 & $58,60 \%$ \\
\hline & $01 / 02 / 2016$ & 298 & 25,7 & $91,38 \%$ & 676 & 135 & $80,03 \%$ \\
\hline & $01 / 03 / 2016$ & 173 & 8,29 & $95,21 \%$ & 471 & 99 & $78,98 \%$ \\
\hline & $01 / 04 / 2016$ & 252 & 180 & $28,57 \%$ & 905 & 695 & $23,20 \%$ \\
\hline & $02 / 05 / 2016$ & 230 & 2,99 & $98,70 \%$ & 537 & 43 & $91,99 \%$ \\
\hline & $01 / 06 / 2016$ & 243 & 2,99 & $98,77 \%$ & 561 & 44 & $92,16 \%$ \\
\hline & $01 / 07 / 2016$ & 269 & 2,99 & $98,89 \%$ & 750 & 96 & $87,20 \%$ \\
\hline & 01/08/2016 & 103 & 40,4 & $60,78 \%$ & 411 & 205 & $50,12 \%$ \\
\hline & $01 / 09 / 2016$ & 362 & 52,7 & $85,44 \%$ & 866 & 205 & $76,33 \%$ \\
\hline & $03 / 10 / 2016$ & 125 & 65,4 & $47,68 \%$ & 332 & 206 & $37,95 \%$ \\
\hline & $01 / 11 / 2016$ & 134 & 46,3 & $65,45 \%$ & 420 & 161,5 & $61,55 \%$ \\
\hline & $06 / 12 / 2016$ & 143 & 27,2 & $80,98 \%$ & 508 & 117 & $76,97 \%$ \\
\hline \multirow{7}{*}{ 공 } & $10 / 01 / 2017$ & 212 & 76 & $64,15 \%$ & 502 & 332 & $33,86 \%$ \\
\hline & $08 / 02 / 2017$ & 111 & 24,1 & $78,29 \%$ & 365 & 63 & $82,74 \%$ \\
\hline & 07/03/2017 & 224 & 29,9 & $86,65 \%$ & 608 & 73 & $87,99 \%$ \\
\hline & $04 / 04 / 2017$ & 83,7 & 69,6 & $16,85 \%$ & 248 & 205 & $17,34 \%$ \\
\hline & $02 / 05 / 2017$ & 314 & 40,5 & $87,10 \%$ & 762 & 102 & $86,61 \%$ \\
\hline & $20 / 06 / 2017$ & 86,7 & 23,4 & $73,01 \%$ & 372 & 101 & $72,85 \%$ \\
\hline & 04/07/2017 & 119 & 29,5 & $75,21 \%$ & 482 & 130 & $73,03 \%$ \\
\hline
\end{tabular}

$\mathrm{O}$ valor médio de $\mathrm{DBO}_{5}{ }^{20}$ no esgoto bruto que chega à estação foi de $177,7 \mathrm{mg} / \mathrm{L}$, com desvio padrão de $115,9 \mathrm{mg} / \mathrm{L}$, e no esgoto tratado pelo sistema a média de entrada foi de $24,2 \mathrm{mg} / \mathrm{L}$, com desvio padrão de $30,7 \mathrm{mg} / \mathrm{L}$, conforme figura 9 : 
Figura 9 - Concentrações de $\mathrm{DBO}_{5}^{20}$

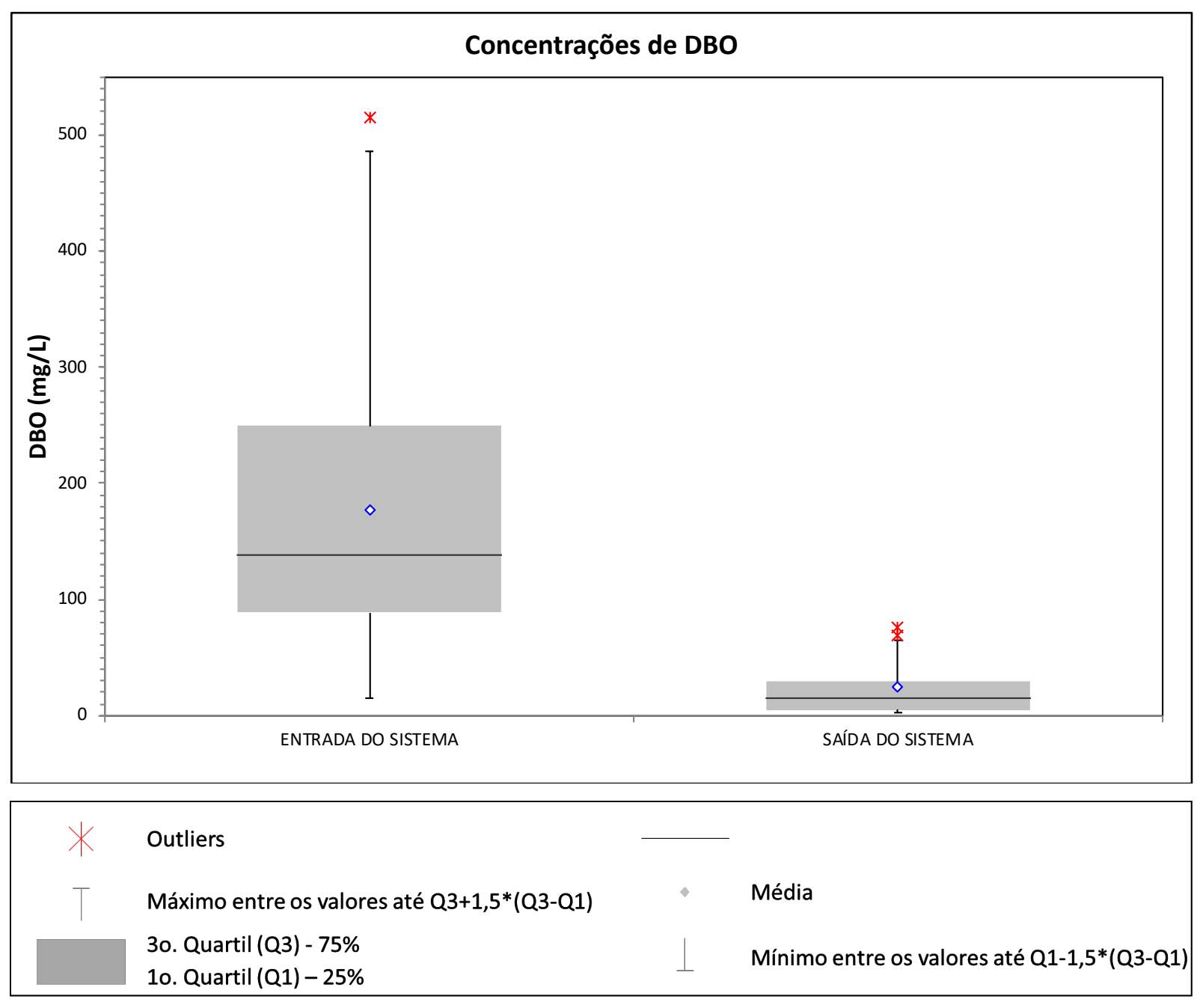

Fonte: Cauê Girão de Abreu, 2019

Para a DQO, o valor médio encontrado no esgoto bruto que chega ao sistema de tratamento foi de $512,3 \mathrm{mg} / \mathrm{L}$, com desvio padrão de $255,6 \mathrm{mg} / \mathrm{L}$, após o tratamento promovido pelo sistema o valor médio no esgoto final foi de 116,2, com desvio padrão de111,4mg/L, como mostra a figura 10. 
Figura 10 - Concentrações de DQO.
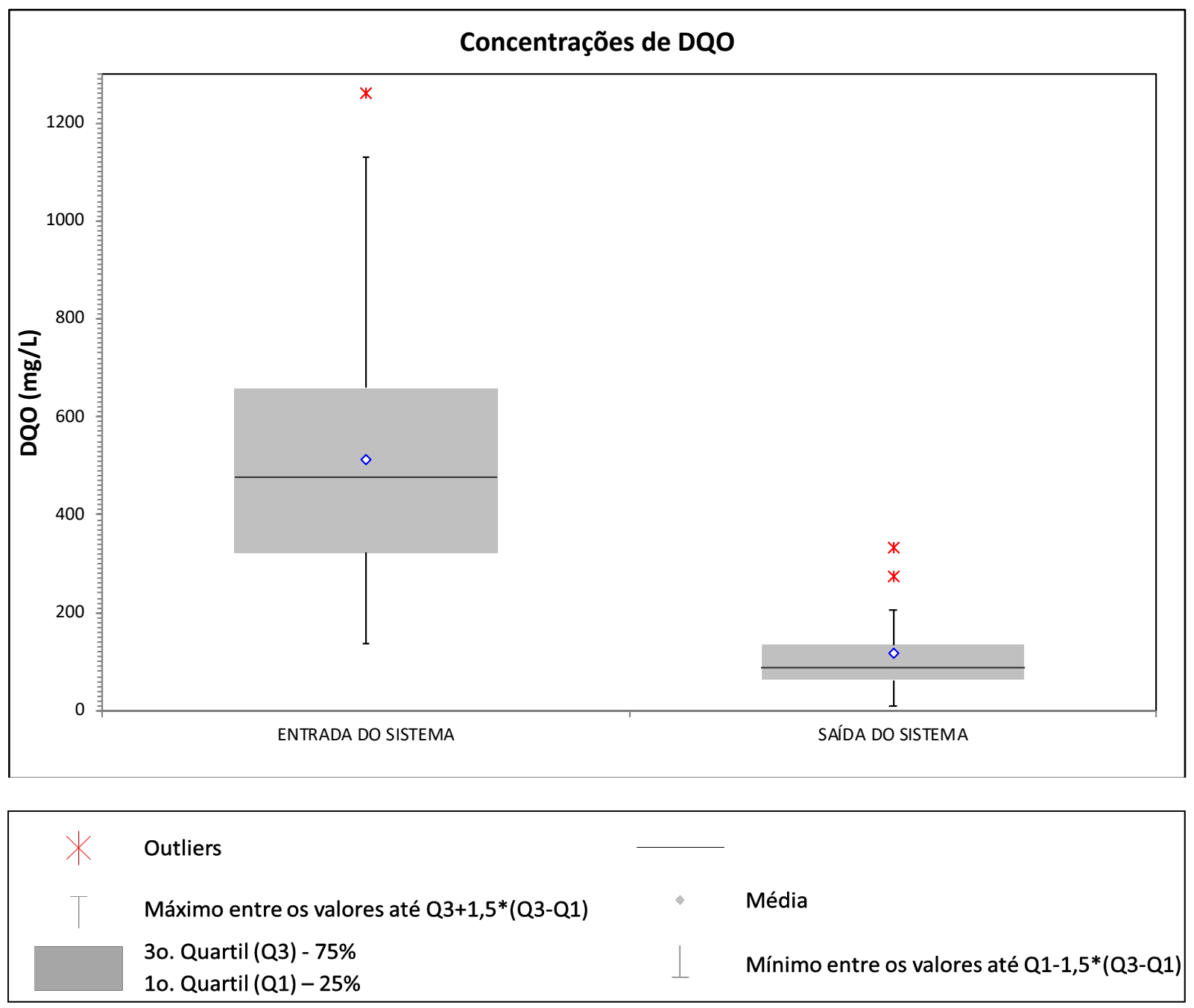

Fonte: Cauê Girão de Abreu, 2019

As médias obtidas no esgoto bruto são características de esgotamento em industrias, com populações pequenas, onde os valores de $\mathrm{DBO}_{5}{ }^{20}$ e DQO assemelham-se aos valores apresentados por Metcalf e Eddy (2003) para um esgoto fraco..

De acordo com estes dados as médias de remoção de $\mathrm{DBO}_{5}{ }^{20}$ e DQO no tratamento do esgoto, promovido pelo sistema de wetlands construídos do estudo, foi de $81,7 \%$ e $72,0 \%$, respectivamente. Esta análise esta apresentada na figura 11: 
Figura 11 - Diagrama de caixas das eficiências de tratamento
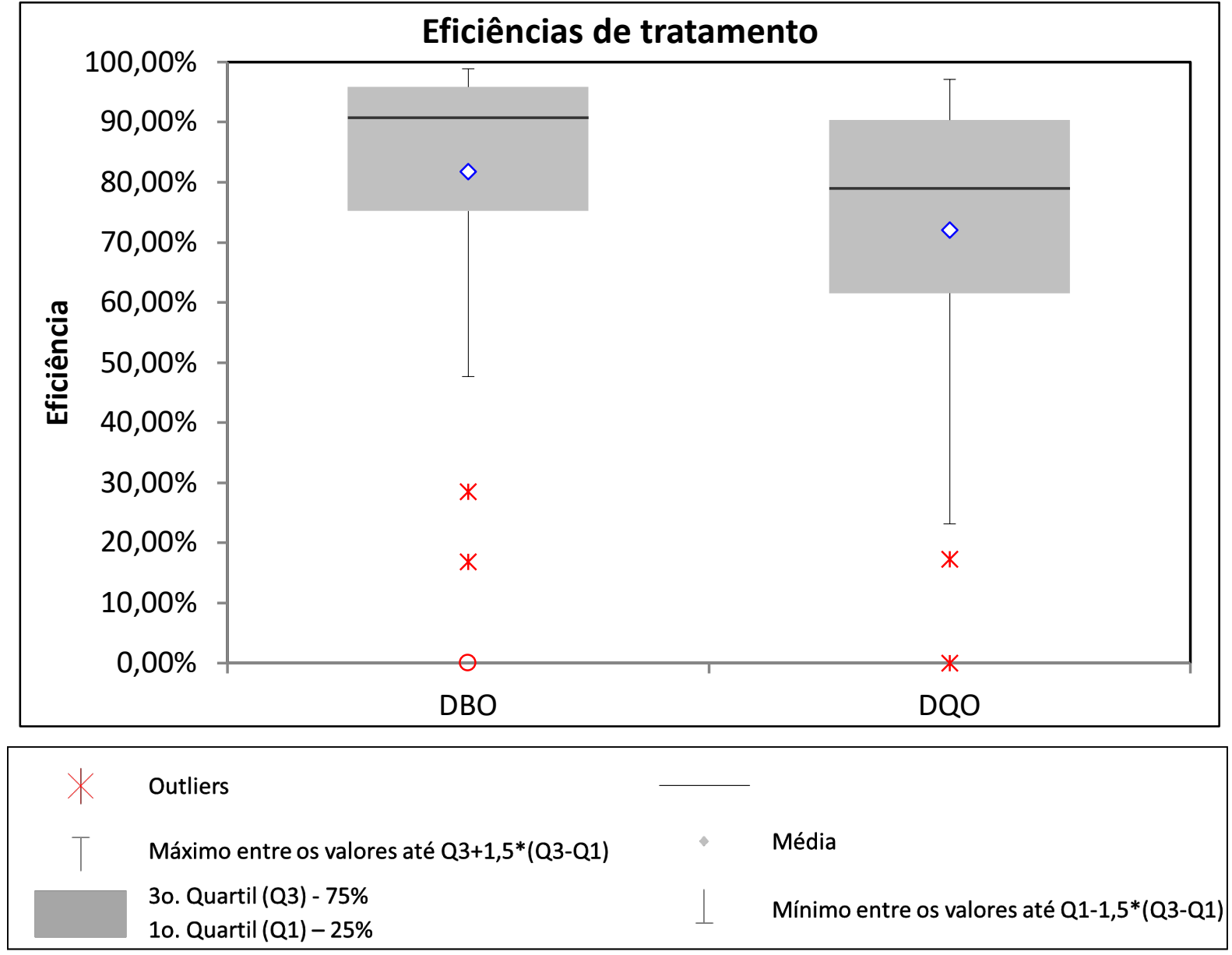

Fonte: Cauê Girão de Abreu, 2019

O desempenho obtido no sistema durante o período monitorado por este estudo foi bastante elevado. Em diversos meses as remoções, tanto de $\mathrm{DBO}_{5}{ }^{20}$ quanto de DQO superaram os $90 \%$. Em nenhum dos meses analisados a $\mathrm{DBO}_{5}{ }^{20}$ foi superior a $120 \mathrm{mg} / \mathrm{L}$, como preconiza a legislação nacional (BRASIL, 2011). Apenas em raras exceções a remoção foi inferior a $60 \%$, que seria o valor mínimo de remoção caso o valor de saída ultrapassasse os $120 \mathrm{mg} / \mathrm{L}$ (BRASIL, 2011).

Estas eficiências corroboram os valores de dimensionamento propostos por VYMAZAL (2005), de 2 a $5 \mathrm{~m}^{2} / \mathrm{PE}$, uma vez que o sistema foi dimensionado com $42 \mathrm{~L} / \mathrm{m}^{2}\left(3,57 \mathrm{~m}^{2} / \mathrm{PE}\right)$ nos wetlands verticais e $94 \mathrm{~L} / \mathrm{m}^{2}\left(1,60 \mathrm{~m}^{2} / \mathrm{PE}\right)$.

As eficiências atingidas reforçam ainda a afirmação proposta (VALIPOUR et al., 2014; KIM et al., 2015; MILLOT et al. 2016) de que os wetlands são eficientes no tratamento de esgoto sanitário quando aplicados como tratamento primário.

A seguir, as eficiências encontradas no estudo são comparadas com outros 6 trabalhos, todos apresentando os sistemas de WC aplicados ao tratamento primário ou secundário de esgoto. A figura 12 mostra as eficiências encontradas: 
Figura 12 - Comparação das eficiências de remoção de $\mathrm{DBO}_{5}^{20}$ e DQO

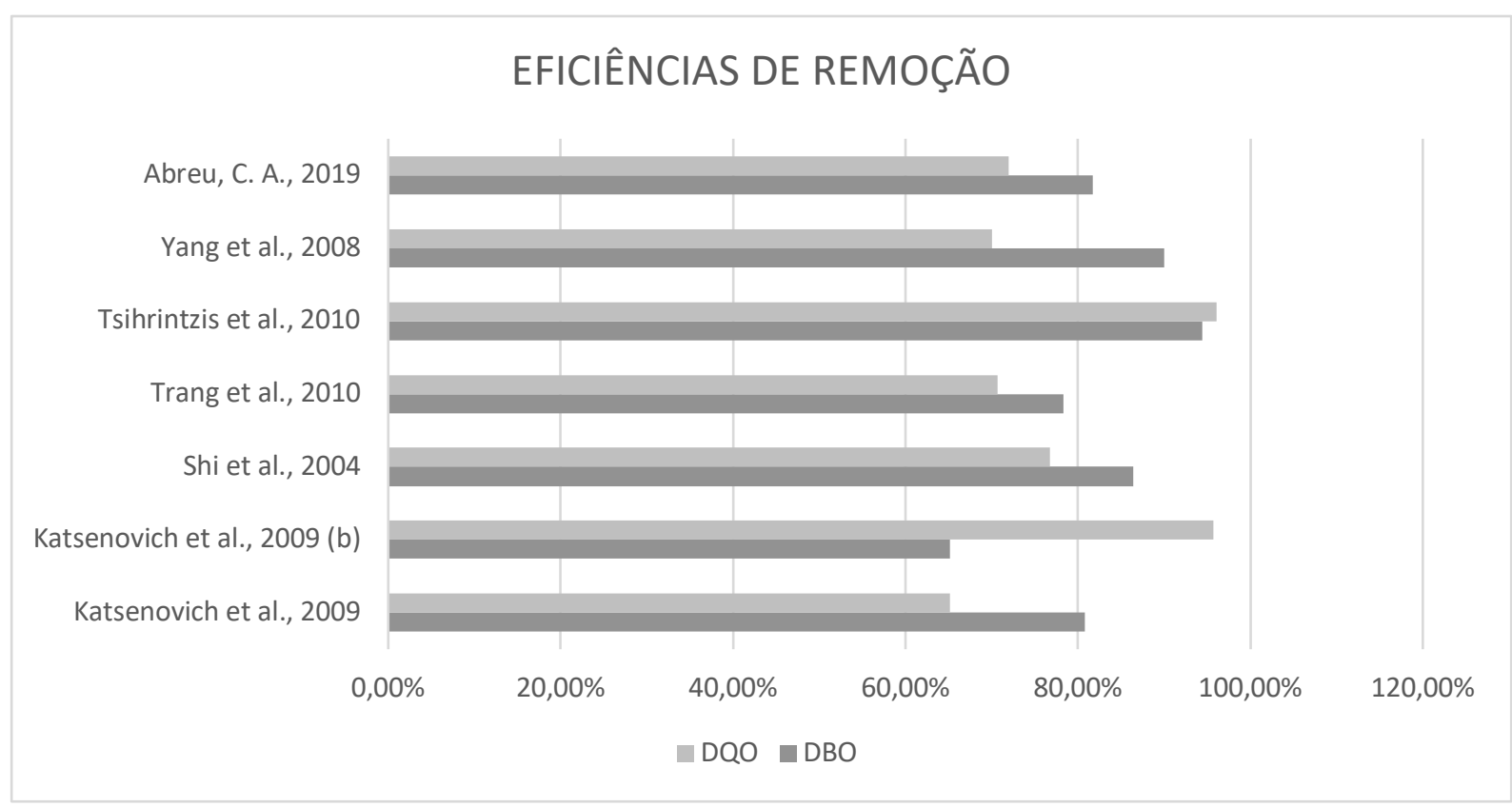

Fonte: Cauê Girão de Abreu, 2019

O resultado encontrado, de acordo com a figura 12, está alinhado com aqueles que vêm sendo apresentados em literatura internacional.

\subsection{QUESTÕES OPERACIONAIS}

O sistema teve um bom desenvolvimento após sua implantação. A comparação das imagens feitas no momento da partida do sistema e das imagens feitas após 2,5 anos (figuras 42 a 50) mostra a boa adaptação e crescimento das espécies selecionadas para a promoção do tratamento. Os resultados em termos de remoção de $\mathrm{DBO}_{5}{ }^{20}$ e DQO também evidenciam uma boa adaptação e desenvolvimento do sistema como um todo.

A operação do sistema de wetlands construídos estudado é bastante simples. Conforme a metodologia operacional apresentada, o sistema do estudo tem sua operação resumida ao controle de algumas válvulas e aos cuidados fitossanitários com as espécies plantadas. Ainda assim, a equipe de operação do sistema relata três problemas operacionais ocorridos durante o período estudado: Um longo período de seca, que prejudicou a saúde das plantas por falta de água, o aparecimento de uma praga que danificou a parte foliar de algumas espécies e a proliferação de uma espécie invasora que tomou espaço na lagoa impedindo a entrada de luz.

\subsubsection{Período de seca}

Os meses de junho, julho e agosto de 2014 foram extremamente secos na região em que se encontra o sistema de tratamento. As precipitações totais médias destes meses foram de $9,3 \mathrm{~mm}$ em junho, 29,4mm em julho e 3,9mm em agosto.

Os WCV foram implantados com três unidades, e duas permanecem sem recebimento de esgoto enquanto apenas uma recebe esgoto e efetua o tratamento.

Como os WCV são não saturados, ou seja, permanecem secos entre os períodos de recebimento de esgoto, a seca ocorrida fez com que as plantas sofressem um estresse hídrico por falta de água nas unidades que não estavam recebendo esgoto e, portanto, estavam sem água. 
Como medida paliativa, para que o sistema não fosse afetado pela falta de água, duas medidas operacionais simples foram tomadas:

I. A rotação da operação foi diminuída, de forma que os WCV ficassem menos tempo sem receber contribuição de esgoto. A rotação que era de uma semana de operação por duas de repouso foi reduzida para dois dias de operação para quatro dias de repouso.

II. Os WCV que estavam em período de repouso, que eram mantidos secos, passaram a ser mantidos cheios ou saturados. Antes de encerrar a operação de um WCV fechavam-se as válvulas de saída e a última batelada de esgoto aplicada permanecia dentro da unidade durante os quatro dias de repouso, sendo completamente drenada algumas horas antes do início do próximo período de operação.

Estas duas medidas foram suficientes para que o sistema se recuperasse e as plantas voltassem a crescer.

\subsubsection{Aparecimento de praga}

No início da operação do sistema, em maio de 2013, quando as espécies plantadas ainda se encontravam jovens e frágeis, uma praga apareceu na lagoa da etapa final do tratamento, colocando em risco a saúde e a sobrevivência das plantas desta etapa.

Começou-se a observar a presença de pequenos insetos nas plantas da lagoa e a perceber-se que algumas plantas estavam morrendo ou apresentando danos em seus tecidos. Os insetos tinham uma cor azulada e apresentavam-se em grande quantidade.

Preocupados com a situação, a equipe de operação convocou um engenheiro agrônomo para auxiliar na solução desta questão.

O engenheiro identificou os insetos como uma espécie conhecida popularmente como cigarrinhas azuis.

Segundo ele os insetos conhecidos como cigarrinhas pertencem à ordem Hemíptera e alimentam-se em tecidos vegetais, prejudicando as espécies em que se alojam e se alimentam.

O especialista afirmou que plantas adultas e saudáveis tem maior resistência e conseguem sobreviver ao aparecimento destes insetos e que estes insetos são sazonais e deveriam desaparecer com o fim da primavera e início do inverno.

A sugestão dele, para que se evitasse maiores danos, foi de fazer um processo de adubação das plantas para que elas tivessem força para resistir ao período de ataque dos insetos.

A adubação foi feita, com misturas de nitrogênio, fósforo e potássio (NPK) e as plantas resistiram ao ataque, voltando a crescer saudavelmente. Nos meses subsequentes a praga desapareceu e não voltou mais a aparecer de forma preocupantes durante o período estudado.

\subsubsection{Espécie invasora}

No período de verão de 2014 e 2015 uma espécie invasora começou a se reproduzir na lagoa que compõe a última etapa do tratamento. Pequenas plantas aquáticas começaram a se reproduzir em grande velocidade, chegando a cobrir completamente a área da lagoa. 
Inicialmente a questão causou preocupação, pois uma das funções desta etapa do tratamento é a desinfecção através da entrada da luz solar, com radiação ultravioleta. O recobrimento da lâmina d'água por esta espécie fazia com que a luz não conseguisse mais penetrar na água, impedindo o processo de desinfeção.

Novamente um engenheiro agrônomo foi chamado para auxiliar na solução do problema. Ele identificou a espécie como sendo a Lemna minor, vulgarmente conhecida como lentilha d'água.

Segundo o especialista esta espécie tem crescimento muito rápido e eficiente, sendo extremamente difícil de controlar.

Por sugestão do engenheiro agrônomo foi adotado um procedimento de retirada manual dos espécimes, através da utilização de redes. Este trabalho foi feito durante aproximadamente 90 dias, até que se esgotasse a presença desta espécie na lagoa.

A retirada manual foi um processo longo e exaustivo, mas teve o efeito planejado, eliminando a presença das Lemnas, que não voltaram a causar problemas durante o período estudado.

\subsection{CORRELAÇÃO DA EFICIÊNCIA DE REMOÇÃO DE CARGA ORGÂNICA E AS VARIAÇÕES CLIMÁTICAS}

Foram obtidos e classificados os dados relativos à temperatura média mensal e a chuva mensal total na região em que se encontra o sistema de tratamento para todos os meses considerados no estudo. Os dados obtidos estão apresentados na tabela 7:

Tabela 7 - Dados de temperatura e pluviometria na região de estudo

\begin{tabular}{|c|c|c|}
\hline Data & Temperatura Média $\left({ }^{\circ} \mathrm{C}\right)$ & Chuva total $(\mathrm{mm})$ \\
\hline abr-13 & 22,14 & 94,34 \\
\hline mai-13 & 20,25 & 58,55 \\
\hline mai-13 & 20,25 & 58,55 \\
\hline mai-13 & 20,25 & 58,55 \\
\hline ago-13 & 19,49 & 10,07 \\
\hline set-13 & 21,60 & 35,41 \\
\hline out-13 & 22,46 & 118,52 \\
\hline jan-14 & 26,59 & 103,04 \\
\hline jun-14 & 20,18 & 9,32 \\
\hline ago-14 & 20,73 & 3,87 \\
\hline set-14 & 23,05 & 88,39 \\
\hline nov-14 & 24,54 & 119,42 \\
\hline jan-15 & 26,70 & 130,75 \\
\hline fev-15 & 24,71 & 250,60 \\
\hline mar-15 & 23,45 & 181,61 \\
\hline abr-15 & 22,87 & 23,95 \\
\hline mai-15 & 19,91 & 113,91 \\
\hline jun-15 & 19,32 & 19,41 \\
\hline jul-15 & 18,98 & 38,33 \\
\hline ago-15 & 20,96 & 29,89 \\
\hline set-15 & 23,06 & 165,34 \\
\hline out-15 & 24,89 & 117,35 \\
\hline nov-15 & 24,33 & 171,40 \\
\hline
\end{tabular}


57

\begin{tabular}{|c|c|c|}
\hline dez-15 & 25,05 & 263,32 \\
\hline jan-16 & 24,72 & 310,51 \\
\hline fev-16 & 25,95 & 207,27 \\
\hline mar-16 & 24,56 & 158,81 \\
\hline abr-16 & 24,71 & 9,15 \\
\hline mai-16 & 19,55 & 95,16 \\
\hline jun-16 & 17,37 & 160,13 \\
\hline jul-16 & 19,12 & 0,90 \\
\hline ago-16 & 20,43 & 37,19 \\
\hline set-16 & 21,36 & 27,37 \\
\hline out-16 & 23,33 & 108,22 \\
\hline nov-16 & 23,33 & 120,23 \\
\hline dez-16 & 24,81 & 21,65 \\
\hline jan-17 & 24,82 & 355,29 \\
\hline fev-17 & 25,69 & 103,38 \\
\hline mar-17 & 24,29 & 160,64 \\
\hline abr-17 & 22,53 & 90,15 \\
\hline mai-17 & 20,60 & 125,29 \\
\hline jun-17 & 18,99 & 27,42 \\
\hline jul-17 & 18,15 & 0,00 \\
\hline
\end{tabular}

A temperaura média mensal obtida para o período do estudo foi de $22,3^{\circ} \mathrm{C}$, conforme figura 13 :

Figura 13 - Chuva média mensal

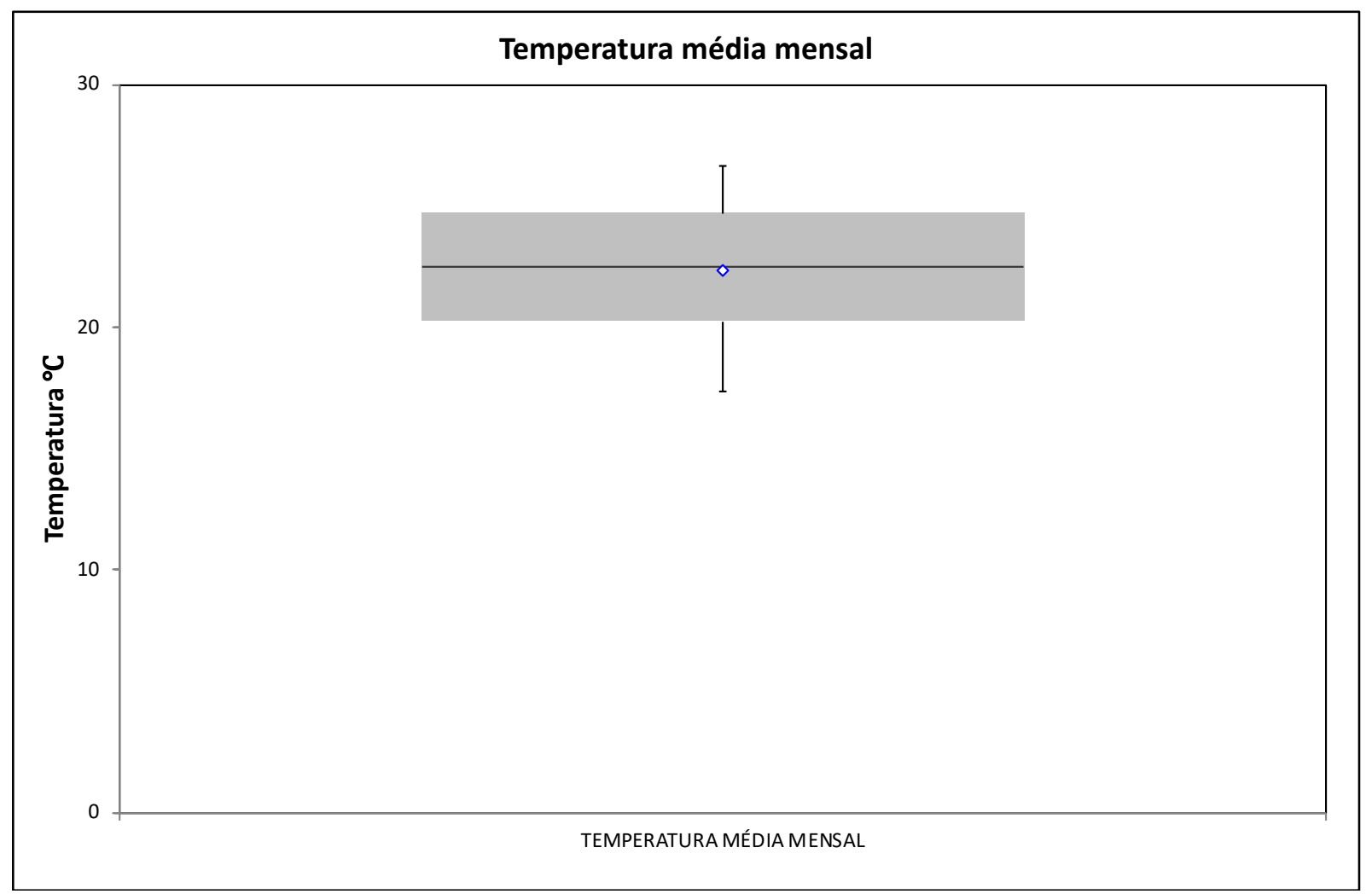




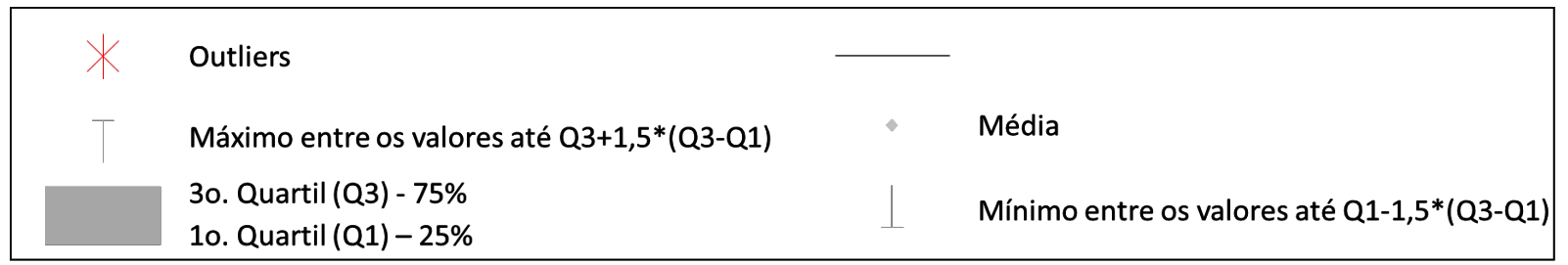

Fonte: Cauê Girão de Abreu, 2019

Analisando ainda as temperaturas de acordo com a estação, temos que a média no período quente (verão) foi de $25,4^{\circ} \mathrm{C}$, na meia estação (outono e primavera) foi de $22,5^{\circ} \mathrm{C}$ e no período frio (inverno) foi de $19,4^{\circ} \mathrm{C}$, conforme figura 14 :

Figura 14 - Temperatura média mensal por período

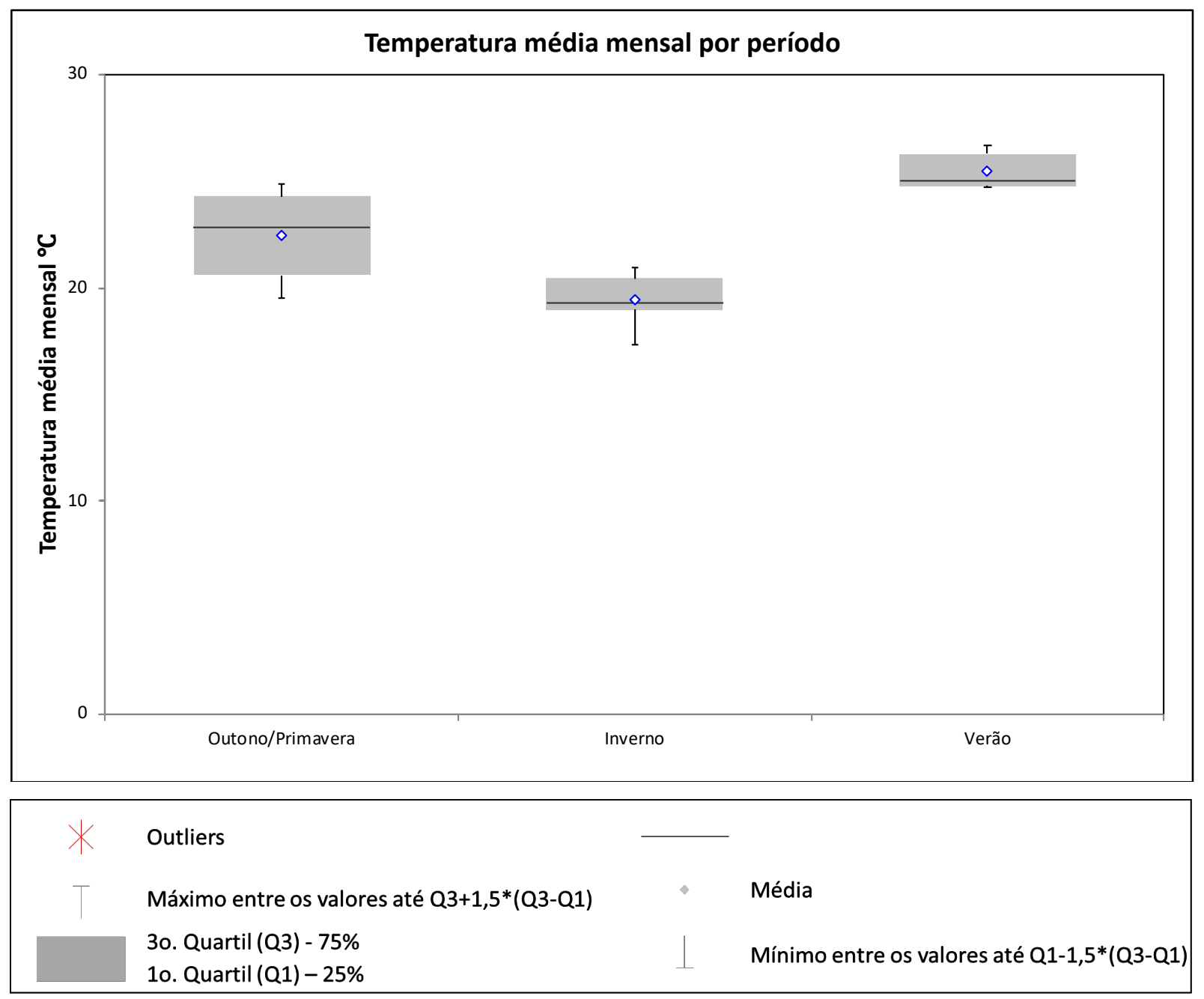

Fonte: Cauê Girão de Abreu, 2019

A análise da figura 14 mostra que a variação de temperatura entre períodos é relativamente pequena, com valor absoluto de variação de $6^{\circ} \mathrm{C}$, equivalente a uma redução de $23,6 \%$ do verão para o inverno.

Esta variação encontrada é bastante inferior às variações estudadas por outros autores. Kadlec e Reddy (2001) estudaram sistemas com variação que chegam a quase $30^{\circ} \mathrm{C}$, com temperaturas próximas de $0^{\circ} \mathrm{C}$ no inverno e de $30^{\circ} \mathrm{C}$ no verão. Picard, Fraser e Steer (2004) apresentam variações indo desde $-11^{\circ} \mathrm{C}$ até $23^{\circ} \mathrm{C}$, com amplitude de $34^{\circ} \mathrm{C}$. 
A chuva total mensal média durante o período estudado foi de $101,9 \mathrm{~mm}$, conforme mostra a figura 15 .

Figura 15 - Chuva total mensal.
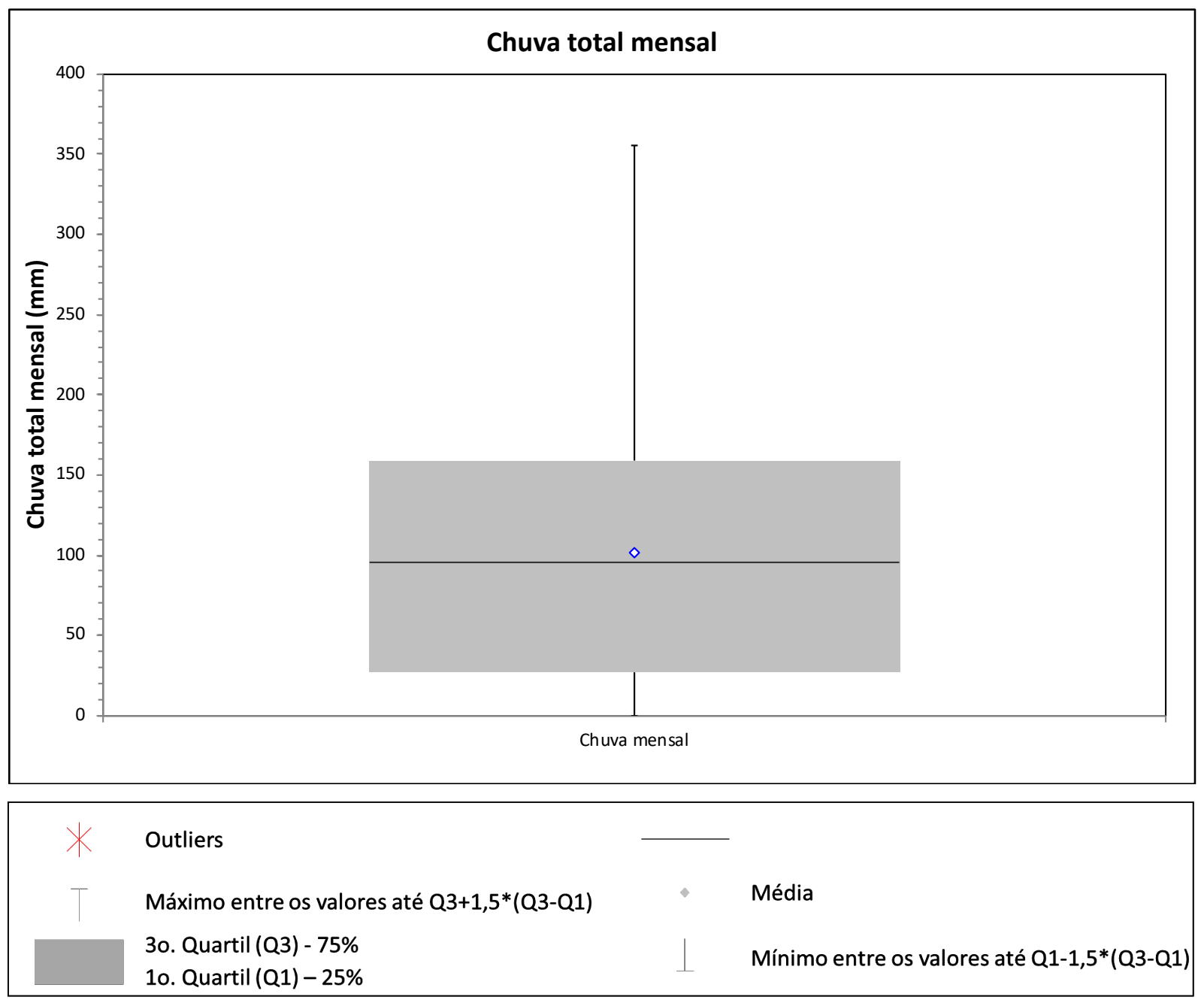

Fonte: Cauê Girão de Abreu, 2019

Analisando ainda as chuvas de acordo com a estação, temos que a média no período chuvoso (verão) foi de $194 \mathrm{~mm}$, na meia estação (outono e primavera) foi de $100 \mathrm{~mm}$ e no período seco (inverno) foi de $30,6 \mathrm{~mm}$, conforme figura 16 : 
Figura 16 - Chuva totoal mensal por período

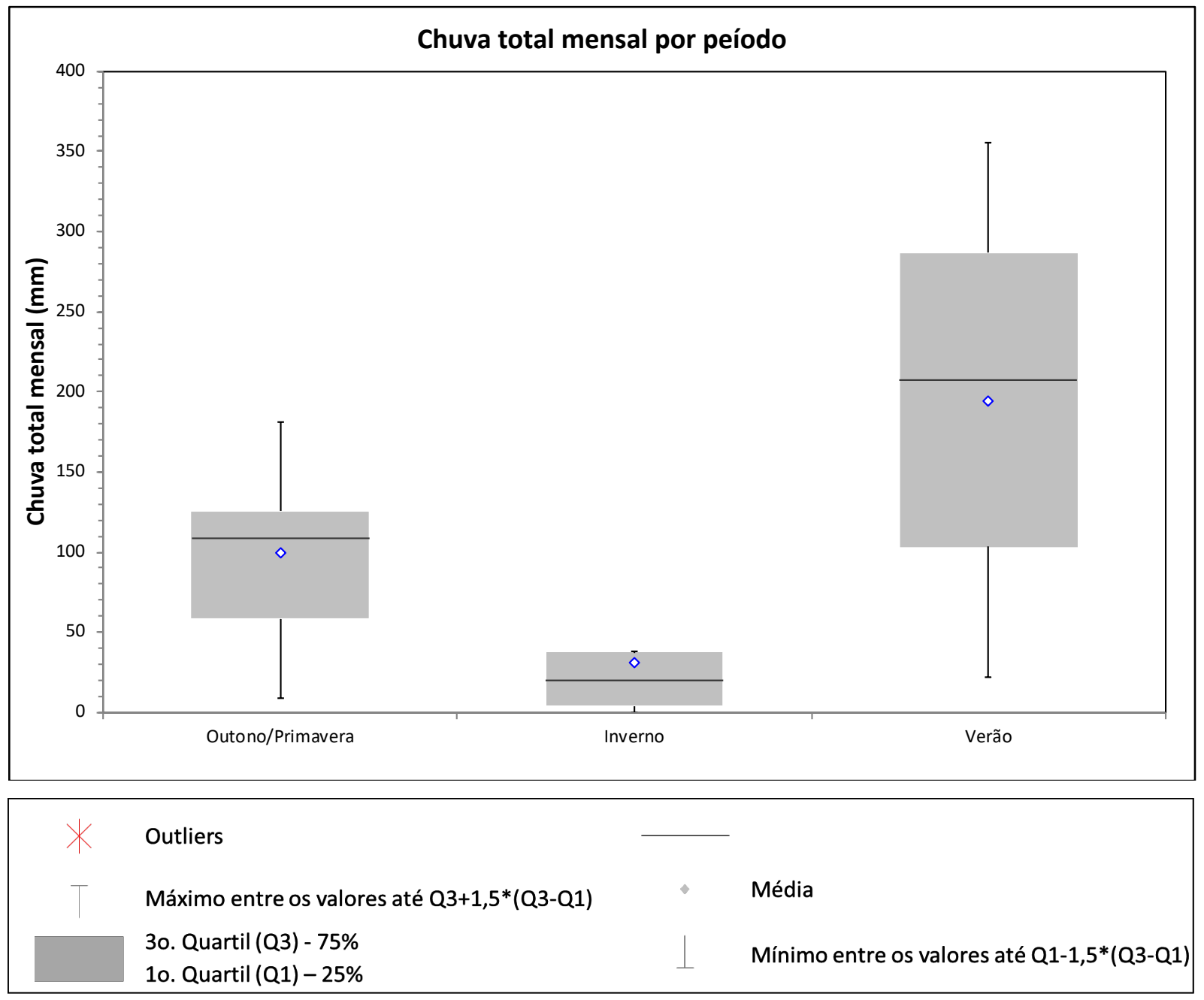

Fonte: Cauê Girão de Abreu, 2019

A análise da figura 16 apresenta uma grande variação de chuvas, com uma diferença de $163,4 \mathrm{~mm}$, equivalente a uma redução de $84,2 \%$ do verão para o inverno.

Outros autores estudaram variações maiores de pluviosidade, como por exemplo Bialowiec et al. (2014) que trabalharam com uma variação de mais de $2000 \%$, variando entre $0,2 \mathrm{~mm} /$ dia e $4,24 \mathrm{~mm} /$ dia e Clay et al. (2004) que trabalhou com precipitações de aproximadamente $5 \mathrm{~mm} / \mathrm{semana}$ a $75 \mathrm{~mm} / \mathrm{semana}$, totalizando uma variação de $1400 \%$.

Para uma análise gráfica, foram plotadas as variáveis chuva, temperatura e eficiências em um único gráfico distribuído ao longo dos meses de operação considerados, o resultado é apresentado na figura 17: 
Figura 17 - Séries de dados de temperatura, chuva e eficiências de remoção

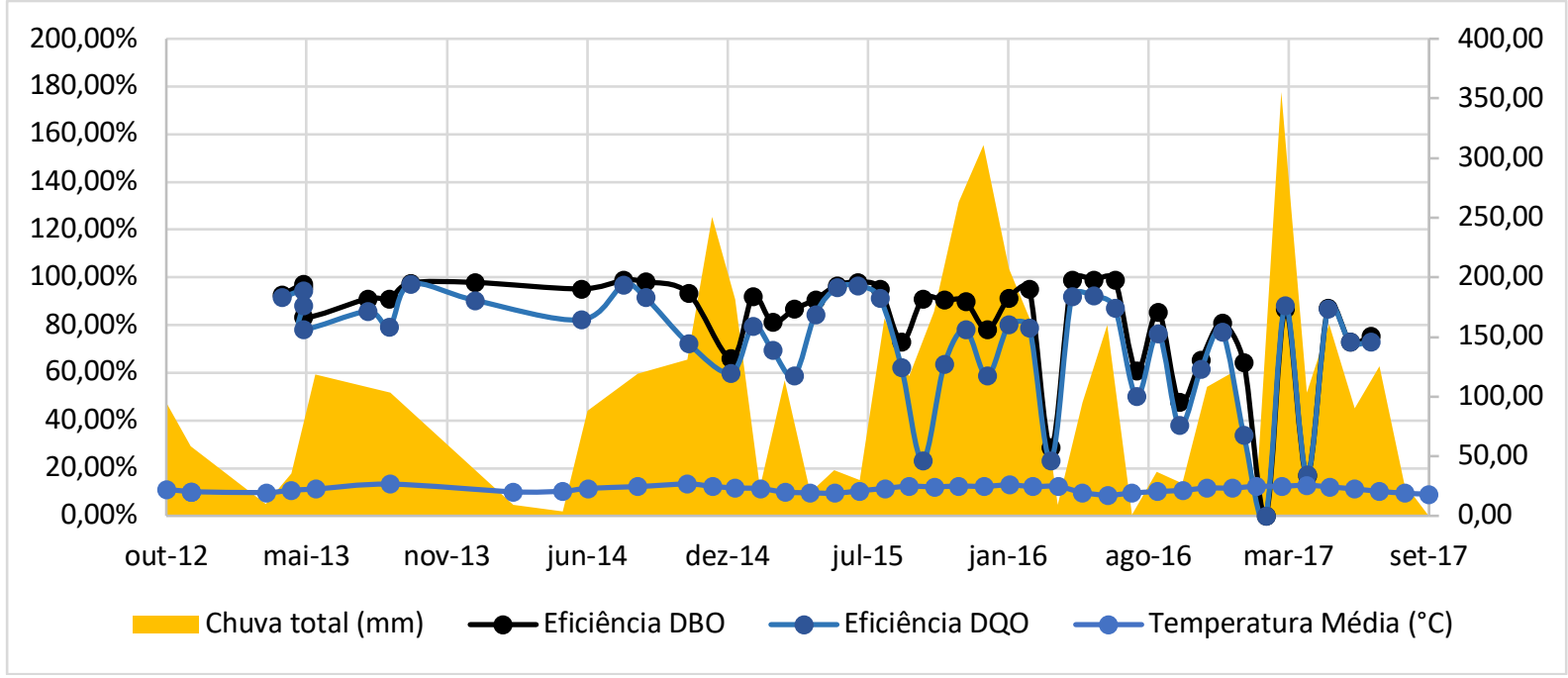

Fonte: Cauê Girão de Abreu, 2019.

Analisando a figura 17 não é possível perceber uma correlação clara entre as variáveis propostas. A seguir é apresentada a análise estatística, através do coeficiente de correlação de Pearson, para a verificação das correlações.

A tabela 8 traz os coeficientes de correlação da eficiência de remoção de $\mathrm{DBO}_{5}{ }^{20}$ e DQO para as variáveis temperatura e chuva.

Tabela 8. Coeficiente de correlação de Pearson

\begin{tabular}{|l|l|l|}
\hline Parâmetro & Chuva & Temperatura \\
\hline DBO $^{\mathbf{2 0}}$ & $-0,04$ & $-0,31$ \\
\hline DQO & $-0,19$ & $-0,46$ \\
\hline \multirow{4}{*}{ Legenda: } & Correlação desprezível \\
\cline { 2 - 3 } & Correlação fraca \\
\cline { 2 - 3 } & Correlação moderada \\
\cline { 2 - 3 } & Correlação forte \\
\hline
\end{tabular}

De acordo com os coeficientes apresentados na tabela 8, a correlação com a chuva foi desprezível, tanto para a $\mathrm{DBO}_{5}{ }^{20}$ quanto para a $\mathrm{DQO}$, já para a temperatura do ar na região do estudo foi evidenciada uma correlação negativa, ainda que fraca.

Para evidenciar as correlações encontradas, foram plotadas no gráfico a seguir as variáveis que apresentaram correlação e foram ainda traçadas linhas de tendência sob a forma de regressão linear, conforme figura 18, a seguir. 
Figura 18 - Correlação entre as eficiências e a temperatura.

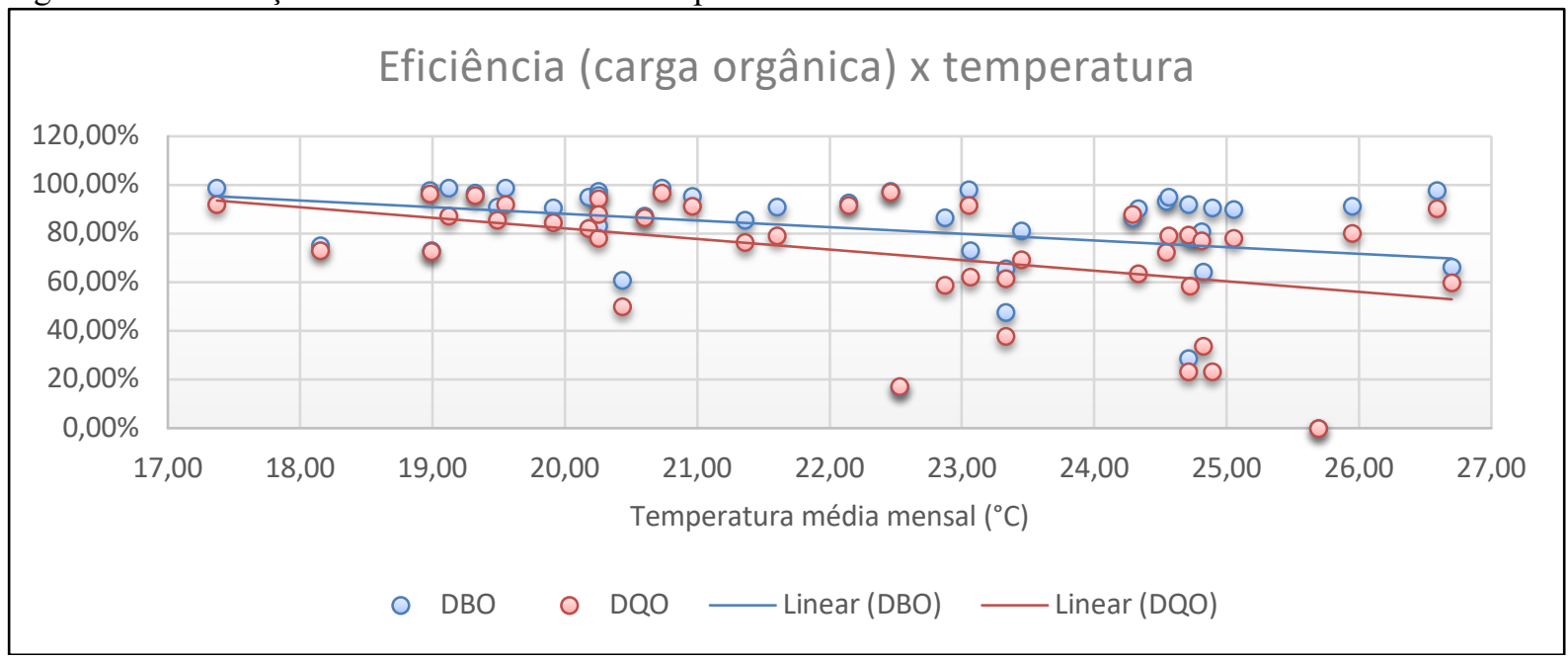

Fonte: Cauê Girão de Abreu, 2019.

A correlação encontrada da eficiência de remoção com a variação de temperatura foi fraca, e as variações não foram significativas a ponto de comprometer o funcionamento do sistema.

Mesmo com variações mais altas, como no estudo de Mucha et al. (2017), onde a variação chegou ficou aproximadamente entre $-15^{\circ} \mathrm{C}$ e $25^{\circ} \mathrm{C}$, foi relatado que as variações nas eficiências de tratamento não foram importantes e que nenhuma medida foi tomada para lidar com a mesma.

Vyamazal (2011) também apresenta esta comparação de eficiência de remoção de $\mathrm{DBO}_{5}{ }^{20} \mathrm{e}$ DQO nas diferentes estações e temperaturas. $\mathrm{O}$ estudo mostra que a influência das variações sazonais não tem influência considerável nas eficiências e afirma ainda que os sistemas podem ser operados com sucesso em climas frios.

Pelo fato de algumas reações bioquímicas envolvidas no processo biológico de biodegradação de poluentes orgânicos serem privilegiadas pelo aumento da temperatura (KADLEC \& REDDY, 2001), esperava-se que a correlação entre as eficiências de remoção e a temperatura fosse positiva, o que não foi confirmado neste estudo.

Existe, porém, uma colocação do mesmo estudo (KADLEC \& REDDY, 2001) que pode explicar a correlação negativa encontrada: $\mathrm{O}$ fato de a temperatura alterar as condições físicoquímicas e desfavorecer alguns processos importantes na remoção dos poluentes, principalmente solubilidade de gases, (especialmente oxigênio), disponibilidade de aceptores de elétrons para as reações, e a capacidade de adsorção e saturação do substrato.

De acordo com Von Sperling (1996) uma das principais reações de decomposição de matéria orgânica é a oxidação, e esta depende diretamente da disponibilidade de oxigênio no meio, conforme equação apresentada na equação 1:

Equação 1- Equação de oxidação da matéria orgânica.

$$
\mathrm{C}_{6} \mathrm{H}_{12} \mathrm{O}_{6}+6 \mathrm{O}_{2} \rightarrow 6 \mathrm{CO}_{2}+6 \mathrm{H}_{2} \mathrm{O}
$$

Fonte: Von Sperling, 1996.

Como as temperaturas máximas e mínimas não foram muito acentuadas, apresentando uma amplitude reduzida (de $17,37^{\circ} \mathrm{C}$ a $27,24^{\circ} \mathrm{C}$ ), conclui-se que o efeito positivo nas reações biológicas foi menos importante que as alterações das condições físico-químicas. 
Kadlec e Redy (2001) concluem ainda em seu estudo que as maiores variações nas eficiências de remoção ocorrem no extremo inferior da temperatura, com valores menores do que $15^{\circ} \mathrm{C}$, faixa que não foi atingida neste estudo.

Uma outra explicação possível para e redução na eficiência com o aumento da temperatura é o fato de o aumento de temperatura aumentar o fenômeno de evapotranspiração, diminuindo o tempo de detenção e concentrando a carga orgânica remanescente pela diminuição do volume de água (KADLEC \& REDDY, 2001).

A influência da pluviometria está ligada ao aumento de volume da massa líquida que é recebida pelo sistema. Esta fenômeno, segundo Kadlec e Reddy (2001) pode alterar significativamente o tempo de detenção do esgoto no sistema, podendo interferir nas reações responsáveis pela remoção de carga orgânica, pois estas precisam de tempo para acontecer.

O sistema estudado, no entanto, não recebe grandes contribuições pluviométricas, uma vez que a rede de esgoto do empreendimento é nova e não sofre muita infiltração de água pluvial, e ainda pelo fato de o sistema ter uma rede de drenagem externa que impede que a chuva do entorno escoe para o sistema.

A contribuição pluvial recebida pelo sistema é basicamente aquela que ocorre diretamente sobre ele, não tendo esta sido suficiente para interferir de forma significativa nas eficiências de remoção de carga orgânica.

\subsection{CORRELAÇÃO COM TEMPO DE TRATAMENTO}

O resultado do cálculo do coeficiente de correlação de Pearson entre as eficiências de remoção e o tempo decorrido no estudo está apresentado na tabela 9:

Tabela 9. Coeficiente de correlação de Pearson

\begin{tabular}{|l|l|}
\hline Parâmetro & Tempo decorrido \\
\hline DBO $_{5}{ }^{\mathbf{2 0}}$ & $-0,47$ \\
\hline $\mathbf{D Q O}$ & $-0,45$ \\
\hline \multirow{4}{*}{ Legenda: } & Correlação desprezível \\
\cline { 2 - 2 } & Correlação fraca \\
\cline { 2 - 2 } & Correlação moderada \\
\cline { 2 - 2 } & Correlação forte \\
\hline
\end{tabular}

O tempo de operação do sistema decorrido no estudo apresentou correlação negativa fraca com as eficiências de remoção de carga orgânica.

Para evidenciar as correlações encontradas, foram plotados no gráfico a seguir as variáveis que apresentaram correlação e foram ainda traçadas linhas de tendência sob a forma de regressão linear, conforme figura 19. 
Figura 19 - Correlação entre a s eficiências e o tempo decorrido.

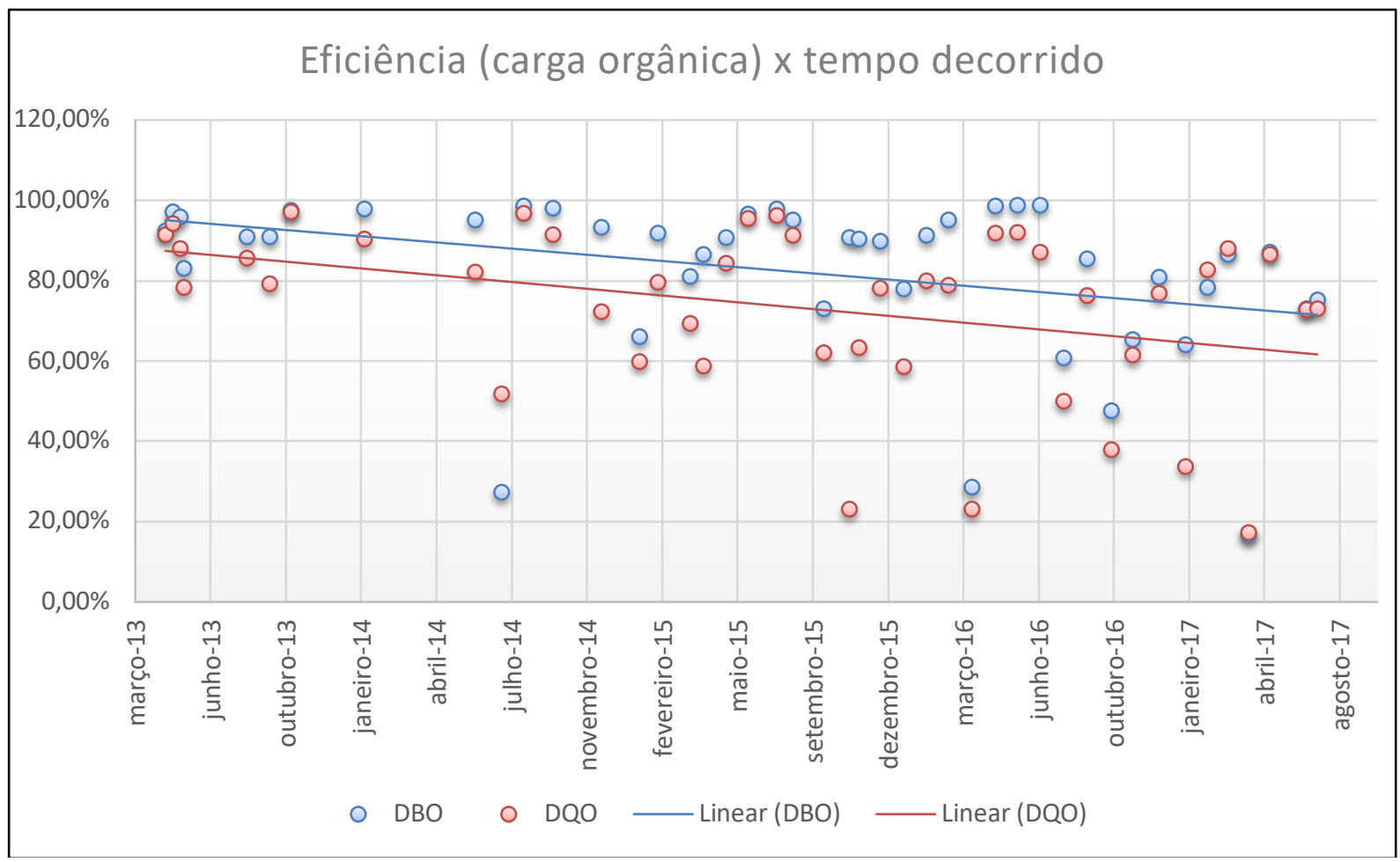

Fonte: Cauê Girão de Abreu, 2019.

A correlação apresentada entre a eficiência de remoção de carga orgânica e o tempo decorrido (idade do sistema) não foi de grande importância, não apresentando reduções que possam comprometer a eficiência dentro do prazo estudado.

O primeiro fenômeno que pode explicar a fraca correlação negativa entre o tempo decorrido no estudo e as eficiências de remoção de carga orgânica é a colmatação do substrato, causada pelos sólidos removidos do esgoto.

Segundo Hua et al. (2014), este fenômeno interfere nos fluxos hidráulicos, prejudicando os processos de sedimentação, filtração, adsorção e biodegradação.

Um outro fenômeno que pode explicar esta correlação é a saturação do substrato, que segundo Drizo et al. (2002) causa diminuição da capacidade de adsorção do mesmo, podendo interferir na remoção de algumas substâncias.

\section{ANÁLISE COMPARATIVA}

Um estudo de 2015 (PAING et al, 2015) analisou a eficiência de remoção de carga orgânica de 169 sistemas de wetlands construídos em escala real e a influência sofrida por esta eficiência em relação aos mesmos fatores aqui estudados: variações de clima e idade dos sistemas.

Paing coletou dados de 169 sistemas de wetlands construídos em escala real efetuando tratamento de esgoto sanitário, todos eles localizados em território francês. Os sistemas foram dimensionados para poulações equivalentes que variam de 48 PE a 2000 PE. Para comparação dos efeitos climáticos os sistemas foram ainda classificados em termos de região, sendo que Paing dividiu em Norte e Sul, e obteve, junto aos órgãos fiscalizadores dos sistemas, as eficiências de remoção de $\mathrm{DBO}_{5}^{20}$ e DQO. 


\subsection{EFICIÊNCIA DE REMOÇÃO DE CARGA ORGÂNICA}

Assim como neste estudo, no estudo francês a eficiências encontradas para a remoção de $\mathrm{DBO}_{5}{ }^{20}$ e DQO foram bastante satisfatórias, encontrando remoções médias de $\mathrm{DBO}_{5}{ }^{20}$ e DQO de $98 \%$ e $94 \%$, respectivamente, conforme mostra a tabela 10 :

Tabela 10 - Remoções e eficiências.

\begin{tabular}{|l|r|r|}
\hline & $\mathrm{DBO}_{5}{ }^{20}(\mathrm{mg} / \mathrm{L})$ & $\mathrm{DQO}(\mathrm{mg} / \mathrm{L})$ \\
\hline Esgoto sanitário bruto & 360 & 841 \\
\hline Saída do tratamento & 6 & 51 \\
\hline Eficiência global de remoção & $98,33 \%$ & $93,94 \%$ \\
\hline
\end{tabular}

Fonte: Adaptado de PAING et al., 2015.

\subsection{RELAÇÃO COM A VARIAÇÃO DE TEMPERATURA}

No estudo de Paing as amplitudes térmicas foram maiores, uma vez que os sistemas considerados se encontram na França, com climas característicos de maior amplitude de temperatura em relação ao clima do sudeste Brasileiro considerado neste estudo. Paing considera temperaturas médias de $7^{\circ} \mathrm{C}$ no inverno e $20^{\circ} \mathrm{C}$ no verão, gerando uma amplitude de $13^{\circ} \mathrm{C}$.

Exatamente como neste estudo, no estudo francês não foram apresentadas interferências importantes ou de maior representatividade entre a temperatura e a eficiência de remoção de carga orgânica. Pequenas variações foram observadas, mas sem o comprometimento do funcionamento do sistema.

Percebe-se ainda uma diferença nas variações de remoção entre norte e sul, sendo que no sul as variações de remoção de $\mathrm{DQO}$ foram maiores. Para a $\mathrm{DBO}_{5}{ }^{20}$ as variações foram muito pequenas e não houve diferenciação notável entre as regiões.

Para caracterização mais expressiva, Paing divide os sistemas em relação à localização geográfica, entre norte e sul da França. As concentrações de carga orgânica no esgoto tratado em cada uma das regiões, no verão e no inverno, estão apresentadas na figura 20:

Figura 20 - Concentrações de $\mathrm{DBO}_{5}^{20}$ e DQO em diferentes estações.

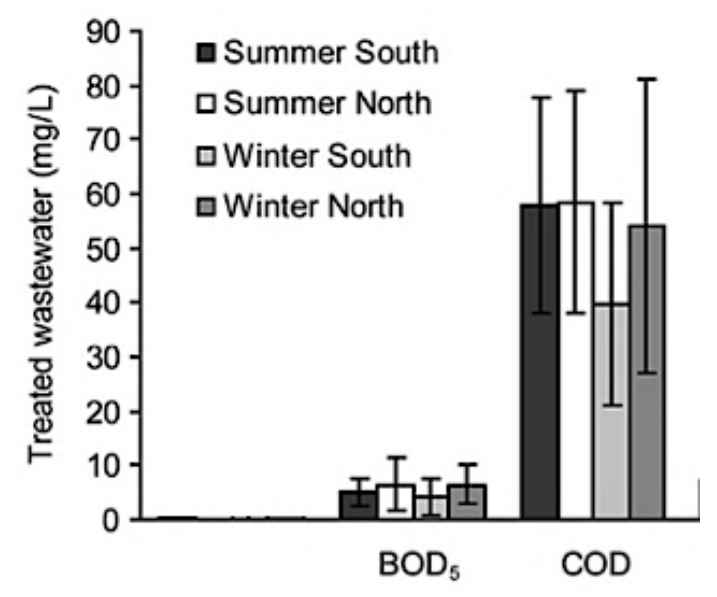

Fonte: Adaptado de PAING et al., 2015.

O gráfico mostra que, mesmo com baixa correlação, existe uma ligeira diminuição das concentrações de saída de $\mathrm{DBO}_{5}{ }^{20}$ e DQO no inverno, ou seja, com a diminuição de 
temperatura. Este resultado assemelha-se ao encontrado neste estudo, mesmo havendo uma sensível diferença entre os dois climas considerados. Enquanto no estudo francês as temperaturas tiveram médias anuais próximas de $11^{\circ} \mathrm{C}$, neste estudo, no sudeste brasileiro, a temperatura mínima encontrada foi de $17,4^{\circ} \mathrm{C}$ e a média de $22,7^{\circ} \mathrm{C}$. Ainda assim, as temperaturas mais baixas da França não foram suficientes para inibir a ação dos microrganismos responsáveis pela remoção.

\subsection{RELAÇÃO COM A IDADE (TEMPO DE OPERAÇÃO) DOS SISTEMAS}

Paing dividiu os resultados do tratamento dos sistemas em faixas de idade de operação. Ele coloca todos os sistemas como sendo semelhantes, uma vez que todos tratam esgoto e todos tem o design semelhante, com 2 estágios de fluxo vertical em série (sistema francês). A figura 21 a seguir ilustra este resultado:

Figura 21 - Concentrações de $\mathrm{DBO}_{5}^{20}$ e DQO em relação à idade do sistema.

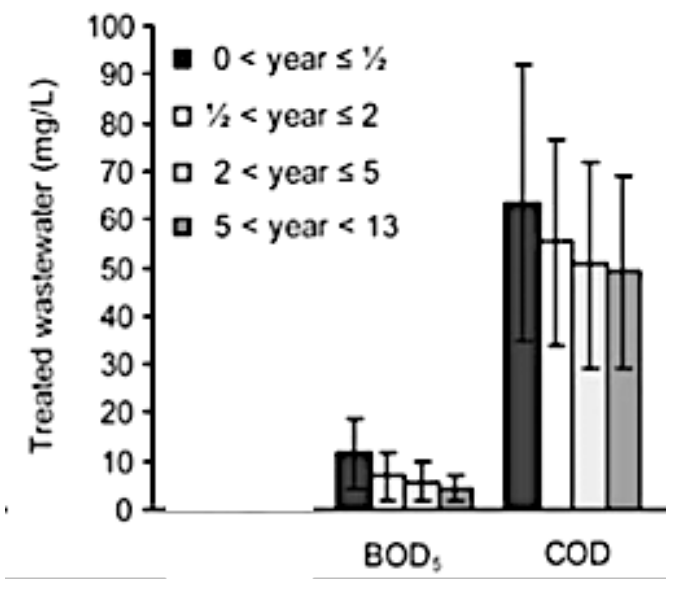

Fonte: Adaptado de PAING et al., 2015.

Os sistemas estudados por Paing mostraram concentrações menores de $\mathrm{DBO}_{5}{ }^{20}$ e DQO no esgoto tratado com o passar dos anos. O resultado do estudo francês se opõe ao resultado do presente estudo, onde houve ligeira diminuição das eficiências com o passar dos anos.

Paing justifica este aumento associando-o ao crescimento e maturidade da biomassa e à formação de uma camada inicial que auxilia na distribuição homogênea do esgoto. Ele afirma ainda que nenhum efeito de colmatação foi observado durante os 12 anos considerados no estudo.

\section{CONCLUSÕES}

Os resultados permitem concluir que os wetlands construídos alcançaram valores de remoção satisfatórios de carga orgânica no tratamento de esgoto sanitário.

Os O sistema estudado composto pela sequência de wetlands subsuperficiais verticais de fluxo não saturado, seguidos por wetlands de fluxo subsuperficias horizontais de fluxo saturado e wetlands superficiais horizontais de fluxo saturado, mostraram-se eficientes a ponto de atender a legislação vigente para lançamento em corpos d'água.

O sistema apresentou uma correlação negativa fraca, segundo o coeficiente de correlação de Pearson, entre as variações de temperatura e as eficiências de remoção de carga orgânica, representadas pela DBO520 e DQO. 
As variações pluviométricas representadas pela chuva total mensal, não interferiu diretamente na eficiência de remoção de carga orgânica. Ressaltando que o sistema estudado recebia contribuição pluviométrica apenas da sua própria área, não recebendo nenhuma drenagem de áreas externas ao sistema.

Quando o fator de análise é o tempo decorrido de operação do sistema, observou-se uma correlação negativa fraca. O tempo decorrido diminuiu levemente as eficiências de remoção de DBO520 e DQO.

As correlações apresentadas indicam que, apesar de afetar de forma leve a eficiência, é importante considerar o fator climático e o tempo de operação previsto para o sistema em seu dimensionamento e operação, de forma a garantir sua eficiência durante todo o tempo de vida do sistema.

Quando comparado a outros sistemas em escala real o comportamento do sistema estudado em relação à eficiência de remoção de carga orgânica e às variações de temperatura é semelhante, com altas eficiências de remoção de matéria orgânica e com baixas variações resultantes das mudanças de temperatura ambiente.

\section{REFERÊNCIAS}

ASSOCIAÇÃO BRASILEIRA DE NORMAS TÉCNICAS. NBR 12209: Elaboração de projetos hidráulicos-sanitários de estações de tratamento de esgotos sanitários. Rio de Janeiro, 2011. 53p.

ASSOCIAÇÃO BRASILEIRA DE NORMAS TÉCNICAS. NBR 13969: Tanques sépticos Unidades de tratamento complementar e disposição final dos efluentes líquidos - Projeto, construção e operação. Rio de Janeiro. 1997.60p.

ASSOCIAÇÃO BRASILEIRA DE NORMAS TÉCNICAS. NBR 7229: Projeto, construção e operação de sistemas de tanques sépticos. Rio de Janeiro, 1993.15p.

ASSOCIAÇÃO BRASILEIRA DE NORMAS TÉCNICAS. NBR 9648: Estudo de concepção de sistemas de esgoto sanitário. Rio de Janeiro. 1986. 7p.

AGÊNCIA NACIONAL DE ÁGUAS E MINISTÉRIO DAS CIDADES. Atlas Esgotos Despoluição de Bacias Hidrográficas. Brásilia, 2017.

AGRITEMPO. Sistema de Monitoramento Meteorológico. Disponível em: http://www.agritempo.gov.br/agritempo/index.jsp. Acesso em: 1 de fev. 2017.

AVELLAN, C. T. et al. The role of constructed wetlands for biomass production within the water-soil-waste nexus. Water Science \& Technology v75. p.2237-2245. 2017.

ÁVILA C. et al. Emerging organic contaminants in vertical subsurface flow constructed wetlands: Influence of media size, loading frequency and use of active aeration. Science of the Total Environment. n.494-495, p. 211-217. 2014. 
ÁVILA, C. et al. Integrated treatment of combined sewer wastewater and stormwater in a hybrid constructed wetland system in southern Spain and its further reuse. Ecological engineering, v. 50, p. 13-20, 2013a.

ÁVILA, C. et al. Three-stage hybrid constructed wetland system for wastewater treatment and reuse in warm climate regions. Ecological Engineering, v. 61, p. 43-49, 2013 b.

BEHRENDS, L. L. et al. Integrated constructed wetland systems: Design, operation, and performance of low-cost decentralized wastewater treatment systems. Water Science and Technology. v. 55, p.155-161. 2007.

BIALOWIEC et al. The influence of evapotranspiration on vertical flow subsurface constructed wetlands performance. Ecological Engineering, v. 67, p. 89-94, 2014.

BRASIL. Fundação Nacional de Saúde. Manual de saneamento. 3ed. rev. Brasília. 408p. 2004.

BRASIL. Lei $\mathbf{n}^{\mathbf{0}}$ 11.445, de 5 de janeiro de 2007. Estabelece diretrizes nacionais para o saneamento básico. Diário Oficial da União de 08 jan. de 2007, Seção 1, Página 3, Brasília, DF, 21 jun. 2010. Disponível em: http://www.planalto.gov.br/ccivil_03/_ato2007010/2007/lei/111445.htm. Acesso em: 13 de abr, 2017.

BRASIL. Ministério do Meio Ambiente, Conselho Nacional do Meio Ambiente. Resolução No 430, de 13 de maio de 2011. Dispõe sobre as condições e padrões de lançamento de efluentes, complementa e altera a Resolução no 357, de 17 de março de 2005, do Conselho Nacional do Meio Ambiente-CONAMA. Publicação DOU nº 92, de 16/05/2011, pág. 89.

BRIX, H. Do macrophytes play a role in constructed treatment wetlands? Water Science Technology, v.35, n. 5, p. 11-17, 1997.

BRIX, H. e SCHIERUP, H. The use of aquatic macrophytes in water-polution control. Ambio vol. 18 n. 2, p. 100-107. 1989.

BRIX, H. Functions of macrophytes in constructed wetlands. Water Science and Technology. v. 29, n. 4, p. 71-78, 1994.

BRIX, H. Sludge dewatering and mineralization in sludge treatment reed beds. Water, v. 9, n. 3, p. 160, 2017.

BRIX, H. Use of constructed wetlands in water pollution control: historical development, present status, and future perspectives. Water Science and Technology. v. 30, n. 8, p. 209223, 1994. 
BRIX, H. Wastewater treatment in constructed wetlands: system design, removal processes, and treatment performance. In: MOSHIRI, G.A. Constructed wetlands for water quality improvement, Lewis Publishers, 1993. p. 9-22.

CAPODAGLIO, Andrea G. Integrated, Decentralized Wastewater Management for Resource Recovery in Rural and Peri-Urban Areas. Resources, 6, 22. 2017.

CARVALHO, P.N., ARIAS, C. A., BRIX, H. Constructed Wetlands for Water Treatment: New Developments. Water 2017, v.9, n.6, a.397. 2017.

CASTRO, A.A. et al. Manual de saneamento e proteçäo ambiental para os municípios: saneamento. Belo Horizonte: Departamento de Engenharia Sanitária e Ambiental, 1995. 221 p.

CENTRO DE PESQUISAS METEOROLÓGICAS E CLIMÁTICAS APLICADAS À AGRICUlTURA (CPMCAA). Clima dos Municípios Paulistas. Disponível em: http://www.cpa.unicamp.br/outras-informacoes/clima-dos-municipios-paulistas.html. Acesso em 1 de fev. 2017.

CENTRO DE PESQUISAS METEOROLÓGICAS E CLIMÁTICAS APLICADAS À AGRICULTURA. Clima de Campinas. Disponível em: http://www.cpa.unicamp.br/outrasinformacoes/clima-de-campinas.html. Acesso em 2 de fev. 2017.

CLAY, A. et al. Using stable isotopes of water to infer wetland hydrological dynamics. Hydrology and Earth System Sciences Discussions, European Geosciences Union, 8 (6), pp.1164-1173. 2004.

CRITES, R.; TECHNOBANOGLOUS, G. Small and decentralized wastewater management systems. USA: McGraw-Hill, 1998.

CRITES, R.W.; MIDDLEBROOKS, J.; REED, S.C. Natural Wastewater Treatment Systems. CRC Press. 2014. 546 páginas.

CUI, L. et al. Removal of nutrients from septic tank effluent with baffle subsurface flow constructed wetlands. Journal of Environmental Management n. 153, p. 33-39. 2015.

DEPARTAMENTO DE ÁGUAS E ENERGIA ELÉTRICA. Banco de Dados Hidrológicos. Disponível em: http://www.hidrologia.daee.sp.gov.br. Acesso em 1 de fev. 2017.

DRIZO, A. et al. Phosphorus Saturation Potential: A Parameter for Estimating the Longevity of Constructed Wetland Systems. Environmental Science and Technology n.36, p.46424648. 2002. 
EMBRAPA. Clima. Disponível em http://www.cnpf.embrapa.br/pesquisa/efb/clima.htm. Acesso em 28 de agosto de 2017.

FENNESSEY M.S. et al. Sediment Deposition Patterns in Restored Freshwater Wetlands Using Sediment Traps. Ecological Engineering n.3, p.409-428. 1994.

FERNANDES, C. Esgotos Sanitários, Ed. Univ./UFPB, João Pessoa, 1997, 435p. Reimpressão Jan/2000.

HELLER, L. Relação entre saúde e saneamento na perspectiva do desenvolvimento. Ciência \& Saúde Coletiva, n.3: p.73-84, 1998.

HENCH, K.R. et al. Fate of physical, chemical, and microbial contaminants in domestic wastewater following treatment by small constructed wetlands. Water Research, v. 37, n.4, p. 921-927, 2003.

HESPANHOL, I. Potencial de Reuso de Água no Brasil Agricultura, Industria, Municípios, Recarga de Aqüíferos. Revista Brasileira de Recursos Hídricos. Brasil, v.7, n.4. p75-95. 2002.

HidroWeb, Agência Nacional de Águas (ANA). Acesso em 05 de agosto de 2017. Disponível em: http://hidroweb.ana.gov.br/

HOFFMANN, H. et al. Technology review of constructed wetlands - Subsurface flow constructed wetlands for greywater and domestic wastewater treatment. Deutsche Gesellschaft für Internationale Zusammenarbeit (GIZ) GmbH - Sustainable sanitation ecosan program. Alemanha, 2011.

HUA, G. F. et al. Effects of plant roots on the hydraulic performance during the clogging process in mesocosm vertical flow constructed wetlands. Environmental Science and Pollution Research n.21, p 13017-13026. 2014.

KADLEC, ROBERT H.; REDDY, K.R. Temperature effects in treatment wetlands. Water Environment Research. Vol. 73, n. 5; 2001.

KATSENOVICH, Y.P. et al. Performance evaluation of constructed wetlands in a tropical region. Ecol. Eng. 35 (10), 1529-1537. 2009

KIM, S.H. et al. Long-term performance of vertical-flow and horizontal-flow constructed wetlands as affected by season, $\mathrm{N}$ load, and operating stage for treating nitrogen from domestic sewage. Environmental Science and Pollution Research International, v.23, n.2, p. 1108$1119,2015$. 
KULMAN, T; FARRINGTON, J. What is Sustainability? Sustainability 2(11), 3436-3448, 2010.

LAZAREVA, O; PICHLER, T. Long-term performance of a constructed wetland/filter basin system treating wastewater, Central Florida. Chemical Geology, v. 269, n. 1-2, p.137-152, 2010 .

LU, S. et al. Impacts of different media on constructed wetlands for rural household sewage treatment. Journal of Cleaner Production, v. 127, p. 325-330, 2016.

MANNARINO, C.M. et al. Wetlands para tratamento de lixiviados de aterros sanitários experiências no aterro sanitário de Piraí e no aterro metropolitano de Gramacho (RJ). Engenharia Sanitária e Ambiental, v. 11, n.2, p. 108-112, 2006.

MANSOR, M.T.C. Uso de leito de macrófitas no tratamento de águas residuárias. 1998. 136p. Dissertação (Mestrado). Universidade Estadual de Campinas, Campinas, 2008.

MBURU, Njenga et al. Performance evaluation of horizontal subsurface flow-constructed wetlands for the treatment of domestic wastewater in the tropics. Journal of Environmental Engineering, v. 139, n. 3, p. 358-367, 2013.

METCALF \& EDDY. Wastewater engineering: treatment and reuse. $4^{\text {th }}$ edition. McGrawHill, 1848 p. 2003.

MEYER, D. et al. Constructed wetlands for combined sewer overflow treatment - comparison of German, French and Italian approaches. Water, v. 5, n. 1, p. 1-12, 2013.

MILLENNIUM ECOSYSTEM ASSESSMENT, 2005. Ecosystems and human well-being: wetlands and water Synthesis. World Resources Institute, Washington, DC.

MILLOT, Y. et al. Effects of design and operational parameters on ammonium removal by single-stage French vertical flow filters treating raw domestic wastewater. Ecological Engineering n. 97, p. 516-523. 2016.

MOLLE, P. et al. How to treat raw sewage with constructed wetlands: an overview of the French systems. Water Science and Technology, v. 51, n. 9, p. 11-21, 2005.

MUCHA, Z. et al. Long-term operation of Kickuth-type constructed wetland applied to municipal wastewater treatment in temperate climate. Environmental Technology, 39:9, pg. 1133-1143. 2017. 
OMS. Investing in Water and Sanitation: Increasing Access, Reducing Inequalities. UNWater Global Analysis and Assessment of Sanitation and Drinking-Water. GLAAS 2014 Report. 2014.

PAING, JOELLE et al. Effect of climate, wastewater composition, loading rates, system age and design on performances of French vertical flow constructed wetlands: A survey based on 169 full scale systems. Ecological Engineering, n.80, p. 46-52, 2015.

PHILIPPI, L.S. Saneamento descentralizado: instrumento para o desenvolvimento sustentável. In: IX SILUBESA - Simpósio Luso-Brasileiro de Engenharia Sanitária e Ambiental, 2000, Porto Seguro - BA. Anais do IX SILUBESA. Rio de Janeiro: ABES, v.1. p.181-184.

PHILIPPI, L.S.; SEZERINO, P.H. Aplicação de Sistemas tipo wetlands no tratamento de águas residuárias: utilização de filtros plantados com macrófitas. Ed. do autor, 2004. 144 p.

PHYTORESTORE BRASIL. Documentação de obra do sistema de wetlands construídos para tratamento de esgoto. 2013.

PHYTORESTORE BRASIL. Documentação de operação do sistema de wetlands construídos para tratamento de esgoto. 2015.

PHYTORESTORE BRASIL. Projeto executivo do sistema de wetlands construídos para tratamento de esgoto. $2013 \mathrm{~b}$.

PIVELI R. P.; KATO, M. Qualidade das Águas e Poluição: aspectos físico-químicos. São Paulo: Editora ABES, 2005. 275 p.

POÇAS, C.D. Utilização de tecnologia de wetlands para tratamento terciário: controle de nutrientes. 2015. 109p. Dissertação (Mestrado) - Faculdade de Saúde Pública da Universidade de São Paulo. São Paulo, 2015.

PROBIO. UFSCAR. O que são Macrófitas Aquáticas? Disponível em http://www.ufscar.br/ probio/info_macrof.html. Acesso em: 25 de mai., 2017.

RACHMADI T. A. et al. Enteric and indicator virus removal by surface flow wetlands. Science of the Total Environment, n.542, p. 976-982. 2016.

RAI, U. N. et al. Seasonal applicability of horizontal sub-surface flow constructed wetland for trace elements and nutrient removal from urban wastes to conserve Ganga River water quality at Haridwar, India. Ecological Engineering, n. 81, p. 115-122. 2015 
REBOUÇAS, A.C. Água no Brasil: abundância, desperdício e escassez. Bahia Análise \& Dados Salvador, v. 13, n. ESPECIAL, p. 341-345, 2003.

RIO DE JANEIRO, 2007. DZ.215-R4. DIRETRIZ DE CONTROLE DE CARGA ORGÂNICA BIODEGRADÁVEL EM EFLUENTES LÍQUIDOS DE ORIGEM NÃO INDUSTRIAL. Publicada no DOERJ de 08 de novembro de 2007.

RIVAS, A., Barceló-Quintal, I., Moeller, G.E. Pollutant removal in a multi-stage municipal wastewater treatment system comprised of constructed wetlands and a maturation pond, in a temperate climate. Water Sci. Technol. 64 (4), 980-987. 2011.

ROEFS, I. et al., Centralised, decentralised or hybrid sanitation systems? Economic evaluation under urban development uncertainty and phased expansion. Water Research, v.109. p.274286. 2017.

RORIZ, A. Enciclopedia 1001 Plantas e Flores. São Paulo. Editora Europa. 1998. 258 p.

ROZARI, P.; GREENWAY, M.; EL HANANDEH, A. Phosphorus removal from secondary sewage and septage using sand media amended with biochar in constructed wetland mesocosms. Science of the Total Environment, v. 569-570, p. 123-133, 2016.

ROZEMA, E.R. et al. A vertical flow constructed wetland for the treatment of winery process water and domestic sewage in Ontario, Canada: Six years of performance data. Ecological Engineering, v., p. 262-268, 2016.

SAEED, T.; SUN, G. A review on nitrogen and organics removal mechanisms in subsurface flow constructed wetlands: Dependency on environmental parameters, operating conditions and supporting media. Journal of Environmental Management, v. 112, p. 429-448, 2012.

SALATI, E. Utilização de sistemas de wetlands construídas para tratamento de águas. Biológico, v.65, n.1/2, p.113-116, jan./dez., 2003.

SÃO PAULO. Decreto No 8468, de 8 de setembro de 1976. Aprova o Regulamento da Lei n. $^{\circ}$ 997, de 31 de maio de 1976, que dispõe sobre a prevenção e o controle da poluição do meio ambiente. D.O.E. Executivo, de 09.09.76.

SARTORI, L. et al. COD, nutrient removal and disinfection efficiency of a combined subsurface and surface flow constructed wetland: A case study. International Journal of Phytoremediation, v. 18, n. 4, p.416-422. 2016.

SEZERINO, P.H. et al. Sistemas naturais aplicados ao tratamento descentralizado de esgotos: uso combinado de lagoas de estabilização e filtros plantados com macrófitas 
(wetlands). In: $23^{\circ}$ Congresso Brasileiro de Engenharia Sanitária e Ambiental. Campo Grande/MS. 2005.

SHI, L. et al. Performance of a subsurface-flow constructed wetland in Southern China. J. Environ. Sci. 16 (3), 476-481. 2004.

SHULSE, D. C. Building better wetlands for amphibians: investigating the roles of engineered wetland features and mosquitofish (Gambusia affinis) on amphibian abundance and reproductive success. Tese (Doutorado) University of Missouri. Faculty of the Graduate School. Columbia, 2011.

SILVA, S.C. Wetlands construídos de fluxo vertical com meio suporte de solo natural modificado no tratamento de esgotos domésticos. 2007. 231 p. Tese (Doutorado) Faculdade de Tecnologia da Universidade de Brasilia. Departamento de Engenharia Civil e Ambiental. Brasília, 2007.

SIMA, J. et al. Removal of Selected Metals from Wastewater Using a Constructed Wetland. Chemical Biodiversity n.13, p. 582 - 590. 2016.

TANAKA, N., Jinadasa, K.B.S.N., Werellagama, D.R.I.B., Mowjood, M.I.M., Ng, W.J., Constructed tropical wetlands with integrated submergent-emergent plants for sustainable water quality management. J. Environ. Sci. Health. 41 (10), 2221-2236. 2006.

TOSCANO, A. et al. Comparison of removal efficiencies in Mediterranean pilot constructed wetlands vegetated with different plant species. Ecological Engineering, n. 75, p. 155-160. 2015.

Trang, N.T.D., Konnerup, D., Schierup, H., Chiem, N.H., Tuan, L.A., Brix, H., Kinetics of pollutant removal from domestic wastewater in a tropical horizontal subsurface flow constructed wetland system: effect of hydraulic loading rate. Ecol. Eng. 36 (4), 527-535. 2010.

TRATA BRASIL. Saneamento Público ou Privado? Disponível em http://www.tratabrasil.org.br/saneamento-no-brasil. 2016. Acesso em 16 de outubro de 2017.

TRATA BRASIL. Situação do Saneamento no Brasil. Disponível em http://www.tratabrasil.org.br/saneamento-no-brasil. Acesso em 16 de outubro de 2017.

TSIHRINTZIS, V.A. et al. Performance and cost comparison of a FWS and a VSF constructed wetland system. Environ. Technol. 28 (6), 621-628. 2010.

TSIHRINTZIS, V. A. The use of vertical flow constructed wetlands in wastewater treatment. Water Resources Management, v. 31, n. 10, p. 3245-3270, 2017. 
UCKER, F.E., et al. 2014. Componentes do sistema de tratamento de esgoto com plantas. Revista Monografias Ambientais, v. 15, n. 1, p. 2974-2981, 2014.

UNITED STATES. ENVIRONMENTAL PROTECTION AGENCY. What is a Wetland? https://www.epa.gov/wetlands/what-wetland. Acesso em: 2 de mai., 2017.

UN-OMS. 2014. Investing in water and sanitation: increasing access, reducing inequalities. UN-Water Global Analysis and Assessment of Sanitation and Drinking-Water. GLAAS 2014 Report.

VALIPOUR, A. et al. Performance of high-rate constructed phytoremediation process with attached growth for domestic wastewater treatment: Effect of high TDS and Cu. Journal of Environmental Management n.145, p. 1-8. 2014.

VALIPOUR, A.; AHN, Y.H. Constructed wetlands as sustainable ecotechnologies in decentralization practices: a review. Environmental Science and Pollution Research International, v. 23, n.1, p.180-197, 2016.

VERHOEVEN, J.T.A.; MEULEMAM, A.F.M. Wetlands for wastewater treatment: opportunities and limitations. Ecological Engineering, v. 12, p. 5-12, 1999.

VITORINO, F.A. et al. Wetlands - processos naturais para remoção de nutrientes em estações de tratamento de esgotos. Disponível em http://www.grupoaguasdobrasil.com.br/wp-content/uploads/2013/01/Wetland-Juturnaiba-.pdf. Acesso em 03 de novembro de 2017.

VON SPERLING, M. Princípios do Tratamento Biológico de Águas Residuárias volume 1: introdução à qualidade das águas e ao tratamento de esgotos. Belo Horizonte: Editora UFMG, 2014. $452 \mathrm{p}$.

VON SPERLING, M. Introdução à qualidade das águas e ao tratamento de esgotos. Editora UFMG, 1996. $403 \mathrm{p}$.

VON SPERLING, M.; SEZERINO, P.H. Dimensionamento de wetlands construídos no Brasil. Boletim Wetlands Brasil, Edição Especial, dezembro/2018. 65 p. ISSN 2359- 0548. Disponível em: http://gesad.ufsc.br/files/2018/12/Boletim-Wetlands-BrasilEdi\%C3\%A7\%C3\%A3o-Especial-Dimensionamento-de-Wetlands-Constru\%C3\%ADdos-noBrasil-von-Sperling-Sezerino-2018-2.pdf. Acesso em 28 de maio de 2019.

VYMAZAL, J. et al. Occurrence and removal of estrogens, progesterone and testosterone in three constructed wetlands treating municipal sewage in the Czech Republic. Science of the Total Environment n. 536; p. 625-631. 2015 
VYMAZAL, J. Horizontal sub-surface flow and hybrid constructed wetlands systems for wastewater treatment. Ecological Engineering n.25, p. 478-490. 2005.

VYMAZAL, J. Long-term performance of constructed wetlands with horizontal sub-surface flow: Ten case studies from the Czech Republic. Ecological Engineering n.37, p. 54-63. 2011.

VYMAZAL, J. The use of hybrid constructed wetlands for wastewater treatment with special attention to nitrogen removal: A review of a recent development. Water Research, v. 47, p.4795-4811, 2013.

VYMAZAL, J.; KRÖPFELOVÁ, L. Multistage hybrid constructed wetland for enhanced removal of nitrogen. Ecological Engineering n.84, p. 202-208. 2015.

VYMAZAL, Jan. The use constructed wetlands with horizontal sub-surface flow for various types of wastewater. Ecological engineering, v. 35, n. 1, p. 1-17, 2009.

WU, S. et al. Treatment of industrial effluents in constructed wetlands: challenges, operational strategies and overall performance. Environmental Pollution, v. 201, p. 107-120, 2015.

YAN, Y.; XU, J. Improving Winter Performance of Constructed Wetlands for Wastewater Treatment in Northern China: A Review. Wetlands, v. 34, p. 243-253, 2014

YANG, W. et al., Ecosystem service value assessment for constructed wetlands: A case study in Hangzhou, China. Ecological Economics, n. 68, p.116 - 125. 2008.

YANG, Z.F. et al. Purification of nitrate-rich agricultural runoff by a hydroponic system. Bioresour. Technol. 99 (17), 8049-8053. 2008.

YIDONG, G.. et al. Occurrence and Fate of Antibiotics in the Aqueous Environment and Their Removal by Constructed Wetlands in China: A review. Pedosphere n.27, p. 42-51. 2017.

ZANELLA, L. Plantas ornamentais no pós-tratamento de efluentes sanitários: wetlands construídos utilizando brita e bambu como suporte. 2008. 219p. Tese (Doutorado). Universidade Estadual de Campinas, Campinas, 2008.

ZHANG, D.Q. et al. Application of constructed wetlands for wastewater treatment in developing countries - A review of recent developments (2000-2013). Journal of Environmental Management, v. 141, p. 116-131, 2014. 
ZHANG, D.Q. et al. Application of constructed wetlands for wastewater treatment in tropical and subtropical regions (2000-2013). Journal of Environmental Sciences, V30, p. 30-46, 2015.

ZHANG, X. et al. Effects of varying particle sizes and different types of LDH-modified anthracite in simulated test columns for phosphorous removal. International Journal of Environmental Research and Public Health, v. 12, p. 6788-6800, 2015. 


\section{APÊNDICE I: LEVANTAMENTO QUANTITATIVO (BIBLIOMETRIA)}

\section{LEVANTAMENTO}

Wetlands construídos (WC) são sistemas naturais de tratamento e melhoria de qualidade da água, caracterizados basicamente pela presença de um substrato e plantas. Esses sistemas têm se tornado uma opção cada vez mais comum para tratamento de águas residuárias (LAZAREVA; PICHLER, 2010).

As pesquisas científicas desta tecnologia iniciaram-se no início dos anos 50, com Dr. Käthe Seidel $^{3}$ na Alemanha e de lá para cá muitos estudos foram feitos, e muitas aplicações da tecnologia foram validadas com sistemas em escala real (VYMAZAL, 2011)

$\mathrm{O}$ aumento do interesse em pesquisa desta tecnologia tem crescido de modo a otimizar os sistemas de tratamento. A exemplo a base de dados Scopus apresenta nos anos de 1980 a média aproximada de 10 publicações por ano sobre o tema, desde 2013 esta média ultrapassa os 600 trabalhos por ano.

Os sistemas de WC já foram pesquisados para tratamento de efluentes em muitas aplicações diferentes, tratando esgoto sanitário, efluentes industriais, lixiviado de aterros sanitários, águas pluviais e até lodo de estações convencionais (VYMAZAL, 2011; BRIX, 2017; VYMAZAL, 2009)

Muitas publicações de revisões já foram feitas com intuito de relatar os desenvolvimentos alcançados (VYMAZAL, 2011; BRIX, 1994; VERHOEVEN, \& MEULEMAN, 1999; CARVALHO et al., 2017; TSIHRINTZIS, 2017; VYMAZAL, 2009), no entanto ainda carecem de revisões com abordagens quantitativas.

A base de dados escolhida para fazer a identificação dos principais estudos dessa área do conhecimento foi a Scopus, e termo de pesquisa utilizado foi "Constructed Wetlands" na categoria "Article title, Abstract, Keywords". A pesquisa retornou 8.568 documentos, publicados entre 1978 e 2017.

A partir dos resultados da pesquisa foram extraídos inicialmente os números de documentos publicados por ano, por região nas 15 regiões com mais publicações, os 10 autores com maior número de publicações e os 10 periódicos com maior número de publicações.

Em seguida os resultados da pesquisa foram ordenados por de citação, para identificar os 50 artigos mais citados no período. Na análise do levantamento ficou evidenciado que alguns artigos não eram específicos sobre o tema e apenas utilizavam o termo pesquisado em algum trecho do documento, sendo estes documentos eliminados. Ainda ordenados por citações os resultados foram filtrados por ano para os últimos 5 anos (2012 a julho de 2017). Esses filtros identificaram, portanto, os 50 artigos mais citados por ano em 2012, 2013, 2014, 2015, 2016 e 2017 até a data da pesquisa, gerando 6 listas de artigos.

${ }^{3}$ Seidel, K. Phenol-Abbau in Wasser durch Scirpus lacustris L. wehrend einer versuchsdauer von 31 Monaten. Naturwissenschaften 1965, 52 (13), 398-406. 
Foram identificados os autores com mais documentos em cada uma das 6 listas de 50 documentos mais citados e a respectiva quantidade de documentos de cada um na mesma lista, o mesmo foi feito cada periódico constante destas listas.

Foi criada uma classificação com 19 categorias, suficientemente genéricas, de temas para que todos os 350 artigos contidos nas 6 listas fossem alocados, de forma a se identificar as classes genéricas de tema mais publicadas e as tendências de temas ao longo dos períodos analisados.

As classes criadas, bem como o conteúdo considerado em cada uma estão apresentados no quadro 1:

Quadro 1 - Classes para os temas dos trabalhos analisados

\begin{tabular}{|c|c|}
\hline Poluentes específicos & $\begin{array}{l}\text { Trabalhos desenvolvidos com intuito de investigar o comportamento dos WC em } \\
\text { relação à poluentes específicos como nutrientes, metais, pesticidas, sulfatos, VOC's } \\
\text { etc. Esta classe não engloba os poluentes chamados de emergentes (medicamentos } \\
\text { humanos e veterinários, produtos de higiene, hormônios, esteroides etc.) }\end{array}$ \\
\hline Poluentes emergentes & $\begin{array}{l}\text { Trabalhos desenvolvidos com intuito de investigar o comportamento dos WC em } \\
\text { relação à poluentes chamados de emergentes (medicamentos humanos e } \\
\text { veterinários, produtos de higiene, hormônios, esteroides etc.) }\end{array}$ \\
\hline Microrganismos & $\begin{array}{l}\text { Trabalhos focados na investigação dos processos microbiológicos e das } \\
\text { comunidades microbianas dentro dos sistemas de WC }\end{array}$ \\
\hline Wetlands - Geral & $\begin{array}{l}\text { Trabalhos com temas mais gerais sobre os WC como revisões bibliográficas } \\
\text { amplas, trabalhos que foquem em diversos aspectos dos sistemas, estudos } \\
\text { geográficos e socioeconômicos etc. }\end{array}$ \\
\hline Plantas & $\begin{array}{l}\text { Trabalhos focados na investigação dos processos exercidos pelas plantas e pela } \\
\text { importância das mesmas dentro dos sistemas de WC, bem como trabalhos } \\
\text { comparando eficiência de diferentes plantas nos sistemas }\end{array}$ \\
\hline $\begin{array}{l}\text { Tratamento de efluentes } \\
\text { industriais }\end{array}$ & $\begin{array}{l}\text { Trabalhos focados em tratamentos de efluentes industriais de diversas fontes, } \\
\text { avaliando eficiências e aplicabilidade dos WC para este tipo de efluentes }\end{array}$ \\
\hline $\begin{array}{l}\text { Tratamento de esgoto } \\
\text { sanitário }\end{array}$ & $\begin{array}{l}\text { Trabalhos focados em tratamentos de esgoto sanitário, avaliando eficiências e } \\
\text { aplicabilidade dos WC para este tipo de efluentes }\end{array}$ \\
\hline Substratos & $\begin{array}{l}\text { Trabalhos focados na investigação dos processos exercidos pelo substrato e pela } \\
\text { importância deles dentro dos sistemas de WC, bem como trabalhos comparando } \\
\text { eficiência de diferentes substratos nos sistemas para remoção e adsorção de diversos } \\
\text { contaminantes }\end{array}$ \\
\hline Aeração & $\begin{array}{l}\text { Trabalhos de investigação sobre a aeração e a presença de oxigênio no sistema, } \\
\text { englobando estudos com aeração natural (troca com atmosfera, introdução pelas } \\
\text { plantas, aeração passiva etc.) e estudos com aeração forçada através de } \\
\text { equipamentos mecânicos }\end{array}$ \\
\hline $\begin{array}{l}\text { Mecanismos de remoção } \\
\text { associados }\end{array}$ & $\begin{array}{l}\text { Trabalhos que analisam simultaneamente diversos mecanismos de remoção, não } \\
\text { focando apenas em um deles, bem como trabalhos focados em investigar influências } \\
\text { externas (temperatura, pluviometria, insolação etc.) no funcionamento e eficiência } \\
\text { do sistema. }\end{array}$ \\
\hline Geração de energia & $\begin{array}{l}\text { Trabalhos que investigam a possibilidade da associação de sistemas de geração de } \\
\text { energia ao tratamento de efluentes em WC. }\end{array}$ \\
\hline $\begin{array}{l}\text { Comparação de } \\
\text { configurações }\end{array}$ & $\begin{array}{l}\text { Trabalhos que comparam configurações diferentes de WC, em relação à fluxo, } \\
\text { saturação, associações etc. }\end{array}$ \\
\hline Modelagem & $\begin{array}{l}\text { Trabalhos que tratam de modelagem matemática e/ou computacional dos sistemas } \\
\text { de WC. }\end{array}$ \\
\hline $\begin{array}{l}\text { Tratamento de águas } \\
\text { pluviais }\end{array}$ & $\begin{array}{l}\text { Trabalhos focados em tratamentos de águas pluviais, avaliando eficiências e } \\
\text { aplicabilidade dos WC para este fim }\end{array}$ \\
\hline Efeito estufa e wetlands & Trabalhos que analisam emissões gasosas e impactos dos WC no efeito estufa \\
\hline Hidráulica & Trabalhos focados nos aspectos hidráulicos e de fluxo de líquido dentro dos WC \\
\hline Procedimentos operacionais & $\begin{array}{l}\text { Trabalhos que investigam os procedimentos operacionais nos wetlands e seus } \\
\text { respectivos impactos no tratamento de diversos efluentes }\end{array}$ \\
\hline Colmatação & $\begin{array}{l}\text { Trabalhos focados em analisar os processos de colmatação do meio filtrante nos } \\
\text { WC }\end{array}$ \\
\hline
\end{tabular}


Os autores com maior quantidade de documentos entre os 50 mais citados desde 1978 e os autores com maior soma de documentos entre os mais citados de 2012 a julho de 2017 foram listados em um rol de 21 autores, para os quais foram levantados os números de documentos na base de dados, o número total de citações e de documentos os citando e o seu h-index.

Para estes mesmos 21 autores foram ainda levantadas todas as publicações de 2017, até início de julho, que se relacionam com o tema Wetlands Construídos e estes documentos foram analisados individualmente para verificar quais os temas de pesquisa estão sendo buscados por estes pesquisadores.

Todo o conjunto de dados obtidos foi organizado e classificado para obtenção e apresentação de resultados quantitativos.

Os nomes dos autores aparece nos quadros e figuras sem espaçamento e sem vírgulas, pois foram trabalhados estatisticamente como dados em planilhas eletrônicas, portanto para um autor com referência na forma Zzzz, X. Y., os quadros e figuras mostrarão na forma ZzzzX.Y.

\section{DOCUMENTOS ENCONTRADOS}

A figura 1 apresenta a distribuição temporal das 8.568 publicações encontradas na base de dados, sem restrições de datas:

Figura 1 - Distribuição temporal dos documentos

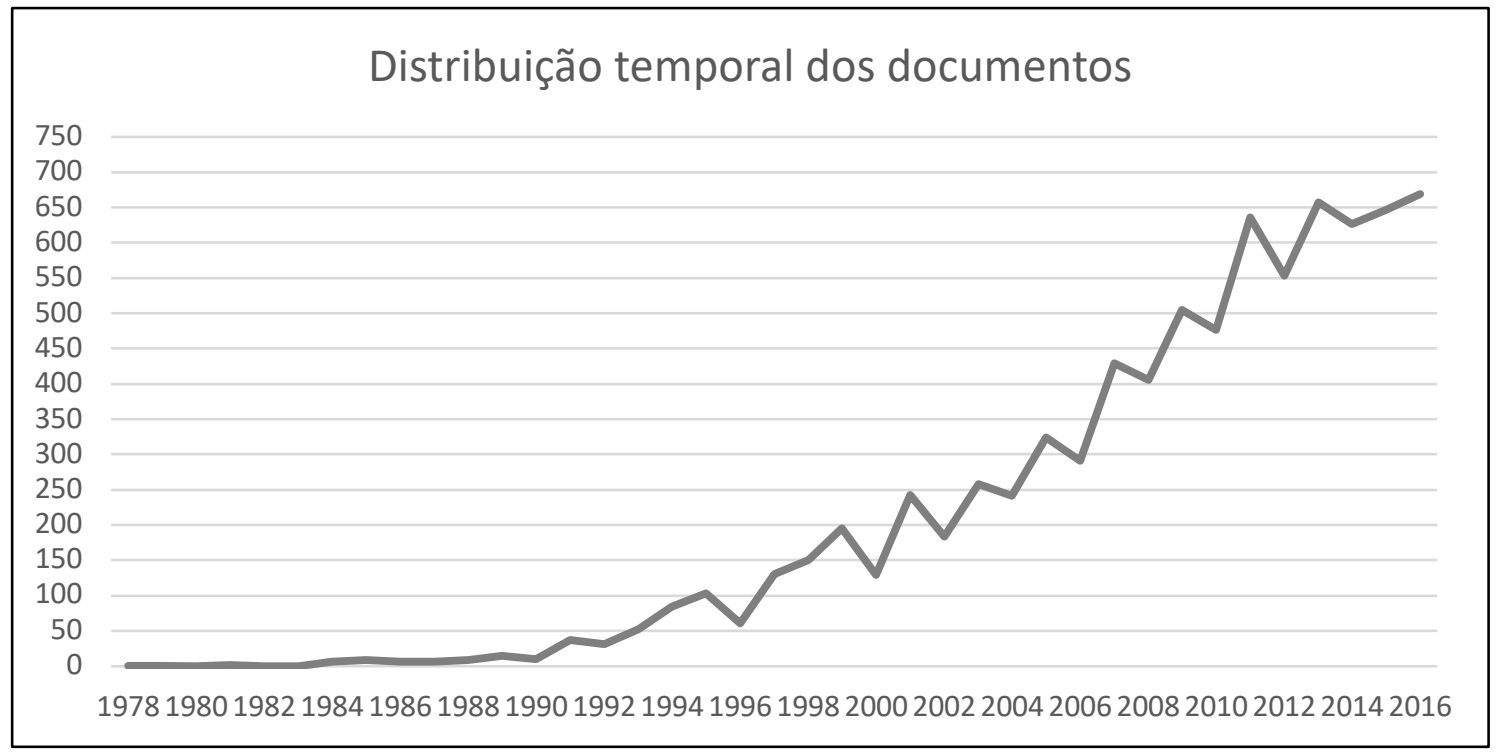

Fonte: Cauê Girão de Abreu, 2019.

Como pode ser observado na figura 1, o tema wetlands construídos já produziam publicações no final dos anos 70, mas essa produção se intensifica no início da década de 90 e continua a aumentar desde então, publicando mais de 650 documentos em 2016.

A distribuição geográfica das publicações, dos 15 países com maior número de documentos, sem restrição de data, pode ser vista na figura 2: 
Figura 2 - Distribuição geográfica dos documentos dos 15 países com maior produção, sem restrição de data

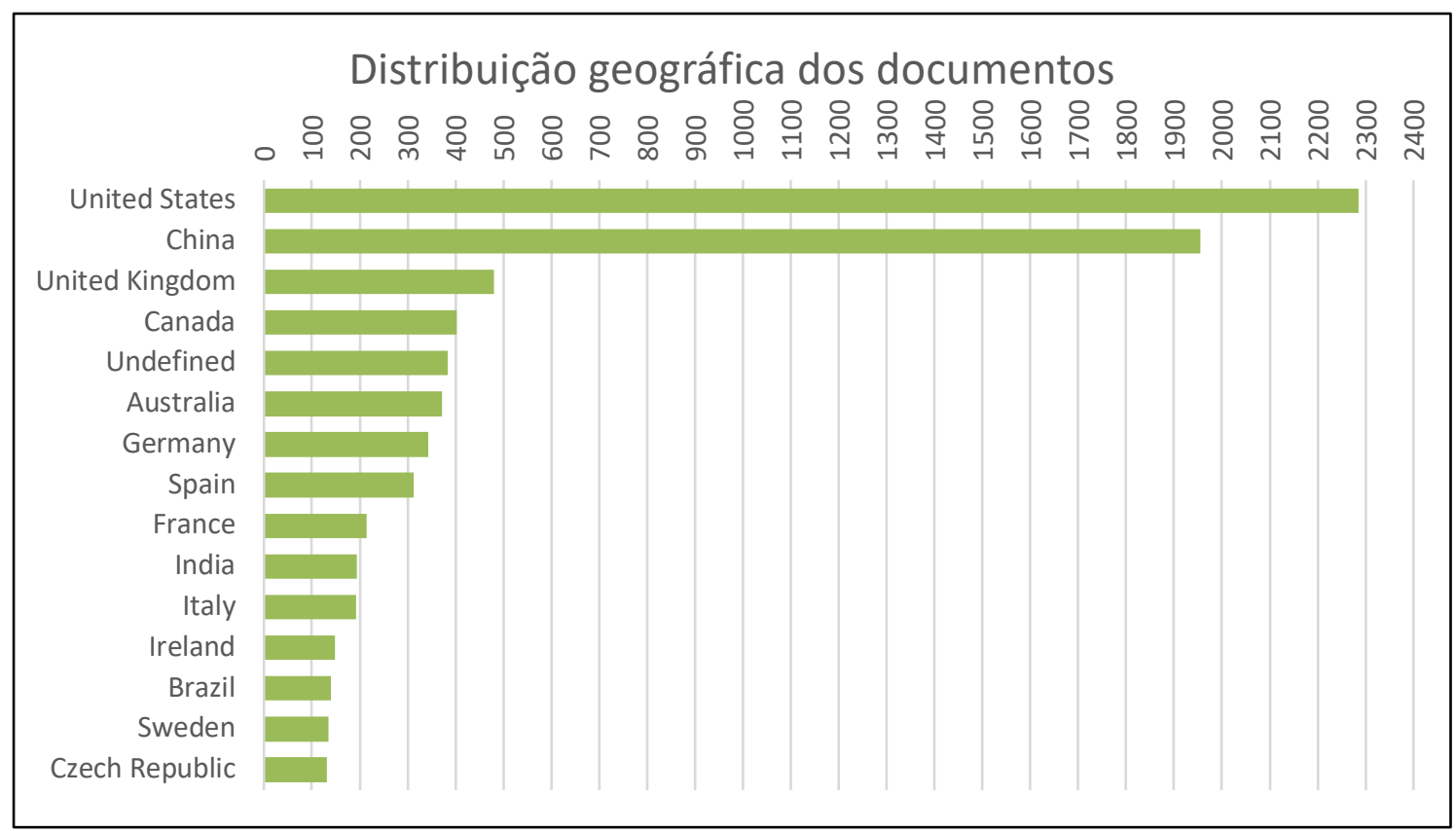

Fonte: Cauê Girão de Abreu, 2019.

A figura 2 mostra que os Estados Unidos e a China lideram o ranking com aproximadamente quatro vezes mais publicações que o terceiro colocado, que é o Reino Unido.

A figura 3 apresenta a mesma distribuição geográfica, porém limitando-se apenas as publicações dos anos de 2012 a jul/2017.

Figura 3 - Distribuição geográfica dos documentos dos 15 países com maior produção, entre 2012 e jul/2017

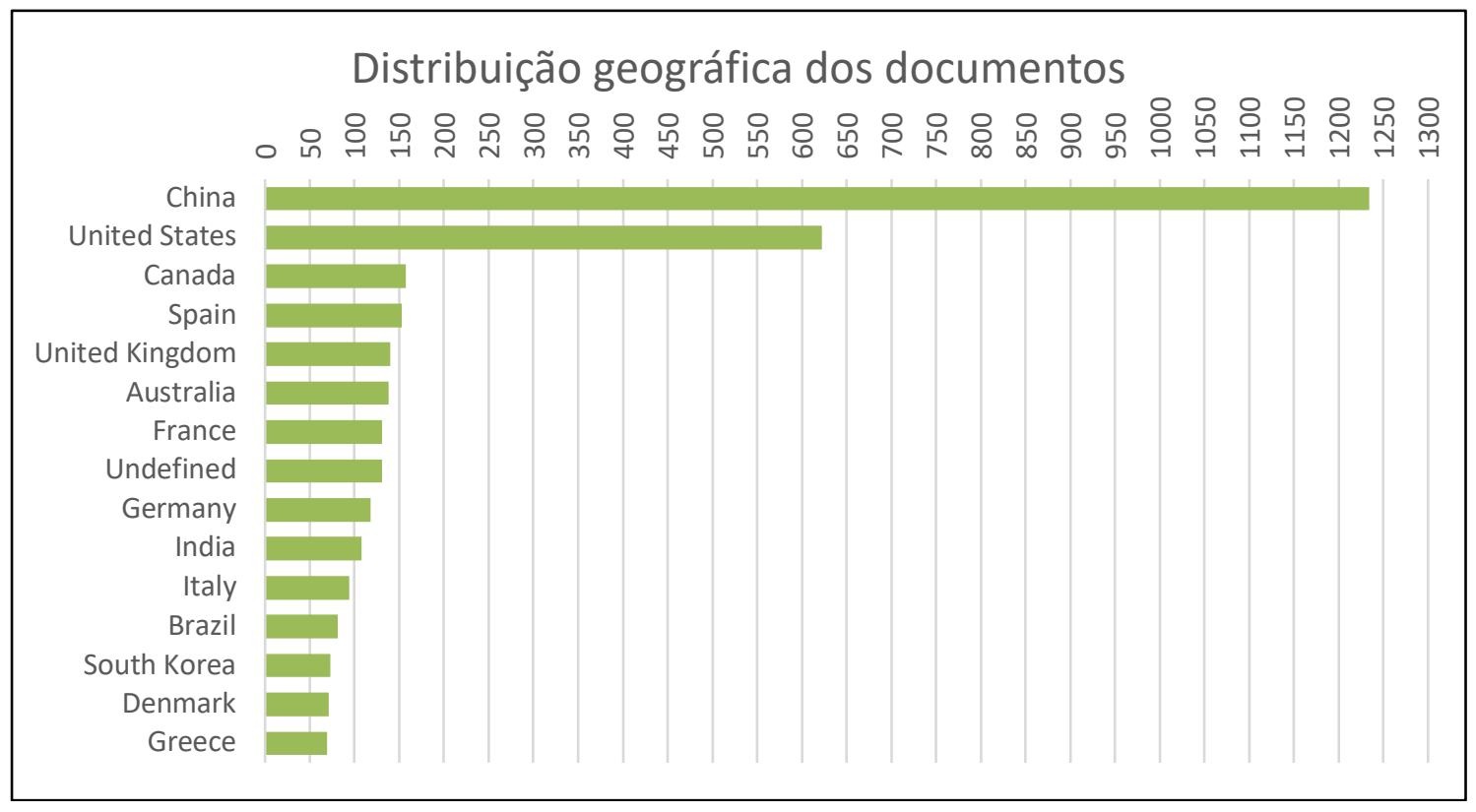

Fonte: Cauê Girão de Abreu, 2019.

Esta distribuição, da figura 3, mostra um aumento significativo na produção chinesa, ultrapassando os Estados Unidos no período analisado, com o dobro de publicações deste país. 


\section{PUBLICAÇÕES E FONTES}

A figura 4 mostra os 10 periódicos que mais publicaram sobre o tema e a quantidade de suas respectivas publicações no período de 1978 a jul/2017:

Figura 4 - Periódicos com maior número de documentos sobre o tema, sem restrição de data

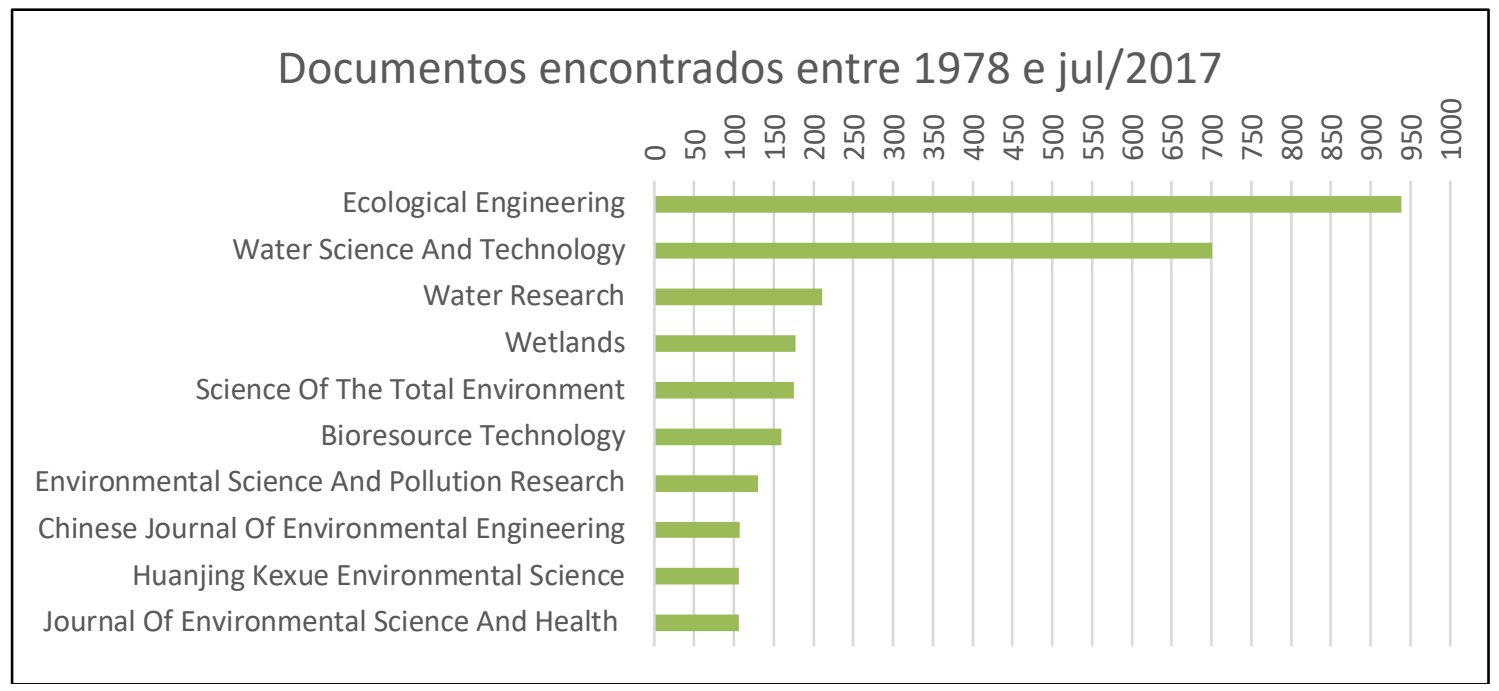

Fonte: Cauê Girão de Abreu, 2019.

A figura 4 mostra que a maioria dos periódicos com grande número de publicações é da área de ciências ambientais e que o Ecological Enginnering e o Water Science and Technology são os periódicos que mais abordaram o tema no período total analisado.

\section{AUTORES}

Dentre os milhares de documentos identificados, os 10 autores com maior número de publicações e suas respectivas quantidade de documentos estão mostrados na figura 5:

Figura 22 - Publicações por autor, entre os 10 mais publicados 


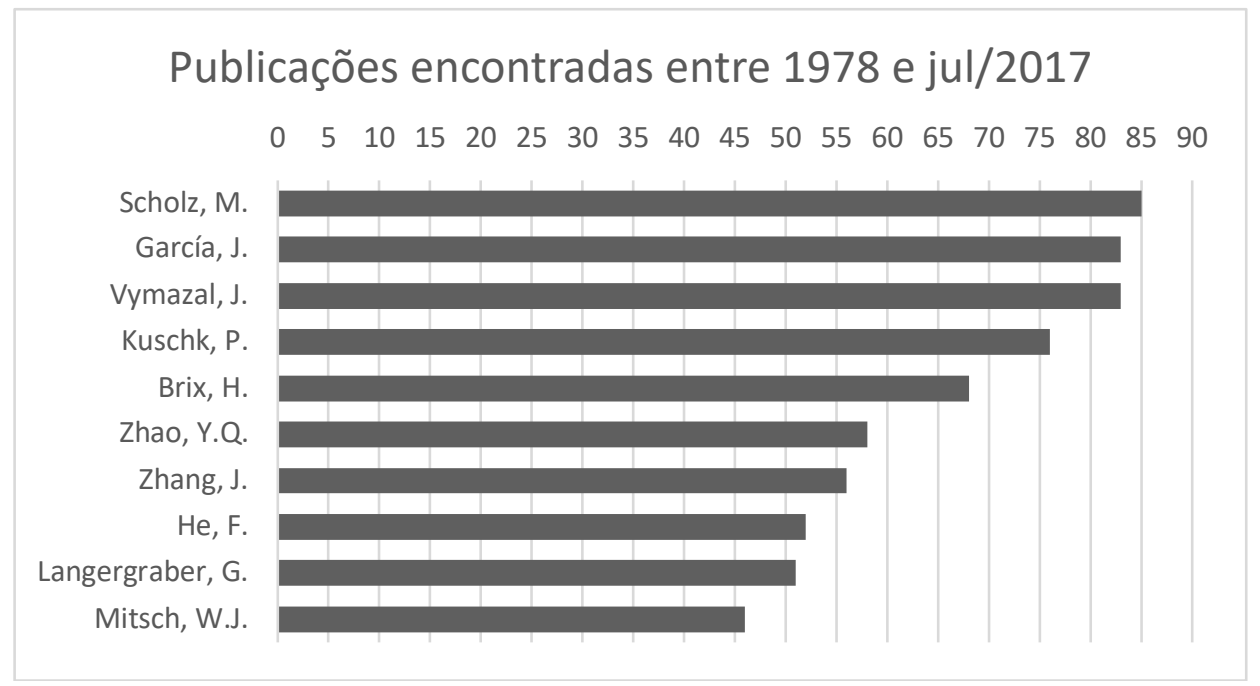

Fonte: Cauê Girão de Abreu, 2019.

Esta figura mostra uma lista de 10 autores importantes para o tema, todos com mais de 45 publicações sobre o tema.

\section{DOCUMENTOS}

A figura 6 mostra o número de documentos encontrados em cada um dos anos entre 2012 e 2016:

Figura 23 - Quantidade de documentos publicados por ano

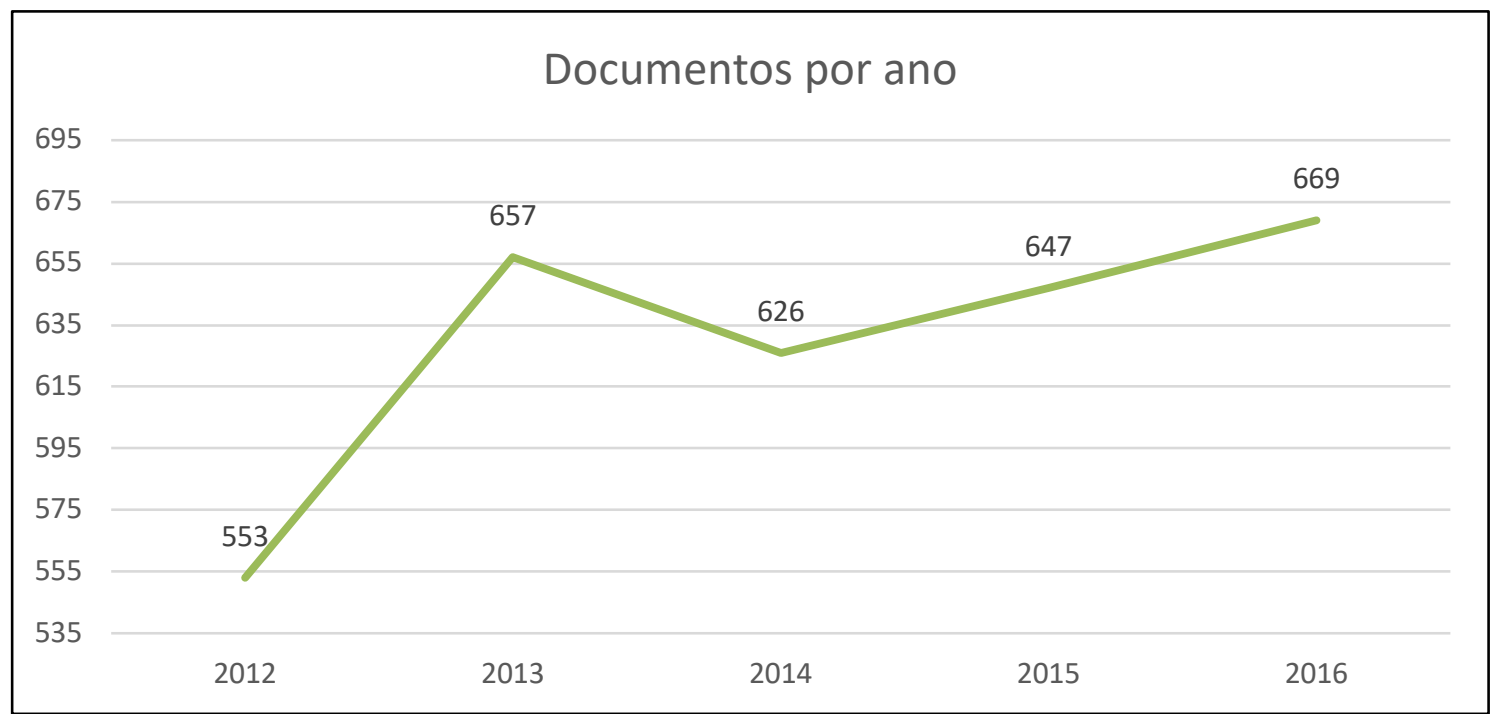

Fonte: Cauê Girão de Abreu, 2019.

Podemos inferir da figura que o número de publicações mostra uma tendência de crescimento, evidenciando um crescimento do interesse pelo tema no meio científico. 


\section{PUBLICAÇÕES E FONTES}

A figura 7 mostra os 10 periódicos encontrados na lista dos 50 artigos mais citados sem restrição de datas e a respectiva quantidade de publicações de cada uma: 
Figura 7 - Distribuição dos 50 artigos mais citados, sem restrição de data, em periódicos

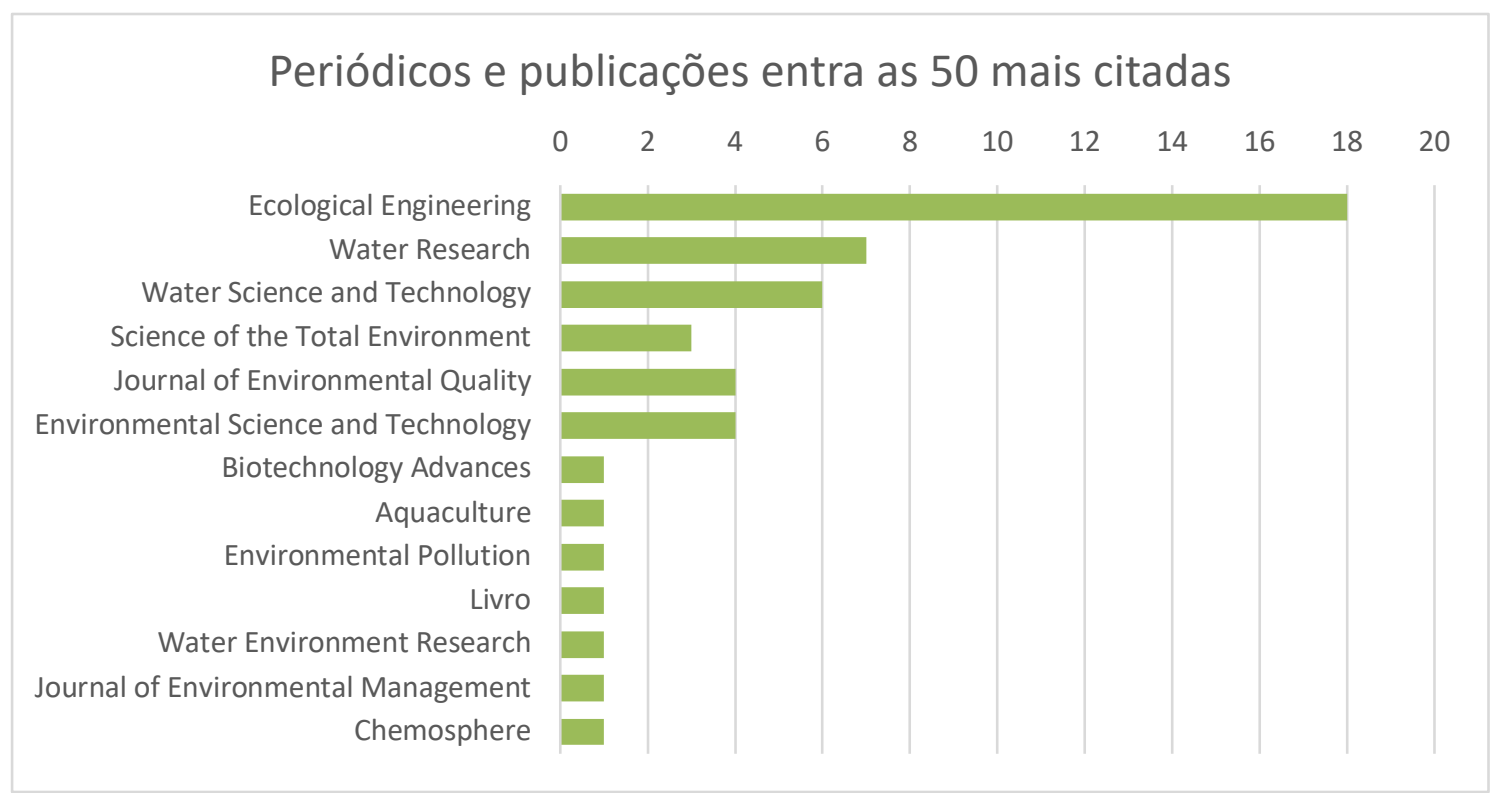

Fonte: Cauê Girão de Abreu, 2019.

Como mostra a figura 7, os periódicos são em sua maioria da área das ciências ambientais e o Ecological Engineering foi o periódico com maior número de publicações, com mais que o dobro de publicações do segundo colocado.

A figura 8 mostra esta mesma distribuição, porém com dados restritos aos anos de 2012 a jul/2017 e com dados agrupados por ano:

Figura 8 - publicações por periódico entre as 50 mais citadas de cada ano 


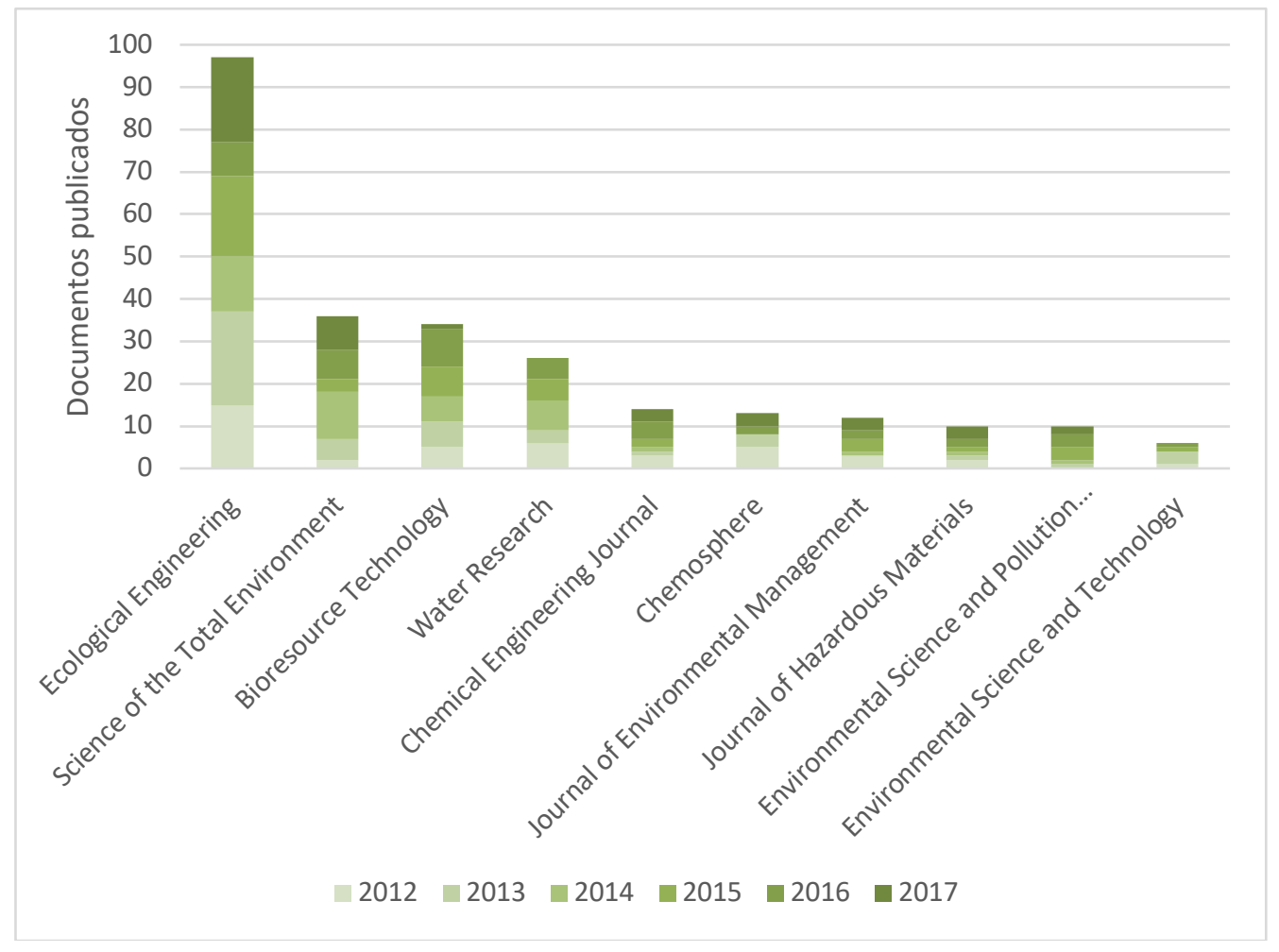

Fonte: Cauê Girão de Abreu, 2019.

A figura 8 mostra o mesmo resultado da figura 6, com o Ecological Engineering publicando mais que o dobro da segunda colocada, porém com alternâncias de periódicos a partir da segunda posição.

O Quadro 2 mostra as métricas e classificações destes periódicos, de acordo com a Coordenação de Aperfeiçoamento de Pessoal de Nível Superior (CAPES - Brasil) e com a base Scopus:

Quadro 2 - Métricas dos periódicos com mias publicações sobre WC

\begin{tabular}{|l|c|c|c|}
\hline Publicação & $\begin{array}{c}\text { Classificação } \\
\text { CAPES }\end{array}$ & $\begin{array}{c}\text { CiteScore } \\
\text { Scopus }\end{array}$ & $\begin{array}{c}\text { Impact } \\
\text { Factor } \\
\text { Scopus }\end{array}$ \\
\hline Water Research & A1 & 7,49 & 6.942 \\
\hline Chemical Engineering Journal & A1 & 6,34 & 6.216 \\
\hline Environmental Science and Technology & A1 & 6,26 & 6.198 \\
\hline Journal of Hazardous Materials & A1 & 6,31 & 6.065 \\
\hline Bioresource Technology & A1 & 5,94 & 5.651 \\
\hline Science of the Total Environment & A1 & 5,09 & 4.900 \\
\hline Chemosphere & A1 & 4,39 & 4.208 \\
\hline Ecological Engineering & A1 & 3,45 & 2.914 \\
\hline
\end{tabular}




\section{AUTORES MAIS CITADOS}

Os autores com mais trabalhos publicados entre os 50 trabalhos mais citados, sem restrição de data, e o número de respectivos trabalhos estão apresentados na figura 9:

Figura 24 - Autores com maior número de artigos entre os 50 mais citados desde 1978

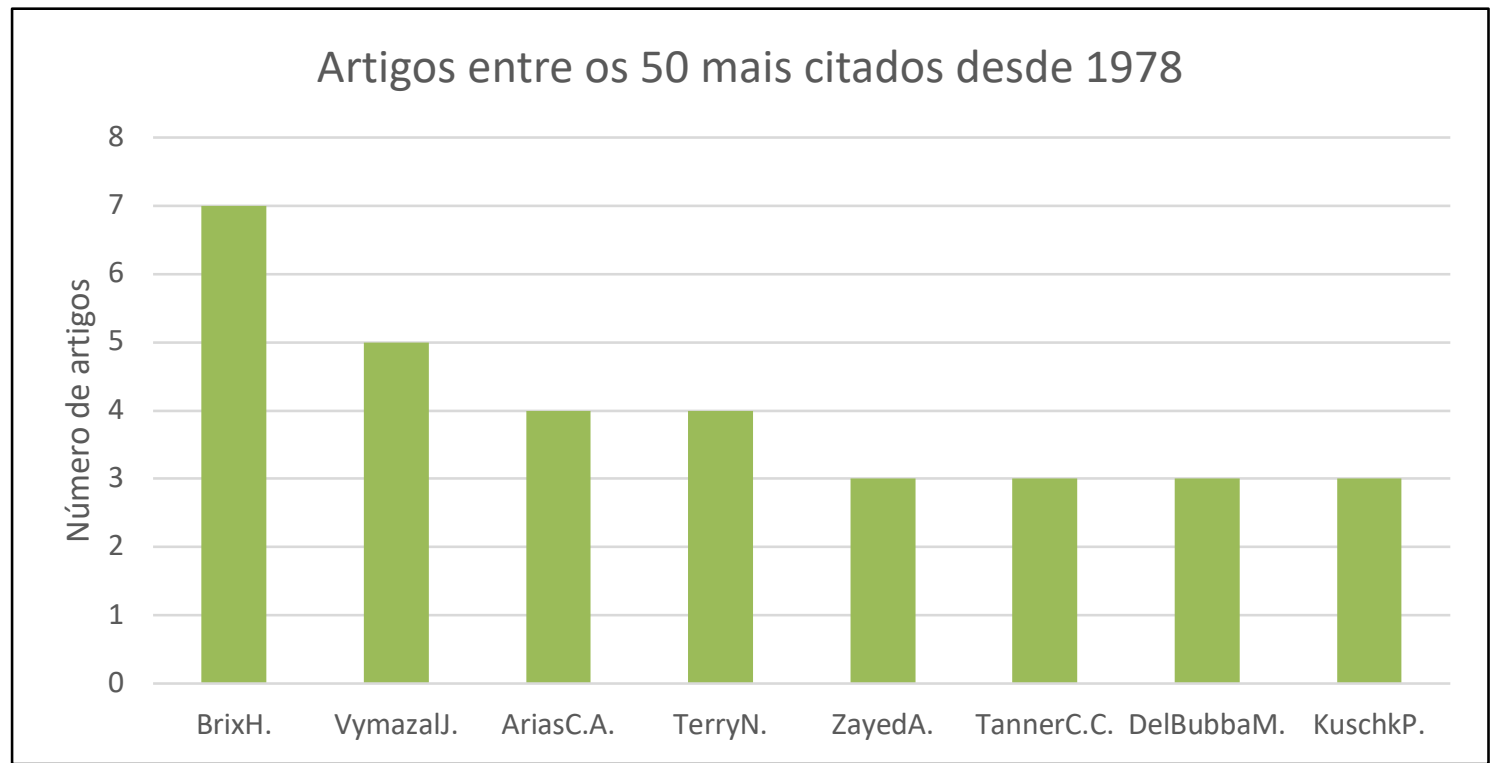

Fonte: Cauê Girão de Abreu, 2019.

A figura 10 mostra os autores com mais artigos entre os 50 mais citados entre 2012 e jul/2017, com dados agrupados por ano:

Figura 10 - Autores com maior número de artigos entre os 50 mais citados entre 2012 e jul/2017 


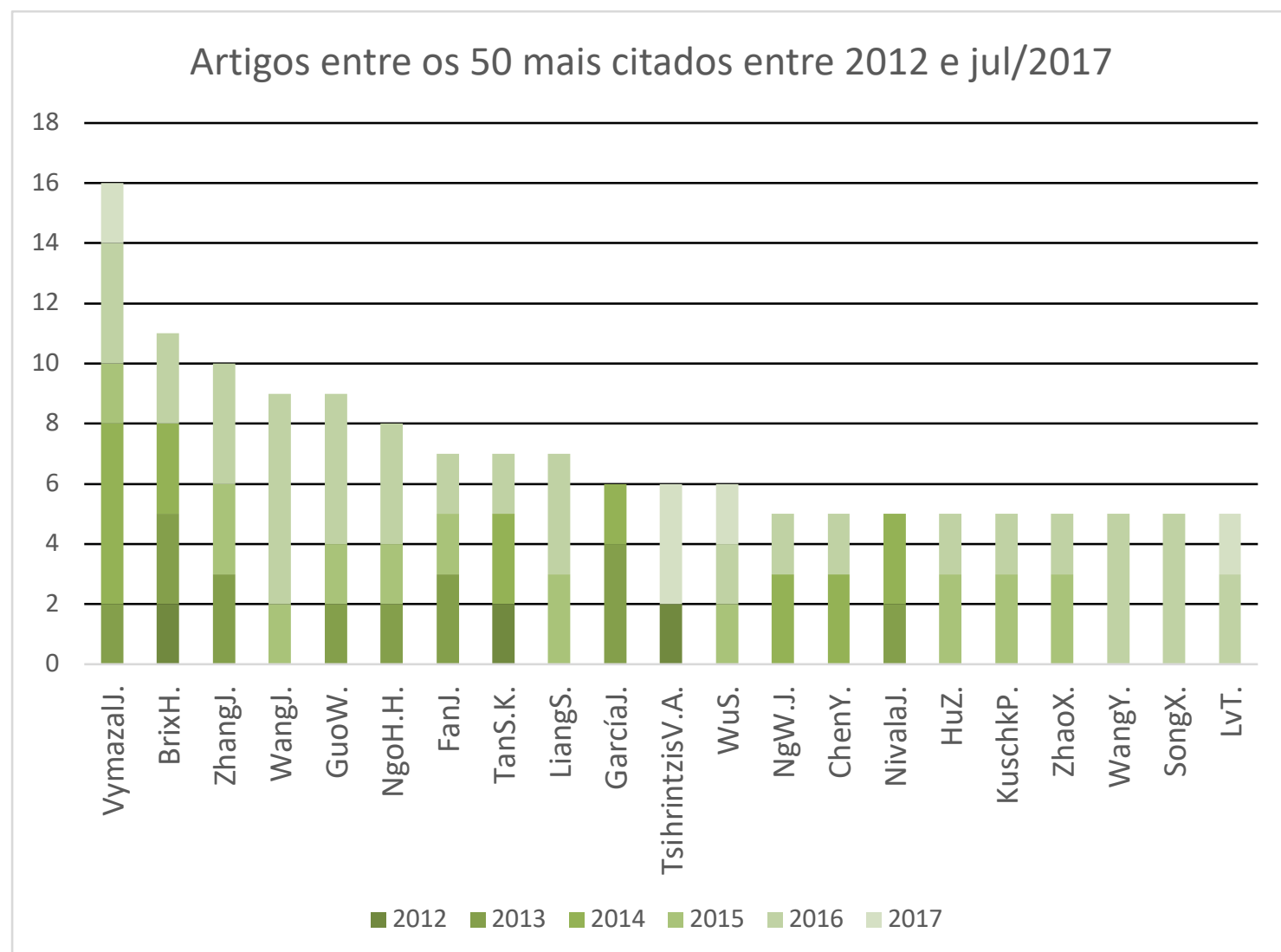

Fonte: Cauê Girão de Abreu, 2019.

O quadro 3 mostra as métricas de produção destes autores encontrados nas figuras 9 e 10:

Quadro 3 - Métricas de produção dos autores mais citados

\begin{tabular}{|c|c|c|c|c|}
\hline Autor & Artigos no Scopus & Citações no Scopus & Documentos citando & h-index \\
\hline BrixH. & 196 & 7825 & 5191 & 48 \\
\hline TerryN. & 123 & 8457 & 5267 & 48 \\
\hline NgoH.H. & 352 & 4973 & 3886 & 35 \\
\hline GarcíaJ. & 123 & 3483 & 1972 & 34 \\
\hline ZhangJ. & 179 & 3928 & 3064 & 32 \\
\hline GuoW. & 231 & 3420 & 2670 & 30 \\
\hline VymazalJ. & 107 & 4407 & 2953 & 29 \\
\hline TsihrintzisV.A. & 157 & 2587 & 1748 & 28 \\
\hline TannerC.C. & 63 & 2806 & 2116 & 28 \\
\hline KuschkP. & 126 & 3313 & 2335 & 28 \\
\hline DelBubbaM. & 78 & 1789 & 1475 & 23 \\
\hline LiangS. & 70 & 1705 & 1498 & 21 \\
\hline LiuL. & 109 & 1535 & 1402 & 21 \\
\hline
\end{tabular}




\begin{tabular}{|c|c|c|c|c|}
\hline ZayedA. & 21 & 4027 & 3185 & 20 \\
\hline AriasC.A. & 40 & 1578 & 1217 & 18 \\
\hline HeadleyT. & 27 & 656 & 521 & 16 \\
\hline CarvalhoP.N. & 31 & 363 & 303 & 12 \\
\hline WangY. & 30 & 173 & 144 & 8 \\
\hline WangJ. & 9 & 27 & 27 & 4 \\
\hline LvT. & 20 & 62 & 48 & 4 \\
\hline ZhangY. & 13 & 60 & 50 & 4 \\
\hline SongX. & 3 & 22 & 22 & 2 \\
\hline
\end{tabular}

\section{TEMAS}

Todos os trabalhos classificados entre os 50 mais citados, sem restrição de data e em cada ano desde 2012, foram alocados dentro das categorias definidas de temas genéricos.

A figura 11 mostra os temas dos 50 documentos mais citados, sem restrição de tempo:

Figura 11 - Temas dos 50 artigos mais citados desde 1978

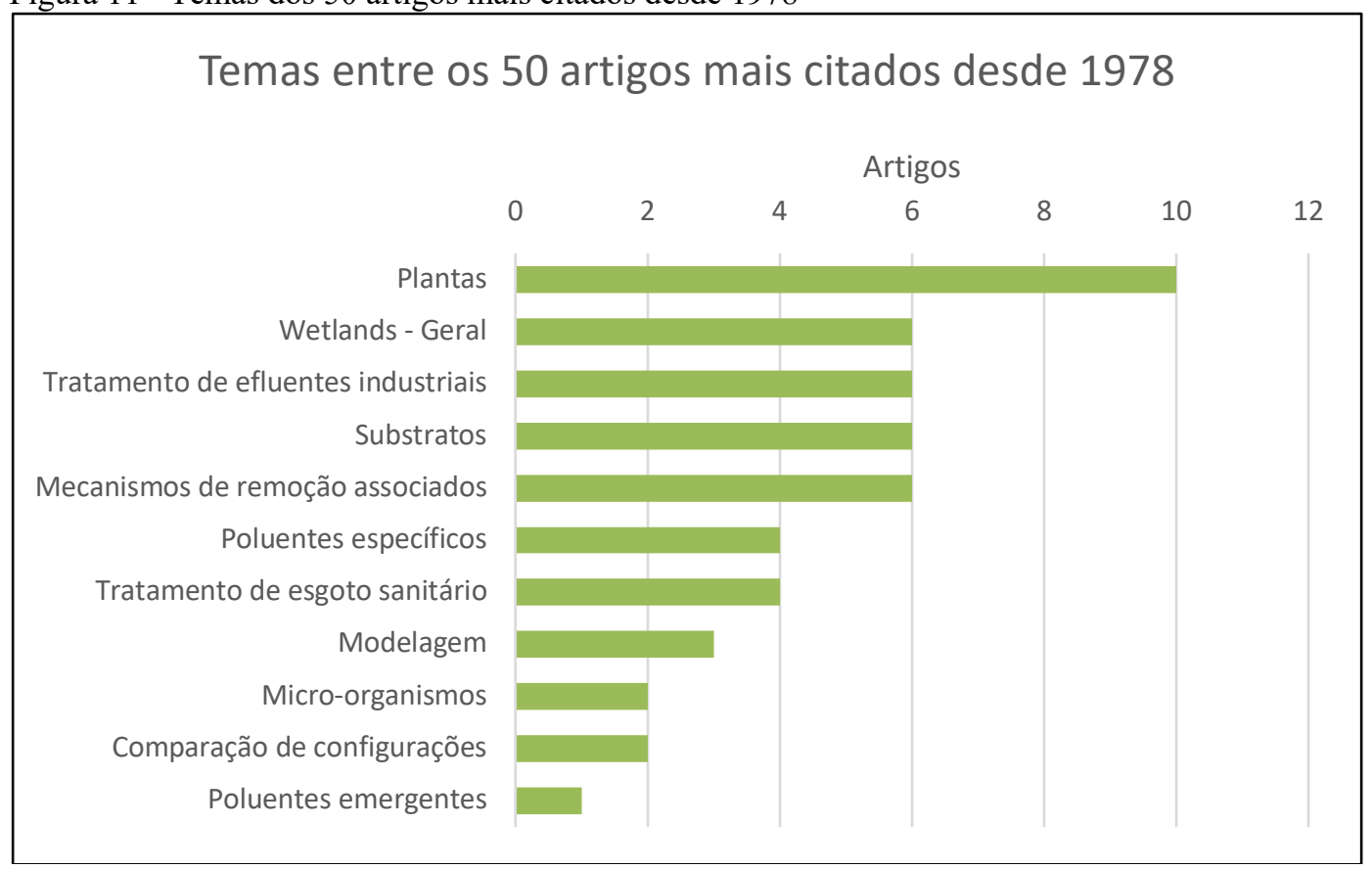

Fonte: Cauê Girão de Abreu, 2019.

De acordo com a figura 11 os trabalhos mais citados desde 1978 tratam principalmente de estudos envolvendo o papel e as funções das plantas nos sistemas de wetlands construídos, seguidos por estudos dos mecanismos de remoção, substratos, tratamento de efluentes industriais e trabalhos de âmbito mais geral. 
A figura 12 mostra a mesma classificação, mas restrita apenas aos trabalhos publicados desde 2012, e agrupando estes dados por ano de publicação:

Figura 12 - Temas dos artigos mais citados entre 2012 e jul/2017

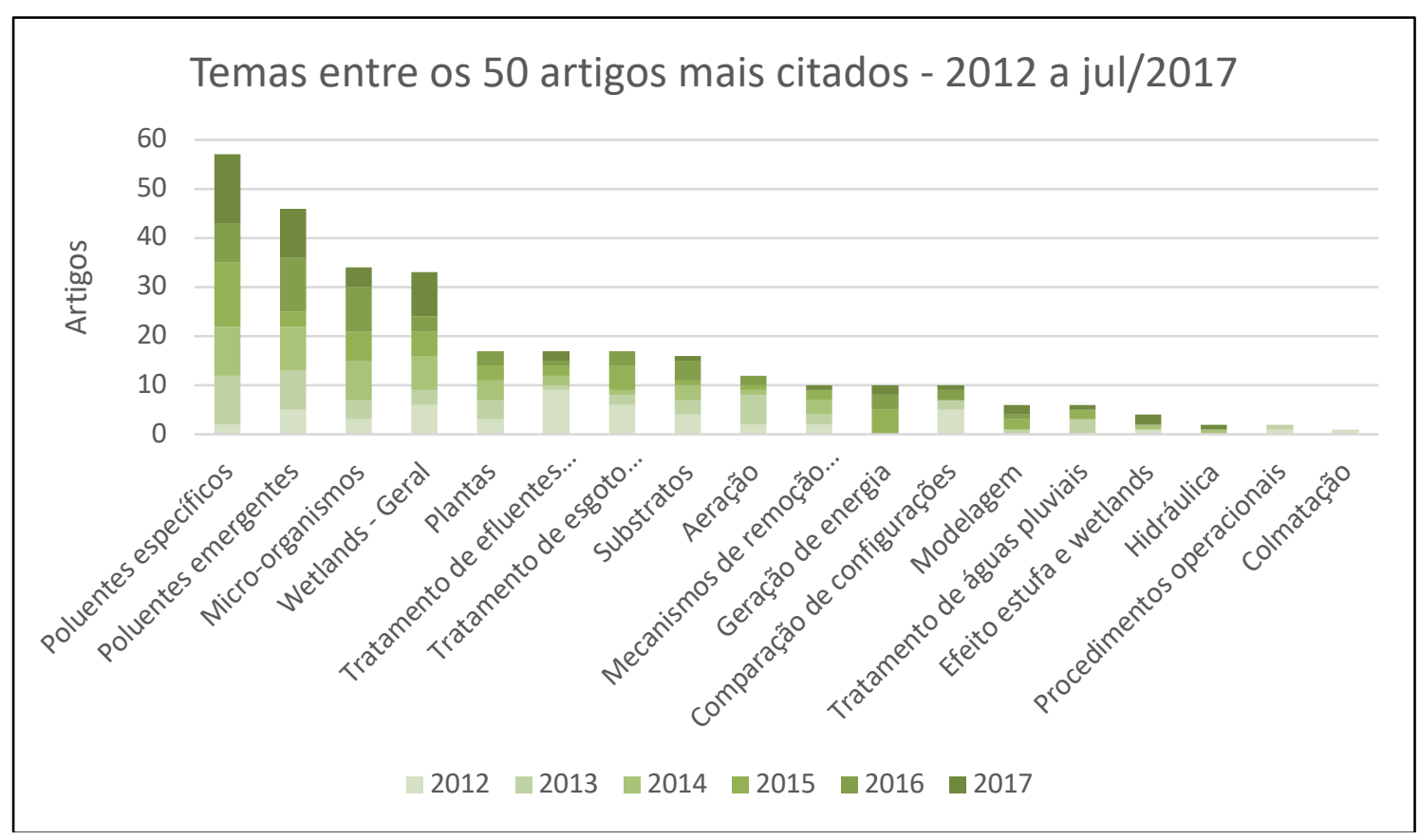

Fonte: Cauê Girão de Abreu, 2019.

A figura 12 mostra que, com exceção dos trabalhos de âmbito mais geral, o foco dos estudos se alterou bastante, colocando os estudos sobre poluentes específicos, principalmente aqueles conhecidos como poluentes emergentes, entre os assuntos mais citados.

A figura 13 mostra esta evolução para os 5 temas mais citados no período de 2012 a jul/2017: 


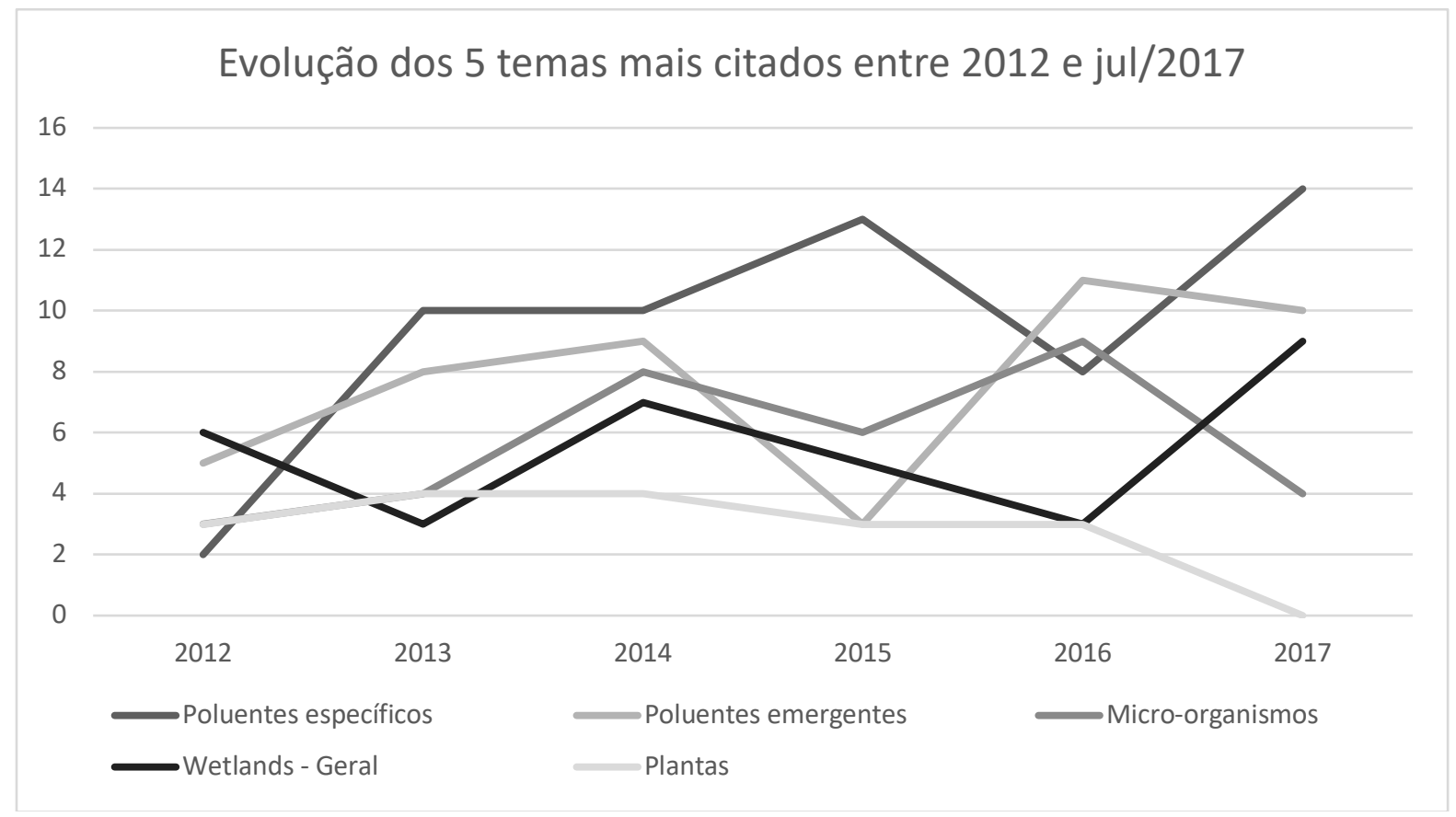

Fonte: Cauê Girão de Abreu, 2019.

A figura ilustra claramente o crescimento dos temas de poluentes específicos e emergentes e a queda dos estudos sobre plantas, antes mostrado como tema mais estudado ou citado.

Com intuito de entender a analisar mais a fundo estas tendências os estudos produzidos em 2017 pelos 22 autores apresentados no quadro 3 foram identificados e analisados em mais detalhes, identificando assim quais são os assuntos que estão sendo estudados nos últimos 6 meses por estes pesquisadores.

\section{CONCLUSÕES ACERCA DO LEVANTAMENTO QUANTITATIVO}

Diversos autores têm publicado trabalhos sobre wetlands construídos nas últimas décadas, o número de trabalhos vem crescendo a cada ano, mostrando a importância do tema e o interesse do meio científico por ele.

Dentre muitos autores identificados, alguns se destacam pela importância de sua produção cientifica e pelo reconhecimento de seu trabalho através de citações. Alguns desses autores merecem ser destacados como leitura de base bibliográfica para pesquisadores da área e são aqui indicados, alguns pela sua produção de trabalhos entre os mais citados durante todo o tempo pesquisado e outros pelo destaque de seus trabalhos mais recentes. Alguns merecem ainda reconhecimento nestas duas categorias, pois produziram trabalhos importantes durante bastante tempo e ainda continuam produzindo.

O quadro 4 mostra estes 22 autores e suas respectivas contribuições: 
Quadro 4 - Autores com mais trabalhos entre os mais citados

\begin{tabular}{|l|c|c|c|}
\hline \multirow{2}{*}{\multicolumn{1}{|c|}{ Autor }} & \multicolumn{3}{|c|}{ Artigos entre $\mathbf{5 0}$ mais citados } \\
\cline { 2 - 4 } & $\begin{array}{c}\text { Desde } \\
\mathbf{1 9 7 8}\end{array}$ & $\begin{array}{c}\mathbf{2 0 1 2} \text { a } \\
\mathbf{2 0 1 7}\end{array}$ & Soma \\
\hline Vymazal, J. & 5 & 16 & 21 \\
\hline Brix, H. & 7 & 11 & 18 \\
\hline Zhang, J. & 0 & 10 & 10 \\
\hline Wang, J. & 0 & 9 & 9 \\
\hline Guo, W. & 0 & 9 & 9 \\
\hline Ngo, H. H. & 0 & 8 & 8 \\
\hline Arias, C. A. & 4 & 3 & 7 \\
\hline Fan, J. & 0 & 7 & 7 \\
\hline Tan, S. K. & 0 & 7 & 7 \\
\hline Liang, S. & 0 & 7 & 7 \\
\hline García, J. & 0 & 6 & 6 \\
\hline Tsihrintzis, V. A. & 0 & 6 & 6 \\
\hline Wu, S. & 0 & 6 & 6 \\
\hline Kuschk, P. & 3 & 2 & 5 \\
\hline Ng, W. J. & 0 & 5 & 5 \\
\hline Chen, Y. & 0 & 5 & 5 \\
\hline Nivala, J. & 0 & 5 & 5 \\
\hline Hu, Z. & 0 & 5 & 5 \\
\hline Zhao, X. & 0 & 5 & 5 \\
\hline Wang, Y. & 0 & 5 & 5 \\
\hline Song, X. & 0 & 5 \\
\hline Lv, T. & 0 & 5 & 5 \\
\hline
\end{tabular}

O quadro destaca ainda a extrema importância de dois autores para a área, pois eles figuram entre os mais citados de todos os tempos e os mais citados desde 2012, tendo ainda a maior soma dos dois valores, são eles: Hans Brix e Jan Vymazal. A leitura dos trabalhos destes dois pesquisadores é indispensável para pesquisadores que desejam trabalhar com WC.

Muitos periódicos de alto impacto têm publicado trabalhos sobre WC no período analisado, sendo estes trabalhos oriundos de diversos países.

Analisando o total dos trabalhos publicados temos os Estados Unidos como líder de publicações, seguido pela China e ambos muito a frente, em quantidade de publicações, dos demais países. 
Analisando a produção mais recente, desde 2012, vemos que a China já supera os Estados Unidos, mas ambos continuam com um número de publicações sobre WC muito maior que os demais países.

Os periódicos que mais publicaram trabalhos sobre WC que estão entre os mais citados são todos de alto impacto e de boa classificação. Um deles se destaca pelo número de publicações da área, o Ecological Engineering, tendo retornado 939 trabalhos na busca realizada e sendo ainda responsável por 18 artigos entre os mais citados desde 1978 e 97 artigos entre os mais citados de 2012 a jul/2017. Para quem deseja publicar sua pesquisa na área de WC este seria um excelente periódico de escolha.

Os temas de maior repercussão nas pesquisas sobre WC foram inicialmente o papel das plantas no tratamento e a eficiência dos sistemas no tratamento de efluentes não domésticos, com o passar dos anos e com respostas a estas perguntas vêm ganhando importância pesquisas relativas ao tratamento e remoção de alguns poluentes específicos, principalmente os poluentes conhecidos como poluentes emergentes que englobam medicamentos, hormônios, produtos de higiene pessoal etc.

Foi feita uma análise dos trabalhos publicados em 2017 com participação destes 22 autores. 27 trabalhos foram encontrados e verificados para identificação do tema que está sendo estudado. A figura 14 mostra o resultado deste levantamento:

Figura 14 - Temas estudados pelos 22 principais autores em 2017

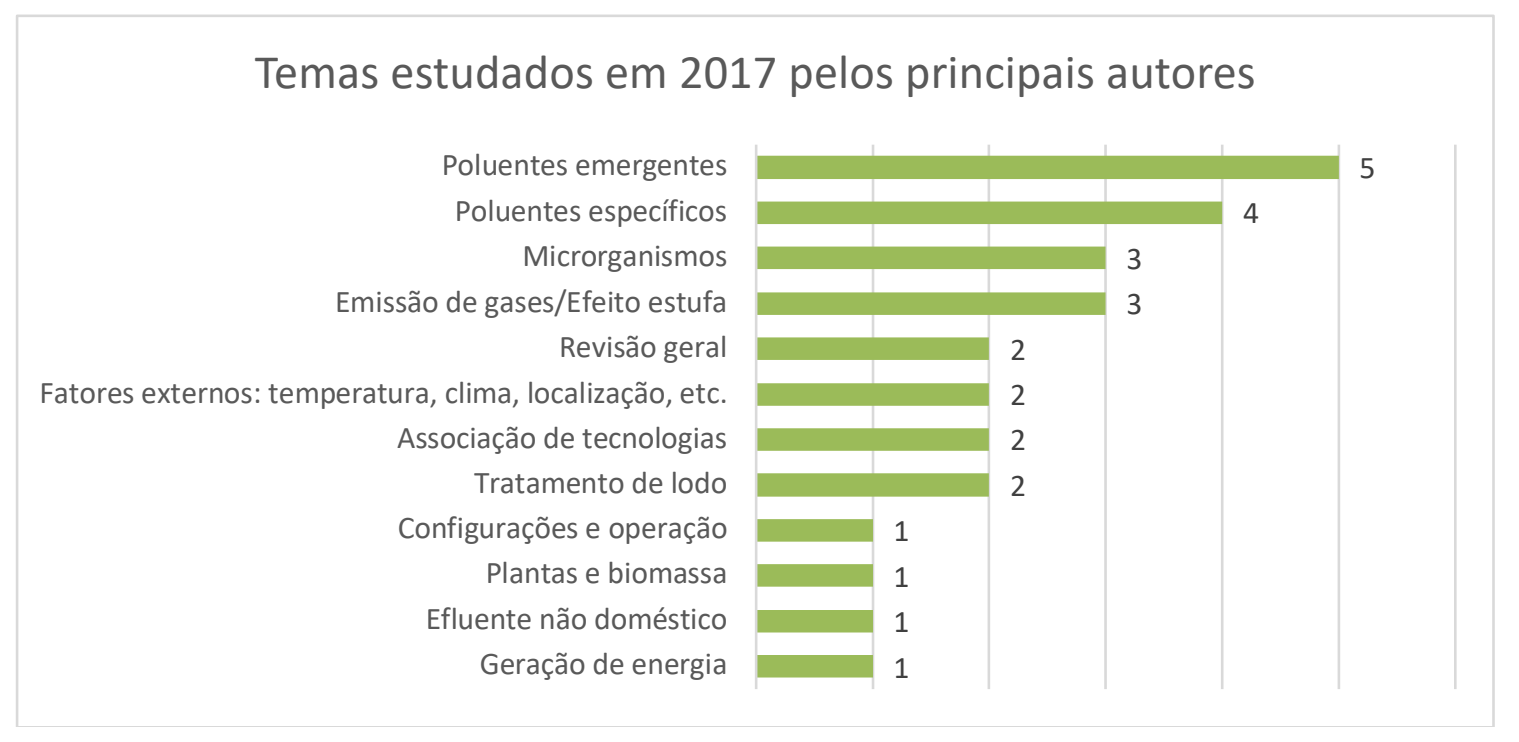

Fonte: Cauê Girão de Abreu, 2019.

Através da análise da figura 14 fica evidente que alguns temas permanecem com maior importância, principalmente os poluentes específicos, e ainda com destaque para os conhecidos como emergentes. Uma outra tendência que aparece neste levantamento é o crescimento da importância dos estudos relacionados às emissões gasosas e relação com o efeito estufa.

Alguns trabalhos devem fazer parte da revisão de teoria obrigatória, por sua repercussão ao longo do período analisado neste estudo. O quadro 5 mostra estes trabalhos: 
Quadro 5 - Trabalhos de maior repercussão no período estudado

\begin{tabular}{|c|c|c|c|}
\hline Autores & Título & Ano & Publicação \\
\hline Vymazal, J. & $\begin{array}{l}\text { Removal of nutrients in } \\
\text { various types of } \\
\text { constructed wetlands }\end{array}$ & 2007 & $\begin{array}{l}\text { Science of the Total } \\
\text { Environment } \\
\text { Volume } 380 \text {, Issue } 1-3,15 \\
\text { July } 2007 \text {, Pages } 48-65\end{array}$ \\
\hline Brix, H. & $\begin{array}{l}\text { Do macrophytes play a } \\
\text { role in constructed } \\
\text { treatment wetlands? }\end{array}$ & 1997 & $\begin{array}{l}\text { Water Science and } \\
\text { Technology } \\
\text { Volume } 35, \text { Issue 5, 1997, } \\
\text { Pages 11-17 }\end{array}$ \\
\hline $\begin{array}{c}\text { Stottmeister, U.; } \\
\text { Wießner, A, Kuschk, } \\
\text { P., Kappelmeyer, U., } \\
\text { Kästner, M., Bederski, } \\
\text { O., Müller, R.A., } \\
\text { Moormann, H. }\end{array}$ & $\begin{array}{l}\text { Effects of plants and } \\
\text { microorganisms in } \\
\text { constructed wetlands } \\
\text { for wastewater } \\
\text { treatment }\end{array}$ & 2003 & $\begin{array}{l}\text { Biotechnology Advances } \\
\text { Volume 22, Issue 1-2, } \\
\text { December 2003, Pages } \\
93-117\end{array}$ \\
\hline Kivaisi, A.K. & $\begin{array}{l}\text { The potential for } \\
\text { constructed wetlands } \\
\text { for wastewater } \\
\text { treatment and reuse in } \\
\text { developing countries: A } \\
\text { review }\end{array}$ & 2001 & $\begin{array}{l}\text { Ecological Engineering } \\
\text { Volume 16, Issue 4, 2001, } \\
\text { Pages 545-560 }\end{array}$ \\
\hline Vymazal, J. & $\begin{array}{l}\text { Horizontal sub-surface } \\
\text { flow and hybrid } \\
\text { constructed wetlands } \\
\text { systems for wastewater } \\
\text { treatment }\end{array}$ & 2005 & $\begin{array}{l}\text { Ecological Engineering } \\
\text { Volume } 25, \text { Issue } 5,1 \\
\text { December 2005, Pages } \\
478-490\end{array}$ \\
\hline $\begin{array}{c}\text { Sakadevan, K., Bavor, } \\
\text { H.J. }\end{array}$ & $\begin{array}{l}\text { Phosphate adsorption } \\
\text { characteristics of soils, } \\
\text { slags and zeolite to be } \\
\text { used as substrates in } \\
\text { constructed wetland } \\
\text { systems }\end{array}$ & 1998 & $\begin{array}{l}\text { Water Research } \\
\text { Volume 32, Issue 2, } \\
\text { February 1998, Pages } \\
\text { 393-399 }\end{array}$ \\
\hline Brix, H. & $\begin{array}{c}\text { Functions of } \\
\text { macrophytes in } \\
\text { constructed wetlands }\end{array}$ & 1994 & $\begin{array}{l}\text { Water Science and } \\
\text { Technology } \\
\text { Volume } 29 \text {, Issue 4, 1994, } \\
\text { Pages } 71-78\end{array}$ \\
\hline $\begin{array}{c}\text { Zayed, A., } \\
\text { Gowthaman, S., Terry, } \\
\text { N. }\end{array}$ & $\begin{array}{l}\text { Phytoaccumulation of } \\
\text { trace elements by } \\
\text { wetland plants: I. } \\
\text { Duckweed }\end{array}$ & 1998 & $\begin{array}{l}\text { Journal of Environmental } \\
\text { Quality } \\
\text { Volume 27, Issue 3, May } \\
\text { 1998, Pages 715-721 }\end{array}$ \\
\hline
\end{tabular}




\begin{tabular}{|c|c|c|c|}
\hline $\begin{array}{c}\text { Faulwetter, J.L., } \\
\text { Gagnon, V., Sundberg, } \\
\text { C., Chazarenc, F., } \\
\text { Burr, M.D., Brisson, J., } \\
\text { Camper, A.K., Stein, } \\
\text { O.R. }\end{array}$ & $\begin{array}{c}\text { Microbial processes } \\
\text { influencing performance } \\
\text { of treatment wetlands: } \\
\text { A review }\end{array}$ & 2009 & $\begin{array}{l}\text { Ecological Engineering } \\
\text { Volume 35, Issue 6, June } \\
2009, \text { Pages 987-1004 }\end{array}$ \\
\hline $\begin{array}{l}\text { Akratos, C.S., } \\
\text { Tsihrintzis, V.A. }\end{array}$ & $\begin{array}{l}\text { Effect of temperature, } \\
\text { HRT, vegetation and } \\
\text { porous media on } \\
\text { removal efficiency of } \\
\text { pilot-scale horizontal } \\
\text { subsurface flow } \\
\text { constructed wetlands }\end{array}$ & 2007 & $\begin{array}{l}\text { Ecological Engineering } \\
\text { Volume 29, Issue 2, } 1 \\
\text { February 2007, Pages } \\
173-191\end{array}$ \\
\hline
\end{tabular}




\section{APÊNDICE II - DETALHES SISTEMA ESTUDADO}

\section{CONFIGURAÇÃO E DADOS DO SISTEMA EXISTENTE}

O estudo de caso em questão constituí um sistema de wetlands construídos em operação há mais de 48 meses, para tratamento de esgoto sanitário na região de Campinas - SP.

Segundo a classificação climática de Koeppen, o clima da região de Campinas é definido como Cwa, conhecido como tropical de altitude. Este tipo de clima apresenta temperatura média acima de $20,7^{\circ} \mathrm{C}$, com invernos secos e não muito intensos e com chuva no período do verão, concomitante com temperaturas moderadamente altas. $\mathrm{O}$ índice pluviométrico esperado para esse tipo de clima é abaixo dos $1350 \mathrm{~mm} /$ ano. A temperatura máxima média esperada é de $23,4^{\circ} \mathrm{C}$, e a mínima média é de $17,2^{\circ} \mathrm{C}$ (CPMAA, 2017).

De acordo com um estudo do Centro de Pesquisas Meteorológicas e Climáticas Aplicadas à Agricultura (CPMAA, 2017) que considerou dados climatológicos de dez anos consecutivos, especificamente em Campinas, as temperaturas médias mensais variaram entre $18,5^{\circ} \mathrm{C}$ e $24,9^{\circ} \mathrm{C}$, com média anual de $22,4^{\circ} \mathrm{C}$, e a chuva média mensal variou entre $22,9 \mathrm{~mm}$ e 280,3 $\mathrm{mm}$, com média anual de $1424 \mathrm{~mm}$. A figura 1, a seguir, mostra estas variações médias, com valores deste mesmo estudo:

Figura 1 - Clima de Campinas.

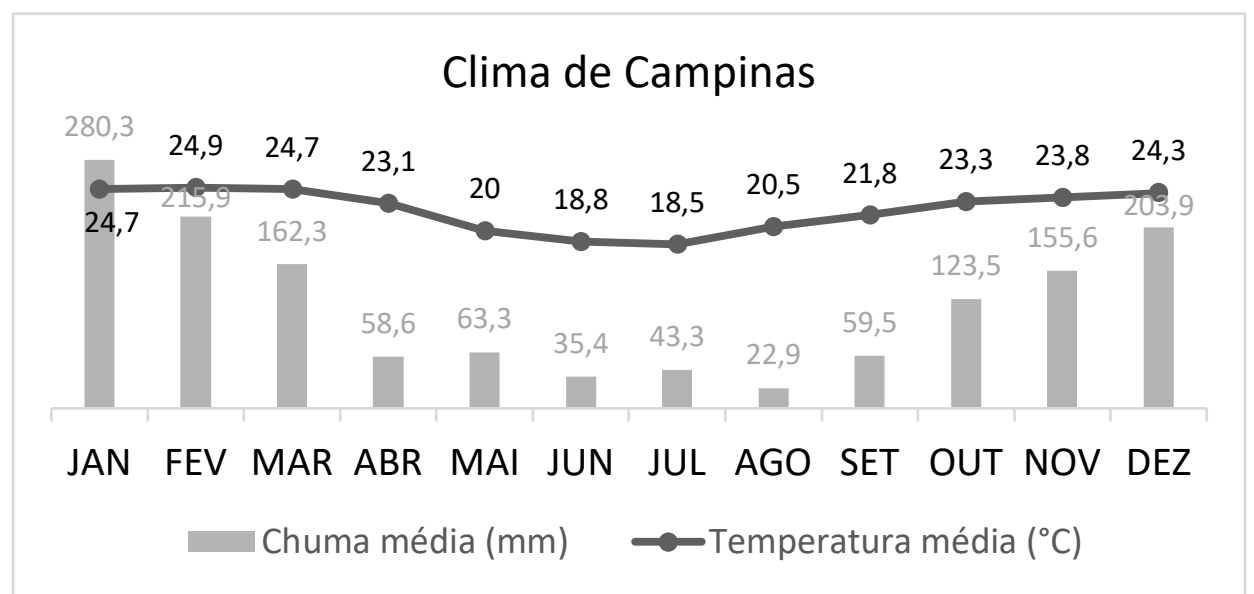

Fonte: Adaptada de CENTRO DE PESQUISAS METEOROLÓGICAS E CLIMÁTICAS APLICADAS À AGRICULTURA, 2017.

O sistema objeto deste estudo foi dimensionado para tratar esgoto sanitário de uma indústria. A contribuição será de esgoto sanitário bruto de uma população máxima de 650 pessoas com contribuição unitária de $160 \mathrm{~L} /$ pessoa*dia, totalizando $104.000 \mathrm{~L} /$ dia ou 1,2L/s. Com uma concentração de carga orgânica, em termos de $\mathrm{DBO}_{5}{ }^{20}$ considerada de $400 \mathrm{mg} / \mathrm{L}$, o sistema foi projetado para receber uma carga de $41,6 \mathrm{~kg}$ de $\mathrm{DBO}_{5}{ }^{20}$ por dia. Estes foram os dados utilizados pela projetista do sistema.

O sistema é composto por pré-tratamento para separação de sólidos grosseiros, tanque de recebimento e equalização do esgoto e aeração do mesmo, wetlands verticais subsuperficiais, wetlands horizontais subsuperficiais e wetlands horizontais superficiais, conforme descrição e detalhamento a seguir. 
O pré-tratamento foi concebido apenas para remoção de sólidos grosseiros, através de um gradeamento simples construído em aço inox com distância entre barras de $10 \mathrm{~mm}$. $\mathrm{O}$ gradeamento foi dimensionado para instalação em uma canaleta de concreto na chegada do esgoto, onde foi também instalada uma calha Parshall com medidor ultrassônico de vazão. Todos os componentes desta etapa foram dimensionados para uma vazão máxima de até 10L/s.

Após o pré-tratamento, o esgoto segue por gravidade para um tanque de equalização e aeração, onde é acumulado até que obtenha o volume necessário para a alimentação dos WC, que trabalham em intervalos intermitentes (bateladas). As bateladas são enviadas a cada vez que se atinge o volume máximo do tanque de equalização, variando de acordo com a vazão de contribuição e com tempo médio de aproximadamente 7 horas.

O tanque de equalização foi dimensionado para um tempo de detenção de aproximadamente 7 horas, com um volume útil total de $30 \mathrm{~m}^{3}$, profundidade útil de $1,6 \mathrm{~m}$ e borda livre de $0,3 \mathrm{~m}$. $\mathrm{O}$ tanque foi construído enterrado em alvenaria. Foi construída ainda uma contenção com $110 \%$ do volume total do tanque para o caso de rompimento ou vazamento do tanque. Dentro do tanque foram instaladas chaves de nível para controle do volume, aeradores submersíveis do tipo venturi, para mistura e oxigenação do esgoto, e bombas submersíveis para a alimentação dos WC.

Os aeradores funcionam ininterruptamente para garantir introdução de oxigênio e impedir que o esgoto não entre em anaerobiose, que libera metano e sulfeto como subproduto do processo microbiológico e pode ocasionar maus odores no seu entorno. Desta forma, o esgoto acumulado é enviado com oxigênio aos WC e homogêneo em relação às variações diárias de carga e vazão.

As bombas de alimentação funcionam automaticamente, através do sinal enviado pelas chaves de nível, sendo ligadas quando o tanque atinge seu nível máximo e desligadas quando ele atinge seu nível mínimo. O volume total enviado para tratamento em cada operação da bomba equivale a $20 \mathrm{~m}^{3}$.

As figuras 2 e 3 a seguir ilustram o projeto do tanque e dos equipamentos instalados.

Figura 2 - Corte transversal do tanque

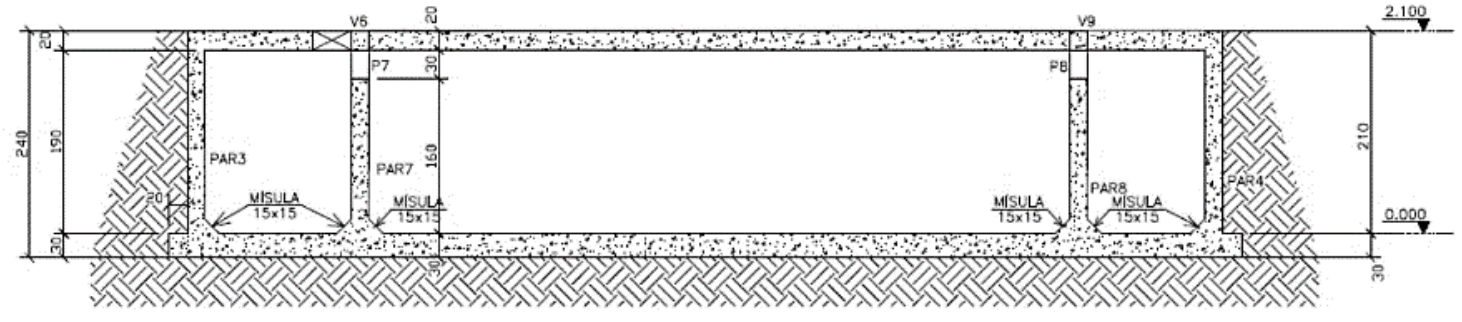

Fonte: Adaptada de Phytorestore Brasil 2013b. 
Figura 3 - Planta do tanque e posição dos equipamentos

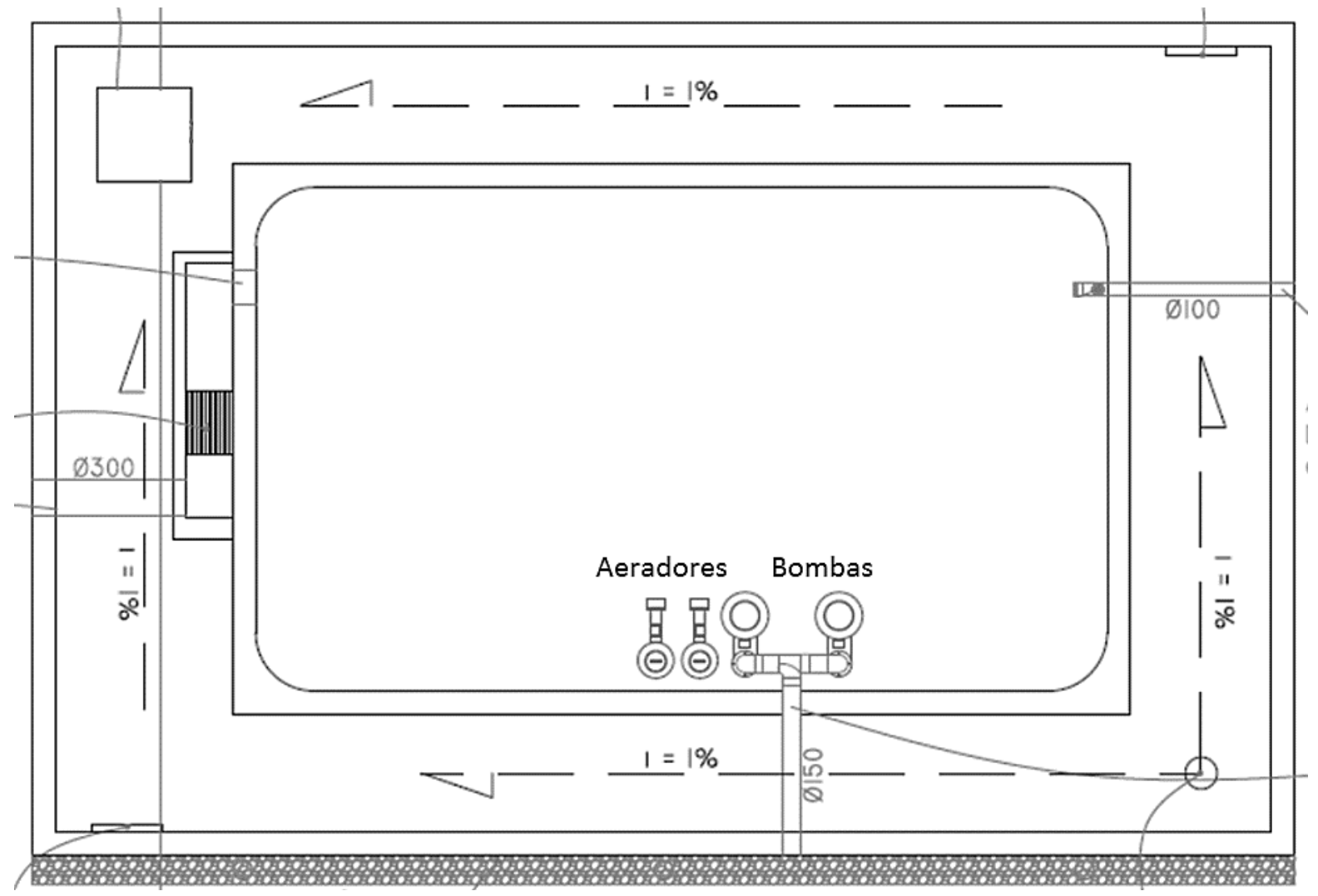

Fonte: Adaptada de Phytorestore Brasil 2013b.

Como o tempo de detenção é consideravelmente baixo, o tanque não tem função de reator aeróbio, não sendo, portanto, considerado um tratamento primário e não tendo grande influência em termos de remoção de carga orgânica.

Após esta etapa o esgoto é encaminhado para o sistema de wetland propriamente dito, em sua primeira etapa, constituída por Wetlands verticais não saturados de fluxo subsuperficial descendente, chamados no projeto de filtros verticais. Estes filtros foram projetados e construídos em triplicatas, ou seja, são três filtros trabalhando paralelamente. A operação é feita de forma que apenas um filtro seja alimentado por vez, enquanto os outros dois entram em um período de recesso da operação a fim de reduzir o stress hídrico e de carga poluente nas plantas.

O dimensionamento destes filtros foi feito seguindo os seguintes critérios:

- Profundidade útil de $70 \mathrm{~cm}$.

- Borda livre de $70 \mathrm{~cm}$ para suportar chuvas intensas com um período de retorno de até 50 anos. 
- Substrato de britas com granulometrias diferentes em diferentes camadas, ocupando toda a profundida útil, sendo os primeiros $30 \mathrm{~cm}$ a partir do fundo preenchidos com brita número 3 (granulometria variando de $25 \mathrm{~mm}$ a $50 \mathrm{~mm}$ ), os $20 \mathrm{~cm}$ intermediários com brita número 2 (granulometria variando de $19 \mathrm{~mm}$ a $25 \mathrm{~mm}$ ) e os $20 \mathrm{~cm}$ superiores com brita número 1 (granulometria variando de 9,5 $\mathrm{mm}$ a $19 \mathrm{~mm}$ ).

- Plantação de espécies variadas (policultura).

- Alimentação na superfície e drenagem no fundo.

- Sistema de aeração passiva (sem motor) através de tubulações perfuradas no fundo do filtro e a $30 \mathrm{~cm}$ dele (acima da brita 3 ).

- Aplicação superficial: $42 \mathrm{~L} / \mathrm{m}^{2 *}$ dia.

Desta forma os filtros ficaram dimensionados com $223 \mathrm{~m}^{2}$ cada. As figuras 4 a 6 , a seguir ilustram o projeto destes filtros e seus detalhes:

Figura 25 - Desenho e organização dos filtros verticais.

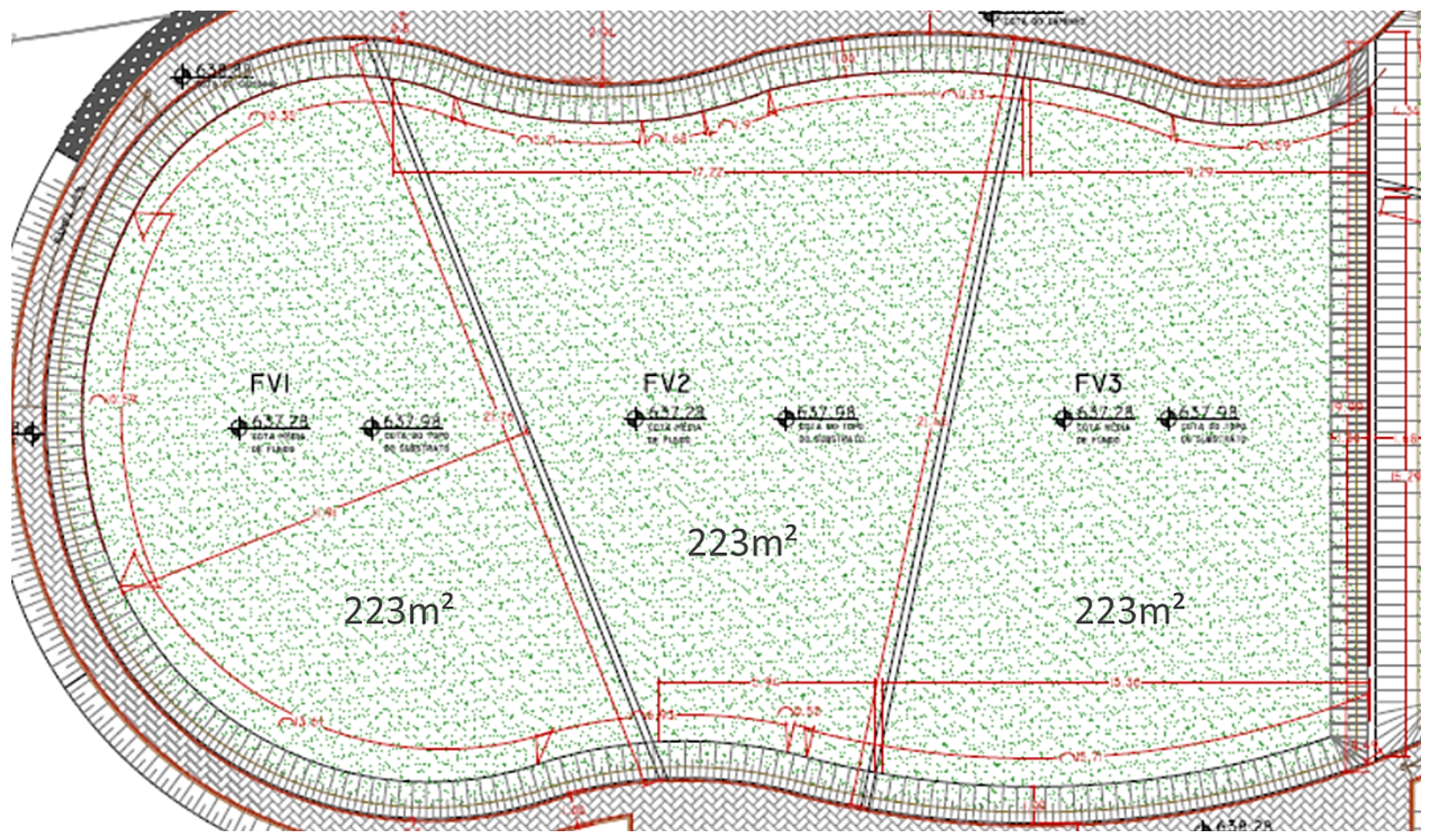

Fonte: Adaptada de Phytorestore Brasil 2013b. 
Figura 5 - Camadas de substrato dos filtros verticais

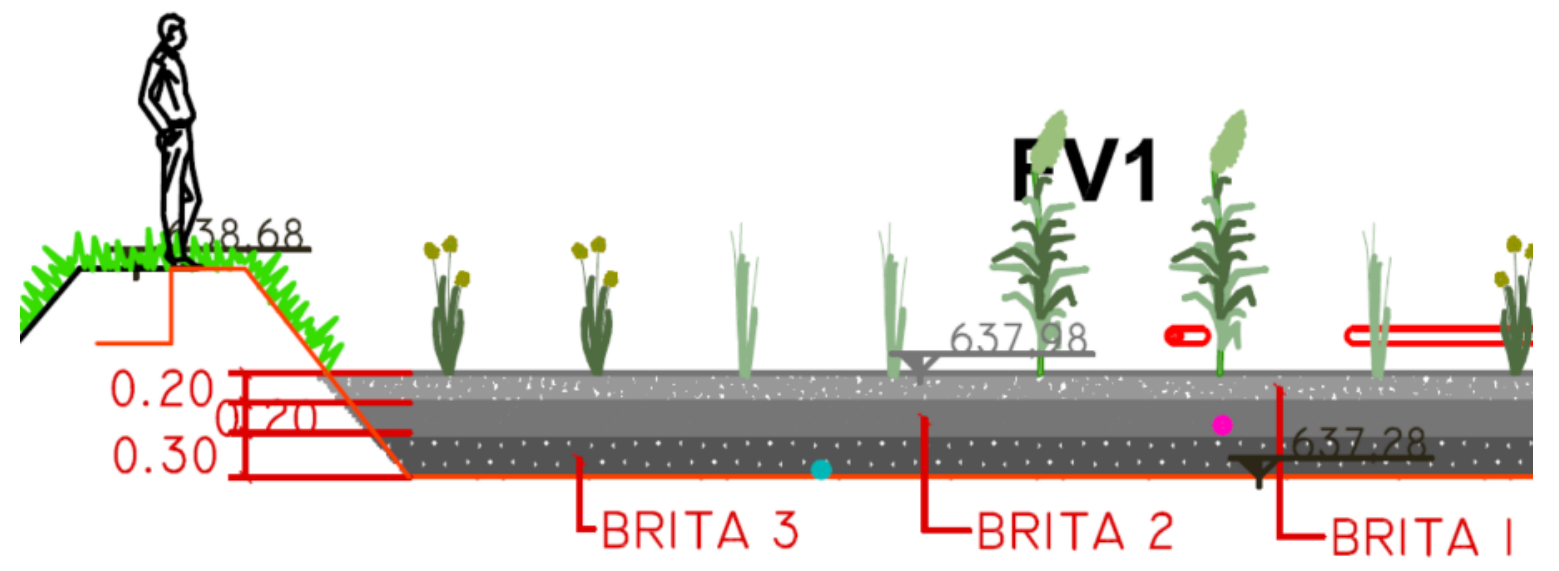

Fonte: Adaptada de Phytorestore Brasil 2013b.

Figura 6 - Esquema hidráulico dos filtros verticais

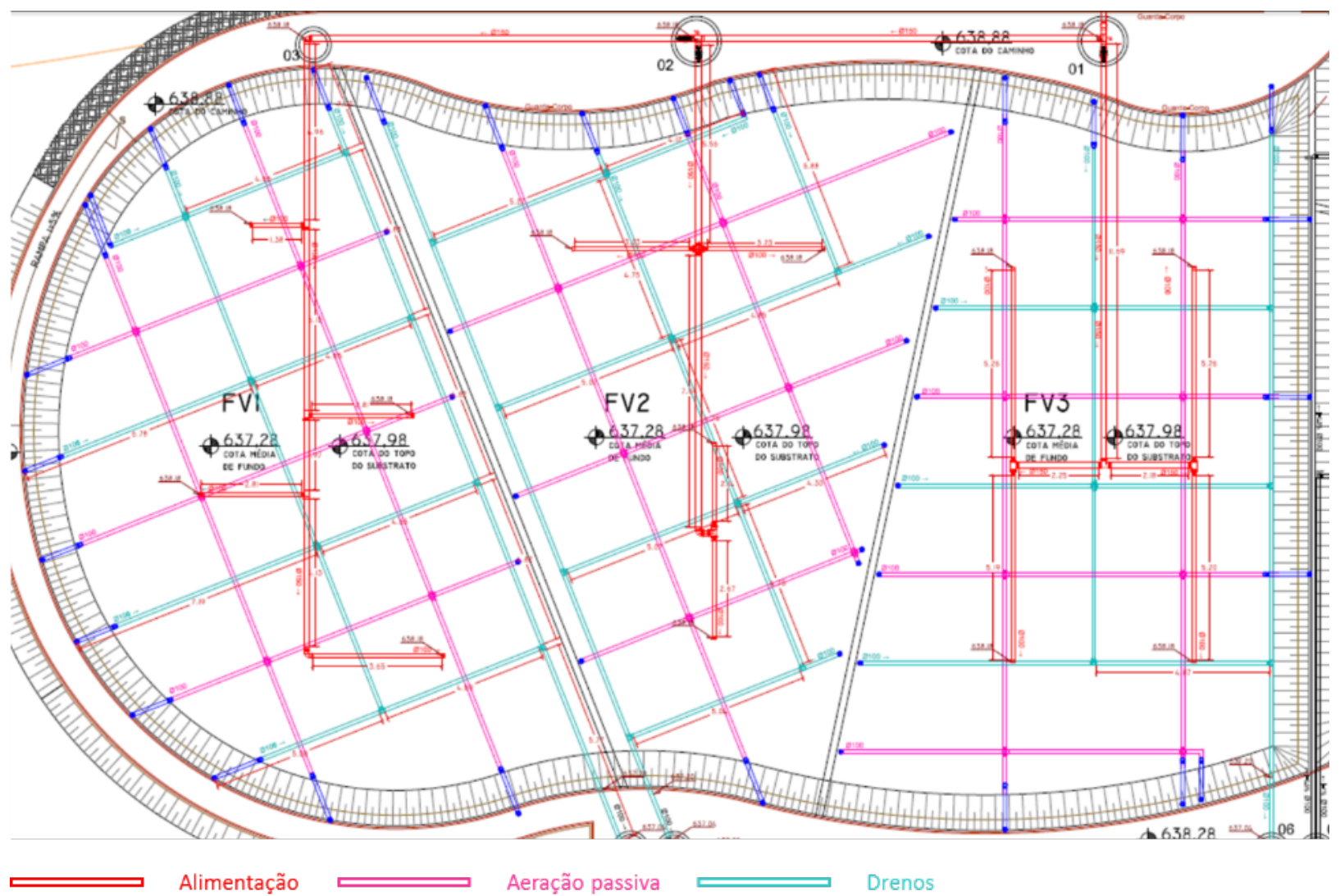

Fonte: Adaptada de Phytorestore Brasil 2013b. 
101

Após a passagem pelos filtros verticais o esgoto segue, ainda por gravidade, para a etapa seguinte, composta de wetlands horizontais saturados de fluxo subsuperficial, chamados no projeto de filtros horizontais. Estes filtros foram projetados e construídos em duplicidade, ou seja, são dois filtros trabalhando em paralelo. A operação é feita de forma que apenas um filtro seja alimentado por vez, enquanto o outro entra em um período de recesso da operação a fim de reduzir o stress hídrico e de carga poluente nas plantas.

O dimensionamento destes filtros foi feito seguindo os seguintes critérios:

- Profundidade útil de $50 \mathrm{~cm}$

- Borda livre de $30 \mathrm{~cm}$ para suportar chuvas intensas com um período de retorno de até 50 anos.

- Substrato de britas número 2 (granulometria variando de $19 \mathrm{~mm}$ a $25 \mathrm{~mm}$ ).

- Plantação de espécies variadas (policultura)

- Alimentação em uma extremidade horizontal e drenagem na outra.

- Saída do esgoto com coleta no fundo e sistema sifonado com altura $5 \mathrm{~cm}$ abaixo do nível do substrato, para manter o sistema sempre saturado e com fluxo subsuperficial

- Aplicação superficial: $94 \mathrm{~L} / \mathrm{m}^{2 *}$ dia.

Desta forma os filtros ficaram dimensionados com $223 \mathrm{~m}^{2}$ cada. As figuras 7 a 9 , a seguir ilustram o projeto destes filtros e seus detalhes: 
Figura 7 - Desenho e organização dos filtros horizontais

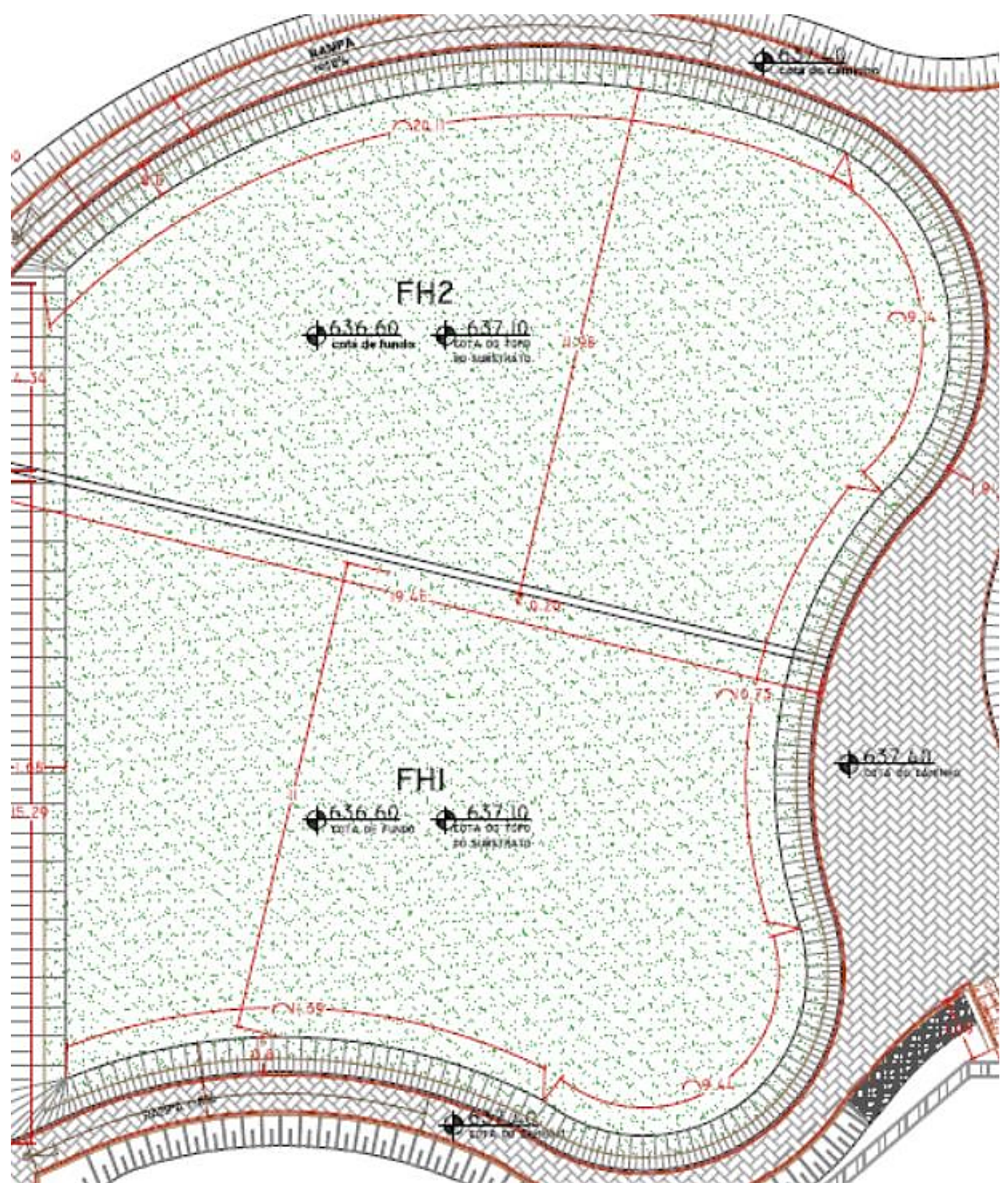

Fonte: Adaptada de Phytorestore Brasil 2013b. 
Figura 8-Camadas de substrato dos filtros Horizontais

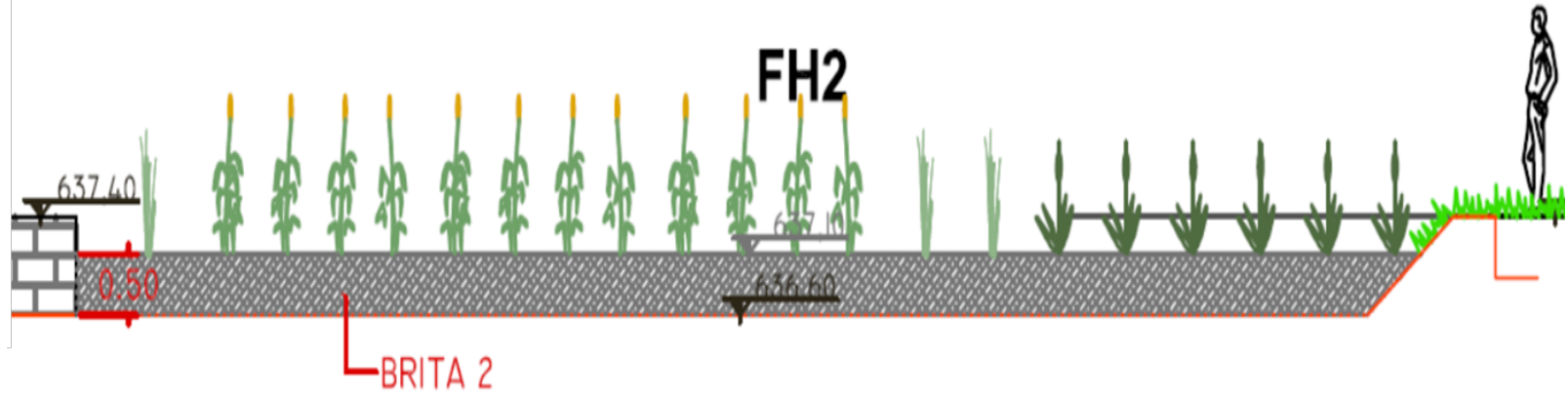

Fonte: Adaptada de Phytorestore Brasil 2013b. 
104

Figura 9 - Esquema hidráulico dos filtros horizontais

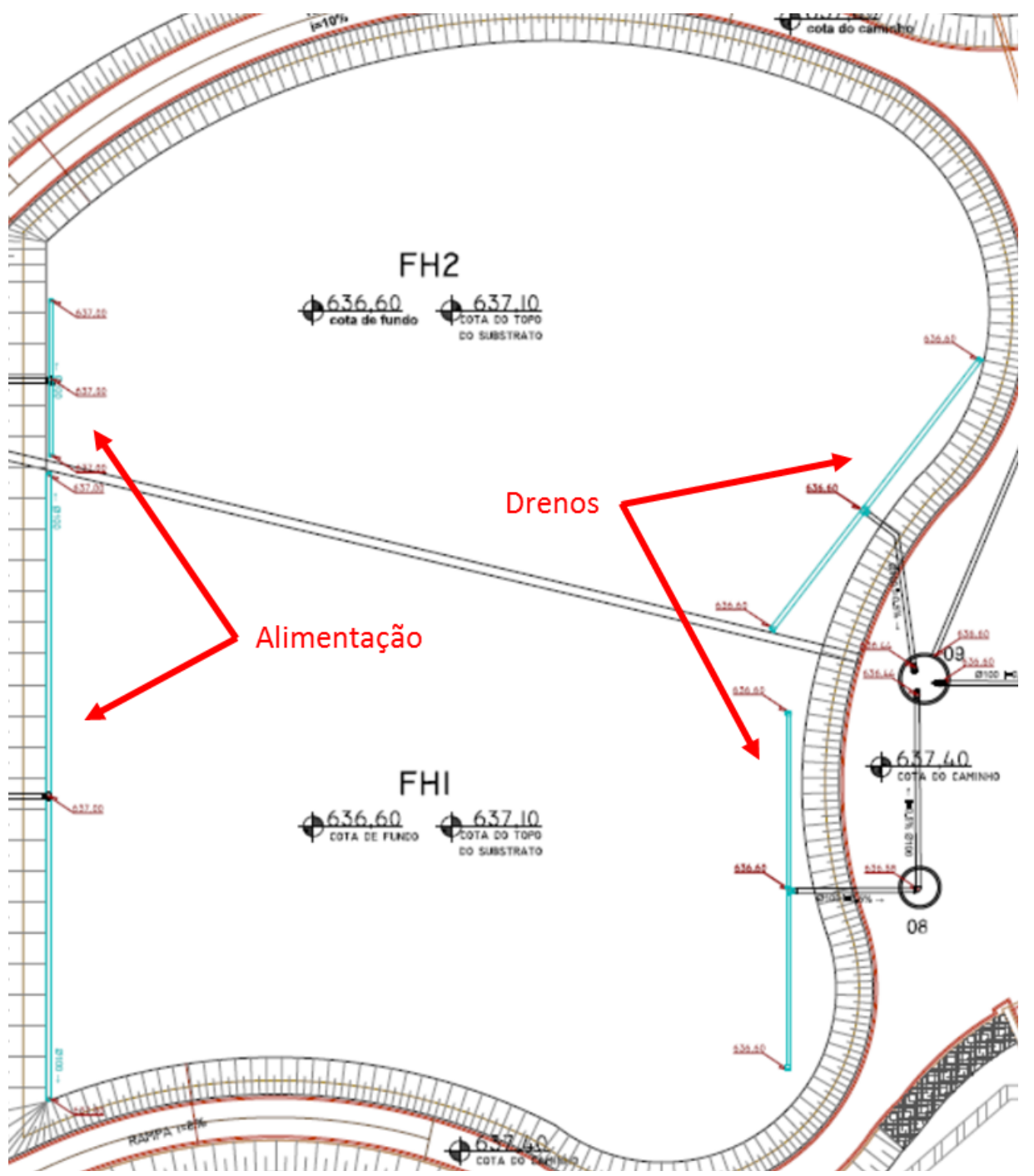

Fonte: Adaptada de Phytorestore Brasil 2013b.

Após a filtração horizontal o esgoto segue para a última etapa do tratamento, composta por um wetland saturado de fluxo horizontal superficial, chamado no projeto de lagoa plantada. $\mathrm{O}$ dimensionamento desta etapa contempla os seguintes critérios:

- Profundidade útil de $80 \mathrm{~cm}$

- Borda livre de $30 \mathrm{~cm}$ para suportar chuvas intensas com um período de retorno de até 50 anos.

- Substrato de terra vegetal apenas no fundo, em uma camada de $30 \mathrm{~cm}$ para plantação das espécies.

- Plantação de espécies variadas (policultura). 
- Alimentação em uma extremidade horizontal e drenagem na outra.

- Saída do esgoto com coleta no fundo e sistema sifonado com altura no nível do espelho d'água, para manter o sistema sempre saturado.

- Tempo de detenção hidráulico de 5 dias.

Desta forma a lagoa foi dimensionada com $520 \mathrm{~m}^{2}$. As figuras 10 a 12 , a seguir ilustram o projeto destes filtros e seus detalhes:

Figura 26 - Desenho e organização da lagoa plantada

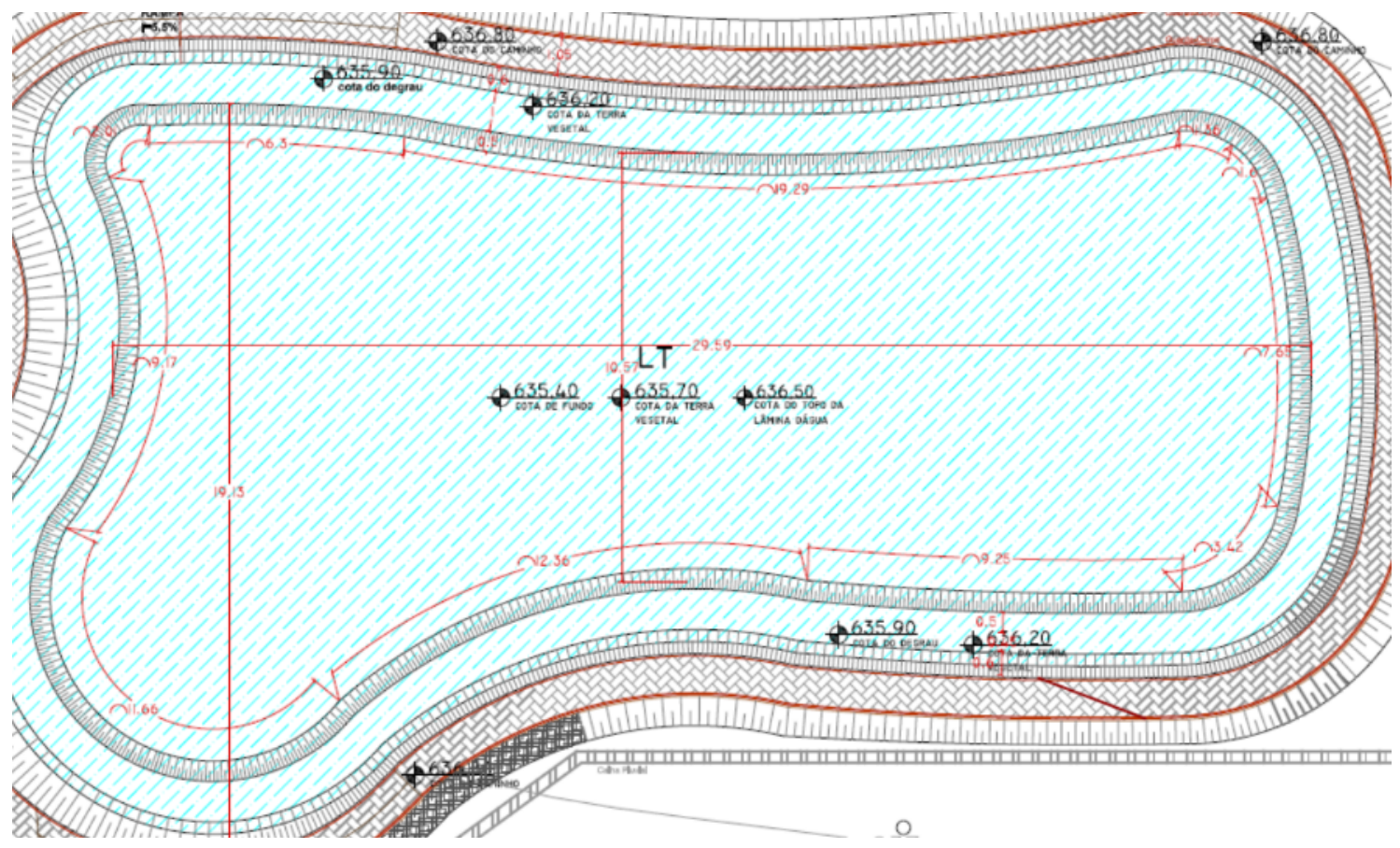

Fonte: Adaptada de Phytorestore Brasil 2013b.

Figura 11 - Camadas de substrato da lagoa plantada

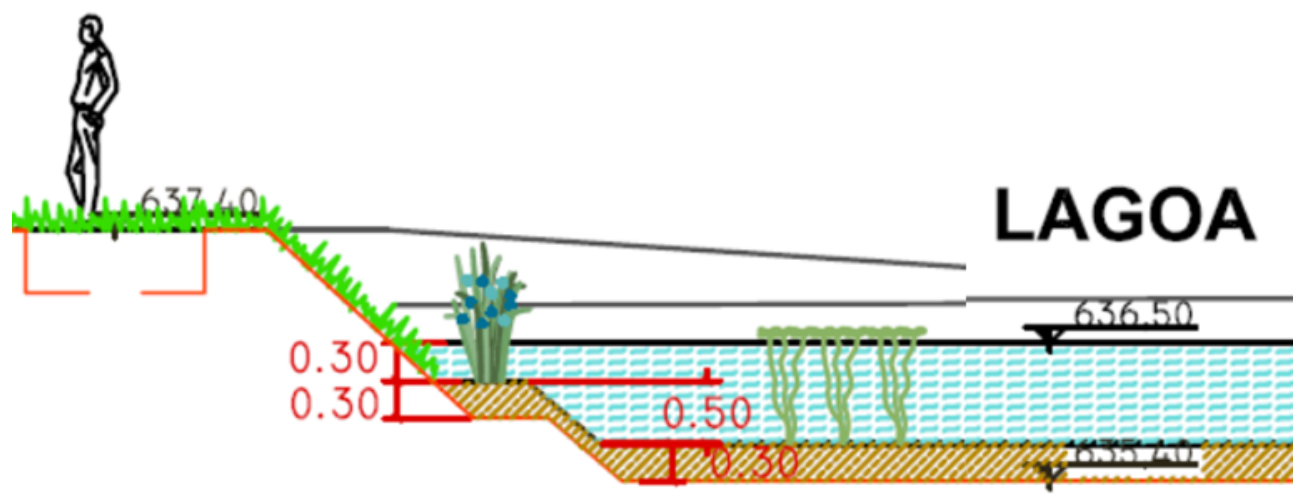

Fonte: Adaptada de Phytorestore Brasil 2013b. 
Figura 12 - Esquema hidráulico da lagoa plantada

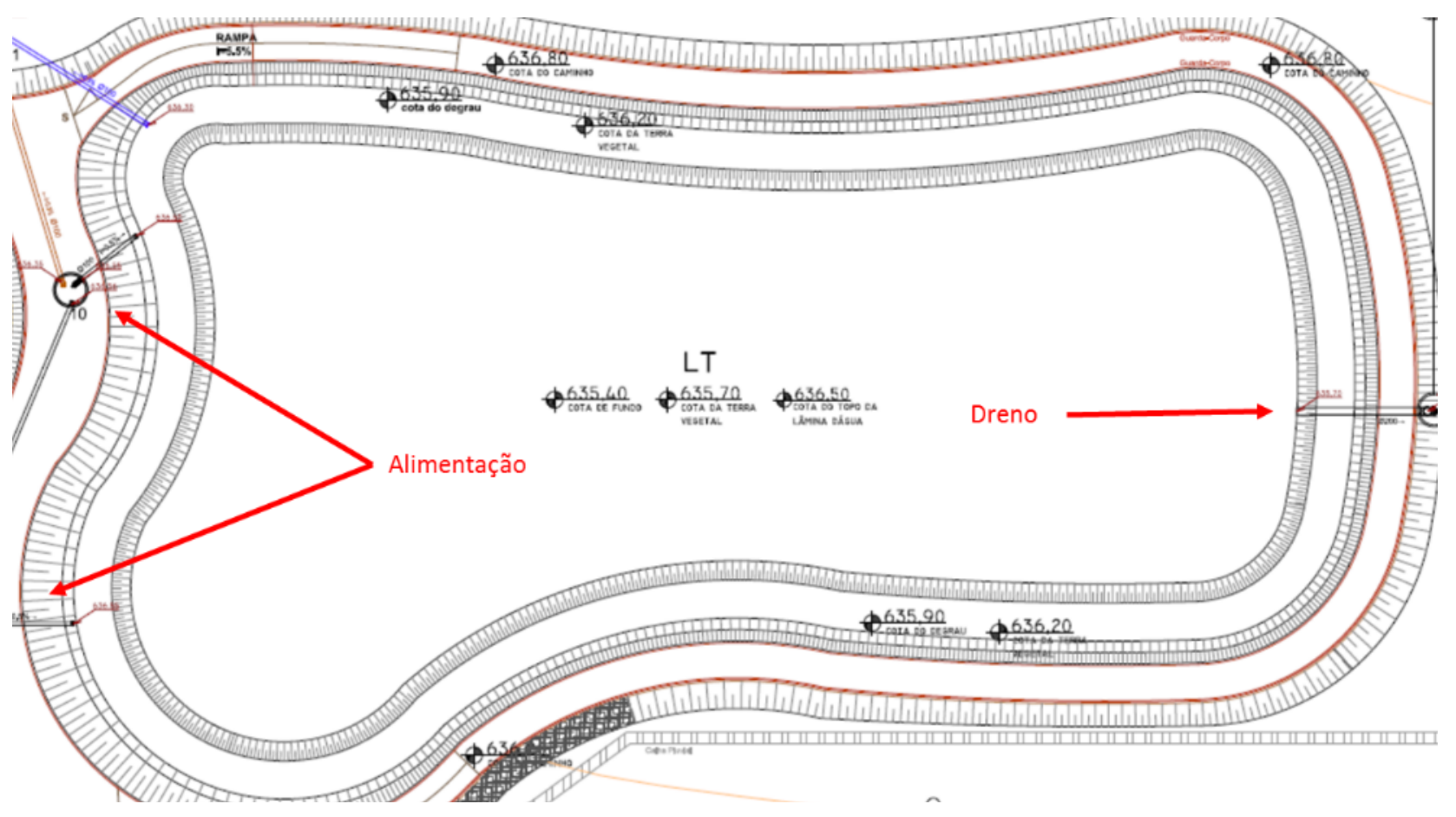

Fonte: Adaptada de Phytorestore Brasil 2013b.

Após o término do tratamento o esgoto passa por uma última canaleta para medição de vazão e é encaminhado para disposição final.

A figura 13 a seguir mostra uma visão geral do projeto do sistema:

Figura 13 - Vista geral do projeto do sistema

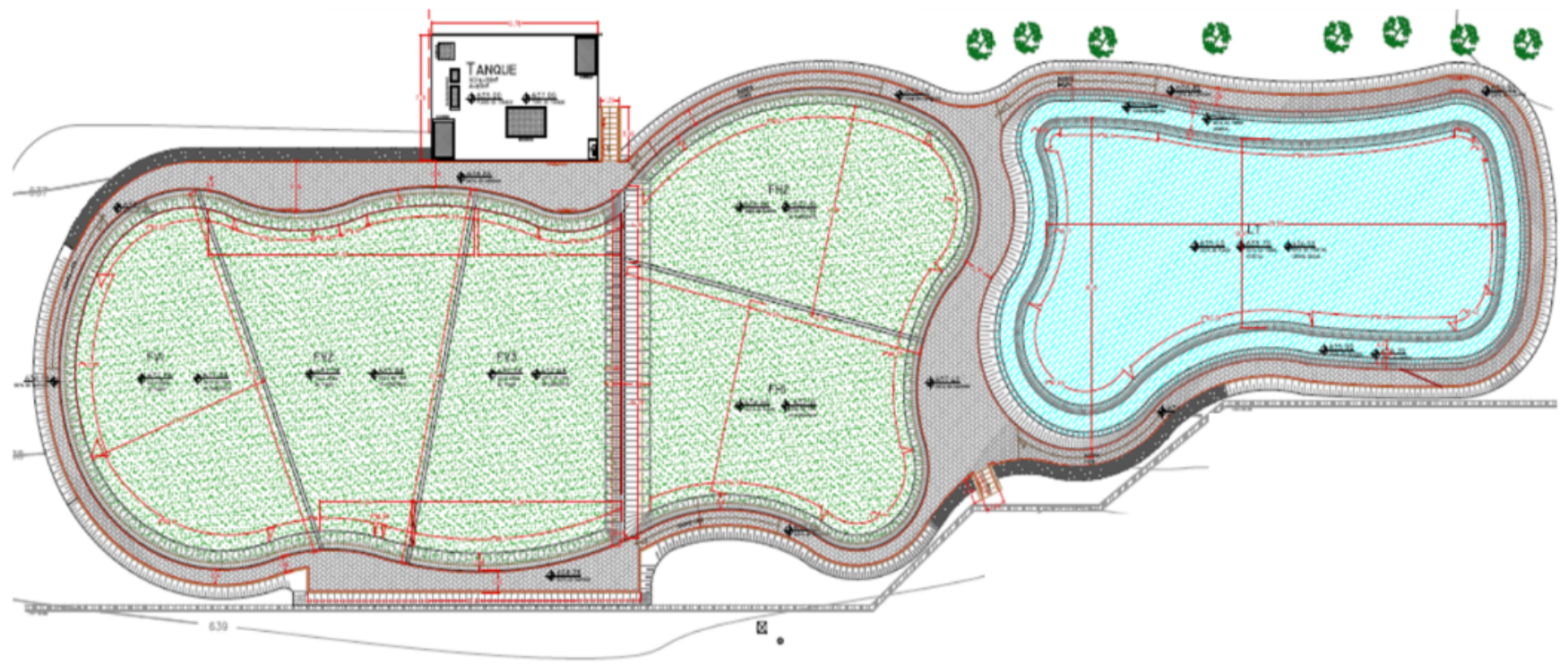

Fonte: Adaptada de Phytorestore Brasil 2013b. 
As plantas selecionadas para o sistema de tratamento são de diversas espécies diferentes, contendo macrófitas emergentes ou emersas e macrófitas com folhas flutuantes. A seguir são apresentadas as espécies selecionadas e suas características, conforme Roriz (1998).

- Echinodorus grandiflorus (Chá-de-campanha, Chá-do-brejo, Chapéu-de-couro, Aguapé, erva-do-pântano, Chá-de-pobre)

Planta aquática, enraizada, perene, ereta, rizomatosa, infestanta de canais de irrigação e drenagem, cursos d'água não muito profundos, margens de rios e lagoas, baixadas pantanosas. Planta atrativa com algum valor ornamental, sendo muito empregada no tratamento de várias doenças (medicina caseira).

Classe : Liliopsida

Ordem : Alimastales

Família : Alismataceae

Descrição:

Origem: todo o Continente Americano.

Altura: de 1,0-2,0 m.

Folhas: alternas, pecioladas, lâminas ovais a elípticas, ápice arredondado e base mais ou menos cordada, marcas translúcidas presentes em folhas secas como pontos ou linhas.

Flores: inflorescência panícula, com flores bissexuadas, actinomorfas.

Reprodução: reproduz-se por sementes, contudo regenera-se facilmente a partir de rizomas após uma geada.

\section{- Cyperus papyrus (Papiro)}

Classe : Liliopsida

Ordem : Poales

Família : Cyperaceae

Descrição:

Origem: África do Norte e Magrheb

Altura: de 1,5-2,0 m.

Folhas: provindos de hastes não ramificadas, cilíndricas e esponjosas, tendo na extremidade folhas pontiagudas.

Flores: inflorescências sem efeito ornamental, de cor marrom-clara formada entre folhas.

Reprodução: multiplica-se pela divisão da touceira, cada planta tendo um pedaço do rizoma.

- Colocasia esculenta (Inhame-imperial, Tinhorão-preto)

Classe : Liliopsida

Ordem : Alismatales

Família : Araceae

Variedade: Illustris 
108

Descrição:

Origem: Pantropical (abrange todos os ambientes tropicais)

Altura: de $0,8-1,5 \mathrm{~m}$.

Folhas: elevadas a partir da base, de margens levemente onduladas, verde-escuras e manchadas irregularmente de preto, sobre pecíolos arroxeados.

Flores: inflorescência típica com espata e espádice, sem importância ornamental.

Reprodução: multiplica-se por divisão de touceira.

\section{- Pontederia spp.}

Classe : Magnoliopsida

Ordem : Commelinales

Família : Pontederiaceae

Descrição:

Origem: América do Sul

Altura: de 0,5 a $0,8 \mathrm{~m}$

Folhas: possuem grandes folhas cerosas, caules suculentos e uma grossa camada de raízes fibrosas.

Flores: inflorescencia de julho a setembro na coloração rocha.

Reprodução: Reproduzem através de mudas ou sementes

- Thalia dealbata (Cana d'água, Pó-de-thalia)

Classe : Liliopsida

Ordem : Zingiberales

Família : Marantaceae

Descrição:

Origem: América do Sul

Altura: de $1,0-2,0 \mathrm{~m}$.

Folhas: alternas, pecíolos estreitos, com bainhas, de lâmina larga oval-lanceolada. As folhas apresentam sobre sua superfície um tipo de pó branco.

Flores: as flores branco-arroxeadas estão presentes ao longo das hastes finas que compõem a planta.

Reprodução: propaga-se através de sementes e também pelos seus rizomas.

- Cyperus alternifolius (Sombrinha-chinesa, Palmeira-umbela, Planta-umbela)

Classe : Liliopsida

Ordem : Poales

Família : Cyperaceae

Descrição: 
Origem: Pantropical (abrange todos os ambientes tropicais)

Altura: de $0,5-1,1 \mathrm{~m}$.

Folhas: coroa de folhas verde-brilhantes, lineares e reclinadas. Há uma forma variegada, com hastes e folhas com estrias creme-amareladas.

Flores: inflorescências localizadas no centro da coroa de folhas, com numerosas flores de cor marrom-clara, de importância ornamental secundária.

Reprodução: multiplica-se facilmente por divisão de touceira e não raramente formam-se mudas por germinação de sementes.

\section{- Andropogon spp.}

Sistema : Linné

Classe: Polygamia

Ordem : Monoecia

Família : Poaceae

Descrição:

Origem: Europa, África, Ásia, Australásia, Pacífico, América do Norte e América do Sul.

Altura: Variável de espécie para espécie.

Folhas: Variável de espécie para espécie.

Flores: flores hermafroditas e unissexuais masculinas ou femininas no mesmo indivíduo.

Reprodução: Variável de espécie para espécie.

- Colocasia gigantea (Orelha-de-elefante-gigante, taioba)

Classe : Liliopsida

Ordem : Alismatales

Família : Araceae

Descrição:

Origem: Brasil

Altura: de 3,7 a 4,6m.

Folhas: Planta perene com folhas com $0,9-1,8 \mathrm{~m}$ de comprimento e 0,6 a $1,2 \mathrm{~m}$ de largura suportadas por talos (pecíolos) de 0,6 a 1,2m de comprimento.

Reprodução: por rizomas.

- Dietes bicolor (Olho de tigre, moréia bicolor, dietes)

Classe: Liliopsida

Ordem: $\quad$ Asparagales

Família: Iridaceae

Origem: África, África do Sul

Altura: 0.4 a 0.6 metros, 0.6 a 0.9 metros 
Folhas: são eretas, planas e rígidas

Flores: flores pequenas semelhantes à íris, com seis pétalas arredondadas dispostas trâs a três, brancas ou na cor creme com pontuação alaranjada ou marrom escuro no centro, reunidas em pecíolos curtos surgindo de um longo, fino e flexível pendão.

Reprodução: multiplica-se facilmente por divisão de touceira

\section{- Typha domingensis (Tabôa, Bucha, Capim-de-esteira, Erva-de-esteira)}

Classe : Lilopsida

Ordem : Poales

Família : Thyphaceae

Descrição:

Origem: Ampla neotropical, Canadá, EUA, Patagonia, Brasil, Europa, Asia, Austrália e Nova Zelândia.

Altura: de 2 a 4 m.

Folhas: Folhas invaginantes na base da planta, acuminadas, glabras, lisas, grossas e esponjosas internamente.

Flores: Flores dispostas em densos e condensados racimos espiciformes cilíndricos, apicais, de cor castanho-avermelhado.

Reprodução: Anemocórica, divisão de touceira ou rizoma

\section{- Colocasia esculenta nigra (Inhame-preto)}

Classe : Liliopsida

Ordem : Alismatales

Família : Araceae

Variedade: Aquatilis

Descrição:

Origem: Pantropical (abrange todos os ambientes tropicais)

Altura: de $0,7-1,2 \mathrm{~m}$.

Folhas: com pecíolo longo, preto arroxeados. O tom negro das folhas diminui em certas épocas do ano. Na base da planta adulta surgem cordões longos e arroxeados (estolões) que crescem sobre a superfície do solo, gerando novas plantas.

Flores: florescimento ocasional, sem importância ornamental.

Reprodução: multiplica-se por divisão de touceira contendo o respectivo rizoma.

\section{- Sagittaria spp. (Flecha, Pato-Batata, Cisne-Batata)}

Classe: Monoecia

Ordem: Alismatales

Família: Alismataceae

Descrição: 
Origem: Nativas do Havaí, Caribe e norte da América do Sul.

Altura: de 0,30 a $0,80 \mathrm{~cm}$

Folhas: Coloração verde

Flores: Inflorescência em julho e agosto na coloração branca

Reprodução: Por meio de semeadura ou divisão em Julho.

- Eleocharis spp.

Classe : Liliopsida

Ordem : Poales

Família : Cyperaceae

Descrição:

Origem: Pantropical (abrange todos os ambientes tropicais)

Altura: de $0.6 \mathrm{~m}$ à $1.2 \mathrm{~m}$

Folhas: Reduzidas a bainhas aglomeradas na base das hastes

Flores: Nascem em uma espigueta terminal com 2 estigmas.

Reprodução: Através de sementes ou mudas

- Equisetum spp. (Cavalinha, Árvore-de-natal, Cauda-de-raposa, Cauda-de-eqüina, Cauda-de-cavalo)

Classe : Equisetopsida

Ordem : Equisetales

Família : Equisetaceae

Descrição:

Origem: América do Sul e América Central

Altura: de 2,00 m - 5,00m.

Folhas:

Reprodução: reprodução assexuada (produz cones contendo esporos).

- Thalia geniculata (Arumarana, Caeté, Agutiguepo-obi)

Classe : Liliopsida

Ordem : Zingiberales

Família : Marantaceae

Descrição:

Origem: Brasil.

Altura: de 1,0-2,5 m.

Folhas: verde-acinzentadas e cerosas na face inferior.

Flores: inflorescência paniculada sustentada por longo escapo floral. 
Reprodução: propaga-se tanto por sementes como através de rizomas.

- Nymphea spp. (Ninféia)

Classe : Magnoliopsida

Ordem : Nymphaeales

Família : Nymphaeaceae

Descrição:

Origem: América Tropical.

Altura: suportam lâmina de até $2,0 \mathrm{~m}$.

Folhas: flutuantes, lisas, grandes, orbiculares, coriáceas, denteadas, verde-escuras e decíduas no inverno, com longo pecíolo.

Flores: solitárias, grandes, brancas quando se abrem tornam-se róseas depois, com estames amarelos, sobre longo pedúnculo que as dispõem alto acima da folhagem, flores formadas no verão.

Reprodução: multiplica-se por meio dos tubérculos rizomatosos e por sementes que germinam espontaneamente na água.

- Typhonodorum lindleyanum (Banana d'água)

Classe: Liliopsida

Ordem: $\quad$ Alismatales

Família: Araceae

Descrição:

Origem: África, Madagascar

Altura: 1.8 a 3.6 metros

Folhas: grandes, sagitado-cordiformes, coriáceas, com margens inteiras e dispostas em roseta

Reprodução: Por divisão do rizoma e por sementes postas a germinar na água ou lodo

- Victoria amazonica (vitória-régia)

Classe: Magnoliopsida

Ordem: Nymphaeales

Família: Nymphaeaceae

Descrição:

Origem: Norte do Brasil

Altura: até $8 \mathrm{~m}$

Folhas: muito grandes, de até $2,5 \mathrm{~m}$ de diâmetro, que flutuam na superfície da água. São bastante espessas, tendo grande resistência na água, devido às nervuras cheias de ar e gases. A superfície inferior, e coberta por espinhos 


\section{3}

Flores: solitárias, flutuantes, com aroma suave (como do abacaxi), com até $40 \mathrm{~cm}$ de diâmetro. Compostas de pétalas externas brancas e as internas púrpura ou rosa-escuro, duram apenas 2 dias, depois morrem. Surgem no verão e são polinizadas por besouros

Reprodução: por sementes e por divisão do rizoma.

As figuras 14 e 15 a seguir ilustram o plano de plantação proposto e adotado pela projetista do sistema, com a localização de cada uma das espécies:

Figura 27 - Plano de plantação dos filtros verticais e horizontais

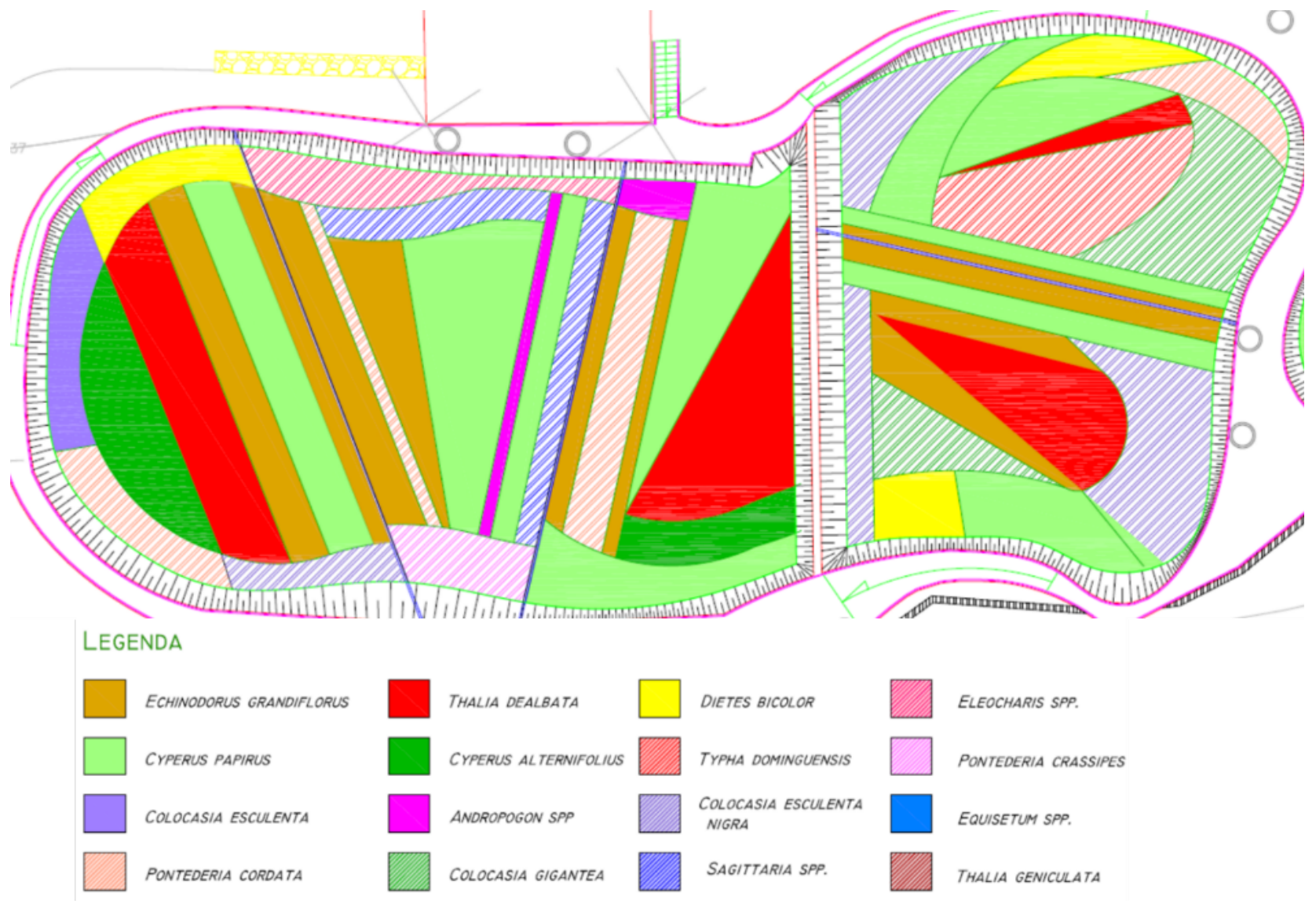

Fonte: Adaptada de Phytorestore Brasil 2013b. 
Figura 15 - Plano de plantação da lagoa plantada

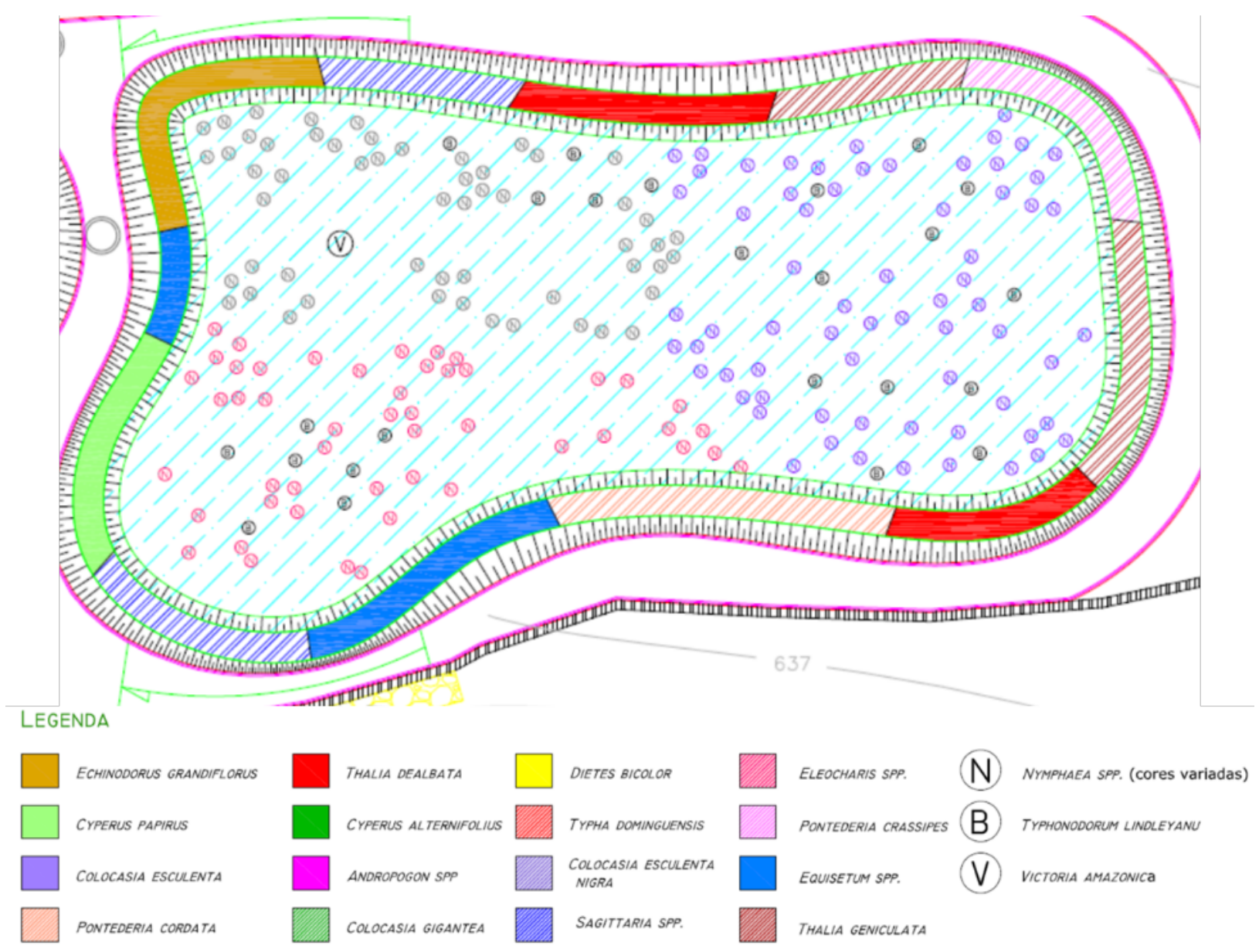

Fonte: Adaptada de Phytorestore Brasil 2013b.

\section{IMPLANTAÇÃO DO SISTEMA}

O sistema foi construído, em sua maioria, em obras de terraplenagem, com a escavação dos WC diretamente em solo natural. A figura 16 a seguir mostra a etapa de terraplenagem para escavação do sistema: 
115

Figura 16 - Terraplenagem

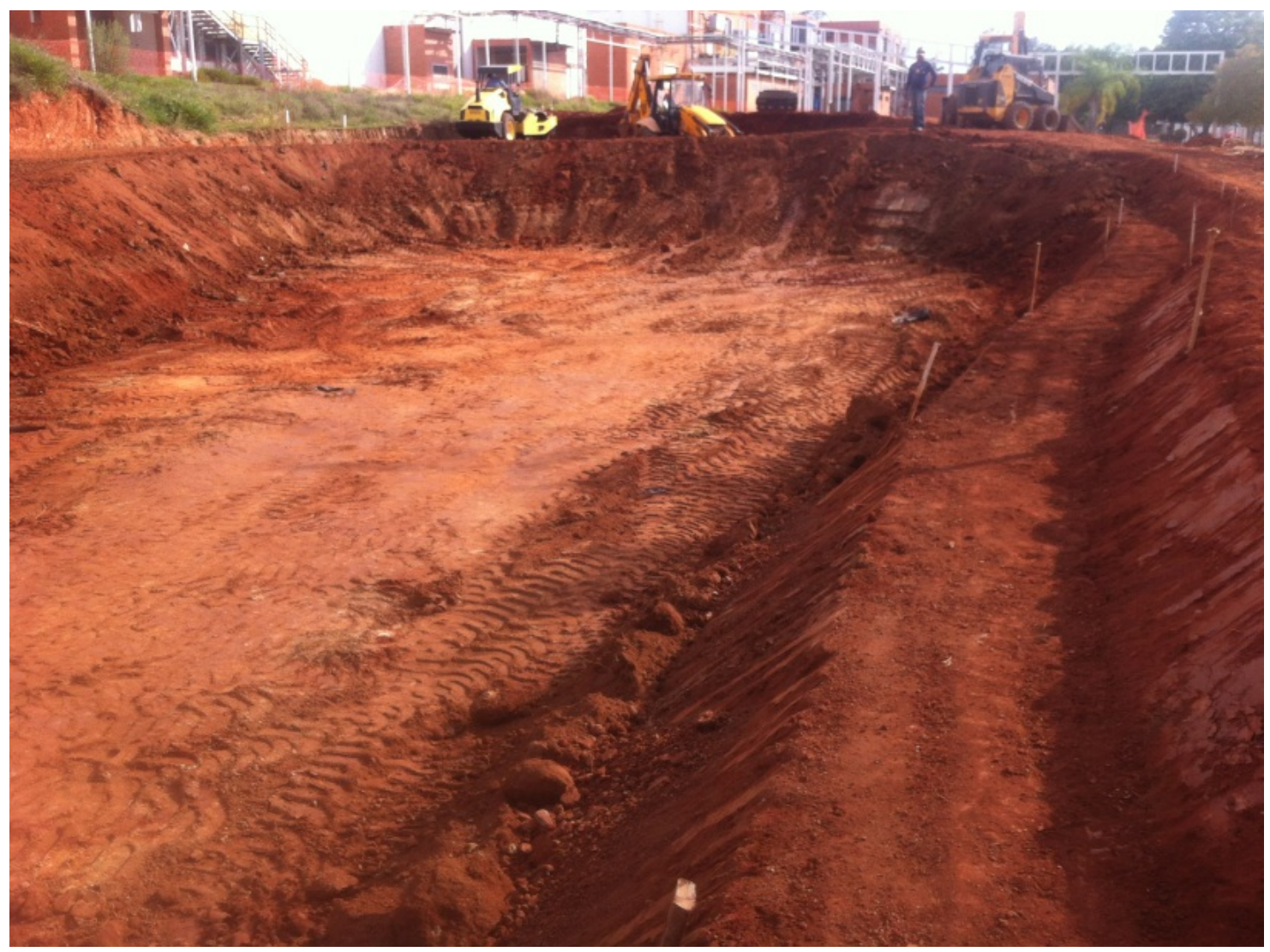

Fonte: Adaptada de Phytorestore Brasil 2013.

Após escavadas e preparadas todas as etapas, elas foram impermeabilizadas para evita o contato do esgoto a ser tratado com o solo natural, sua percolação e possível contaminação do lençol freático.

A impermeabilização foi feita através de aplicação de geomembrana de PEAD de 1,0mm de espessura. Para proteção mecânica foi instalada uma camada de geotêxtil não tecido abaixo da geomembrana e outra acima. A figura 17 a seguir mostra a construção desta impermeabilização. 


\section{6}

Figura 17 - Impermeabilização

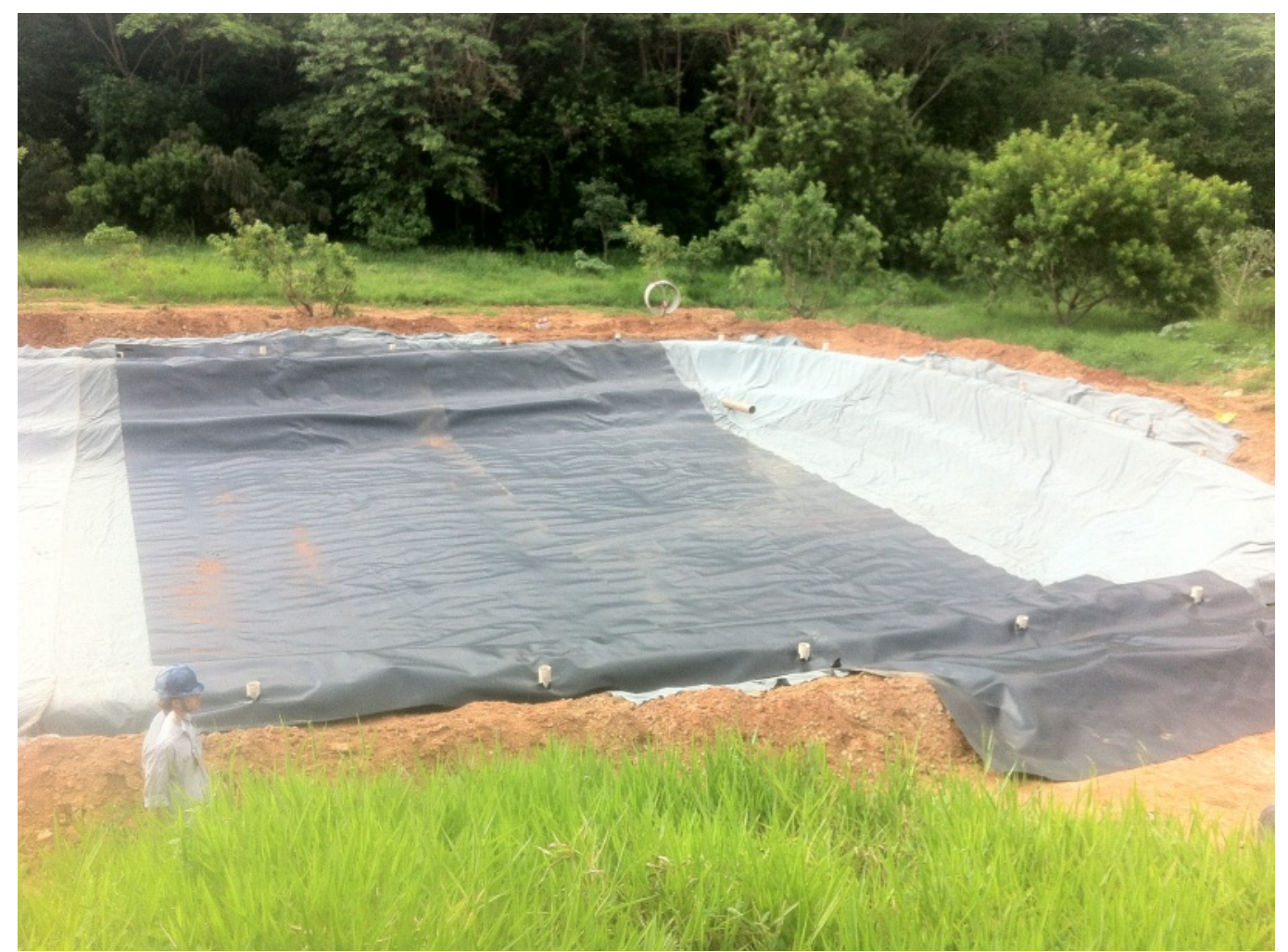

Fonte: Adaptada de Phytorestore Brasil 2013.

Após a impermeabilização foram implantadas as redes hidráulicas de alimentação, drenagem e aeração passiva, concomitantemente com a colocação do substrato. As figura 18 a 21 a seguir ilustram esta etapa da implantação. 


\section{7}

Figura 18 - Construção da aeração dos filtros verticais e colocação do substrato

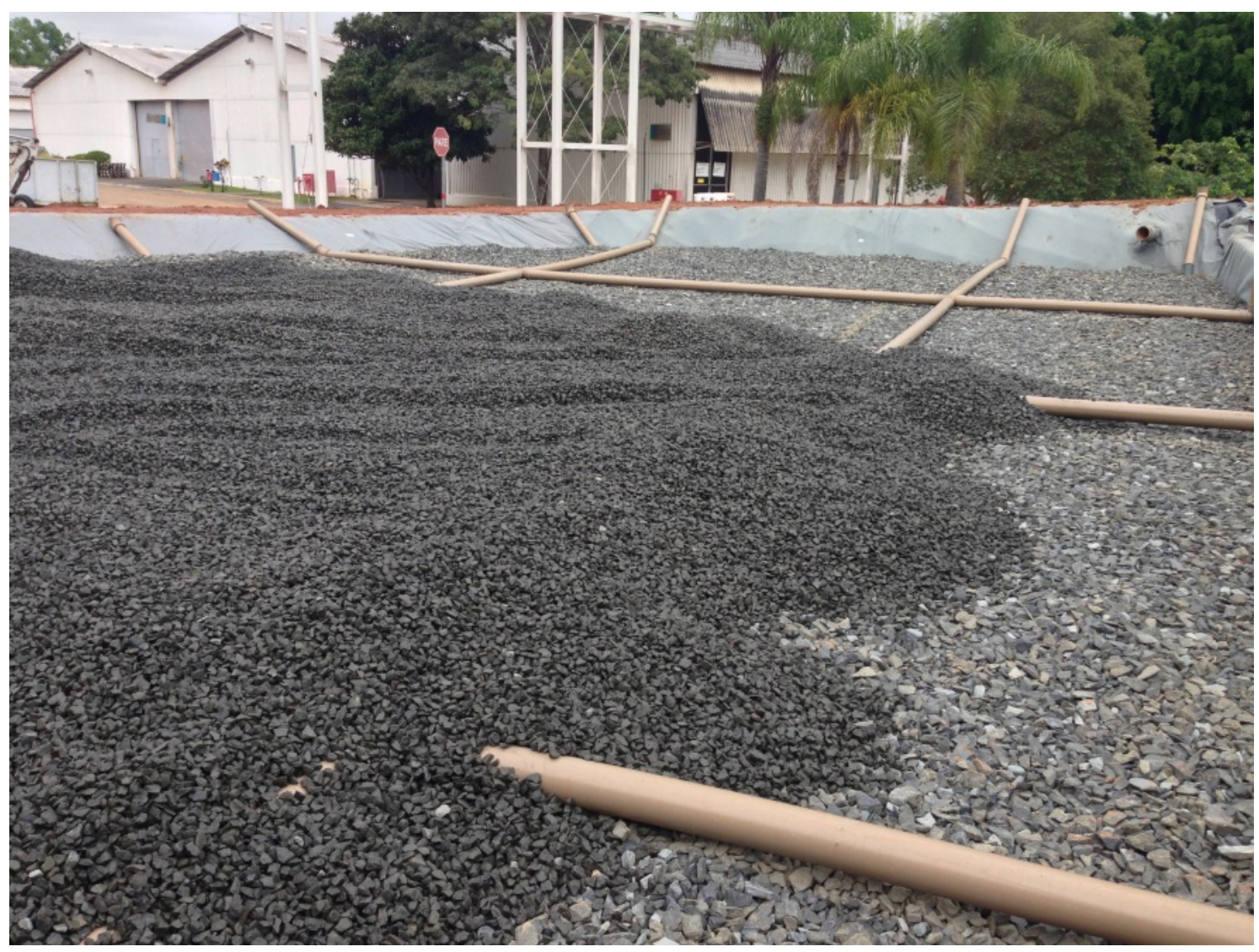

Fonte: Adaptada de Phytorestore Brasil 2013. 


\section{8}

Figura 19 - Construção da alimentação dos filtros verticais

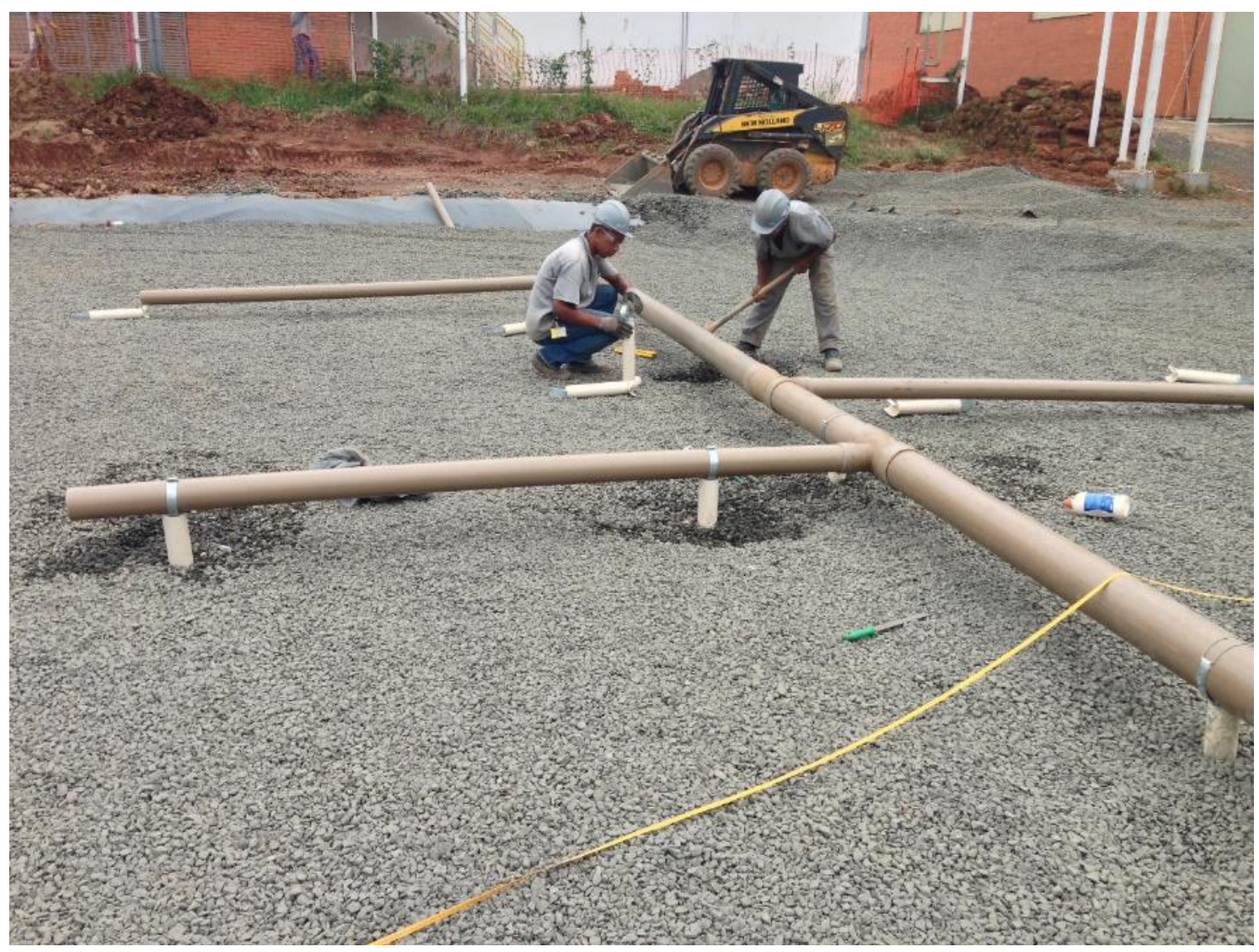

Fonte: Adaptada de Phytorestore Brasil 2013. 
119

Figura 20 - Construção dos filtros horizontais

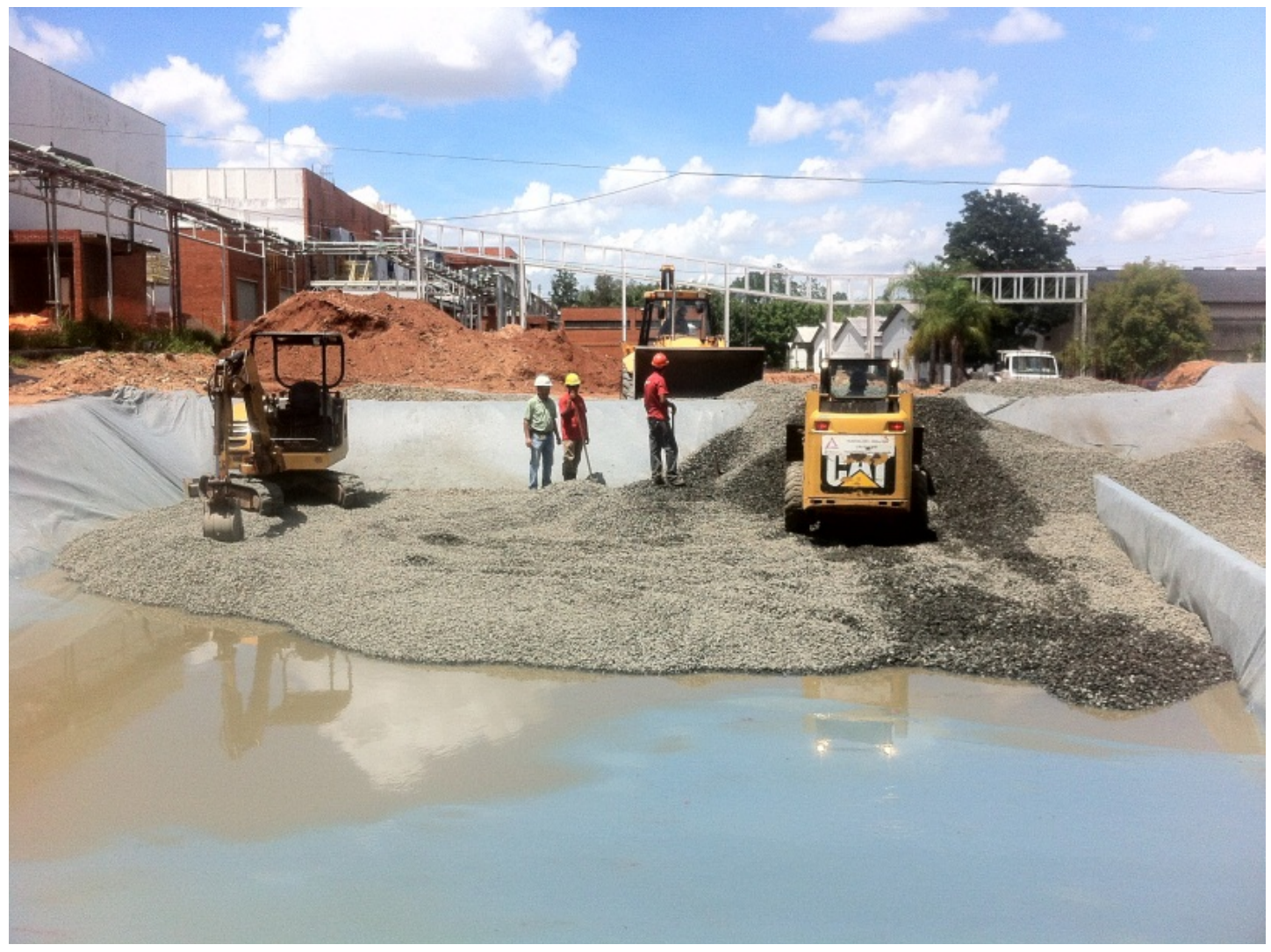

Fonte: Adaptada de Phytorestore Brasil 2013. 
Figura 28 - Construção da lagoa plantada

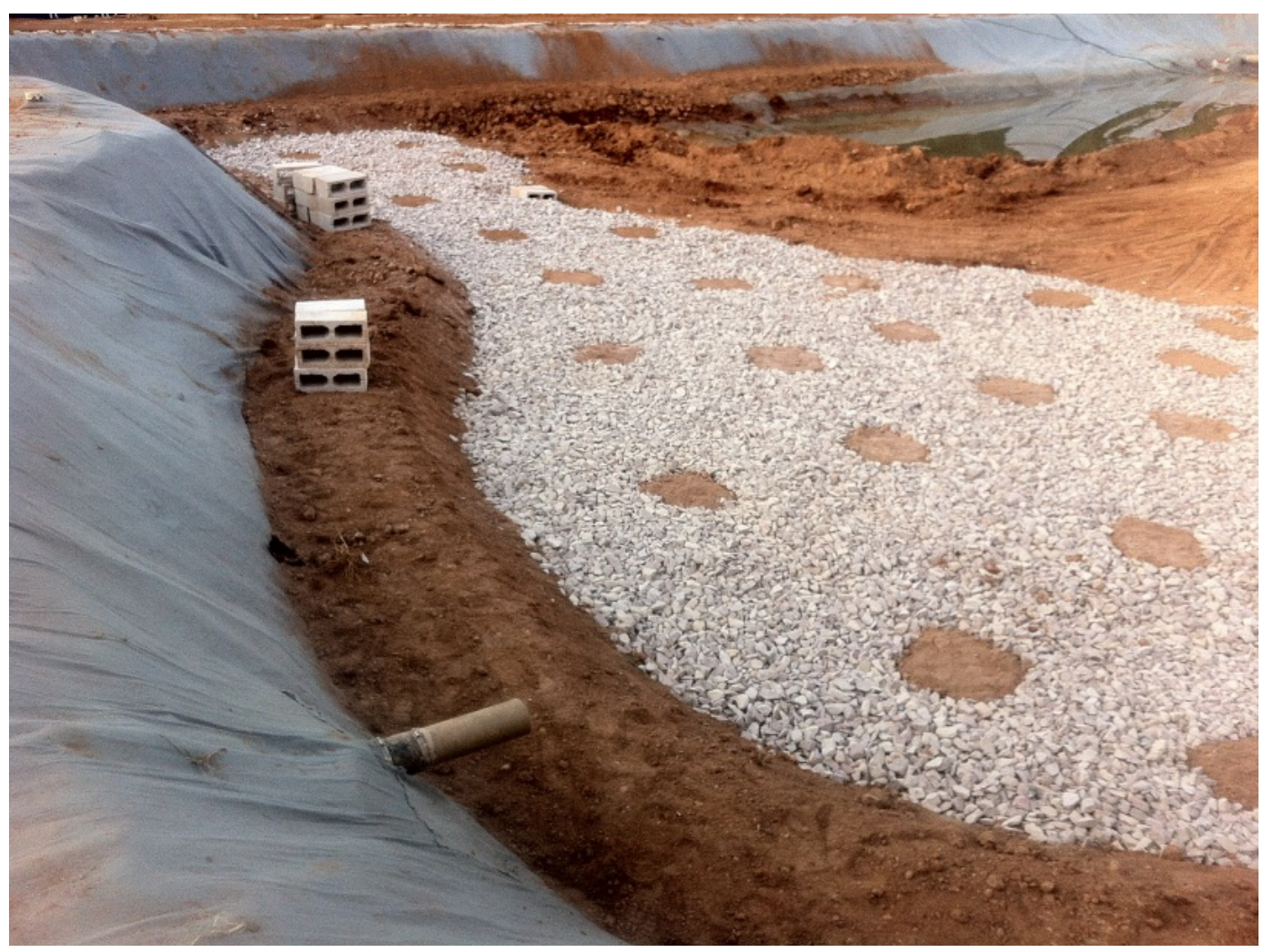

Fonte: Adaptada de Phytorestore Brasil 2013.

Foram construídos também o tanque de recebimento de esgoto e o pré-tratamento, além de estruturas de acesso como escadas, passarelas e corrimãos. As figuras 22 a 24 a seguir mostram estas etapas e estruturas. 
Figura 22 - Construção do tanque de recebimento

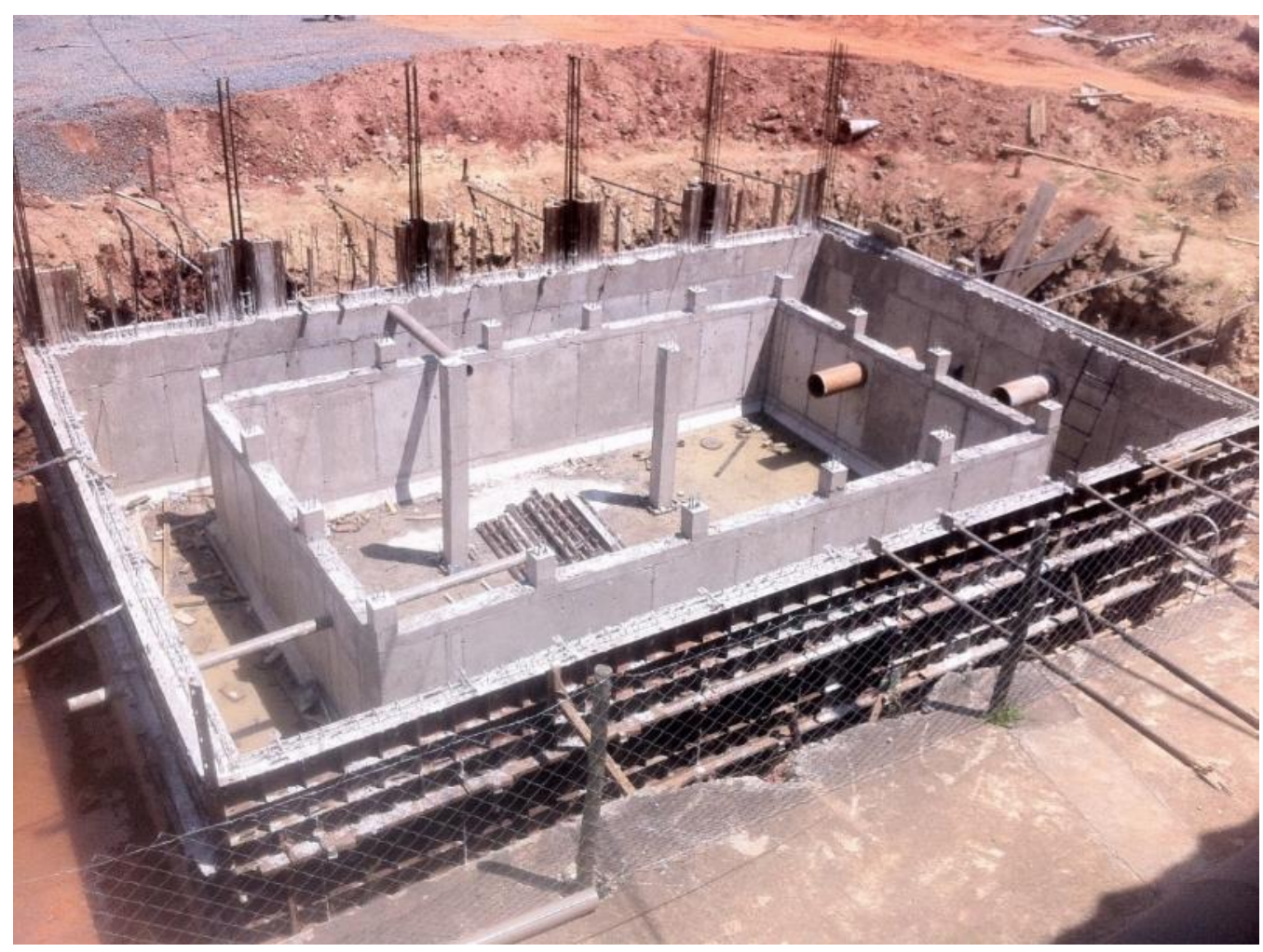

Fonte: Adaptada de Phytorestore Brasil 2013.

Figura 23 - Instalação das bombas e aeradores no tanque 


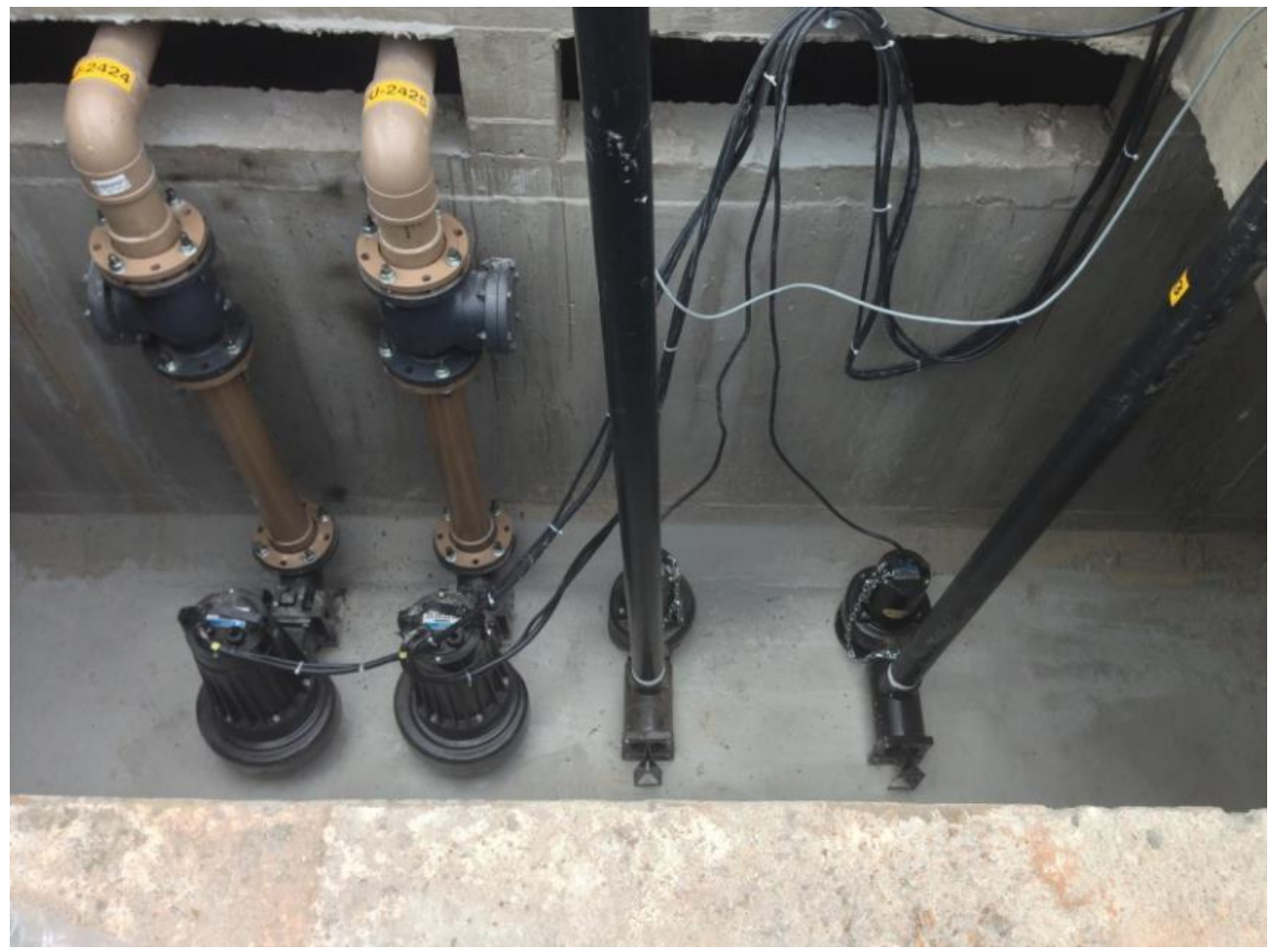

Fonte: Adaptada de Phytorestore Brasil 2013.

Figura 24 - Tanque de recebimento acabado e estruturas de acesso

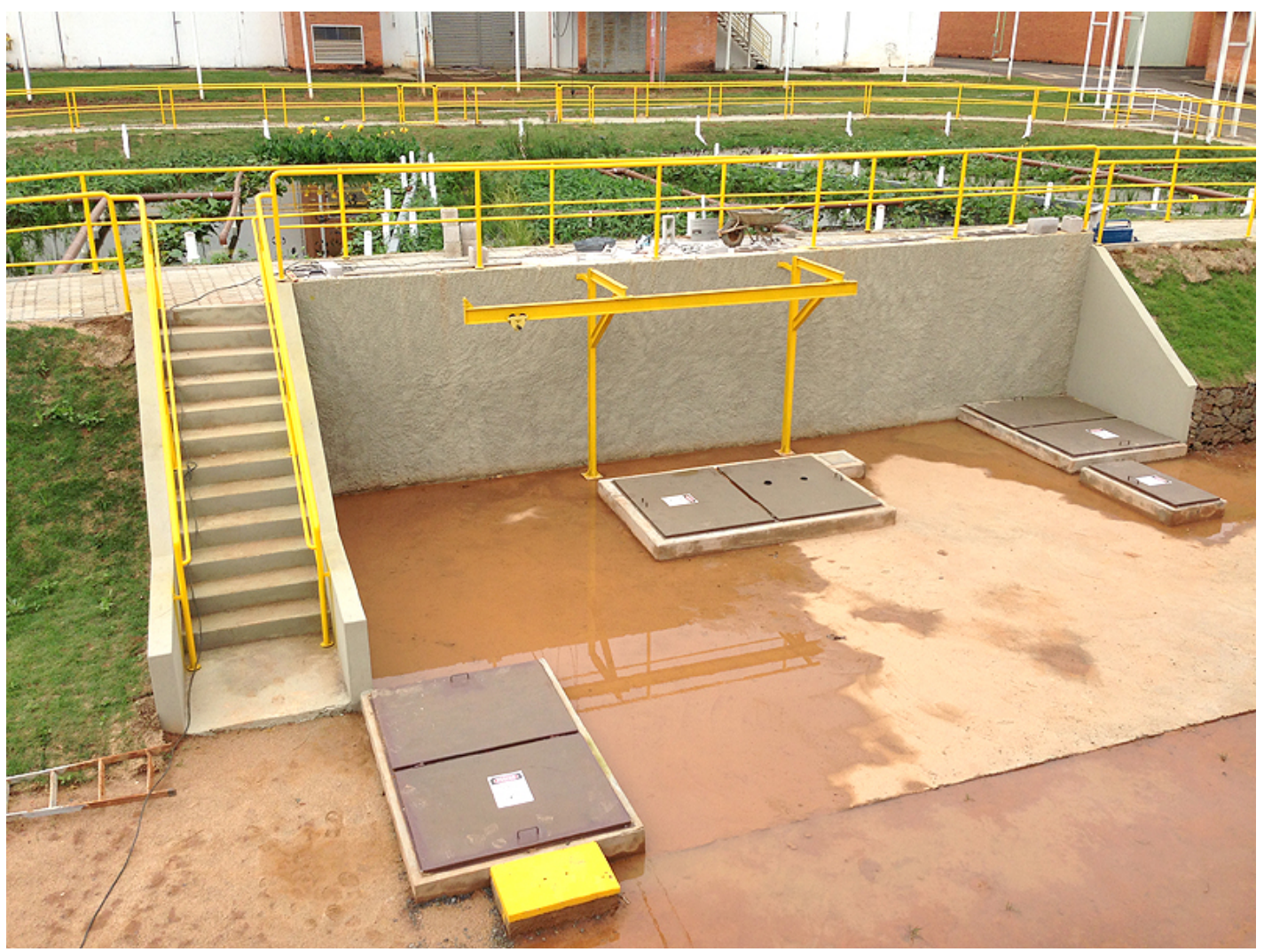

Fonte: Adaptada de Phytorestore Brasil 2013. 
A última etapa da implantação contemplou a plantação das espécies selecionadas, conforme mostrado nas figuras 25 e 26 .

Figura 25 - Plantação das espécies na lagoa 
124

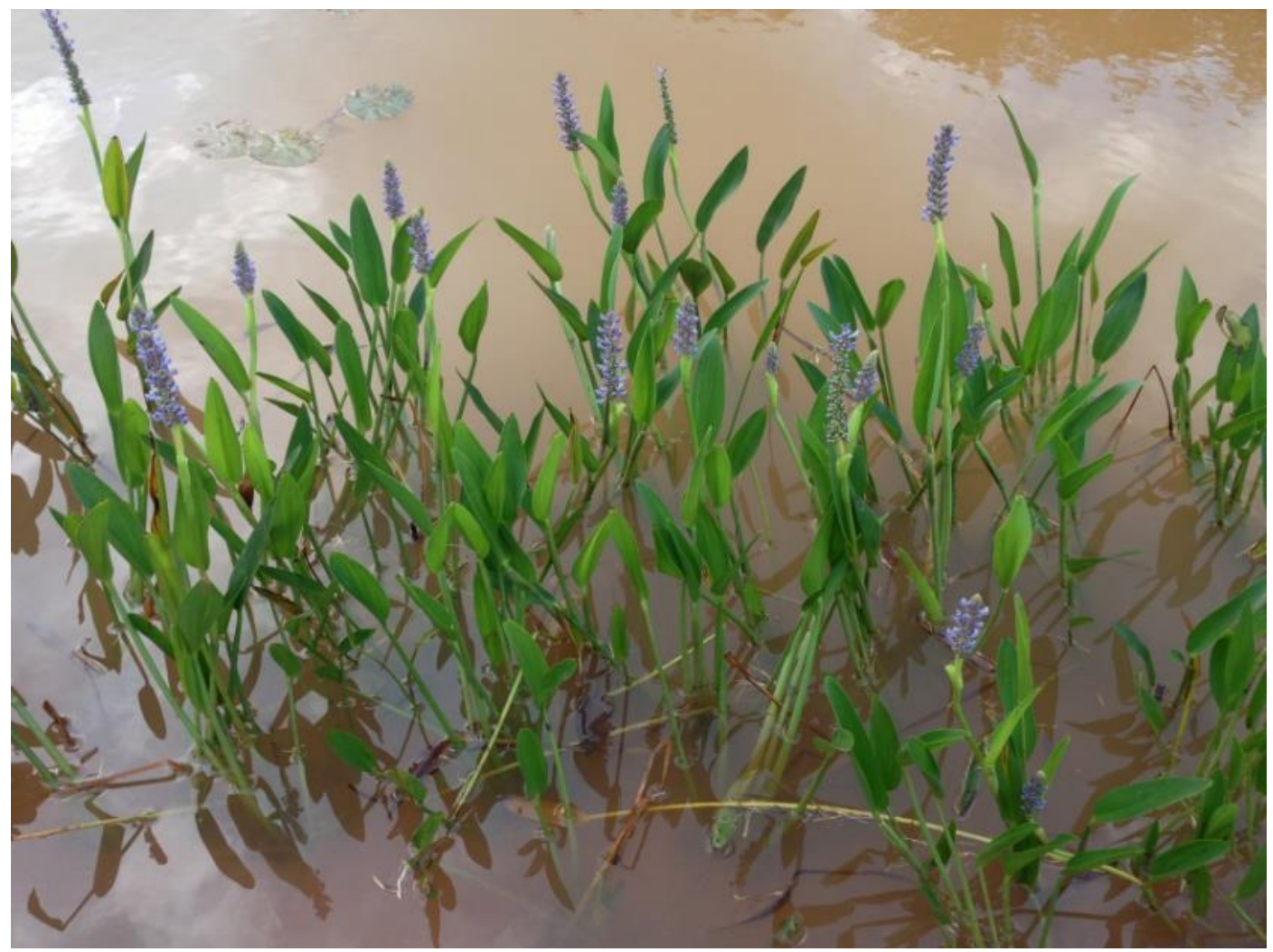

Fonte: Adaptada de Phytorestore Brasil 2013. 
Figura 26 - Plantação das espécies nos filtros

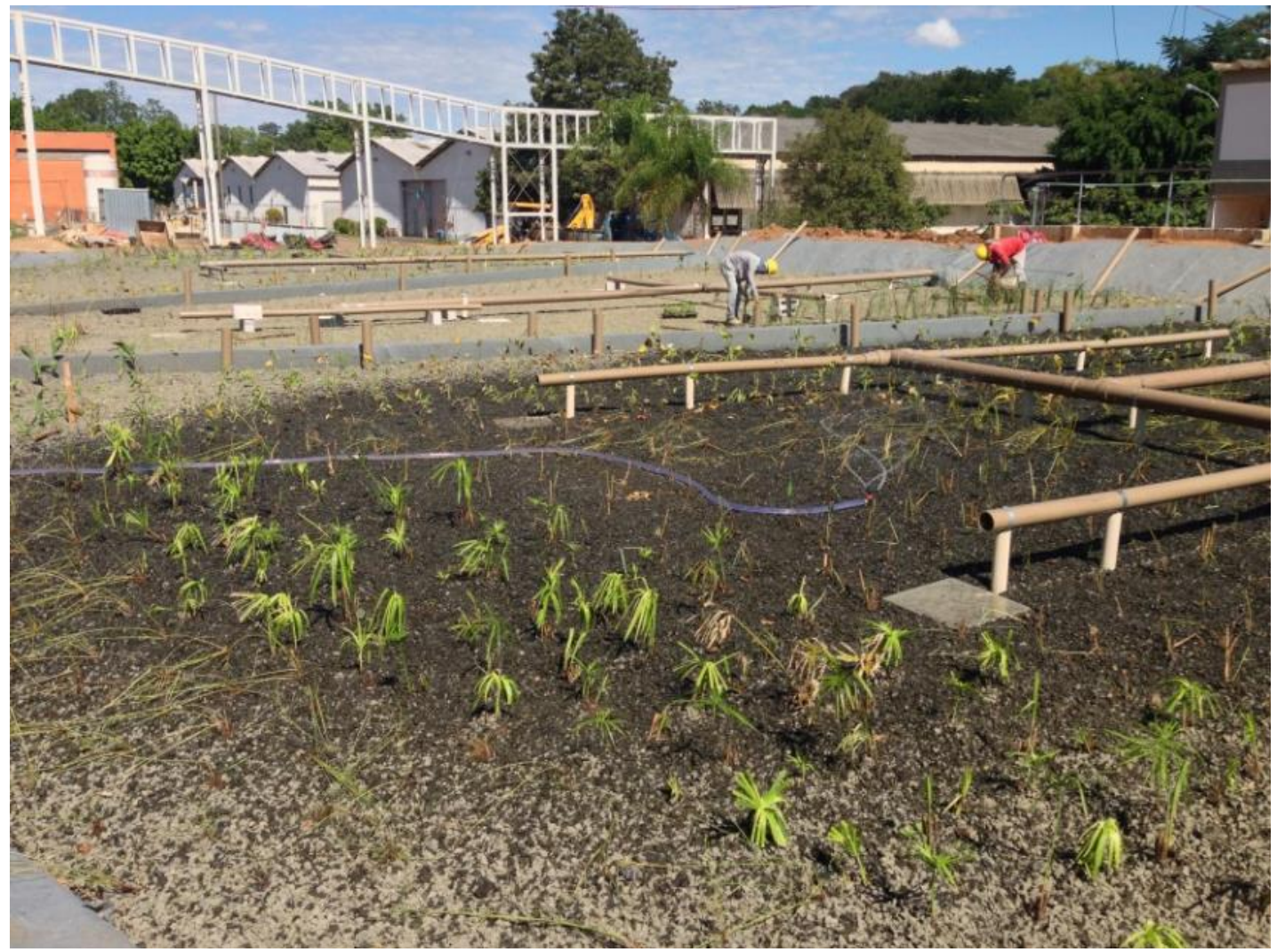

Fonte: Adaptada de Phytorestore Brasil 2013.

O sistema, após implantado, partiu e começou a operar, com desenvolvimento das espécies durante os primeiros períodos de operação. As figuras 27 a 32 a seguir mostram o sistema em sua partida e a evolução das espécies vegetais ao longo da operação. 
Figura 27 - Filtros acabados, durante partida do sistema

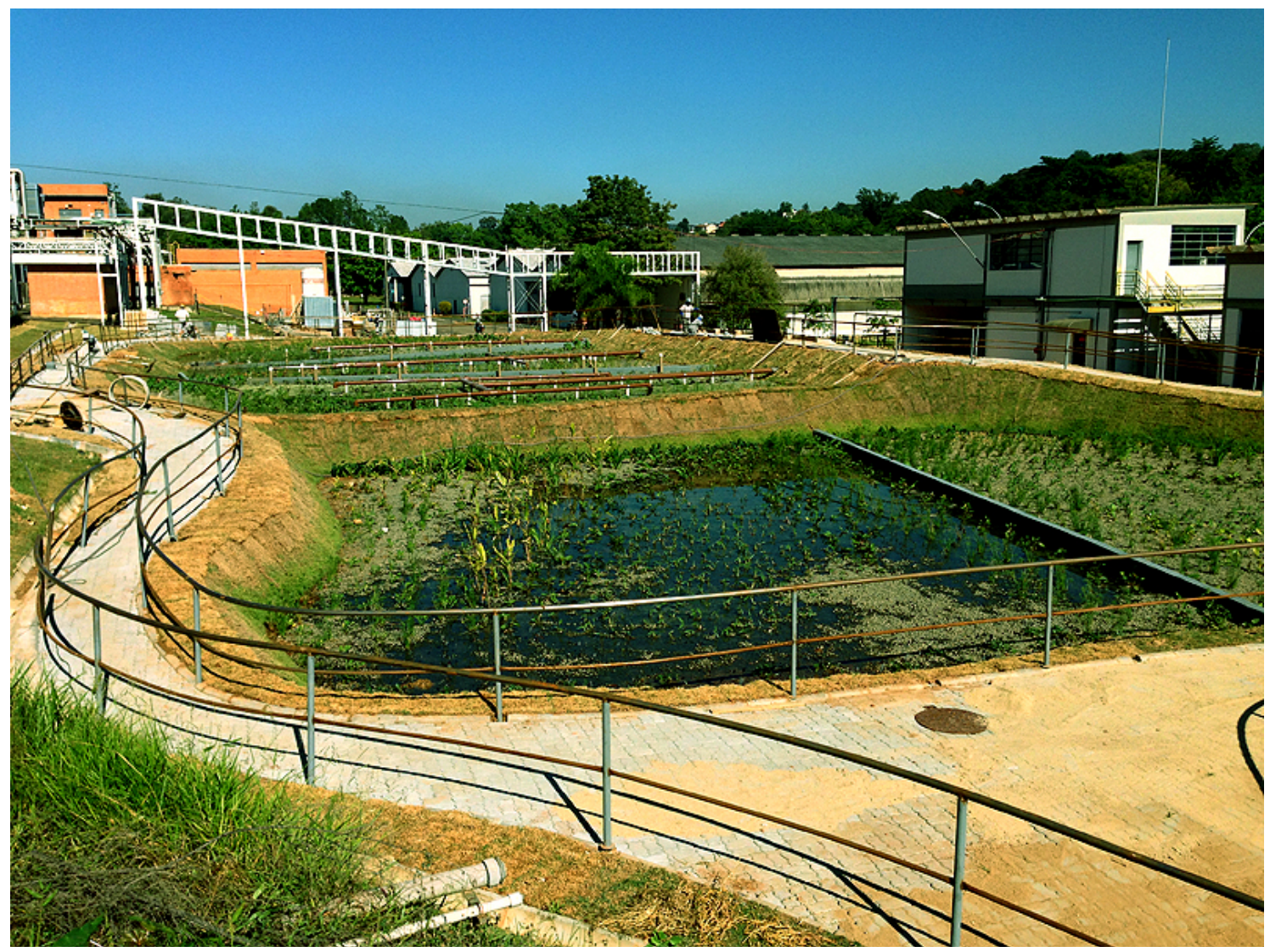

Fonte: Adaptada de Phytorestore Brasil 2013. 
Figura 28 - Lagoa acabada, durante parida do sistema

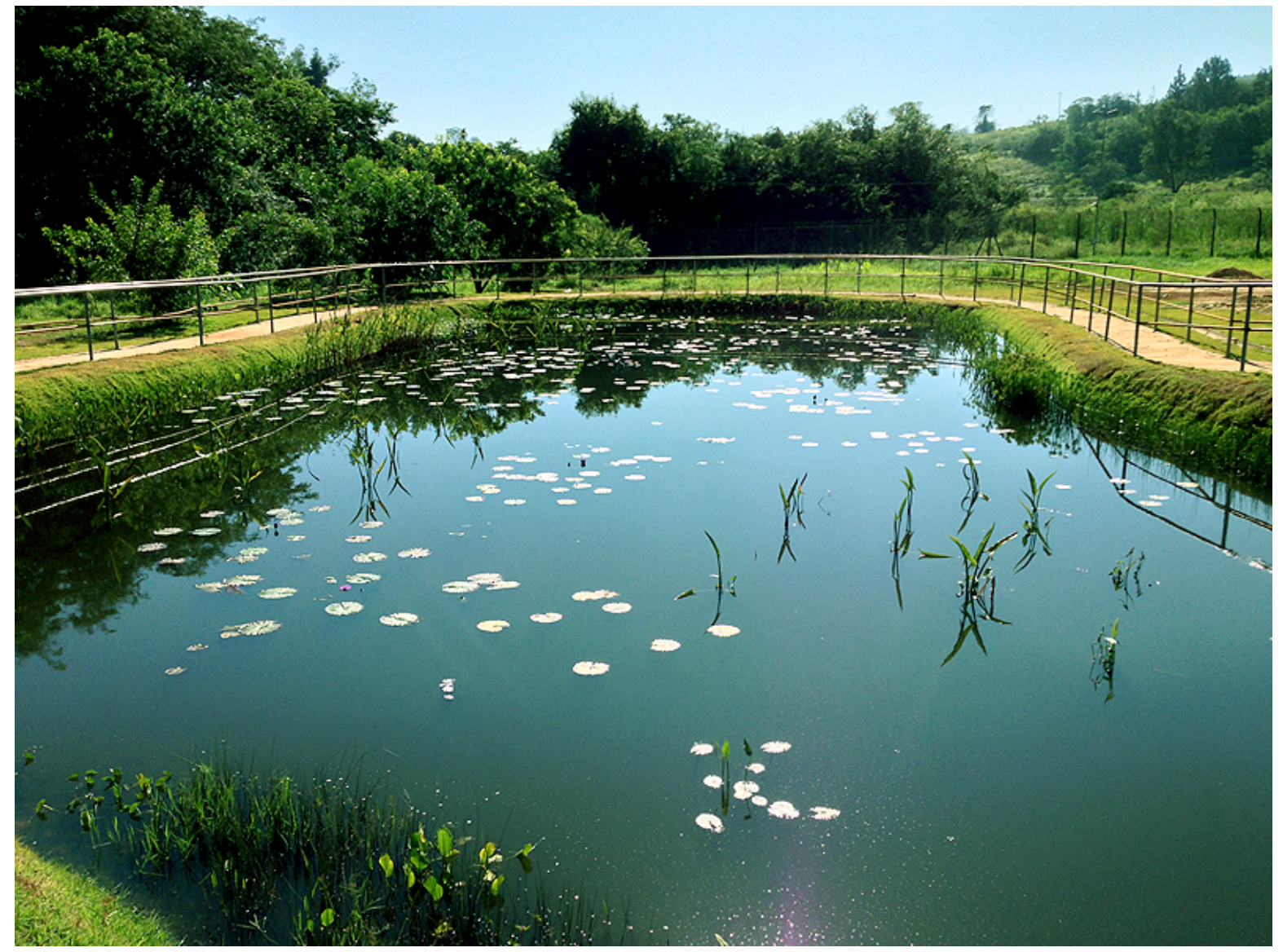

Fonte: Adaptada de Phytorestore Brasil 2013.

Figura 29 - Panorâmica do sistema durante sua partida 


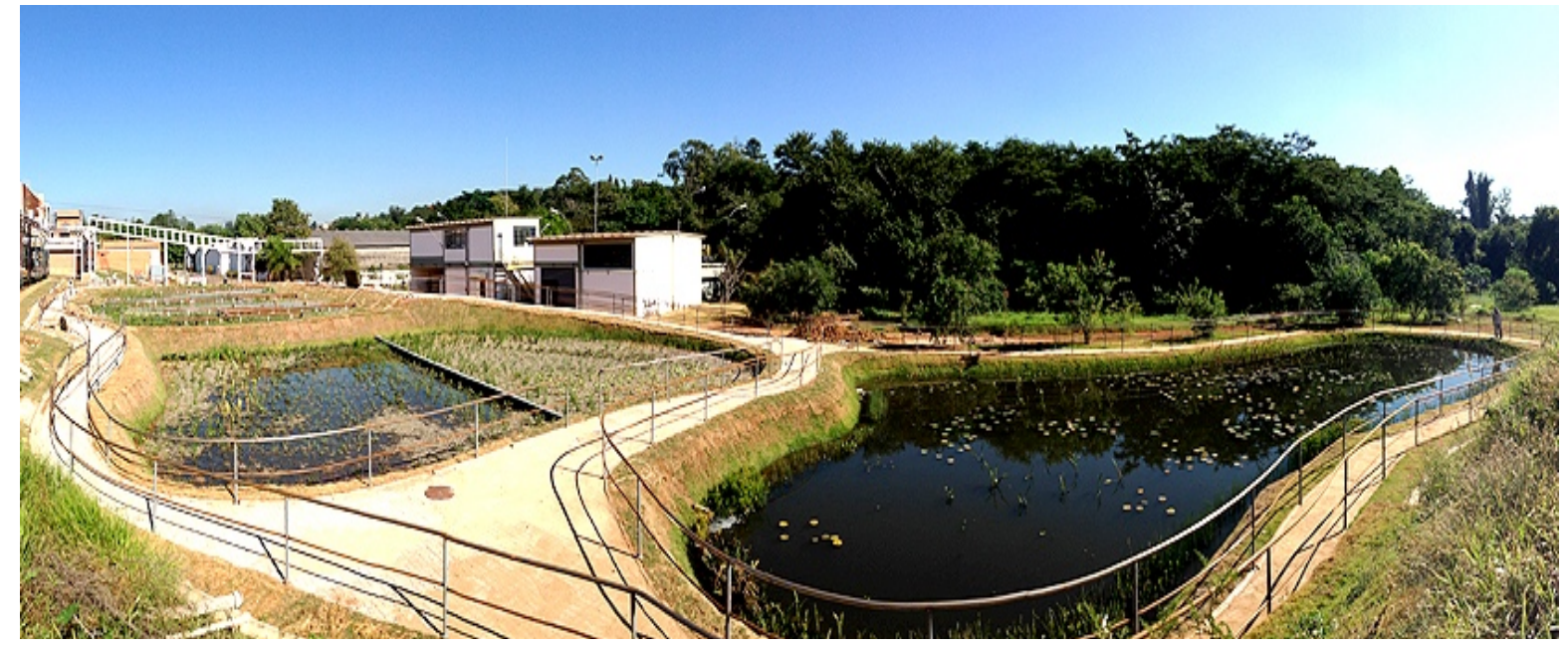

Fonte: Adaptada de Phytorestore Brasil 2013.

Figura 30 - Filtros verticais, após 2,5 anos de operação

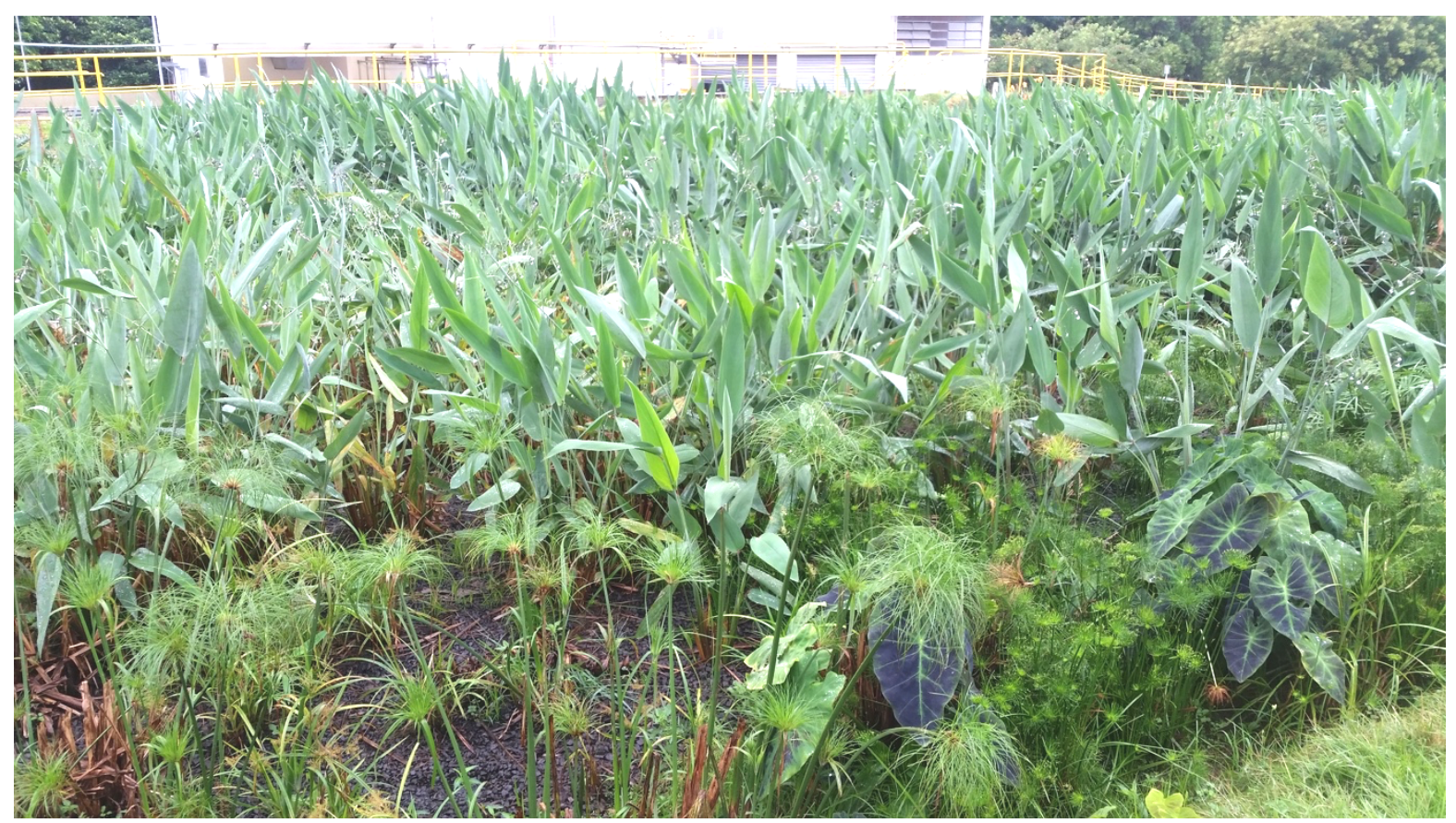

Fonte: Adaptada de Phytorestore Brasil 2015. 
Figura 31- Filtros horizontais, após 2,5 anos de operação

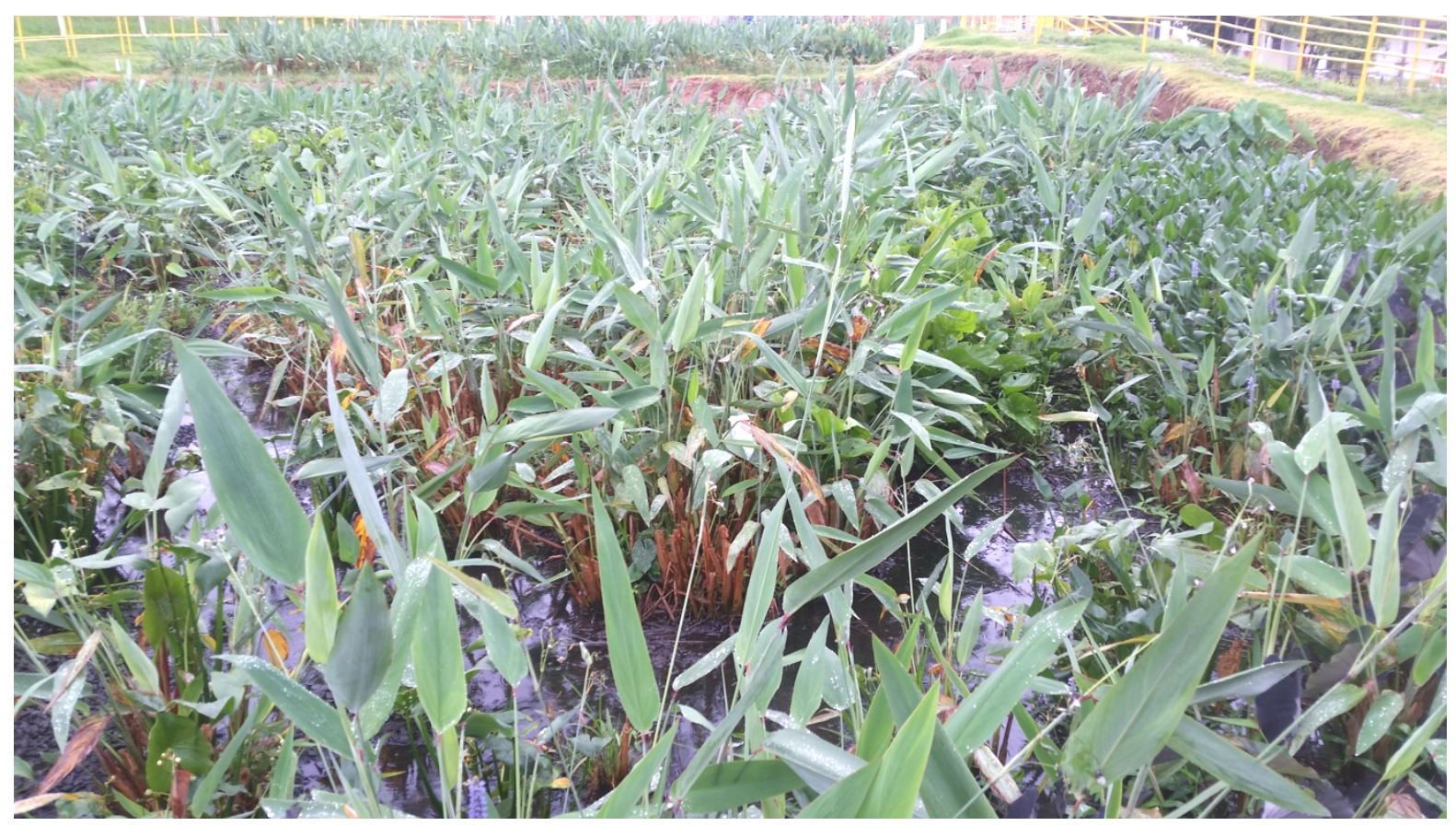

Fonte: Adaptada de Phytorestore Brasil 2015.

Figura 32 - lagoa plantada, após 2,5 anos de operação 


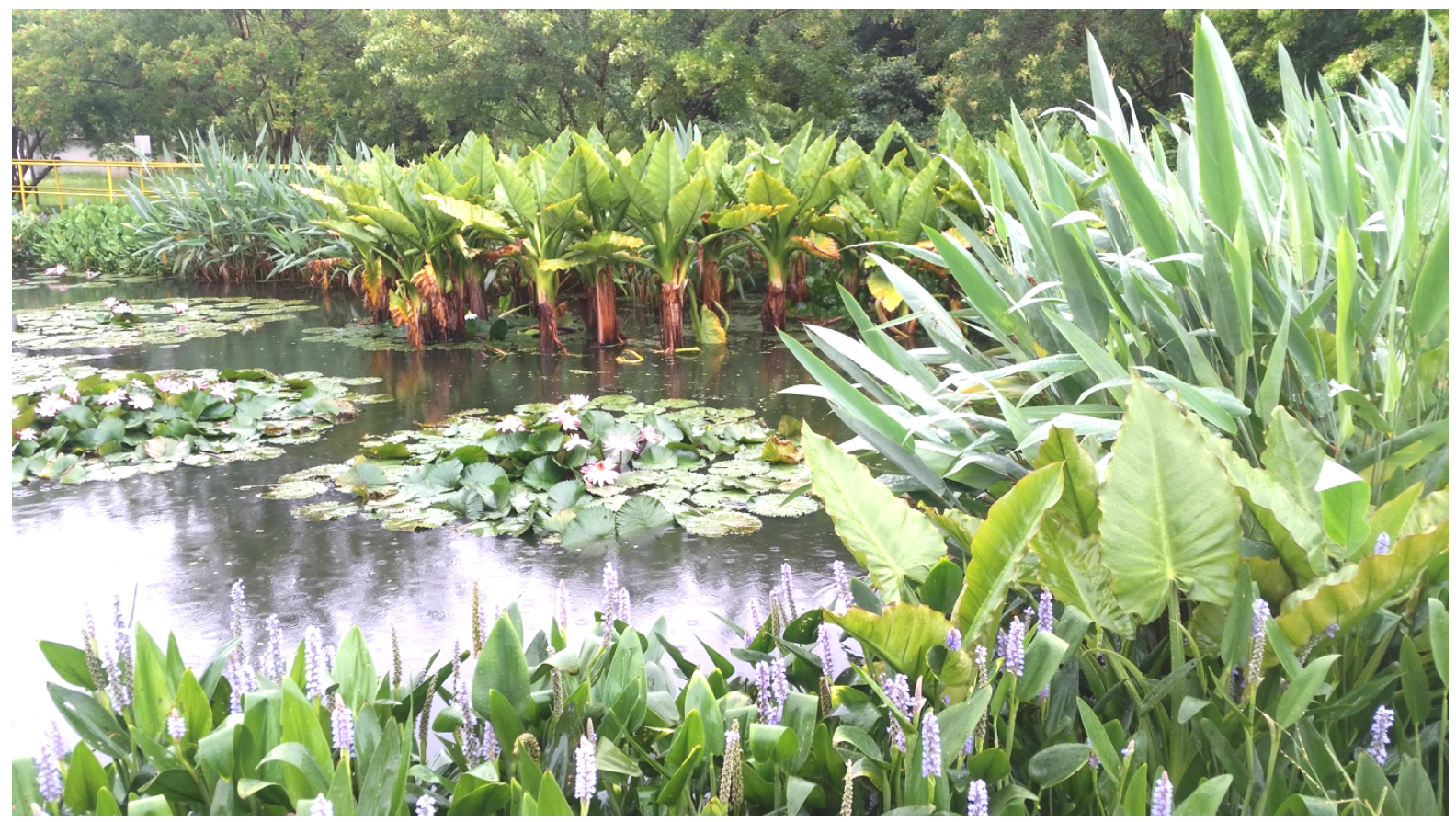

Fonte: Adaptada de Phytorestore Brasil 2015.

\section{METODOLOGIA OPERACIONAL ADOTADA PELO PROPRIETÁRIO DO SISTEMA}

O esgoto chega através da rede à entrada do tanque de recebimento, onde se inicia o tratamento. A metodologia operacional descrita a seguir foi elaborada pelo projetista do sistema e adotada pela empresa proprietária do mesmo.

Tanque de equalização

$\mathrm{Na}$ entrada do tanque existem dois gradeamentos, um no tanque e outro na calha de medição, que fica ao lado do tanque, estes gradeamentos tem a função de retenção de sólidos grosseiros.

Estes gradeamentos devem ser limpos através da passagem de rastelo para remoção dos sólidos. É importante que a limpeza seja feita cuidadosamente para garantir que a operação não ocasione a passagem de sólidos por cima do gradeamento para dentro do tanque.

Após entrar no tanque o esgoto é constantemente aerado pelo funcionamento de um aerador, para se evitar sua entrada em anaerobiose e a geração de maus odores.

$\mathrm{O}$ aerador conta com equipamento reserva e ambos são alternados periodicamente de forma automática, através de timer no painel de controle.

Através da medição de nível, efetuada por boias de nível, o volume de esgoto no tanque é controlado até que se atinja o volume necessário para a execução da batelada.

Ao atingir-se o volume necessário a bomba de alimentação entra em funcionamento automaticamente. Esta bomba conta com equipamento reserva e ambas são alternadas periodicamente de forma automática, através de timer no painel de controle. 
Após ligar a bomba o volume do tanque começa a baixar, pela saída de esgoto para os wetlands verticais. Ao atingir o nível de término da batelada, controlado por boia de nível, a bomba desliga automaticamente.

Além das duas boias de operação existem ainda duas boias de segurança, que impedem o esvaziamento completo e o transbordamento do tanque. Se o nível do tanque ultrapassar a boia de nível máximo, será disparado um alarme luminoso e sonoro, avisando ao operador que o tanque corre risco de transbordo.

Da mesma forma, se o nível atingir a boia de mínimo um alarme será ativado, e além do alarme ocorrerá o desligamento das bombas e aeradores, para que não trabalhem sem fluido.

A seguir, a figura 33 mostra um esquema ilustrativo dos níveis de operação e de segurança: 
Figura 3 - Esquema operacional do tanque de recebimento

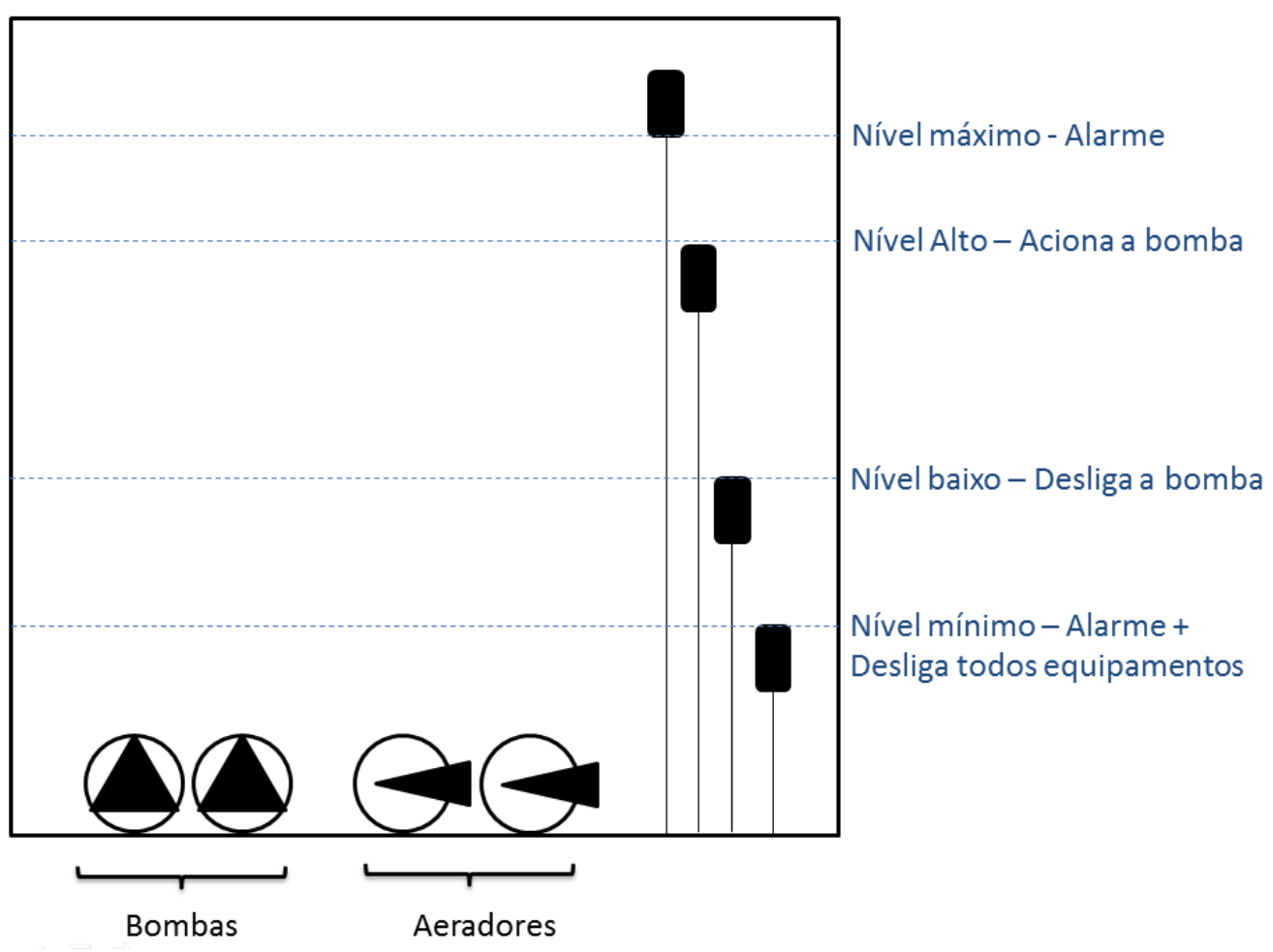

Fonte: Cauê Girão de Abreu, 2019.

Wetlands construídos verticais e horizontais

Nos WC verticais e horizontais são feitas apenas as operações de manipulação de válvulas, manutenção das plantas e observação geral do funcionamento.

Manipulação de válvulas

Wetland Construído Vertical (WCV):

A alimentação dos WCV é feita pela manipulação de uma válvula. A operação normal está planejada para alimentar um WCV de cada vez, assegurando que uma válvula estará sempre aberta para não danificar a descarga à montante, e as demais fechadas. $O$ tempo de trabalho de um WCV é, em média, uma semana; e o de repouso, duas. Este prazo pode ser reduzido em caso de seca prolongada, para que as plantas não fiquem sem água durante duas semanas.

Um sistema de ventilação (chaminés ligadas aos drenos) mantém a natureza aeróbica desta etapa e garante o seu bom funcionamento, sem a geração de maus odores. Portanto, este sistema é essencial para o funcionamento do sistema, e por isso, as chaminés não devem ser obstruídas.

Os WCV são drenados em seu nível mais baixo, permanecendo sempre vazios entre as bateladas (não saturados).

Wetland Construído Horizontal (WCH):

A alimentação do WCH é realizada pela manipulação de válvulas. Para alimentar um dos filtros, basta abrir a válvula correspondente. O tempo de trabalho de um único $\mathrm{WCH}$ é, em média, uma semana, assim como o tempo de repouso, sendo que este prazo poderá ser reduzido em caso de condições meteorológicas extremas. 
Os $\mathrm{WCH}$ permanecem cheios entre as bateladas, com nível mantido pouco abaixo do nível de substrato. O controle de nível dos $\mathrm{WCH}$ é feito por um dispositivo chamado de "válvula rústica", que são tubulações perfuradas no nível exato em que se deseja manter o esgoto dentro do WCH. O transbordo é feito por "vasos comunicantes", mantendo sempre o mesmo nível no WCH e na "válvula rústica". A figura 34, a seguir, ilustra uma "válvula rústica":

Figura 29 - Válvula rústica

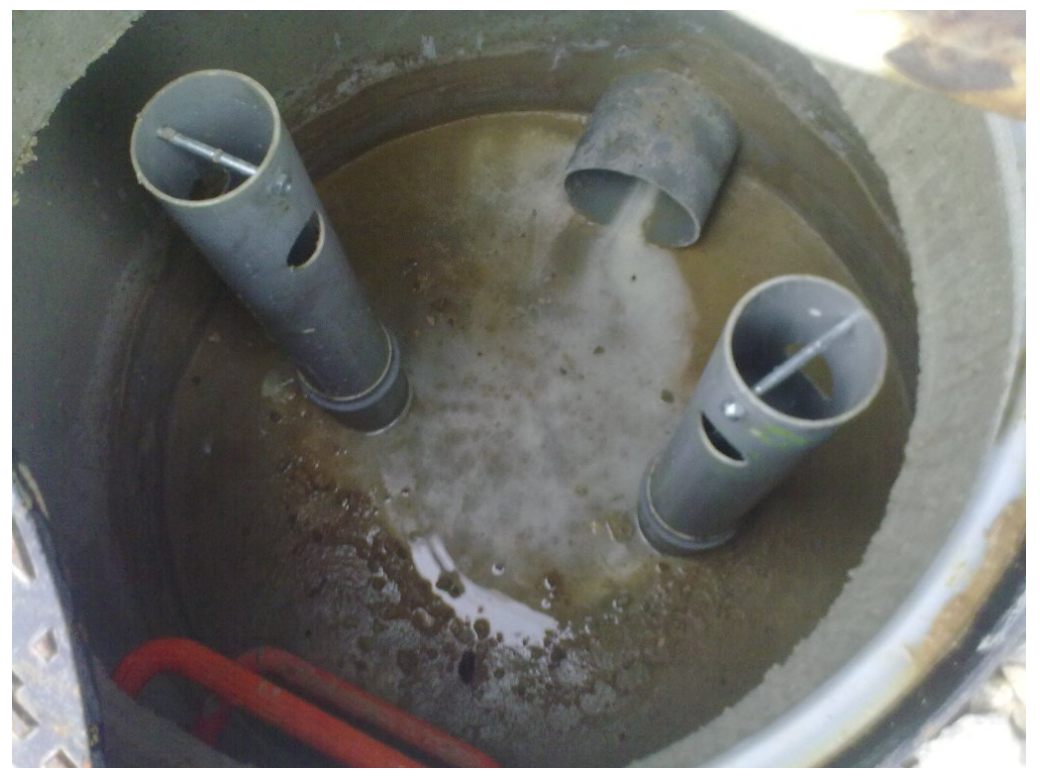

Fonte: Cauê Girão de Abreu, 2019.

Para manter a função anóxica, o WCH deve estar sempre com carga de esgoto. Por esta razão, a "válvula rústica" na saída do sistema não deve ser manipulada, exceto em casos excepcionais, onde por qualquer razão se deseje esvaziar totalmente os WCH.

Não deve haver esgoto acima do nível do substrato nos intervalos entre bateladas em nenhum $\mathrm{WCH}$, caso isso aconteça deve-se verificar a posição das válvulas, o funcionamento das válvulas rústicas ou algum possível entupimento de tubulação.

Todas a caixas de passagem e poços de visitas foram nomeados e numerados, assim como todas as válvulas manuais e válvulas rústicas. Foram instaladas em campo plaquetas de identificação em inox com a nomenclatura adotada para cada um dos itens.

O quadro 1 a seguir mostra a nomenclatura adotada e localização de cada uma das válvulas de operação: 
Quadro 1 - Válvulas do sistema.

\begin{tabular}{|l|c|l|l|}
\hline \multicolumn{1}{|c|}{ Localização } & $\begin{array}{c}\text { Poço de } \\
\text { visita }\end{array}$ & Válvula & \multicolumn{1}{c|}{ Função } \\
\hline Talude entre o tanque de recebimento e os WCV & PV-01 & VM-01 & Alimentação do WCV-03 \\
\hline Talude entre o tanque de recebimento e os WCV & PV-02 & VM-02 & Alimentação do WCV-02 \\
\hline Talude entre o tanque de recebimento e os WCV & PV-02 & VM-03 & Alimentação do WCV-01 \\
\hline Talude entre os WCV e o prédio adjacente & PV-06 & VM-04 & Alimentação do WCH-01 \\
\hline Talude entre os WCV e o prédio adjacente & PV-06 & VM-05 & Alimentação do WCH-02 \\
\hline
\end{tabular}

A seguir é mostrado o quadro 2 de orientação para a manipulação das válvulas:

Quadro 2 - Manipulação dasa válvulas.

\begin{tabular}{|c|c|c|c|c|c|}
\hline 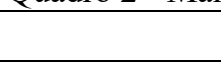 & \multicolumn{3}{|c|}{ WCV } & \multicolumn{2}{|c|}{$\mathrm{WCH}$} \\
\hline WC & 01 (VM-03) & $02(\mathrm{VM}-02)$ & 03 (VM-01) & 01(VM-04) & $02(\mathrm{VM}-05)$ \\
\hline SEMANA 1 & $\overline{\mathbf{A}}$ & F & $\mathrm{F}$ & $\overline{\mathbf{A}}$ & $\mathbf{F}$ \\
\hline SEMANA 2 & F & $\mathbf{A}$ & F & $\mathbf{F}$ & $\mathbf{A}$ \\
\hline SEMANA 3 & $\mathbf{F}$ & $\mathbf{F}$ & $\mathbf{A}$ & $\mathbf{A}$ & $\mathbf{F}$ \\
\hline SEMANA 4 & $\mathbf{A}$ & $\mathbf{F}$ & F & $\mathbf{F}$ & $\mathbf{A}$ \\
\hline SEMANA 5 & $\mathbf{F}$ & $\mathbf{A}$ & $\mathbf{F}$ & $\mathbf{A}$ & $\mathbf{F}$ \\
\hline SEMANA 6 & $\mathrm{~F}$ & F & $\mathbf{A}$ & F & $\mathbf{A}$ \\
\hline
\end{tabular}

\section{LEGENDA:}

A : Válvula ABERTA

: Válvula FECHADA

Manutenção das plantas

Estado das plantas

Uma robservação das condições fitossanitárias deve ser feita com cuidado e regularidade. Os pontos a observar são:

$$
\begin{aligned}
& \checkmark \text { A cor (amarelo) } \\
& \checkmark \quad \text { Os sinais exteriores de doença, } \\
& \checkmark \quad \text { A presença de parasitas e predadores } \\
& \checkmark \quad \text { A presença de roedores. }
\end{aligned}
$$

No caso de ser observado qualquer um destes sinais, um especialista deve ser chamado para lidar com o problema.

Poda:

Existem 03 tipos de poda a serem realizados regularmente no sistema:

$\checkmark$ Poda de limpeza: feita com maior frequência, quinzenalmente. É feita para tirar galhos e folhas velhas e doentes. 
$\checkmark$ Poda de conformação: feita em épocas específicas. É feita para dar forma ou recuperar a forma das plantas;

$\checkmark$ Poda de contenção: feita em função da necessidade. São podas feitas para diminuir o porte da planta ou direcionar o desenvolvimento para cima ou para o lado ou ainda para melhorar a paisagem.

$\rightarrow$ Meses ideais para poda de conformação e contenção: junho, julho e agosto.

Outros pontos a considerar:

Deve-se notar que a distribuição de plantas vai mudar naturalmente. É altamente recomendável manter um cronograma de manutenção para os fenômenos diferentes, para formar uma intervenção completa manual e ter um histórico de eventos e ações tomadas em conformidade.

Deverá ser executada uma inspeção visual das plantas e da qualidade dos WC. A troca dos substratos e da impermeabilização dos WCV deve ser considerada após aproximadamente10 anos de operação para remover a camada formada pelo acúmulo de sólidos em suspensão removidos, e para garantir que a impermeabilização esteja dentro da garantia do fornecedor.

Como os WC permanecem secos acima do nível de substrato, é possível andar normalmente na área interna do filtro para fazer a observação e manutenção das plantas.

Wetland construído superficial (Lagoa Terminal)

$\mathrm{Na}$ lagoa terminal devem ser feitas as mesmas operações dos filtros, porém neste local não é possível andar dentro da área, pois estará sempre com água (esgoto tratado). Como as plantas estão em sua maioria nas área das bordas é possível observá-las de fora da lagoa.

Caso necessário, o acesso ao interior da lagoa deve ser feito por um funcionários treinado, munido de EPI's, incluindo macacão de saneamento, para não haver contato direto com o esgoto.

A saída da lagoa é controlada por uma "válvula rústica", de forma que o nível deve sempre ser mantido e apenas o excesso de esgoto tratado seguirá por transbordo para a estrutura de saída e lançamento do esgoto tratado.

Deve-se observar nesta etapa também os níveis de água. Caso suba além do previsto (nível de transbordo) pode representar entupimento ou obstrução da saída ou da "válvula rústica, e caso baixe muito pode representar vazamento ou falta de esgoto no sistema.

Recirculação

Caso haja a necessidade de alguma manutenção programada no sistema, ou caso o esgoto não esteja com qualidade desejada para fazer o lançamento, existe a possibilidade de recircular o esgoto, fazendo com que retorne para o tanque de recebimento. A qualidade inadequada do esgoto para lançamento pode ser percebida de duas formas, através de observação visual das características do esgoto (presença de espuma, alteração da cor, presença de odor, qualquer característica que não seja típica da operação normal) ou através da medição online de qualidade instalada na saída do esgoto tratado.

Esta recirculação pode ser feita de duas formas: 
1. Diretamente após a saída dos WCH, fechando-se as válvulas de alimentação da lagoa (VM-06 e VM-07) e abrindo-se a válvula de recirculação (VM-08).

2. Da lagoa, abrindo-se a válvula de recirculação da lagoa (VM-09).

Medição e lançamento

Após a saída da lagoa existe uma estrutura para medição e lançamento final do esgoto. Nesta estrutura existem dois equipamentos:

a. Medidor de vazão da concessionária de esgoto: medidor ultrassônico instalado em calha Parshall com leitura apenas local.

b. Medidor de vazão e sonda multiparâmetro para controle da operação: Equipamento que conta com medição de vazão e sonda com leitura dos seguintes parâmetros: Temperatura, $\mathrm{pH}, \mathrm{OD}$ e condutividade. Este equipamento contará com leitura remota no computador instalado na sala do operador da ETE.

Neste trecho do sistema devem ser feitas limpezas periódicas de gradeamento e das calhas, bem como manutenção e calibração dos equipamentos.

Após as duas medições o esgoto tratado será lançado na rede da concessionária.

Estabelecimento de um acompanhamento analítico

A descarga de esgoto tratado na rede da concessionária de esgoto deve atender aos padrões específicos da legislação. Portanto, deve ser realizada uma série de análises legais e também análises de acompanhamento.

O acompanhamento periódico deve ser feito para monitorar os parâmetros físicos e químicos no esgoto tratado, para garantir que estejam dentro do exigidos pela legislação vigente, a frequência destas análises deve ser de acordo com a exigência do órgão responsável. 